\title{
ANATOMÍA Y MORFOLOGÍA FUNCIONAL DEL ESQUELETO DE PINGÜINOS (AVES, SPHENISCIFORMES) ACTUALES,
}

\section{APLICACIONES EN LOS FÓSILES}
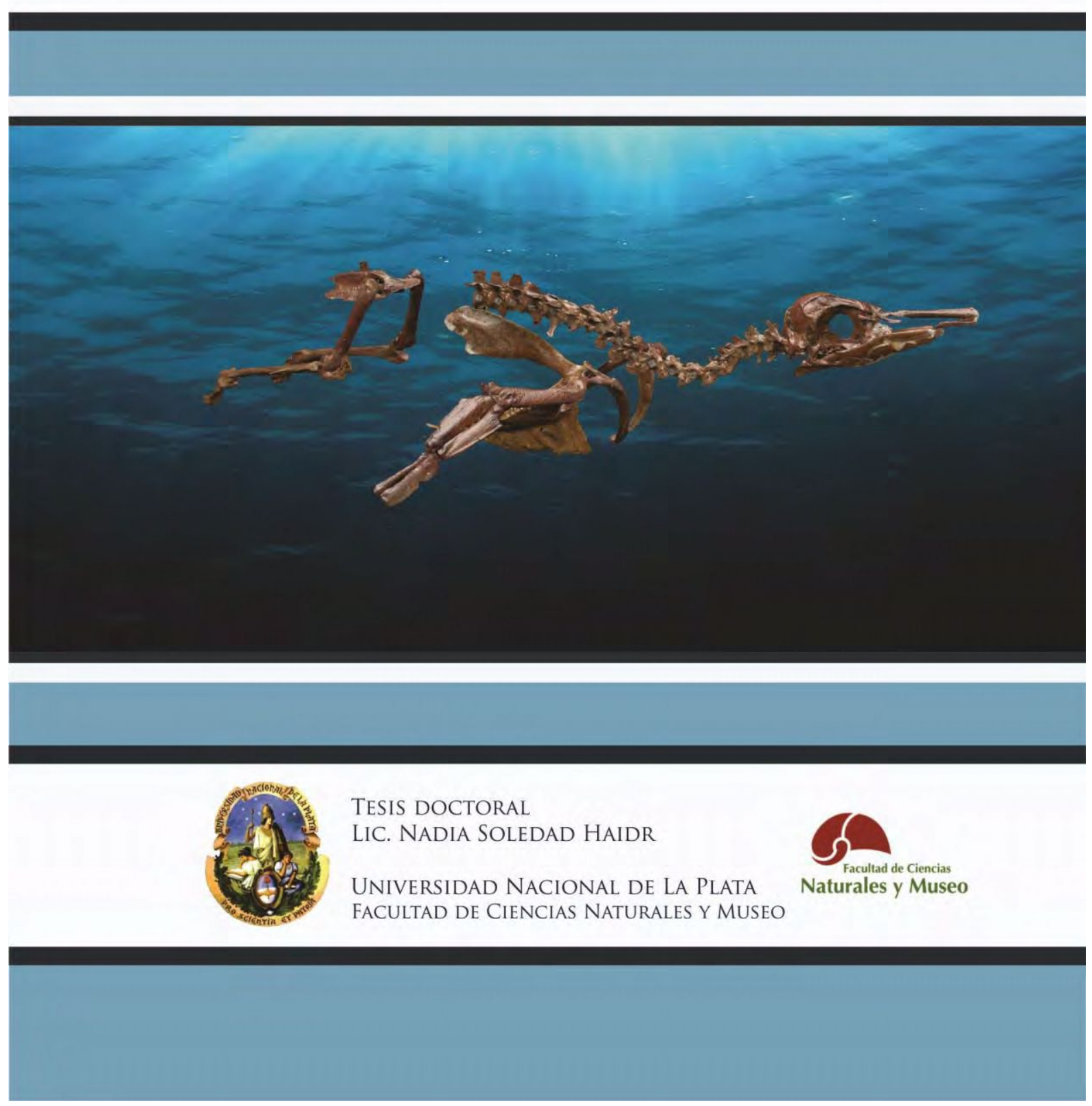


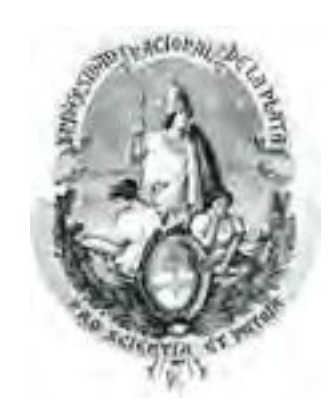

Facultad de Ciencias Naturales y Museo, Universidad Nacional de La Plata

\title{
Anatomía y morfología funcional del esqueleto de pingüinos (Aves, Sphenisciformes) actuales, aplicaciones en los fósiles
}

Lic. Nadia Soledad Haidr

\author{
Dirección
}

Dra. Carolina Acosta Hospitaleche

Dr. Flavio Quintana 


\section{ÍNDICE}

AGRADECIMIENTOS I

\begin{tabular}{lr} 
RESUMEN & IV \\
\hline
\end{tabular}

ABSTRACT $\quad$ V

CAPÍTULO I INTRODUCCIÓN

MODIFICACIONES ADAPTATIVAS AL MEDIO ACUÁTICO

PALEOBIOLOGÍA, MORFOLOGÍA FUNCIONAL Y ECOMORFOLOGÍA

PINGÜINOS ACTUALES: BUCEO Y DIETA

OBJETIVO GENERAL

\section{CAPÍTULO II MATERIALES Y MÉTODOS}

MATERIALES

ABREVIATURAS INSTITUCIONALES

MÉTODOS

TERMINOLOGÍA EMPLEADA

ABREVIACIONES ANATÓMICAS

DISECCIONES MUSCULARES

ANÁLISIS DE LOS PESOS DE LOS MÚSCULOS

MORFOMETRÍA GEOMÉTRICA

ANÁLISIS ESTADÍSTICOS

\section{CAPÍTULO III CRÁNEO}

INTRODUCCIÓN

MORFOLOGÍA Y HÁBITOS ALIMENTICIOS

CIERRE Y APERTURA DEL PICO Y LA MANDÍBULA

OBJETIVO

MATERIALES

MÉTODOS

RESULTADOS: MIOLOGÍA COMPARADA

CAPA SUPERFICIAL

CAPA PROFUNDA

LIGAMENTOS

RESULTADOS: ANÁLISIS CRÁNEO

CONFIGURACIÓN DEL CRÁNEO, VISTA DORSAL

CONFIGURACIÓN DE LA CAJA CRANEANA, VISTA DORSAL

CONFIGURACIÓN DEL PICO, VISTA DORSAL

RESULTADOS: ANÁLISIS MANDÍBULA

CONFIGURACIÓN DE LA MANDÍBULA VISTA DORSAL 
DISCUSIÓN Y CONCLUSIONES

\title{
CAPÍTULO IV ALA
}

\author{
INTRODUCCIÓN \\ ADAPTACIONES OSTEOMUSCULARES DEL ALA Y CINTURA PECTORAL \\ OBJETIVOS \\ MATERIALES \\ MÉTODOS \\ RESULTADOS: MIOLOGÍA COMPARADA \\ MIOLOGÍA COMPARADA \\ PRIMERA CAPA \\ SEGUNDA CAPA \\ MÚSCULOS DE LA TERCERA CAPA \\ MÚSCULOS DE LA CUARTA CAPA \\ MÚSCULO DE LA QUINTA CAPA \\ ANÁLISIS DE LOS PESOS DE LOS MÚSCULOS \\ RESULTADOS: ANÁLISIS HÚMERO \\ CONFIGURACIÓN DEL HÚMERO VISTA DORSAL \\ CONFIGURACIÓN DEL HÚMERO VISTA VENTRAL \\ DISCUSIÓN INTEGRAL DE LOS ANÁLISIS DEL HÚMERO \\ RESULTADOS: ANÁLISIS CORACOIDES \\ CONFIGURACIÓN DEL CORACOIDES EN VISTA ESTERNAL \\ CONFIGURACIÓN DEL CORACOIDES EN VISTA DORSAL \\ CONFIGURACIÓN DEL CORACOIDES EN VISTA VENTRAL \\ DISCUSIÓN INTEGRAL DE LOS ANÁLISIS DEL CORACOIDES \\ RESULTADOS: ANÁLISIS ESTERNÓN \\ CONFIGURACIÓN DEL ESTERNÓN EN VISTA LATERAL \\ CONFIGURACIÓN DEL ESTERNÓN EN VISTA VENTRAL \\ DISCUSIÓN INTEGRAL DE LOS ANÁLISIS DEL ESTERNÓN \\ DISCUSIONES Y CONCLUSIÓN
}

\section{CAPÍTULO V MODULARIDAD, INTEGRACIÓN Y CORRELACIÓN ENTRE}

\section{ESTRUCTURAS}

INTRODUCCIÓN

MATERIALES

MÉTODOS

RESULTADOS

HIPÓTESIS DE MODULARIDAD

COVARIACIÓN ENTRE ESTRUCTURAS: PLS

DISCUSIÓN Y CONCLUSIONES 


\section{CAPÍTULO VI PINGÜINOS FÓSILES, EL CASO DE MADRYNORNIS MIRANDUS}

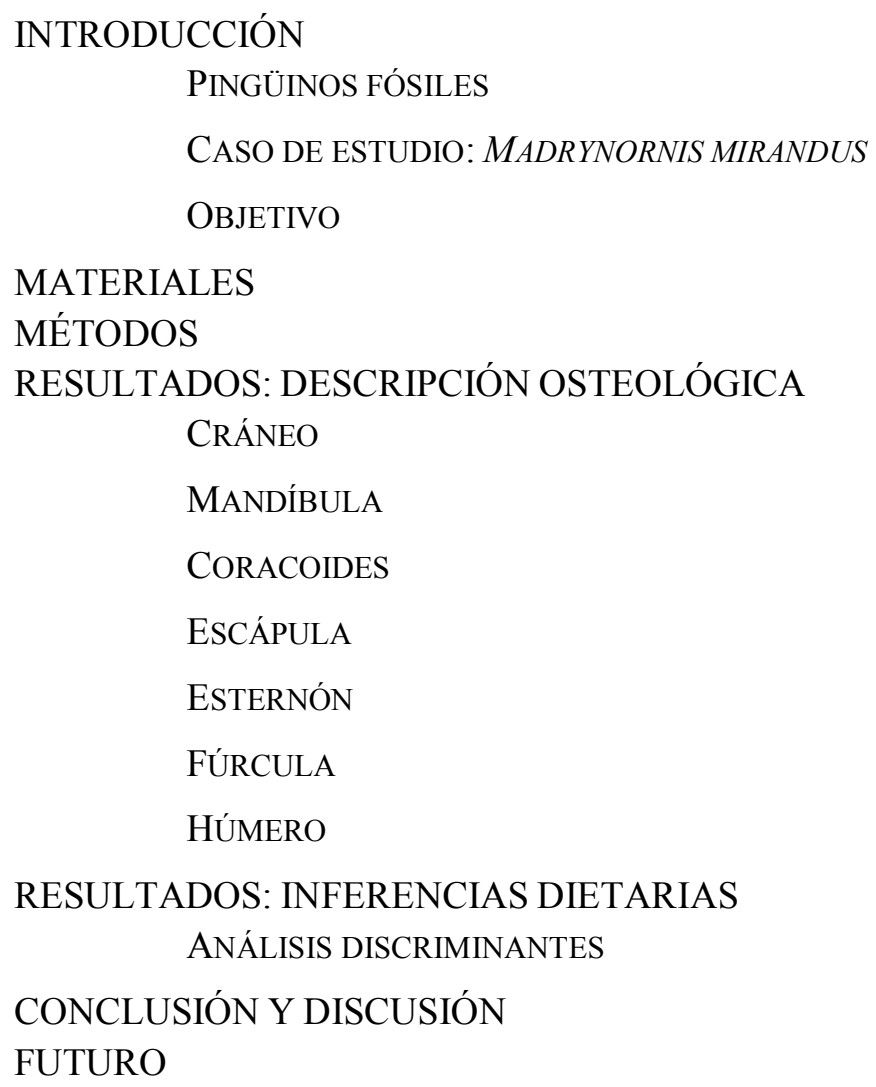

\section{CAPÍTULO VII BIBLIOGRAFÍA}




\section{AGRADECIMIENTOS}

A mi directora, Carolina Acosta Hospitaleche. Por tantos años de confianza y apoyo, por estar presente en todo momento y al instante, en la distancia y cercanía.

A mi director, Flavio Quintana, quien me dio una inmensa oportunidad sin siquiera conocerme. Y a todo el LEPTOMAR por la ayuda brindada.

A los jurados, Dr. Eduardo Tonni, Dr. Jorge Noriega, y Dr. Diego Montalti por sus valiosos comentarios.

A la Facultad de Ciencias Naturales y Museo, Universidad Nacional de La Plata, por los años de invaluable formación.

A CONICET, por financiar esta tesis. Y al IBIOMAR-CENPAT por brindarme un lugar de trabajo.

A Puerto Madryn, el que fue mi hogar estos cinco años, uno de los lugares más maravillosos de la Tierra.

A mis compañeros de oficina en el CENPAT. Nori Lisnizer, Cristian Marinao, Taty Kasinsky, Gaby Torchio, Ramiro Braga y Julián Pontones, gracias por los mates, las risas, y la compañía diaria.

A Pablo Yorio, Nicolás Suárez, Nora Lisnizer, Alejandro Gatto, Tatiana Kasinsky, Cristian Marinao, y Cynthia Ibarra, por haberme ayudado en la recolección de pingüinos, invitado de campaña a las costas de Chubut, y por haberme hecho sentir bienvenida desde el primer día.

A Julio Torres y Mirsha Quinto Sánchez, por las largas charlas sobre morfometría geométrica.

A Luciana Gallo, y a Rodrigo Amado, Olalla Martínez, Ariel Serra, Germán Solveira y todo el equipo del Parque Interjurisdiccional Marino Costero Patagonia Austral, quienes desinteresadamente colaboraron en la colección de especímenes.

A María Teresa Dozo, por su amable colaboración durante estos años en el CENPAT.

A Eduardo Ruigómez, por permitirme acceso a Madrynornis mirandus.

A Mercedes Santos, quien donó especímenes para disección.

A la Fundación Natalie Goodall, Diego Montalti, Mariana Picasso, Marcelo Reguero, y Yolanda Davis, por recibirme en las colecciones tan amablemente, haciendo que todo fuese más fácil.

A Natalie Goodall, por haberme abierto las puertas de su Museo tantas veces, e invitarme a volver una vez más.

A Moni Torres, Ani San Martín, y Kta Marchesi, por su ayuda en el museo y darme un lugar en mis estadías en Ushuaia.

A los compañeros pasantes del Museo Acatushún, en especial a Laura Diaz Burgos, Flor Leone, y Facundo Deforel, por la compañía en esos largos días frente al canal Beagle. Del fin del mundo me llevo muchos momentos felices. Hasta siempre, Acatushún. 
A Andrés Ibáñez, por haber confiado en mí ayudándome, a la vez, a cumplir un sueño. Y por compartir sus materiales colectados para las disecciones musculares.

A todos los integrantes de la Sección de Ornitología del Museo de La Plata. En especial a Daniela Fuchs, Lucas Garbin, Andrés Ibáñez, Juan Manuel Girini, y Diego Montalti, quienes me brindaron un lugar para trabajar siempre que lo necesité.

A Eduardo Etcheverry y Luis Pagano, quienes también en muchas oportunidades abrieron desinteresadamente las puertas de su taller para que pudiera diseccionar pingüinos.

A Walter Acosta, quien hizo que diseccionar pingüinos se convirtiera en una tarea mucho más sencilla después de sus enseñanzas.

A la División de Paleontología Vertebrados, por brindarme un lugar para trabajar, y permitirme el uso del escáner 3D.

A Agustín Ruella, quien me ayudó con los escaneos 3D de Madrynornis mirandus haciendo un excelente trabajo. Y por su incondicional amistad.

A aquellos que fueron parte del camino. Adriana y Jerry, quienes me ayudaron en una etapa fundamental de mi educación, y señalaron el camino que me llevó a conocer gente como Joe Bopp, mi primer mentor y quien me mostró por primera vez este mundo de los museos.

A Federico Laos, quien me ayudó muchas veces con su perfecto inglés.

A mis amigos de la facultad por todos esos inolvidables años vividos, y por seguir presentes en cada encuentro. Sabri Hochman, Mai Scheffer, Mili Laborde, Agus Cremaschi, Agus Perez, Pato Santamarina, Agus Ruella, Jesica Sansiñena y Nico Kass, gracias.

A Kristin, Victoria y Tari, por su amistad a lo largo de los años y los kilómetros.

A Facu, por su compañía y cariño, que hizo que la Patagonia no fuera tan lejana. A la tesis le debo el haberlo conocido.

A mi familia, quienes me acompañaron en cada etapa de mi vida. Y a quienes les debo y dedico cada logro.

A mi mamá, por haberme dado siempre la libertad y el apoyo para seguir mis sueños.

A mi papá, por transmitirme su amor a los animales marinos y alentarme siempre.

A mi abuela Norma, por seguir esperándome con ese cariño, como cuando iba a la escuela.

Al abuelo Juan Carlos, por sus historias, su bondad, y por haberme acompañado desde chica a la biblioteca.

A los abuelos, José y Susana, por los hermosos recuerdos de la infancia.

A Leia y Pip, quienes todavía me reciben como si no me hubiese ido nunca.

Y a mis hermanos. Josefina, Lucía y Mauro, mis compañeros de la vida, por hacerme reír como nadie. Son mi tesoro más grande. 
Al Abuelo y a la Abuela 


\section{RESUMEN}

Los pingüinos (Aves, Sphenisciformes) poseen una serie de modificaciones anatómicas, fisiológicas, y comportamentales relacionadas con el buceo. Su abundante registro fósil se remonta al Paleoceno, y cuenta con especímenes fósiles en excelente estado de conservación como por ejemplo Madrynornis mirandus (Mioceno Medio tardío de Patagonia), el cual resulta un interesante caso de estudio por su cercanía filogenética con las especies actuales y porque presenta un esqueleto casi completo. El estudio morfológico de formas actuales, de las cuales se posee información sobre el tipo de presa y buceo, sirve de base para obtener modelos anatómicos que podamos relacionar con el hábito de vida que poseen los pingüinos. Esto nos permite inferir y proponer el posible hábito que la especie fósil habría tenido. En la presente tesis se diseccionaron un gran número de pingüinos de diferentes especies, para estudiar en detalle la musculatura del cráneo y aquella relacionada con el movimiento del ala. También se tomaron fotos en diferentes vistas del cráneo, mandíbula, húmero, coracoides, y esternón, de un gran número de especímenes, para realizar análisis de morfometría geométrica. Esto nos permitió llevar a cabo análisis exploratorios de la variación de forma que incluyeron un gran número de especies actuales, estudiar si existen diferencias morfológicas entre las categorías dietarias asignadas a las especies actuales, determinar de qué manera varía la morfología entre categorías, y por último estudiar si los cambios morfológicos entre estructuras diferentes (como por ejemplo entre el cráneo y el húmero) se correlacionan. Además se re-describió a Madrynornis mirandus, el espécimen fósil bajo estudio, y se lo incluyó en los análisis. Resultó que las categorías alimentarias pre-asignadas presentan diferencias morfológicas significativas para todas las estructuras analizadas. Se determinó además, que existe una moderada correlación en la variación de forma entre estructuras tales como el cráneo y el húmero, y que el cráneo-pico varían como una estructura integrada. En particular, para Madrynornis mirandus se obtuvieron diferentes clasificaciones en categorías dietarias dependiendo del hueso analizado, pero mayoritariamente fue clasificado como piscívoro. Los resultados demuestran la factibilidad y la utilidad de la aplicación de estos modelos de modo predictivo para establecer la dieta y los hábitos tróficos en los pingüinos fósiles, a partir de los elementos del ala, la cintura pectoral, y el cráneo. Inferimos que Madrynornis mirandus habría sido un pingüino piscívoro, aunque oportunista y con una posible tendencia a la captura de presas pequeñas como crustáceos. 


\section{ABSTRACT}

Penguins (Aves, Sphenisciformes) have several anatomical, physiological, and behavioral adaptations related to diving. Their abundant fossil record dates back to the Paleocene and presents many fossil specimens with a good preservation state. Such is the case of Madrynornis mirandus (Middle late Miocene from Patagonia), an interesting case for its close phylogenetic relationships with modern taxa, and also because it presents an almost complete skeleton. Morphological studies on extant species from which we have information on prey and diving performance, are fundamental to obtain anatomical models that relate to the mode of life that the penguins have. A large number of different penguin species were dissected in order to study the cranial musculature and also the muscles involved in wing movements. Photographs of different views of the skull, mandible, humerus, coracoid, and sternum, were taken on several specimens in order to perform morphogeometric analyses. These analyses included, principal component analyses to explore shape variation; multivariate analyses of variance, to test if the morphological differences among preassigned diet categories were significantly different; canonical variate analyses to study the maximized morphological differences among dietary categories; and partial least square analyses to test if the morphological changes among different structures (e.g. between the skull and humerus) correlates. A redescription of Madrynornis mirandus, the fossil specimen under study, was performed. The fossil was also included in some of the morphogeometric analyses. The results show that there are differences among the dietary categories pre-assigned to the extant taxa. A moderate correlation between shape variation among different skeletal elements, such as the skull and humerus, was also found. The neurocranium and beak were found to vary as an integrated structure. In particular, Madrynornis mirandus was classified in different dietary categories depending on which bone was analyzed, however, it was mostly found to be among the piscivores. The results show the feasibility and utility of these anatomical models to be applied in a predictable manner to establish the diet and trophic habits in the fossil penguins from elements of the wing, scapular girdle, and skull. We infer that Madrynornis mirandus might have been a piscivorous penguin, also with a tendency to capture prey of small sizes such as crustaceans. 


\section{INTRODUCCIÓN}

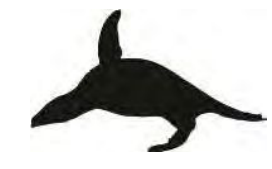

\section{MODIFICACIONES ADAPTATIVAS AL MEDIO ACUÁTICO}

Los pingüinos (Aves, Sphenisciformes) poseen una serie de modificaciones anatómicas, fisiológicas, y comportamentales relacionadas con su hábito de vida íntimamente vinculado con el mar y al buceo. Esto incluye la pérdida de pneumaticidad, el acortamiento y aplanamiento de los huesos del ala, la reducción de la musculatura distal alar a tendones (Schreiweis, 1982), el gran tamaño del músculo elevador del ala $m$. supracoracoideus (Schreiweis, 19 ), la modificación extrema de las plumas conformando "escamas" (Watson, 1883), la reducción de zonas de apteria a un parche temporal de incubación y una zona de pérdida de calor en la cabeza (en algunas especies), la bipartición de la tráquea (Zeek, 1951), entre muchas otras.

Algunas de las características intrínsecas del esqueleto de los pingüinos, como la pérdida de la pneumaticidad, la alta densidad de los huesos y la reducción de la médula ósea (Meister, 1962), se suman a otros factores tales como los hábitos gregarios, y el uso de las mismas zonas de nidificación año tras año, generando un contexto altamente ventajoso en términos preservacionales. El registro fósil de los pingüinos se encuentra caracterizado por extensas y abundantes acumulaciones óseas en áreas cercanas a la línea de costa. Esto ha generado que sean, además, especialmente abundantes entre las aves (Ksepka \& Ando, 2011).

Actualmente, se considera que los pingüinos habrían evolucionado a partir de un ancestro volador (Simpson, 1946, 1 , ) y, a pesar de que los resultados obtenidos a partir de los análisis cladísticos realizados en las últimas décadas han sido variables, se estima que los Procellariiformes serían su grupo hermano (Giannini \& Bertelli, 2004; Bertelli \& Giannini, 2005; Ksepka et al., 2006). No obstante, gran parte de la historia evolutiva del grupo resulta ser aún un tema sin resolver. 


\section{PALEOBIOLOGÍA, MORFOLOGÍA FUNCIONAL Y ECOMORFOLOGÍA}

Las formas fósiles nos brindan solo información parcial de los organismos, ya que los organismos difícilmente se preservan completos. Las aves constituyen un grupo con un registro sumamente heterogéneo, ya que su preservación depende de la resistencia mecánica de sus esqueletos (lo cual varía en los distintos grupos), el tipo de acumulación (dependiente de los hábitos de nidificación y del ambiente de acumulación), y de los procesos destructivos a los cuales se ven sometidos. No obstante, estos restos constituyen, en muchos casos, la única evidencia disponible para analizar la paleobiología de muchas especies hoy extintas.

Los Sphenisciformes son un grupo ideal para realizar análisis de esta índole, ya que constituyen un grupo muy conservador y relativamente homogéneo desde sus orígenes. Si bien las tendencias adaptativas se han acentuado a lo largo de su historia evolutiva, muchos caracteres presentan escasa o nula variación a lo largo de más de 60 millones de años. Debido a esto, las especies actuales constituyen un grupo proxy por excelencia, donde se registran variaciones dietarias, en el tipo de buceo, de hábitos migratorios, de estrategias para la captura de los alimentos, etc, que nos permiten generar una base de datos sólida y confiable para la comparación y análisis de las formas fósiles.

El registro fósil de los pingüinos se ha incrementado notablemente en los últimos años gracias a los nuevos hallazgos, que combinados con tecnologías recientes, permiten extraer información de calidad para las estimaciones paleobiológicas y las reconstrucciones paleoambientales. Los estudios relacionados con la biología de animales que se han extinguido y de los cuales solo poseemos registro fósil, están enmarcados dentro de la paleobiología (Abel, 1912). En esta tesis, se analizará el caso de Madrynornis mirandus, un representante del Mioceno medio tardío, que habitaba las costas patagónicas hace más de 9 millones de años (Ver Capítulo VI). Se ha seleccionado esta especie por dos motivos en particular: M. mirandus es conocido a partir de un esqueleto completo articulado (MPEF PV

) con un grado de preservación excepcional, que brinda un detalle anatómico único para las especies fósiles de pingüinos. Además, M. mirandus constituye la especie más antigua del grupo corona de los pingüinos. Estos dos factores (la completitud del esqueleto y la estrecha relación con los grupos proxies o indicadores indirectos analizados), garantizan un mayor grado de certeza durante el análisis e interpretación de los datos. 
En esta tesis, el marco de referencia para el análisis del hábito alimenticio de $M$. mirandus está constituido por información ecológica, morfológica y funcional de detalle (estructuras óseas y musculares) de las especies actuales. Con estos datos, se realizaron análisis exhaustivos sobre las posibles correlaciones entre el complejo forma y función de cada estructura y de rol ecológico de cada una de las especies. Los resultados de estos análisis fueron integrados a la información morfo-anatómica de $M$. mirandus para estimar su hábito alimenticio.

Por consiguiente, las interpretaciones se han basado en la morfología de los elementos analizados, en especial aquellos caracteres que están involucrados con la función de las estructuras analizadas (Radinsky, 1987; Bock \& von Wahlert, 1965). Se seleccionaron estructuras que tengan implicancias en el desarrollo muscular, o las superficies de articulación, que nos pueden indicar los tipos de movimientos y nos brindan una idea sobre la magnitud de las fuerzas musculares que podrían ejercer (e.g. Rayner, 1988; Vizcaíno et al,

En este marco, las adaptaciones morfológicas pueden ser analizadas a partir de un estudio conjunto entre la morfología, función y la interacción entre complejos forma y función (Bock \& von Wahlert, 1965). Resulta importante definir algunos conceptos antes de continuar. Entendemos a la forma de un elemento, como su apariencia y configuración, a la función, como su acción o a la manera en que funciona, a la facultad, como el complejo forma-función, y al rol biológico, como el uso de la facultad (por parte del organismo) en su vida. Un detalle mayor de estas definiciones puede consultarse en Bock \& von Wahlert ( )

Volviendo entonces al caso particular de la dieta, el tipo de presa (que varía desde pequeños crustáceos gregarios como el krill, calamares, o hasta peces como la anchoíta o sardina, se relaciona con muchos atributos anatómicos como la forma del pico, o el desarrollo de las inserciones craneanas para la musculatura de apertura y cierre del pico (Zusi, 1975). Al estudio de la relación entre la morfología y el rol ecológico de una estructura se lo denomina ecomorfología (e.g Bock, 1994; Fortelius \& Solounias, 2000; Hopson, \& Ballance, 2001; Hopson, 2001; Esteban Trivigno, 2011; Vizcaíno et al., 2011). La ecomorfología (Karr \& James, 1975), busca cuantificar la variación de forma en relación, en este caso, con el tipo de hábito alimenticio. Algunos autores postulan que la morfología de las estructuras de los animales define el nicho (Keast, 1970). Cabe aclarar que ecomorfología y morfología funcional son dos aproximaciones de análisis diferentes. La ecomorfología, parte del concepto de rol biológico (Bock \& von Wahlert 1965) y depende de la información ecológica 
de las especies bajo estudio, mientras que la morfología funcional estudia la forma relacionada con la función (Bock, 1994). De todas maneras, están relacionadas, en tanto que la ecomorfología es dependiente de estudios morfofuncionales exhaustivos, relación que no es recíproca (Bock, 1994).

El estudio exhaustivo de la morfología de forma cuantitativa relacionada con su función, y analizando la correlación que puede existir con el rol ecológico de las especies, puede ayudarnos a inferir y proponer los hábitos de vida que las especies fósiles han tenido.

\section{PINGÜINOS ACTUALES: BUCEO Y DIETA}

Existe aún controversia en cuanto al número de especies de pingüinos que existen en la actualidad, que ronda entre los 17 y 19 (Ksepka \& Ando, 2011; García Borboroglu \& Boersma, 2015), siendo 18 el número más aceptado hoy en día. Este número incluye dos especies del género Aptenodytes (A. forsteri y A. patagonicus), siete del género Eudyptes (E. chrysocome, E. chrysolophus, E. moseleyi, E. pachyrhynchus, E. robustus, E. schlegeli, E. sclateri), dos géneros monoespecíficos que son Eudyptula minor y Megadyptes antipodes, cuatros especies del género Spheniscus (S. magellanicus, $S$. demersus, $S$. humboldti, $S$. mendiculus) y tres del género Pygoscelis (P. adeliae, P. antarctica, y P. papua).

Todos los pingüinos actuales atrapan a sus presas mediante buceos de persecución (Williams, 1995), ya sea que se trate de pequeños crustáceos como el krill antártico (Euphausia superba) o bogavantes (Munida gregaria), peces (como la anchoíta Engraulis anchoita, sardinas, o merluza común Merluccius hubbsi, entre otros), y calamares (Williams, 1995). Los pingüinos bucean a grandes profundidades, con una máxima registrada de 564 metros para los pingüinos emperadores (Wienecke et al., 2007). Si bien se sabe que las profundidades máximas se correlacionan con la masa corporal de los individuos (Williams, 1995), este parámetro al igual que los tipos de buceo, son también dependientes del tipo de presas que capturan (Wilson et al., 1991). El rango de presas que los pingüinos consumen es muy variable, así como también lo son la velocidad y las estrategias de escape de las mismas. Por tanto, los movimientos subacuáticos de los pingüinos no serán los mismos para aquellos que consumen pequeños crustáceos que para los que se alimentan de peces. 
A continuación se tratarán de manera general los hábitos alimenticios y de buceos para cada una de las especies incluidas en los diferentes análisis que se presentarán a lo largo de esta tesis. Se trata de información édita actualizada que puede ser ampliada a partir de las referencias brindadas.

\section{Aptenodytes}

El género está conformado por dos especies de pinguïnos de gran porte, Aptenodytes forsteri, y A. patagonicus. El pingüino emperador (Aptenodytes forsteri) es el de mayor talla en la actualidad. Ambos tienen picos alargados y parches de color amarillo/anaranjado en el pico y los laterales de la cabeza. Ambas especies tiene un período reproductivo largo que va de diez a trece meses (de tres a cuatro meses para las demás especies de pingüinos), donde las crías en guardería pasan un tiempo prolongado de ayuno durante el invierno. A. forsteri reproduce a lo largo de la costa de la Antártida, y A. patagonicus en islas subantárticas entre los paralelos $45^{\circ}$ y $55^{\circ}$ Sur (Williams, 1995; Otley et al , )

Aptenodytes forsteri (Fig. 1), o pingüino emperador posee una dieta que incluye principalmente peces (en su mayoría Pleuragramma antarcticum), y en menor medida calamares y krill (Offredo \& Ridoux 1986; Klages, 1989; Wienecke \& Robertson, 1997; Kirkwood \& Robertson, 1997; Cherel \& Kooyman 1998; Zimmer et al., 2007). Si bien en muchos casos la presa dominante por más del 90\% de masa fueron los peces, diversos autores han reportado la importancia del krill, que llega a ser un ítem predominante en masa en determinadas poblaciones y épocas del año (Klages, 1989; Kooyman et al., 2004). Los emperadores registran las velocidades de nado y profundidad de inmersión record entre los pingüinos, superando los 500 metros en algunos casos (Kooyman \& Kooyman, 1995, Wienecke et al., 2007), aunque en promedio bucean a profundidades menores a 200 metros (Wienecke et al., 2007). Realizan buceos pelágicos y bentónicos persiguiendo a sus presas (Kirkwood \& Robertson, 1997, Rodary et al., 2000a; Zimmer et al., 2008) y pueden llegar a viajar más de 1000 kilómetros en un mismo viaje de forrajeo (Williams, 1995). Aptenodytes forsteri será considerado como generalista y buceador pelágico de profundidad.

Aptenodytes patagonicus (Fig. 1), o pingüino rey es una especie pelágica (Bost et al., 2002) que bucea a profundidades de medias a grandes y principalmente durante las horas de luz (Kooyman et al., 1992; Wilson et al., 1993; Bost et al., 2002; Shiomi et al., 2016). Bost y 
colaboradores (2002) registraron buceos desde 120 a 250 metros en promedio, con profundidades máximas de $318 \mathrm{~m}$ (Sato et al, ) Su dieta se basa principalmente en peces $(95,3 \%$ en número en Bost et al., 2002), entre los cuales los peces Myctophidae son los más abundantes y en menor medida los calamares (e.g. en las islas Crozet siendo el porcentaje de pescado $100 \%$ de la biomasa total en otoño y primavera, y en invierno llegando a ser casi un 57\% de la biomasa de calamares: Cherel \& Ridoux, 1992; Cherel et al., 1996; Raclot et al., 1998; Bost et al., 2002; Gauthier-Clerc et al., 2002; Wienecke \& Robertson, 2006). Para futuras referencias Aptenodytes patagonicus será considerado como piscívoro y buceador pelágico de profundidad.

\section{Eudyptes}

Los pingüinos del género Eudyptes (Fig. 1) poseen un plumaje con el dorso negro, vientre blanco y una banda amarilla por encima de los ojos a modo de penacho. Sus ojos, además, son de un particular color rojo parduzco. Se distribuyen en Nueva Zelanda, islas subantárticas y templadas del océano Índico, Atlántico Sur, y Pacífico, costas patagónicas del Sur, y Antártida.

Eudyptes chrysocome (Fig. 1) o pingüino de penacho amarillo, es un pingüino que posee una distribución circumpolar, anidando en islas subantárticas y templadas del Atlántico, Océano Índico y Pacífico. Se reconocen actualmente dos subespecies, E. chrysocome chrysocome, y E. c. fiholi. Es una especie oportunista con una dieta generalista a lo largo de su distribución circumpolar. Para las poblaciones de Tierra del Fuego, por ejemplo, los crustáceos (el krill Euphasia sp, y el anfípodo Themisto gaudichaudii) representan la mayor ocurrencia en cuanto a número de especímenes, aunque los calamares presentan una mayor proporción en cuanto a biomasa, quedando los peces con un número más bajo tanto en número de presas como en masa total (Raya Rey \& Schiavini, 2005). De todas maneras, la proporción de cada una de estas presas varía por población, por temporada y año (Brown \& Klages, 1987; Tremblay et al., 1997; Hindell, 1988; Cherel et al., 1999; Clausen \& Pütz, 2002; Deagle et al., 2007; García Borboroglu \& Boerma, 2015 y bibliografía allí citada). Durante la época reproductiva, al menos, los buceos son cercanos a la costa y a bajas profundidades (Tremblay et al., 1997; Cherel et al., 1999; Putz et al. 2006). Cherel y colaboradores (1999) determinaron para poblaciones de penacho amarillo del norte una actividad de forrajeo costero principalmente con una profundidad máxima de $109 \mathrm{~m}$, y un 
promedio de 18,4 m. Eudyptes chrysocome será considerado como generalista y buceador nerítico de poca profundidad para los fines de nuestros análisis.

Eudyptes chrysolophus (Fig. 1) o pingüino de penacho anaranjado o macaroni posee una dieta basada en krill y anfípodos, peces y cefalópodos. Dependiendo de la zona y las temporadas, se ha reportado que se alimentaron principalmente de krill (>94\%) (Brown \& Klages, 1987; Croxall et al., 1988), mientras que otros estudios han mostrado una mayor abundancia de peces por sobre el krill y otros crustáceos, aunque en un porcentaje menor (Green et al., 1998; Waluda et al., 2010; Niemandt et al., 2016). Si bien esta especie es oportunista y generalista, se observa una preferencia marcada por el consumo de krill. Son buceadores de profundidades bajas (30 a 60 metros) pero llegan con más frecuencia a realizar buceos más profundos que los pingüinos de penacho amarillo (Croxall et al., 1993; Green et al., 1998; Whitehead et al., 2016). Realizan viajes lejos de la costa (a más de 400 kilómetros) fuera de la época reproductiva, mientras que durante la época reproductiva, se mantienen más cercanos, aunque fuera de la costa (Croxall \& Prince 1980; Barlow \& Croxall, 2002). En este estudio será considerado como generalista y buceador de costa afuera de poca profundidad.

\section{Eudyptula}

Eudyptula minor (Fig. 1), o pingüino azul o enano, habita en Nueva Zelanda y el Sur de Australia incluida Tasmania (García Borboroglu \& Boersma, 2016). Es la especie de pingüino de menor tamaño, y pesa en promedio entre 900 y 1.300 gr (Williams, 1995). Se alimenta principalmente de peces, en especial de anchoíta y sardinas, aunque es altamente oportunista y consume una amplia gama de peces que encuentra en su área de alimentación además de calamares (Klomp, 1987; Klomb \& Wooller, 1988; Montague \& Cullen, 1988; Chiaradia et al., 2003; Chiaradia et al, ). Se alimentan a pocos kilómetros de la costa (de 5 a $30 \mathrm{~km}$ ) y en zonas poco profundas (Montague, 1982; Klomb \& Wooller, 1988), buceando en general a menos de 15 metros de profundidad (Gales et al., 1990; Bethge et al., 1997; Hoskins et al., 2008). Para los fines de este trabajo, Eudyptula minor será considerado como piscívoro y buceador nerítico de poca profundidad. 


\section{Megadyptes}

Megadyptes antipodes (Fig. 1), o pingüino de ojo amarillo, es endémico de Nueva Zelandia. Posee una característica franja amarilla que empieza en el ojo y se extiende posteriormente rodeando la cabeza en los adultos. Es un pingüino de talla mediana y su periodo reproductivo va de septiembre a marzo como en la mayoría de las especies. Se alimenta casi exclusivamente de peces y en su mayoría de peces demersales (Seddon \& Van Heezik, 1990; Van Heezik, 1990a, b; Moore, 1999). Las profundidades máximas promedio registradas rondan los 40 a 120 metros (Seddon \& Van Heezik; 1990, Moore et al., 1995, Mattern et al., 2007), con una distancia máxima de la costa usualmente no mayor a unos 30 kilómetros (Moore et al., 1995). Para este estudio consideraremos a Megadyptes antipodes como piscívoro y buceador nerítico bentónico de poca profundidad (ver van Heezik, 1988; Seddon \& van Heezik, 1990; Moore et al. 1995; Moore \& Wakelin 1997; Mattern et al,

\section{Pygoscelis}

Los pingüinos pigoscélidos están conformados por tres especies que viven, en muchos casos, en simpatría en el continente antártico, islas antárticas y subantárticas. Estos son, Pygoscelis adelia (pingüino de adelia), Pygoscelis antarctica (pingüino de barbijo), y Pygoscelis papua (pingüino de papua) (Fig. 1). Viven en colonias, generalmente de más de una especie, y construyen sus nidos sobre el suelo con rocas que seleccionan y transportan desde los alrededores cercanos.

Pygoscelis antarctica (Fig. 1), según lo registrado por Kokubun y colaboradores (2010), usa la capa media epipelágica de la columna de agua para alimentarse, alcanzando en ocasiones profundidades mayores a las del pingüino papua, aunque nadando en zonas de mayor profundidad y más alejadas de la costa. Según lo observado por estos autores, el área de forrajeo central es mayor a los $200 \mathrm{~m}$ de profundidad y externa a la plataforma marina. Muy pocas veces realizan buceos bentónicos (Kokubun et al., 2010) y las distancias de buceo desde la costa resultan variables. Los buceos más profundos registrados fueron de 179 metros (Takahashi et al, 2003), con una distribución de frecuencias con picos de entre 90 y $95 \mathrm{~m}$ de máxima profundidad. Su dieta se basa casi exclusivamente en krill ( $>99 \%)$, más específicamente en krill antártico (Euphausia superba) (Takahashi et al., 2003; Niemandt et 
al., 2016), que capturan en el bentos (no pelágicamente de acuerdo a Takahashi et al., 2003). La especie es caracterizada como un buceador pelágico típico de aguas superficiales por Takahashi y colaboradores (2003). Para este estudio Pygoscelis antarctica será considerado como crustacívoro ${ }^{1}$ y buceador pelágico de poca profundidad (Mattern et al., ）

Pygoscelis adeliae (Fig. 1) se alimenta principalmente de krill (Ridoux \& Offredo 1989; Wienecke et al., 2000; Ainley, 2002; Takahashi et al., 2004; Cherel, 2008; Juáres et al., 2016). En invierno, la presa predominante es el krill antártico (Euphausia superba) (Clarke et al., 2003), mientras que en época reproductiva pueden incorporar a su dieta otras especies de krill (e.g. E. crystallorophias) y peces como Pleuragramma antarcticum (Ainley, 2002; Juáres et al., 2016). Aquellos que viven en la Península Antártica viajan una distancia menor y se alimentan principalmente de krill, mientras que aquellos que viven en el continente viajan distancias mayores y se alimentan de un espectro más amplio de presas que viven a diferentes profundidades (Clarke et al., 1998, ver para Península Antártica Juáres et al., 2016; y para continente Adelie Land Ainley, 2002). En cuanto al buceo, la profundidad promedio resultó estar por encima de los $100 \mathrm{~m}$, rango en el cual se encuentra el krill (Coudert et al, 001). Coudert y colaboradores (2001), registraron velocidades de ascenso y descenso de 2,1 m/s para los pingüinos adelia. No obstante, estos valores son mucho menores cuando la presa es localizada. Las variaciones en las velocidades de buceo son interpretadas en función de la búsqueda o manipulación de las presas, y sus velocidades de buceo son apenas superiores a la de sus presas (Kanda et. al, 1982). Esto ha sido motivo de análisis para Coudert y colaboradores (2001), quienes lo explican asumiendo que cuando las presas aumentan de tamaño las aves deben lograr mayores velocidades de captura para minimizar las persecuciones largas. Pygoscelis adeliae será considerado como crustacívoro y buceador pelágico de poca profundidad (ver Rodary et al., 2000b; Wienecke et al., 2000) en esta tesis.

Pygoscelis papua (Fig. 1) no migra y tiende a cazar cerca de la costa. Es un animal oportunista, cuya estrategia reside en consumir todo lo que encuentra en su camino, mientras permanece cerca de su nido. Para ello, amplía el espectro de ítems alimenticios a cazar. Como es esperable, se alimenta en proporciones variables de peces y krill mayoritariamente, y calamares, siendo considerado como un pingüino generalista (Croxall et al., 1988; Clausen \& Pütz, 2002; Xavier et al., 2018). Algunos estudios (Kokubun et al., 2010) muestran esta condición en la cual los pingüinos papua presentan un solapamiento con el área de forrajeo de

\footnotetext{
1 crustacívoro: pingüino que se alimenta de crustáceos de tamaño chico en especial krill. Si bien el término crustacívoro no es de uso común, en la presente contribución se ha decidido implementarlo a fines prácticos.
} 
los pingüinos de adelia de un 68,5\%. No obstante, y debido a que los pingüinos adelia forrajean en un área mayor, solo ven solapada su superficie en un $26 \%$ dado que las áreas aprovechadas por los pingüinos papúa son mucho menores. Realizan buceos bentónicos, aunque no necesariamente profundos (Kokubun et al., 2010). Se ha reportado un área de forrajeo central dentro de la plataforma marina, a una profundidad menor a los $200 \mathrm{~m}$, donde los especímenes de krill antártico capturados por los papua corresponden a hembras, o a ejemplares de mayor tamaño, respecto de los atrapados por los pingüinos adelia (Kokubun et al., 2010). Si bien hay trabajos que muestran que la distribución del krill es por parches y que la composición del sexo o el tamaño corporal pueden variar entre parches cercanos (Watkins et al., 1992; Watkins \& Murray, 1998), no existe evidencia que el krill hembra, o los de mayores tallas, se ubiquen más hacia el fondo. Los pingüinos papua habitualmente bucean a mayor profundidad alimentándose de mayor proporción de peces pelágicos en comparación con sus congéneres (Volkman et al., 1980; Croxall et al., 1988; Mori \& Boyd 2004), incluso Volkman y colaboradores (1980) sugieren una partición de nichos entre sexos, indicando que los machos comen un $23 \%$ más peces que las hembras. Esta estrategia de alimentarse en el fondo tendría que ver con un aumento de las probabilidades de hallar presas y un incremento en la eficiencia del buceo con fines de alimentación (Kokubun et al., 2010). A lo largo de este trabajo Pygoscelis papua será considerado como generalista y buceador nerítico de poca profundidad (ver Mattern et al., ）

\section{Spheniscus}

El género está representado por cuatro especies, Spheniscus demersus (pingüino africano) que anida en las costas de Sudáfrica, Spheniscus magellanicus (pingüino magallánico) de las costas patagónicas desde lo $40^{\circ}$ a los $55^{\circ} \mathrm{S}$ (García Borboroglu \& Boersma, 2 ), Spheniscus humboldti (pingüino de Humboldt) en las costas pacíficas sudamericanas desde los $5^{\circ}$ hasta los $42^{\circ} \mathrm{S}$ (García Borboroglu \& Boersma, 2015) y Spheniscus mendiculus (pingüino de Galápagos) endémico de las islas Galápagos. Poseen un patrón de coloración blanco y negro con anillos, con variaciones inter-específicas. Son los pingüinos con distribución más tropical, llegando incluso hasta el Ecuador en el caso del pingüino de las Galápagos, aunque siempre se vinculan con corrientes de aguas frías. Son principalmente piscívoros, a excepción de Spheniscus mendiculus que es más generalista (Steinfurth, 2007), se alimentan en grupo de peces pelágicos y costeros (esto último en el 
caso del pingüino de Galápagos) a profundidades bajas, confundiendo a sus presas por el patrón de coloración de su plumaje.

Spheniscus magellanicus (Fig. 1) es una especie migratoria que se reproduce en Patagonia y permanece pelágica a lo largo de miles de kilómetros (Martínez, 1992) de la costa. Se alimentan de cardúmenes de peces (principalmente anchoíta, sardinas y pejerrey), y calamares en menor medida (Illex y Loligo), y en su distribución más austral su dieta también incluye Munida (Clausen \& Pütz, 2002; Schiavini et al., 2005; Scioscia et al., 2014; Silva et al., 2015). Sus presas son de 25-160 mm de tamaño e incluyen Engraulis ringens, E. anchoita Sprattus fuegensis, Ramnogaster arcuate, Merluccius hubbsi, y Austratherina smitta (Martínez, 1992). La profundidad de buceo promedio, en zonas cercanas a varios sitios de nidificación en Patagonia, es de 25 m, con un pico máximo de 88,7 m (Sala et al., 2014). El pingüino de magallanes caza en grupo (Croxall, 1987; Boersma, 1976), y presenta estrategias de captura complejas. Han sido reportados casos de calamares atrapados desde abajo (Boswall \& MacIver, 1975), además de cardúmenes acarreados para luego ser atrapados (Wilson et al , ) Spheniscus magellanicus será considerado como piscívoro y buceador pelágico de poca profundidad para los análisis siguientes.

\section{OBJETIVO GENERAL}

El objetivo general en el cual se enmarca el presente trabajo de tesis es el de proponer modelos anatómicos-funcionales para los pingüinos piscívoros y crustacívoros que permitan interpretar los requerimientos ecológicos de las especies extintas. 


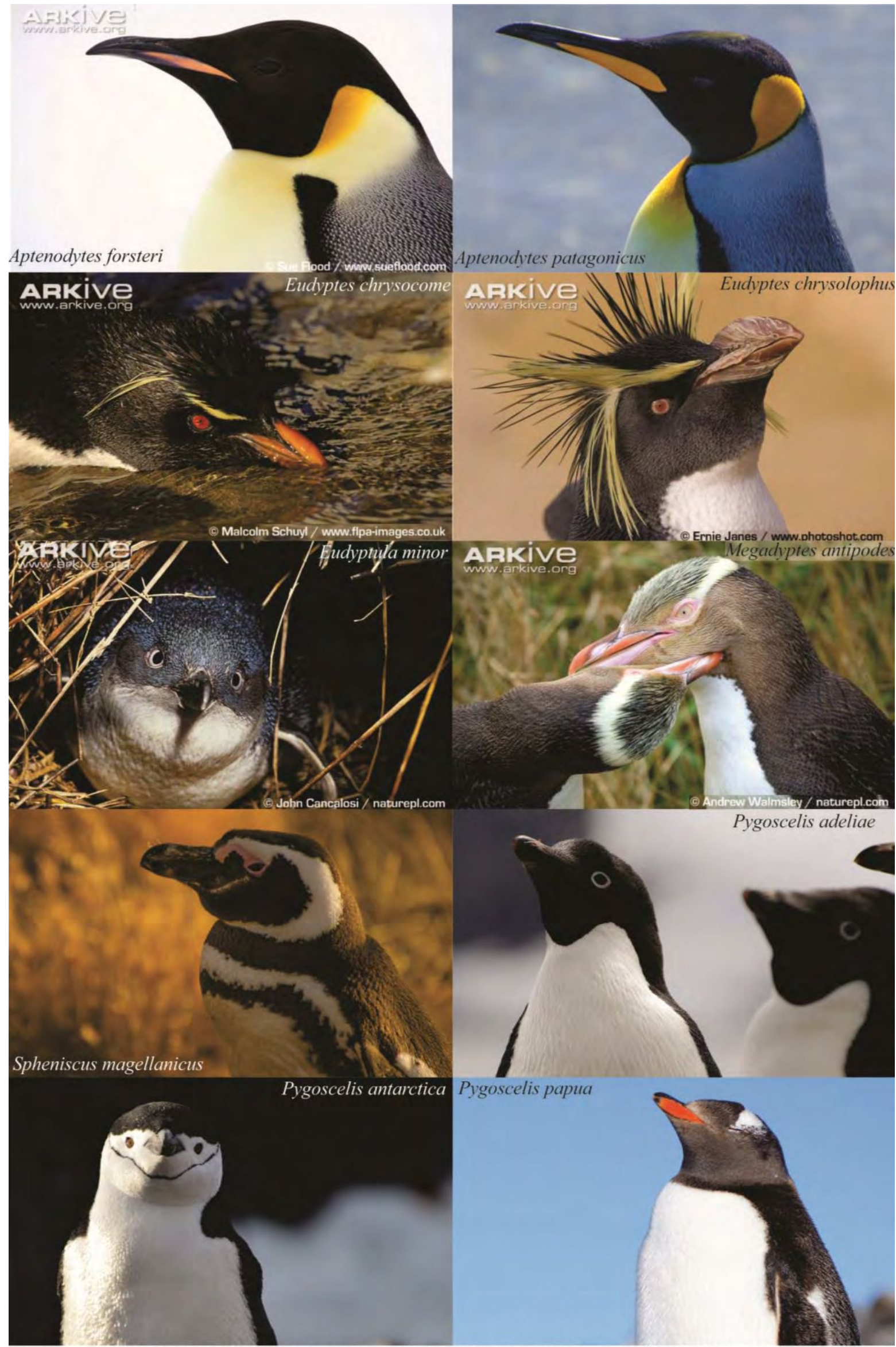

Figura 1 Pingüinos actuales, fotos de algunas de las especies que fueron incluidas en los análisis. Fotos tomadas de www.arkive.org o propias de no estar aclarado. 


\section{II}

\section{MATERIALES Y MÉTODOS}

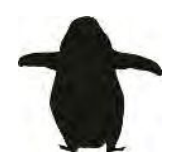

\section{MATERIALES}

La totalidad de los materiales utilizados en los análisis de morfometría geométrica corresponden a individuos adultos, la mayoría de sexo indeterminado, variable que se ha dejado al margen de nuestro análisis sabiendo que las variaciones debidas al dimorfismo sexual fueron desestimadas en publicaciones previas (Kerry et al., 1992; Acosta Hospitaleche \& Tambussi, 2006; Livezey, 1989). Lamentablemente, no se han realizado análisis que ratifiquen estos resultados, ya que sería necesario contar con una gran cantidad de especímenes frescos que puedan ser sexados fehacientemente. En el Anexo I se agrupan los materiales empleados para cada una de las configuraciones utilizadas. En el Anexo II, se incluyen los especímenes utilizados en los análisis de Partial Least Square (PLS), en los cuales es requisito la correspondencia individuo a individuo de los dataset a analizar.

Un total de 30 ejemplares fueron diseccionados. La muestra incluye dos especímenes de Eudyptes chrysocome, 20 de Pygoscelis adeliae, cinco de P. papua y tres de Spheniscus magellanicus de diferentes edades. Las categorías etarias fueron establecidas como: pichones (en nido y emplumando), juveniles (individuos con plumaje juvenil al momento de ser encontrado) y adultos (plumaje adulto, es decir mayor al año de edad).

Los individuos de Spheniscus magellanicus fueron recolectados oportunísticamente en las costas de la provincia del Chubut, en las localidades de Puerto Madryn y en Punta Norte, con permisos otorgados por la Dirección de Flora y Fauna, y por la Secretaría de Turismo de la Provincia del Chubut (2014/2015: Disposición n²2 -DGGTyO/14, Disposición n $n^{\circ}$ 61/2014-DF y FS -SSGyA; 2015/2016: Disposición nº96 -SsCyAP/15, Disposición $n^{\circ}$ 62/2015-DF y FS -SSGyA; 2016/2017: Disposición nº93 -SsCyAP/16, Disposición $n^{\circ}$ 62/2016-DF y FS). Mientras que, los individuos de Pygoscelis adelia y $P$. papua fueron recolectados durante las campañas antárticas del Instituto Antártico Argentino (IAA) de la Dirección Nacional del Antártico (DNA), grupos a cargo de la Dra. Mercedes 
Santos (IAA-DNA), Dr. Diego Montalti (IAA-DNA, CONICET) y Dr. Andrés Ibáñez (CONICET), en las colonias reproductivas cercanas a la Base Esperanza (Península Antártica) y Base Carlini (Isla 25 de Mayo, Islas Shetlands del Sur), Antártida.

Todos los especímenes colectados corresponden a aves muertas por causas naturales. Se descartaron los especímenes con signos de descomposición avanzada, lo cual redujo la cantidad de materiales disponibles para las disecciones y observaciones de tejidos frescos. Las altas temperaturas alcanzadas en la provincia del Chubut durante los períodos de anidada resultaron totalmente desfavorables durante los muestreos en el campo.

\section{Abreviaturas institucionales}

Los especímenes consultados se encuentran depositados en las siguientes colecciones:

MACN, Museo Argentino de Ciencias Naturales Bernardino Rivadavia, Buenos Aires.

MLP O, Museo de La Plata, División Vertebrados, Sección Ornitología, La Plata.

MLP PV, Museo de La Plata, División Paleontología Vertebrados, La Plata.

MNH, Natural History Museum, Londres.

NRM, Naturhistoriska riksmuseet, Estocolmo.

MPEF PV, Museo paleontológico Egidio Feruglio, Trelew.

RNP A, Museo Acatushún de Aves y Mamíferos Marinos-Fundación Natalie Goodall, Tierra del Fuego.

\section{MÉTODOS}

\section{Terminología empleada}

Las descripciones osteológicas siguen la terminología propuesta por Baumel (1993). Sólo cuando resultó necesaria la incorporación de bibliografía más actualizada, se empleó la terminología osteológica propuesta por Livezey y Zusi (2006). Esta decisión se tomó 
teniendo en cuenta la consideración de que a pesar de que la propuesta de Livezey y Zusi (2006) es más actual y cubre una mayor cantidad de caracteres osteológicos, la contribución de Baumel (1993) posee un uso ampliamente aceptado en el ámbito de la comunidad ornitológica y paleornitológica.

Para la nomenclatura miológica, en cambio, se sigue la propuesta de Schreiweis (1982) para la musculatura alar, ya que se basa en la anatomía derivada que presentan los Sphenisciformes, y se ajusta más apropiadamente a los casos descritos. Los términos propuestos por Baumel (1993) y por Zusi (1975) fueron empleados para la musculatura craneal.

\section{Abreviaciones anatómicas}

Sólo incluiremos las abreviaciones de los términos anatómicos que aparecen reiterativamente en el texto. Estas son, c., cotyla; lig., ligamentum; m., musculus; y proc., processus. El resto de los términos serán usados en su forma completa para facilitar la lectura.

\section{Disecciones musculares}

Los individuos colectados frescos fueron inmediatamente frizados para su preservación y luego descongelados oportunamente varias horas previas a la disección. Los músculos fueron removidos por orden de aparición, desde su origen hasta su inserción con uso de escalpelo y tijera quirúrgica. Se describieron por capas, tanto para la cabeza como para el complejo cintura escapular/ala, como se detalla en la metodología del capítulo III y IV.

Se llevó a cabo una descripción exhaustiva del origen e inserción de cada músculo haciendo énfasis en la visualización de las diferencias que pudieran hallarse entre las especies estudiadas y entre los estadios ontogenéticos incluidos. Las observaciones realizadas a partir de las disecciones fueron comparadas y discutidas con las de Schreiweis (1982), detallando los casos en los que se no encontraron correspondencias claras.

Para la descripción de la musculatura se consideró al animal en posición de nado (Fig. 1), siguiendo a Baumel (1993). Tomamos al origen como la unión más proximal del músculo, 
y a la inserción como el lugar de fijación más distal. En el caso particular del húmero, se sigue a (Jadwiszczak, 2012), en cuyo caso el ala está paralela al plano longitudinal del animal.
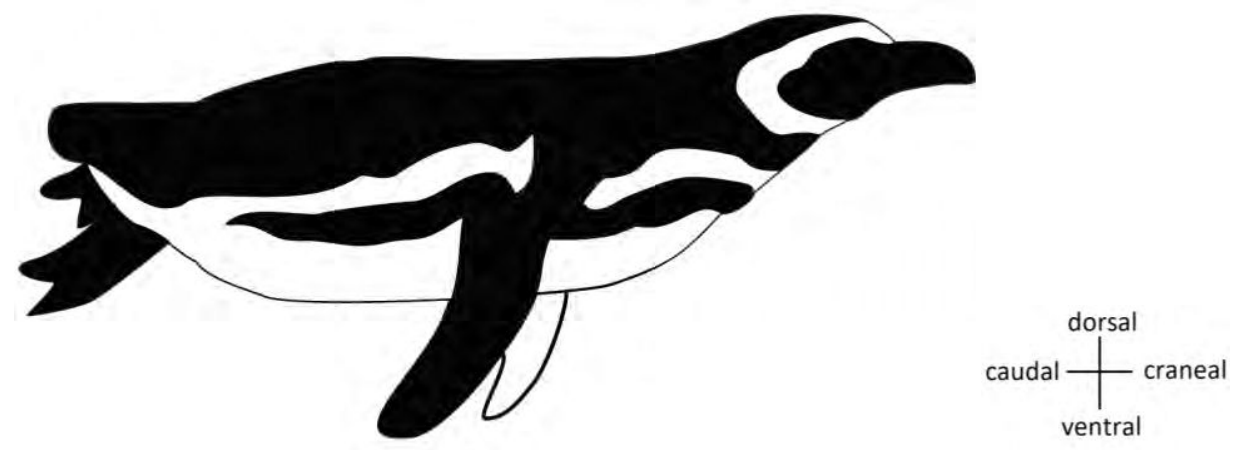

Figura 1 Pingüino en posición de nado, con los ejes para ubicación anatómica.

\section{Análisis de los pesos de los músculos}

Una vez removidos los músculos desde su origen hasta su inserción, fueron pesados en una balanza analítica Shimadzu modelo TX323L 0.02 × 320 g. Los valores obtenidos de los pesos del $m$. pectoral thoracica, y del $m$. supracoracoideus (principales músculos en la adducción y elevación del ala respectivamente) fueron utilizados en una regresión con el largo del culmen (proxy) del tamaño y edad del animal. Esto se hizo a fin de observar cómo era el aumento en peso de ambos músculos por separado para los diferentes estadios.

\section{Morfometría Geométrica}

La morfometría geométrica es una aproximación al estudio de la morfología que busca analizar la forma cuantitativamente. En complemento con la morfometría tradicional que estudia distancias entre dos puntos de interés, la morfometría geométrica, generalmente mediante coordenadas de landmarks, cubre todas las combinaciones posibles entre los puntos a estudiar. Resultando en un estudio integral de la forma, y no de distancias puntuales. 


\section{Forma}

La forma la entendemos según Kendall (1977) como "toda la información geométrica que permanece cuando los efectos de ubicación, escala y rotación son filtrados de un objeto".

\section{Tamaño: tamaño del centroide}

El tamaño de centroide se calcula como la raíz cuadrada de la suma de las distancias al cuadrado de los landmarks al centroide.

$$
C S(X)=\sqrt{\sum_{i=1}^{K} \sum_{j=1}^{M}\left(X i j-C_{j}\right) 2}
$$

Este valor adimensional (tamaño de centroide) permite escalar la configuración de landmarks, y calcular las distancias de procrustes. Conservar este valor para cada especiemen de cada configuración nos podrá servir para realizar, por ejemplo, estudios de alometría.

\section{Landmarks}

Una de las maneras mediante la cual la morfometría geométrica estudia la geometría de la forma es a través de landmarks (Bookstein, 1978). Estos son puntos en el espacio que indican estructuras anatómicas homólogas.

Los landmarks deben cumplir ciertas condiciones (Rohlf, 2005) como:

- no alterar su posición con respecto a los demás landmarks,

- proveer adecuada cobertura morfológica,

- ser encontrados de manera certera en todos los especímenes,

- yacer en el mismo plano.

La elección de una configuración de landmarks (es decir el conjunto de landmarks para una estructura dada) depende de las características del hueso a analizar y de la pregunta que se quiera afrontar. En este caso, nuestras preguntas son morfofuncionales, por lo que nos interesa estudiar estructuras relacionadas con los puntos de inserción y origen muscular y 
superficies de articulación. Además de estas estructuras, la configuración debe lograr captar la morfología general del elemento óseo a estudiar.

Los landmarks se clasifican en, tipo I o anatómicos, tipo II, o matemáticos, y tipo III de contorno, construidos, pseudo-landmarks o semilandmarks (Bookstein, 1991).

Tipo I o anatómicos: Son los óptimos. Estos landmarks se encuentran en puntos de yuxtaposición de diferentes tejidos como pueden ser las suturas de tres huesos diferentes (Bookstein, 1978). Son puntos anatómicamente homólogos e indiscutibles. Las aves presentan alto grado de fusión en su cráneo, y los huesos largos no poseen naturalmente gran cantidad de puntos que cumplan con la definición para estos landmarks. Por lo tanto, pocos son los landmarks anatómicos que se pudieron ubicar para nuestro estudio.

Tipo II o matemáticos: Son puntos de máxima o mínima curvatura (Bookstein, 1978). Estos landmarks son respaldados sólo por la geometría de la estructura. Al contrario de la situación de los landmarks anatómicos, los landmarks geométricos fueron ampliamente usados para las diferentes estructuras óseas en la presente contribución.

Tipo III o de contorno: Este tipo es definido a partir de otros landmarks. Son considerados como puntos extremos (Bookstein, 1978), construidos (Lele y Richtsmeier,

) y "pseudo-landmarks" (Dryden y Mardia ( ) y se refieren a puntos localizados en cualquier lugar a lo largo de un contorno o entre dos landmarks anatómicos o matemáticos. Este tipo de landmark fue ampliamente usado en esta tesis para estudiar los contornos de diferentes huesos como el cráneo, coracoides, esternón, y superficies de articulación como la del coracoides y la mandíbula. Los semilandmarks se ubican a lo largo de una curva y no son homólogos per se entre individuos. Por el contrario, la curva que queremos representar con ellos, debería serlo (Bookstein et al., 2002, Pérez et al., 2006). Es por esta razón que la variación tangencial a la curva de los semilandmarks no nos interesa (Bookstein et al, ) y debe ser desestimada como se verá más adelante (Deslizamiento de semilandmarks).

\section{Espacio de forma de Kendall}

Una vez definida la configuración a analizar, podemos proceder a estudiar su forma. Para esto debemos cambiar del espacio euclidiano al espacio de forma, lo que conlleva perder las diferencias dadas por la traslación, la escala y la rotación. 
Las dimensiones de este nuevo espacio son:

$$
(\mathrm{KM})-(\mathrm{M}+1)-(\mathrm{M}(\mathrm{M}-1) / 2)=2 \mathrm{~K}-\quad \text { para dos dimensiones. }
$$

Existen métodos de superposición que nos van a permitir perder las diferencias dadas por la escala, la traslación y la rotación. En este caso hemos elegido el método de superposición generalizado de procrustes conocido como GPA por sus siglas en inglés (Generalized Procrustes Analysis), o GLS (Generalized Least Square) como fue llamado en un principio (Bookstein, 1978).

En el GPA las formas son superpuestas de tal manera que la suma de las distancias al cuadrado entre los landmarks de las diferentes configuraciones resultan mínimas. Este método es ampliamente aceptado (Viscosi \& Cardini 2011 y referencias allí citadas) y es el más consistente con la teoría de la forma.

Sintéticamente, el GPA centra todos los centroides de cada configuración, luego escala las configuraciones dividiendo cada coordenada de cada landmark por el tamaño del centroide (Bookstein, 1986) y por último elige una configuración de referencia y rota la segunda configuración de modo de minimizar la suma de las distancias al cuadrado entre landmarks homólogos (Rohlf, 2005). Si bien es el método más aceptado, presenta algunas desventajas como ser sensible a configuraciones en las que uno o pocos landmarks quedan más alejados de la configuración general, lo que es conocido como el efecto pinocho (Rohlf,

\section{Deslizamiento de semilandmarks}

Para las configuraciones con semilandmarks se debió desestimar el movimiento tangencial a la curva de los mismos. Esto se logró mediante el método de procrustes que además de trasladar, escalar y rotar, desliza los semilandmarks a lo largo de la curva hasta que se ajustan lo más cercanamente posible a un individuo de referencia (Adams et al., 2004). Hay varios métodos mediante los cuales esto puede ser logrado, los más utilizados son la energía mínima de flexión (BE por sus siglas en inglés de bending energy) (Bookstein, 1996) y la distancia mínima de procrustes (Sampson et al , )

Para la energía mínima de flexión, los semilandmarks se deslizan paralelos a la curva de manera tal que la energía de flexión hasta llegar a la forma consenso sea la mínima (Pérez 
et al., 2006). En tanto que con el criterio de Distancia Mínima de Procrustes los semilandmarks se deslizan de manera tal que la distancia tangencial con la forma consenso sea mínima (Pérez et al, )

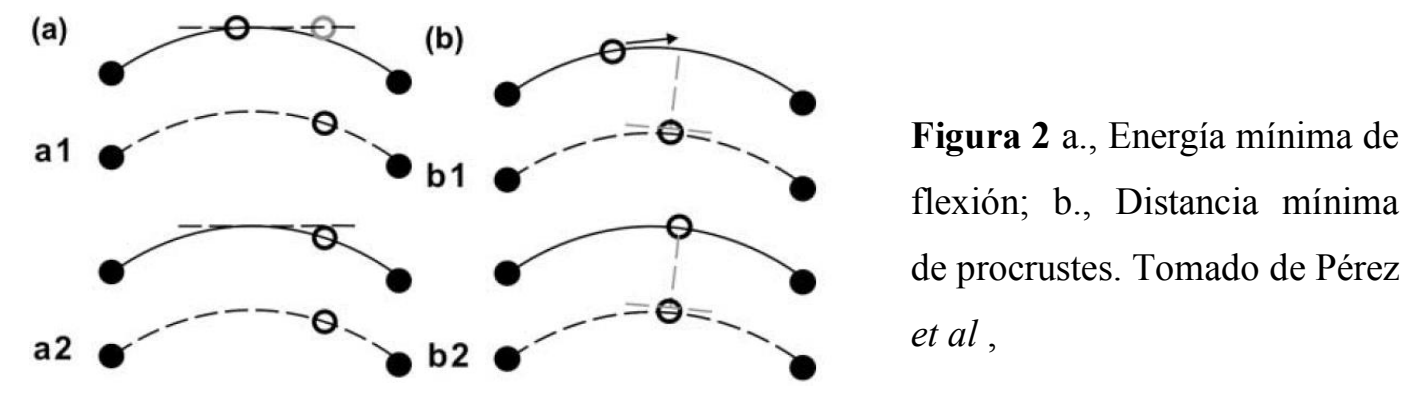

\section{Toma de datos/Configuración de landmarks}

Para los análisis, y en el marco de los objetivos 1 y 2 (ver Objetivos específicos, Capítulo III y IV), se tomaron fotografías de los elementos del ala-cintura pectoral (escápula, coracoides, fúrcula, esternón, húmero), del cráneo (cráneo, pico) y la mandíbula, en diferentes vistas (Ver tabla Capítulo III y IV). Se seleccionaron aquellas vistas en las cuales se pudieron definir configuraciones de landmarks que resultaron informativas a la hora de visualizar superficies de articulación y áreas de inserción muscular. Existieron algunas configuraciones de huesos que no pudieron ser incluidas como la fúrcula, y escápula, debido a la deformación que sufren estos huesos post-mortem, y a la casi total ausencia de landmarks de tipo I y II.

\section{Toma de imágenes}

Se utilizó una cámara Nikon D5100 y un trípode de mesa, manteniendo una distancia fija del hueso al cuerpo de la cámara, y una distancia focal variable para cada elemento (Ver Tabla 1). Para minimizar el error por asimetría fluctuante se seleccionó arbitrariamente el lado izquierdo del esqueleto para la toma de fotos. Sólo en los casos en los cuales no se contaba con el elemento izquierdo, o no estaba en óptimas condiciones, se empleó el lado derecho espejando las imágenes para minimizar la reducción del n total de la muestra. 
Tabla 1 Distancia focal utilizada para las diferentes vistas de cada hueso.

\begin{tabular}{llll} 
Hueso & \multicolumn{2}{c}{ Vistas/Distancia focal (mm) } \\
\hline Coracoides & dorsal/35 & ventral/35 & distal/45 \\
Húmero & caudal $/ 35$ & craneal/35 \\
\hline Esternón & lateral/24 & ventral/24 \\
Cráneo & & \\
& lateral/24 & dorsal/24 \\
Mandíbula & superficie articular/55 & \\
\hline
\end{tabular}

\section{Digitalización}

Las configuraciones de landmarks fueron digitalizadas con el paquete de programas TPS (Rohlf, 2004). Los archivos con las fotografías de las diferentes vistas fueron creadas por el TPS Util, mientras que el escalado de cada fotografía y la puesta de landmarks se realizó con el TPS Dig. Los semilandmarks fueron obtenidos mediante la herramienta de curva del TPS Dig y luego remuestreados por distancia (para mantener una separación constante entre cada semilandmark a lo largo del contorno a estudiar). Posteriormente, se creó un archivo (slider) con el TPS Util señalando los semilandmarks, y por último, el TPS Relw permitió obtener un archivo alineado con los semilandmarks deslizados.

\section{Análisis Estadísticos}

Los análisis se realizaron en el programa MorphoJ 1.06d (Klingenberg, 2011). El análisis generalizado de procrustes se realizó en el programa MorphoJ para todas las configuraciones y se eligió la opción de alinear según los ejes principales con excepción del cráneo en vista dorsal y esternón en vista ventral, en este caso se eligió alinear según dos landmarks ubicados en la línea sagital. En el caso de las configuraciones que poseían semilandmarks, como paso previo se creó desde el TPS Util, un archivo .NTS de 
deslizamiento (Create slider file), en el cual se le indicó al programa cuáles eran los semilandmarks. Luego, en el TPS Rewl, se abrió el archivo original con los landmarks y el archivo de deslizamiento recientemente creado y se calculó el consenso. Los semilandmarks fueron relajados por energía mínima de flexión (BE) que es el criterio que usa TPS por defecto. Luego se salvó el archivo alineado y el archivo con la información de tamaño de centroide para cada espécimen. El archivo alineado es el que contiene a los semilandmarks deslizados y, por lo tanto, es el que se puede utilizar en el programa MorphoJ para correr los análisis, mientras que el valor de centroide y su logaritmo se importaron al MorphoJ como covariables. Esto se realizó así porque el MorphoJ siempre realiza un alineamiento previo a cualquier análisis y como los archivos que contenían semilandmarks ya estaban alineados, los valores de tamaño de centroide que MorphoJ calcula terminan siendo igual a uno. Los valores de tamaño de centroide fueron recuperados para posteriormente realizar análisis de alometría. Además se importaron los classifiers, archivos con la clasificación de dieta asignada para cada espécimen. Una vez hecho todo esto se buscaron Outliers, especímenes aberrantes que pueden ser productos de un error en la digitalización.

\section{Análisis de Alometría}

Si bien la morfometría geométrica mediante los ajustes de procrustes permite estudiar la forma independiente del tamaño, nuestros datos pueden conservar un efecto alométrico. Para evaluar la alometría presente en los datos, se realizó una regresión entre las coordenadas de procrustes y el logaritmo del tamaño del centroide. Partiendo de la hipótesis nula de que el tamaño y la forma son independientes (isometría), la regresión nos permitió estudiar si existía un efecto alométrico. Si obtenemos que parte de la variación de forma es explicada por el tamaño, entonces existe un efecto alométrico en los datos, por lo que el tamaño y forma no son totalmente independientes (Klingenberg, 2016). En los casos en los que el porcentaje de variación de la forma explicada resultó significativa, se realizaron los análisis posteriores en duplicado, es decir con los datos originales de las coordenadas de procrustes y con los corregidos con los residuos de la regresión, es decir sin el efecto alométrico (e.g. Klingenberg, 2016; Jojic et al., 2012; Klingenberg \& Marugán-Lobón, 2013; Paschetta \& González-José, 2014). 


\section{Estudio de la variación de la forma}

\section{Análisis de Componentes Principales (PCA)}

En primera medida, se realizó un PCA para explorar la distribución y agrupamiento de los individuos de las diferentes especies en el morfoespacio. Se discutieron los agrupamientos de los individuos, y la variación de forma explicada por los dos primeros componentes, ya que juntos explican en todos los casos más del 60\% de variación. Como se mencionó anteriormente, en los casos en los que se detectó un efecto alométrico, se realizaron dos PCA en simultáneo. Los análisis de componentes principales se realizaron también con el programa MorphoJ.

\section{Categorías de hábitos alimenticios}

Se definió una categoría dietaria para cada especie (Tabla 2), basada en información bibliográfica (Ver Introducción, Pingüinos actuales: buceo y dieta). Esta información fue luego usada para los análisis que a continuación se detallan. A lo largo de la tesis, se denominará crustacívoro a los pingüinos que se alimentan de crustáceos de tamaño chico en especial krill. Si bien este término no es de uso común, se ha decidido implementarlo a fines prácticos.

Tabla 2 Categorías dietarias asignadas a las especies bajo estudio.

\begin{tabular}{lllll} 
Especie & Dieta & Especie & Dieta \\
\hline Aptenodytes forsteri & generalista & & Megadyptes antipodes & piscívoro \\
\cline { 5 - 6 } Aptenodytes patagonicus & piscívoro & Pygoscelis adeliae & crustacívoro \\
\hline Eudyptes chrysocome & generalista & Pygoscelis antarctica & crustacívoro \\
\hline Eudyptes chrysolophus & generalista & Pygoscelis papua & generalista \\
& & &
\end{tabular}




\begin{tabular}{llll}
$\begin{array}{l}\text { Eudyptes pachyrhynchus } \\
\text { Eudyptes sclateri }\end{array}$ & generalista & Spheniscus humboldti & piscívoro \\
\hline Eudyptula minor & piscívoro & Spheniscus magellanicus & piscívoro \\
\hline Eadrynornis mirandus & & $?$
\end{tabular}

\section{Análisis multivariante de la varianza (MANOVA)}

Se realizó un análisis multivariante de la varianza (MANOVA por sus siglas en inglés Multivariate analysis of variance) para los primeros 10 PC, los cuales garantizan la cobertura del mayor porcentaje de variación explicada. Este análisis nos permitió examinar si los grupos preasignados tienen la misma media, es decir si las diferencias entre las categorías estaban o no dadas por el azar. Para el análisis, especificamos un valor de restricción de 4, que es lo recomendado por el programa para datos de landmarks ajustados por procrustes. El MANOVA devuelve un valor de Wilk's Lambda que va de cero a uno, siendo un valor cercano a cero el que indica alta discriminación. Este análisis también permitió calcular las distancias de Mahalanobis (D), que estima las distancias morfológicas entre grupos. El MANOVA se realizó empleando el PAST Versión 3.20 (Hammer et al ， )

\section{Análisis de las variables canónicas (CVA)}

El análisis de las variables canónicas (CVA por sus siglas en inglés Canonical Variates Analysis) nos permite maximizar las diferencias entre las categorías preasignadas (Ver Tabla 2) al tiempo que nos indica cuales son las características que varían poco dentro de los grupos en relación con la variación entre ellos (Rohlf, 2005). Un CVA en sí mismo no puede usarse para calcular la significancia de las diferencias entre grupos (Rohlf, 2005), por lo que al hacer el CVA debe realizarse un test de permutación. En este caso, además, realizamos previamente un MANOVA. El CVA construye un nuevo sistema de coordenadas en el cual se maximizan las diferencias mientras se describen las diferencias entre las medias de los grupos, lo que lo diferencia de un PCA el cual analiza diferencias entre individuos (Rohlf, 2005). Los ejes son reescalados usando los patrones de variación dentro de los

\footnotetext{
${ }^{2}$ Madrynornis mirandus, es la especie fósil a estudiar y por tanto no posee una clasificación preasignada.
} 
grupos, resultando en que el CV1 es la dirección en la cual los grupos pueden ser más efectivamente discriminados (Rohlf, 2005). Además, las distancias de Mahalanobis (D) calculadas durante el CVA se utilizaron para saber por cuánto difieren los grupos. La distancia de Mahalanobis es justamente usada como unidad de cambio en los ejes de variación canónica.

\section{Variación de tamaño}

También se estudió el tamaño de algunas superficies de inserción de la facies sternalis articularis para saber el grado de desarrollo de esta estructura relativas al tamaño del hueso completo. Utilizando el logaritmo del tamaño de centroide como proxy del tamaño, se realizó una regresión entre el tamaño del centroide de la configuración de la estructura a estudiar sobre el tamaño del centroide de la configuración del hueso completo. Este análisis se realizó en el PAST.

\section{Co-variación entre estructuras}

\section{Examen de Modularidad}

En estudios craneales, la existencia o no de modularidad entre sus partes resulta interesante, sobre todo en estudios morfofuncionales (Ver Capítulo VI). Conocer si existen módulos en el cráneo o si se ha desarrollado como una estructura integrada, puede ser evaluado mediante un test de modularidad en el MorphoJ. Esto se logra comparando la fuerza de covariación entre las particiones de landmarks en subconjuntos correspondientes a los módulos propuestos y particiones alternativas en subconjuntos de landmarks al azar (Klingenberg, 2009), mediante el coeficiente RV (Escoufier, 1973). Al compararlos, si el RV obtenido a partir de los módulos propuestos es menor que el obtenido a partir de particiones al azar, podemos concluir que existiría modularidad (Klingenberg, 2009). Este coeficiente representa una medida escalar de la fuerza de covariación entre módulos propuestos, y toma valores de cero a uno, siendo cero si la covariación entre los dos conjuntos (módulos propuestos) es nula, es decir si existe modularidad, y uno si la correlación entre los conjuntos es completa, y la estructura varía de manera integrada (Klingenberg, 2009). 
En el capítulo V, se propondrán dos módulos para el cráneo, caja craneana y pico. El MorphoJ permite indicar los módulos hipotéticos que queremos evaluar y correr el análisis.

\section{Análisis de mínimos cuadrados parciales (PLS)}

Para examinar si existía una covariación entre las variables de forma de las diferentes configuraciones se realizó un análisis de mínimos cuadrados parciales (PLS, por sus siglas en inglés Partial Least Squares). Este análisis es muy usado en integración morfológica, ya que a partir de módulos preestablecidos, nos puede informar si estos covarían o no en conjunto (Rohlf \& Corti, 2000; Klingenberg, 2009; Laffont et al., 2009; Gómez-Robles et al., 2011; Parsons et al, )

El PLS trata las variables como iguales, es decir como si ninguna dependiera de la otra, y busca aquellas que mejor predicen las variables del otro bloque (Rolhf, 2005). El análisis fue acompañado por una prueba de permutación para saber si la correlación era significativa. El resultado es un coeficiente RV (coeficiente cuadrático de correlación de Pearson al cuadrado), el cual toma valores de cero a uno, siendo cero equivalente a "total independencia de entre bloques" y uno a "dependencia entre bloques" (Klingenberg \& Marugán Lobón, 2013). El PLS nos permitió estudiar el cráneo, separando los presuntos módulos: cráneo posterior/pico/mandíbula. Por otro lado, se estudió si los diferentes huesos del ala y la cintura pectoral covarían, y por último y más importante, si existía una covariación entre los elementos del cráneo y del ala.

Al estudiarse estructuras separadas, el ajuste de procrustes entre configuraciones se realiza de manera independiente. En el caso de los estudios de integración, en una misma configuración de landmarks como es el caso del cráneo, hubo que tomar una decisión entre realizar ajuste por procrustes de toda la configuración o si hacer un ajuste por separado de las partes a estudiar. Debido a que una superposición de procrustes por separado no considera la covariación dada por disposición y tamaños relativos entre las partes a estudiar (Klingenberg, 2009), se decidió optar por una superposición conjunta de toda la configuración. 


\section{Discriminantes: Clasificación dietaria de Madrynornis mirandus}

Madrynornis mirandus posee un grado de preservación excepcionalmente bueno, pero lamentablemente el pico no se encuentra unido al cráneo y está fracturado. Por esta razón, se separó la configuración del cráneo en caja craneana y pico. Para todos los análisis en los que se incluyó a M. mirandus se utilizó la configuración del cráneo sin el pico.

Se recurrió al PAST para clasificar el espécimen fósil dentro de las categorías preasignadas para las especies de pingüinos actuales. Esto se realizó por medio de un análisis de discriminantes de las coordenadas de procrustes obtenidas a partir del MorphoJ. Al fósil se le asignó el valor incógnita “?” para las columnas de categoría de dieta Aunque Madrynornis mirandus no se usó para calcular el factor discriminante, una vez resuelto el análisis, el PAST lo clasificó dentro de una de las categorías. 


\section{III}

\section{CRÁNEO}

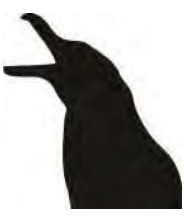

\section{INTRODUCCIÓN}

\section{Morfología y hábitos alimenticios}

El cráneo de los pingüinos ha sido ampliamente estudiado en el pasado, desde aportes puramente descriptivos (Pycraft, 1898; Shufeldt, 1901; Stephan, 1979), con un enfoque funcional y con aportes sobre la miología (Zusi, 1975; Tambussi \& Acosta Hospitaleche, 2008; Haidr \& Acosta Hospitaleche, 2012, 2014, 2018), ontogenéticos (Sosa \& Acosta Hospitaleche, 2018), y basados también en especímenes fósiles (Acosta Hospitaleche \& Tambussi, 2006; Ksepka \& Bertelli, 2006; Acosta Hospitaleche \& Haidr, 2011; Acosta Hospitaleche, 2011, 2013; Haidr \& Acosta Hospitaleche, 2017), o enfocados en la paleoneurología (Ksepka et al., 2012a; Carabajal et al., 2014; Proffit et al., 2016), entre muchos otros.

La morfología craneana está relacionada con la fuerza de mordida, (Herrel et al. 2005, 2010; van der Meij \& Bout 2008; Rayfield, 2011) en especial la región temporal del cráneo, donde se originan los músculos adductores que elevan la mandíbula. El pico y la mandíbula, además, reflejan el hábito trófico (Proctor \& Lynch 1993; Feduccia 1999; Grant \& Grant 1992), ya que poseen directa relación con el tamaño y movilidad de la presa (ver por ejemplo Lederer, 1984 y bibliografía allí citada).

Richard Zusi en su excelente trabajo de 1975, sobre la estructura craneal de los pingüinos, propone que las diferencias estructurales craneales se encuentran influenciadas por una serie de factores, como lo son las propiedades cinéticas de los palatinos, pico, y mandíbula. De esta manera un mayor ángulo de apertura del pico como en Spheniscus respecto de otros géneros, indicaría la captura de presas de tamaños más grandes, mientras 
que mandíbulas arqueadas, lenguas largas con un mayor número de papilas, acompañado de sínfisis reducidas como en Pygoscelis y Eudyptes se relacionarían más con la captura de pequeños crustáceos. Complementariamente, la longitud del pico relativo a otras proporciones craneales se relaciona con un mayor alcance de la mandíbula y pico, para la captura de presas más grandes y escurridizas. En este caso por ejemplo, picos más alargados son descriptos para Aptenodytes, seguido por Spheniscus, mientras que Pygoscelis presenta un pico mucho más corto.

Otros estudios más recientes sobre ecomorfología en aves han notado que el largo del pico, además del tamaño de la presa que capturan, puede ser un indicativo de la movilidad propia de la presa o también puede ser relacionado con el tipo de forrajeo (Lederer, 1984 y bibliografía allí citada). Picos grandes cerrarían, además, con mayor fuerza debido a que la fuerza depende de la energía cinética de la mandíbula en movimiento que a su vez depende de la masa del pico (Bock, 1964).

Este tipo de estudios, sin embargo, ha ido más allá de la osteología, incluyendo el análisis de la musculatura craneal (Zusi, 1975). Este autor señala dos patrones de desarrollo para el $m$. adductor mandibulae externo, y un diferente grado de desarrollo del $m$. depressor mandibulae, correspondiente por un lado a Spheniscus y Eudyptes, y por el otro a Pygoscelis y Aptenodytes.

Desde la morfometría geométrica, también se ha abordado el estudio de los cráneos de pingüinos, ya sea para analizar la variabilidad inter e intraespecífica de algunas especies (Acosta Hospitaleche, 2009; Acosta Hospitaleche \& Tambussi, 2006), o la variación morfológica de la mandíbula entre taxones actuales y fósiles (Haidr \& Acosta Hospitaleche, 2014; Haidr \& Acosta Hospitaleche, 2018). Como resultado, se ha extraído información morfológica que estaría vinculada con el hábito alimenticio de los pingüinos. Un ejemplo de ello es el análisis de la morfología de las cótilas de articulación mandibular, a partir de lo cual se ha propuesto que el desarrollo como estructuras independientes de la cotyla lateralis y la cotyla caudalis brindaría una mayor estabilidad de la mandíbula durante los movimientos de apertura y cierre, y que estaría típicamente presente en los pingüinos piscívoros (Haidr \& Acosta Hospitaleche, 2018). También, se plantearon relaciones directas entre la robustez de las crestas nucales y las fosas temporales expandidas que dejan un amplio espacio para la musculatura implicada en el cierre de la mandíbula (que se encuentran en Spheniscus) con la piscivoría (Acosta Hospitaleche \& Tambussi, ) 


\section{Cierre y apertura del pico y la mandíbula}

En el estudio del movimiento de la mandíbula y pico de aves debe tenerse en cuenta, en principio, que el cráneo de las aves es cinético. Es decir, el pico se mueve independientemente al cráneo, al igual que el cuadrado, incluso el lagrimal no es una estructura fija al cráneo sino que se mueve junto al pico usando el cráneo de pivote (Zusi, 1975). Las características osteológicas del cráneo, del pico y de la mandíbula, la musculatura asociada, y los ligamentos que conectan la región del cráneo con la mandíbula juegan un rol fundamental en la kinesis craneana. Todas estas estructuras actúan en conjunto limitando movimientos, aplicando fuerzas y generando las necesarias para el movimiento de otras estructuras. Los ligamentos sostienen la mandíbula, limitan sus movimientos, y habilitan, por acoplamiento, movimientos de estructuras óseas que no están asociadas a músculos particulares. La cinética craneal involucra también movimientos del rostro que incluyen protracción, donde el rostro o parte superior del pico se mueven hacia arriba, y de retracción, donde se mueven hacia a abajo (Zusi, 1984). Los pingüinos, en particular, presentan rhynchokinesis proximal (Zusi 1975), en la cual la línea de curvamiento se encuentra a nivel de los proc. premaxillaris nasalis y los proc. frontalis premaxillare, la cual llamaremos charnela. Todo esto ha sido estudiado en detalle por Bock (1960, 1964, 1999; Bock \& Kummer, 1968), Buhler (1981), Zusi (1959, 1967, 1984), entre muchos otros.

Los músculos que intervienen en la apertura mandibular son el $m$. depressor mandibulae y el $\mathrm{m}$. protractor pterygoidei. Mientras que los músculos que actúan en la adducción o elevación de la mandíbula son el $\mathrm{m}$. adductor mandibulae externo, el $\mathrm{m}$. pseudotemporalis, y el m. pterygoideus (Bock, 1964; Zusi, 1967; Vanden Berge \& Zweers, 1993). A su vez, el cierre del pico y la mandíbula, se logran mediante la acción conjunta de todos los adductores (Bock, 1999). Bock propone que el cierre de la mandíbula puede lograrse sólo con la contracción del $m$. pseudotemporalis profundus y el $m$. pterygoideus, pero que aunque efectivos, estos músculos estarían inhabilitados a devolver el centro de masa del complejo de mandíbula y pico a su posición original y que esto solo sería logrado con los m. adductor mandibulae externo, y m. pseudotemporalis superficialis (Bock, 1999). Esto es debido a que el $m$. pseudotemporalis profundus y el $m$. pterygoideus originan e insertan dentro del complejo mandíbula pico (Bock, 1999).

Los ligamentos tienen un rol importante en la cinemática craneal, en especial el lig. postorbitalis el cual origina en el proc. postorbitalis e inserta anterior a la articulación 
mandibular y lateral en la rama mandibular. El lig. postorbitalis habilita un movimiento acoplado de la mandíbula con el pico, es decir que el depresor al bajar la mandíbula por la presencia del ligamentum, mueve el cuadrado anteriormente lo que hace que el pico se abra (Bock 1964, 1999). La depresión de la mandíbula por parte del m. depressor mandibulae, implicaría que se eleve el pico en aves que poseen un ligamentum postorbitalis (Bock 1964, 1999; Zusi, 1967). Si la distancia entre la inserción del depresor con respecto al lig. postorbitalis incrementa, entonces incrementa la componente fuerza vertical, y la fuerza de protracción del cuadrado que luego da lugar a la elevación del pico (Zusi, 1967). A mayor distancia del ligamento a la articulación, mayor será la protracción alcanzada (de acuerdo a Zusi, 1967, quien propone, al igual que Bock $(1960,1999)$ que el depressor mandibulae se encuentra también involucrado en este mecanismo).

Además, una articulación secundaria aparece en los pingüinos (y algunos otros grupos de aves), entre el proc. medialis de la mandíbula y el proc. lateralis parasphenoidalis. Este "refuerzo" colabora en mantener en posición a la mandíbula inferior (Bock, 1960; 1999), habilitando un punto de apoyo extra en el momento de menor estabilidad, que se produce cuando está abierta (Bock, 1960).

Otra característica cinética de la mandíbula de los pingüinos es el streptognatismo, la flexibilidad lateromedial de las ramas mandibulares. Esta condición es típica de los animales que ingieren grandes presas o cuyas crías ingresan toda la cabeza en la boca de los progenitores al alimentarse (Zusi, 1993). Entre las diferentes especies de pingüino, la sínfisis corta y las ramas mandibulares aplanadas presentes en Eudyptes y Pygoscelis, podrían favorecer este arqueamiento lateromedial mandibular (Zusi, 1975).

\section{Objetivo}

En este capítulo se propone identificar caracteres osteo-musculares craneales que diferencien a pingüinos con diferentes categorías dietarias y participen en la función de apertura y cierre mandibular, con el fin de inferir si existe una relación forma-dieta. 


\section{MATERIALES}

Los especímenes empleados en las disecciones musculares son los enumerados en el Capítulo II. La mayor cantidad de individuos que estuvieron disponibles para las disecciones corresponde a Pygoscelis adelia, y en menor medida a P. papua, Spheniscus magellanicus, y Eudyptes chrysocome. En cuanto a los análisis de morfometría geométrica, el Anexo I presenta una lista detallada de los especímenes utilizados para cada estudio.

\section{MÉTODOS}

Para las descripciones musculares, se estableció una capa superficial y una profunda. Las descripciones se realizaron siguiendo un orden predeterminado, comenzando con los más superficiales. La capa superficial del cráneo incluyó al $m$. depressor mandibulae, $m$. adductor mandibulae externus, m. pseudotemporalis superficialis, mientras que la capa profunda al $m$. pseudotemporalis profundus, $m$. protractor quadrati, $m$. protractor pterygoidei, y m. pterygoideus. Se describió de manera comparativa la musculatura craneal en base a disecciones hechas en individuos adultos y pichones de Pygoscelis adeliae, pichones de P. papua, juveniles y adultos de Spheniscus magellanicus y un adulto y juvenil de Eudyptes chrysocome.

Los análisis de morfometría geométrica incluyeron regresiones, análisis de componentes principales, análisis multivariante de la varianza, y análisis de variación canónica (Ver capítulo II para más detalles). Estos análisis fueron realizados a partir de configuraciones de landmarks del cráneo, y mandíbula (Tabla 1 y 2). Si bien el cráneo fue estudiado como una unidad, incluyendo la configuración de la caja craneana y el pico, al analizar los materiales de Madrynornis mirandus del Mioceno de Patagonia se dividió la configuración en una parte craneal y una referida al pico. Se procedió de esta manera debido a que Madrynornis mirandus no presenta el pico completo, por lo que no podía ser incluido en el análisis. 
Tabla 1 Configuración de landmarks del cráneo en vista dorsal, número de landmarks y definición.

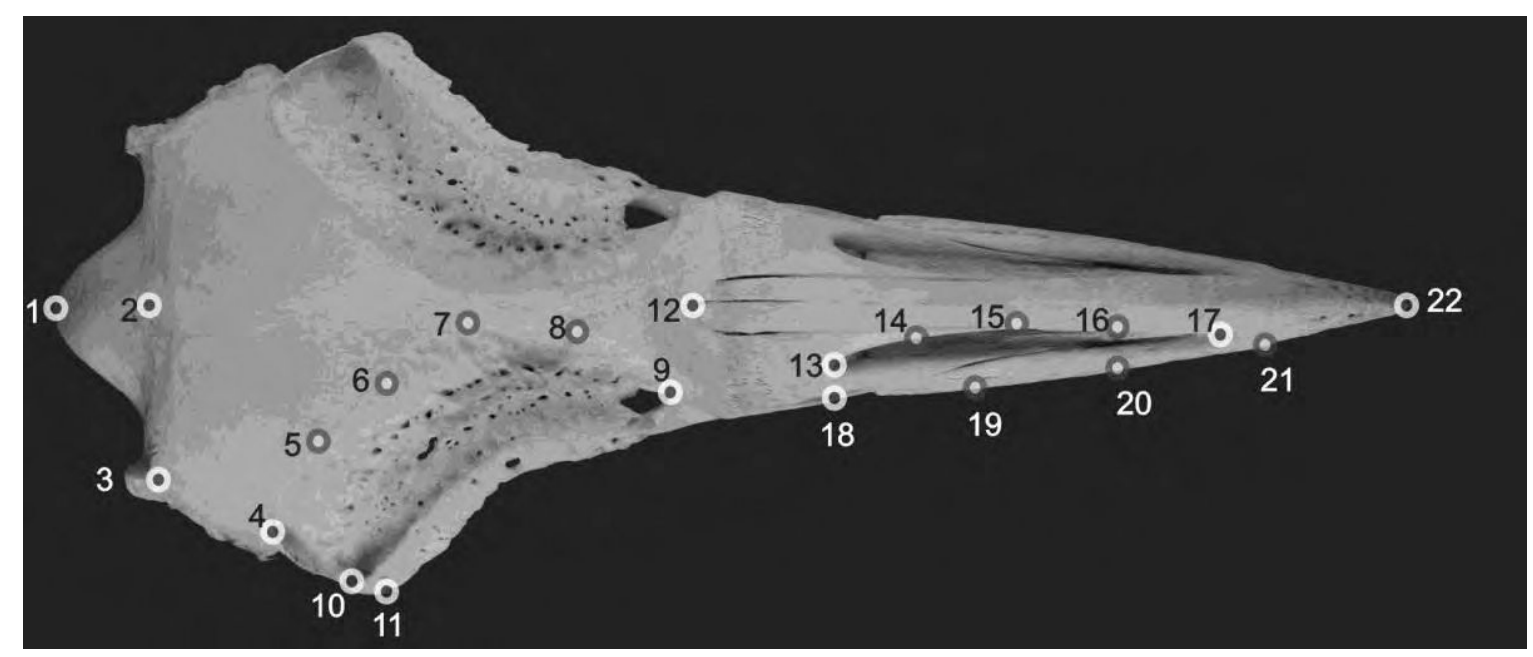

\section{Lmk Nombre}

prominentia cerebellaris

punto sobre plano sagital de la crista nuchalis transversa

unión de la crista temporalis con la crista nuchalis transversa

, fossa glandulae nasalis: punto medioposterior, punto anterior, punto lateroposterior

fossa glandulae nasalis, contorno medio

processus postorbitalis

unión entre los proc. frontalis nasalis y la unión entre los proc. frontralis premaxillare.

apertura nasi ossea, punto posterior y anterior

apertura nasi ossea, contorno medio

extremo posterior del pico, a la altura de landmark

contorno del pico

punta del pico 
Tabla 2 Configuración de landmarks de la mandíbula en vista dorsal, número de landmarks y definición.

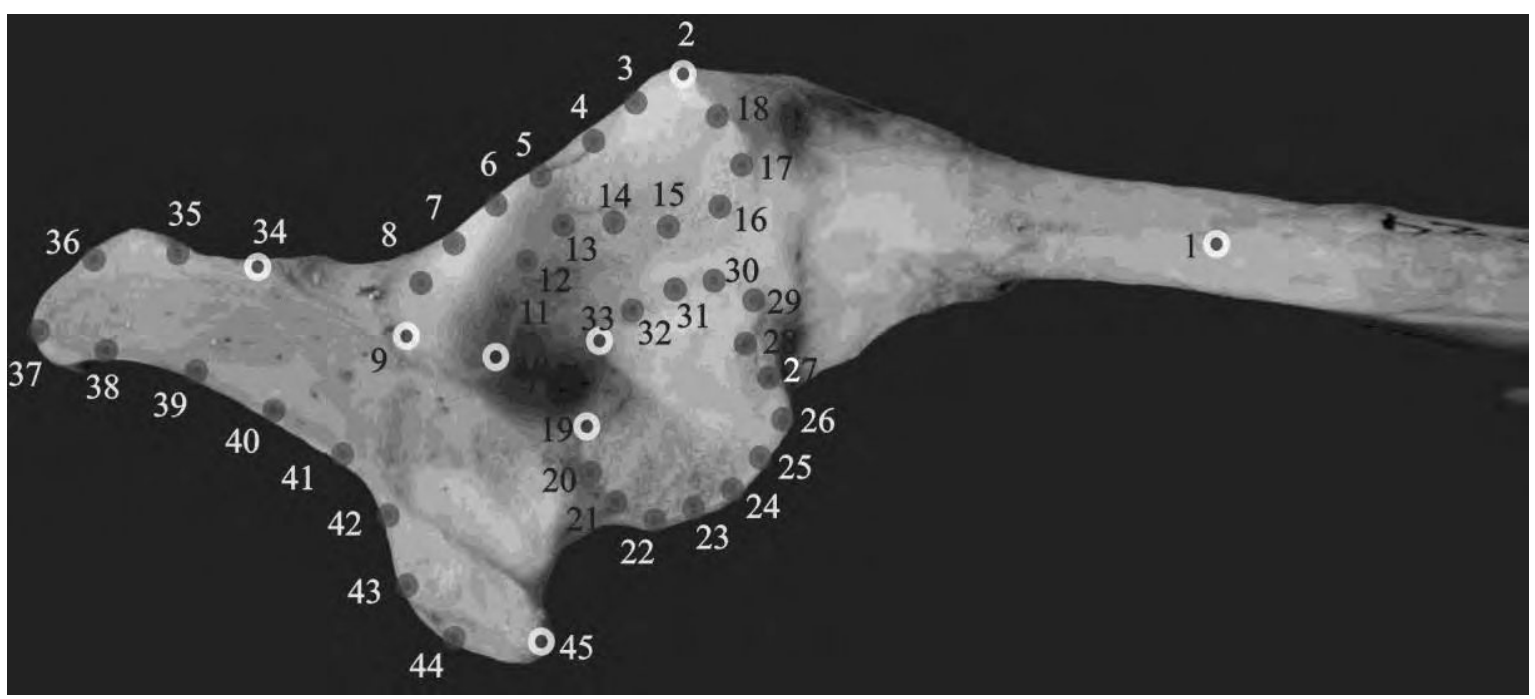

Lmk Nombre

processus coronoideus

punto de inflexión de la cotyla lateralis con la rama mandibulae

contorno lateral de la cotyla lateralis y cotyla caudalis

puntos posteriores de la cotyla caudalis

contorno medial de cotyla lateralis y cotyla caudalis

inicio posteromedial y anteromedial del contorno de la cotyla medialis

contorno de la cotyla medialis

processus lateralis

contorno del processus retroarticularis

punta del processus medialis

A partir de estas configuraciones (Tabla 1 y 2), se realizaron una serie de análisis con el programa Morpho J. Se evaluó si existía un efecto alométrico en los datos, a partir de una regresión entre las coordenadas de procrustes y el tamaño del centroide. En los casos en los que se halló un efecto alométrico, es decir que un porcentaje significativo de la variación de forma estaba explicada por el tamaño, se realizaron todos los análisis posteriores de dos maneras: uno con las coordenadas de procrustes originales, y otro con los datos corregidos 
por los residuos de la regresión. Entonces, se exploraron los datos de los diferentes especímenes a estudiar y su distribución en el morfoespacio a través de un análisis de componentes principales (PCA). Luego, para corroborar que las diferencias morfológicas entre las categorías dietarias asignadas para cada especie (Ver en Tabla 2 en el Capítulo II) fuesen significativas, se realizó un análisis multivariante de la varianza (MANOVA).

Por último, para estudiar las diferencias morfológicas entre grupos de diferentes categorías y calcular las distancias morfológicas entre las categorías dietarias, se realizó un análisis de variación canónica (CVA). Para más detalles de los diferentes análisis ver el Capítulo II.

\section{RESULTADOS: MIOLOGÍA COMPARADA}

\section{Capa superficial}

M. depressor mandibulae, m. adductor, m. pseudotemporalis superficialis

\section{M. depressor mandibulae}

Se trata de un músculo robusto (Fig. 1a), incluso en pichones, aunque con un menor grado de desarrollo. Es el primero en observarse en los planos de disección, el más voluminoso y el segundo más pesado de los músculos involucrados en la de apertura y cierre mandibular.

Se origina aponeuróticamente a lo largo de la crista nuchalis transversa y carnosamente sobre la porción más posterior del adductor pars ventralis, y la región posterior del proceso zigomático, del meato auditivo sobre donde articula el cuadrado (muy cercano a la inserción con la mandíbula). Sus fibras corren ventralmente hasta su inserción. 
Inserción

La inserción es carnosa sobre el proceso retroarticular.

Comentarios

En Spheniscus, la aponeurosis se ve en vista occipital, en el extremo más dorsal, con su inserción en la crista nuchalis transversa. En Pygoscelis papua y $P$. adelia pichón, está apenas desarrollada. En pichones, donde los huesos no se encuentran completamente fusionados, se observa que el músculo está adherido al os zygomaticus completo. El $m$. depressor mandibulae, es el encargado de la apertura de la mandíbula. Algunos autores afirman que su contracción también hace que se eleve el pico, ya que la porción posterior al ligamento postorbital de la mandíbula se eleva con su contracción, haciendo que el cuadrado se desplace hacia adelante desencadenando el movimiento de apertura del pico (Zusi, 1975; Bock, , )

\section{M. adductor mandibulae externus}

Este músculo consta de tres partes que Baumel (1993) denomina como pars rostralis, pars ventralis y pars profunda (Fig. 1a,b). Zusi (1975) reconoce el mismo número de partes, pero los nombra como A, M y B respectivamente y encuentra, de acuerdo al grado de desarrollo, un primer grupo formado por Pygoscelis y Aptenodytes en los cuales la partes A y B están menos desarrolladas e insertan prácticamente sólo por aponeurosis a la mandíbula, y un segundo grupo con un músculo más desarrollado e inserciones carnosas y de mayor envergadura formado por Eudyptes y Spheniscus. Durante las disecciones, se observaron las mismas partes descritas por estos autores. Spheniscus evidencia un mayor grado de desarrollo del adductor en general, sobre todo en lo que respecta a la inserción de la mandíbula, la cual es mucho más robusta y carnosa y se extiende más anterior y ventralmente que en Pygoscelis o Eudyptes. Si bien se observaron las tres partes en todos los estadios ontogenéticos, en los pichones las divisiones no fueron tan claras como en los individuos de mayor edad. $\mathrm{Su}$ función es la de cerrar la mandíbula. 


\section{M. adductor mandibulae externus pars rostralis}

Es un músculo acintado (Fig. 1b) con dos puntos de origen divergentes. El ancho entre sus orígenes se va angostando hasta su inserción en la mandíbula. Es llamado superficialis según Lakjer (1926), y parte A para Zusi (1975).

Origen $\overline{\text { El origen es carnoso sobre el proceso postorbital y el proceso escamoso. }}$ Externamente se ve una medialuna que une el proc. postorbitalis y el escamoso. En pichones el proceso postorbital es completamente cartilaginoso por lo que las fuerzas que allí pueden actuar están limitadas. Sus fibras corren anteroventralmente hasta su punto de inserción.

Inserción $\mathrm{Su}$ inserción es carnosa en el proceso coronoideo y margen lateral de la mandíbula adyacente al proceso. Se inserta más superficialmente que las demás pars en el proceso coronoideo.

Comentarios

Esta pars es diferenciable en su origen pero se une fuertemente en su cuerpo con la pars ventralis. Si bien el origen es similar en Spheniscus y Pygoscelis adelia, la inserción es más amplia y se extiende más anteriormente en Spheniscus.

\section{M. adductor mandibulae externus pars ventralis}

Origen Se origina carnoso en la fossa temporalis (Fig. 1a, b), os parietale como se puede observar en los pichones que no poseen los huesos fusionados. Por el contrario, en $P$. adeliae (adulto) la pars no llega a contactar la crista nuchalis transversa completamente. Por el contrario, en pichones de $P$. papua, la pars se extiende hasta la crista nuchalis transversa al igual que en Eudyptes chrysocome (adulto). En Spheniscus, el origen está claramente extendido hasta la crista nuchalis transversa y está adherida a la misma. Las fibras musculares corren anteroventralmente hasta la inserción. 
$\mathbf{a}$

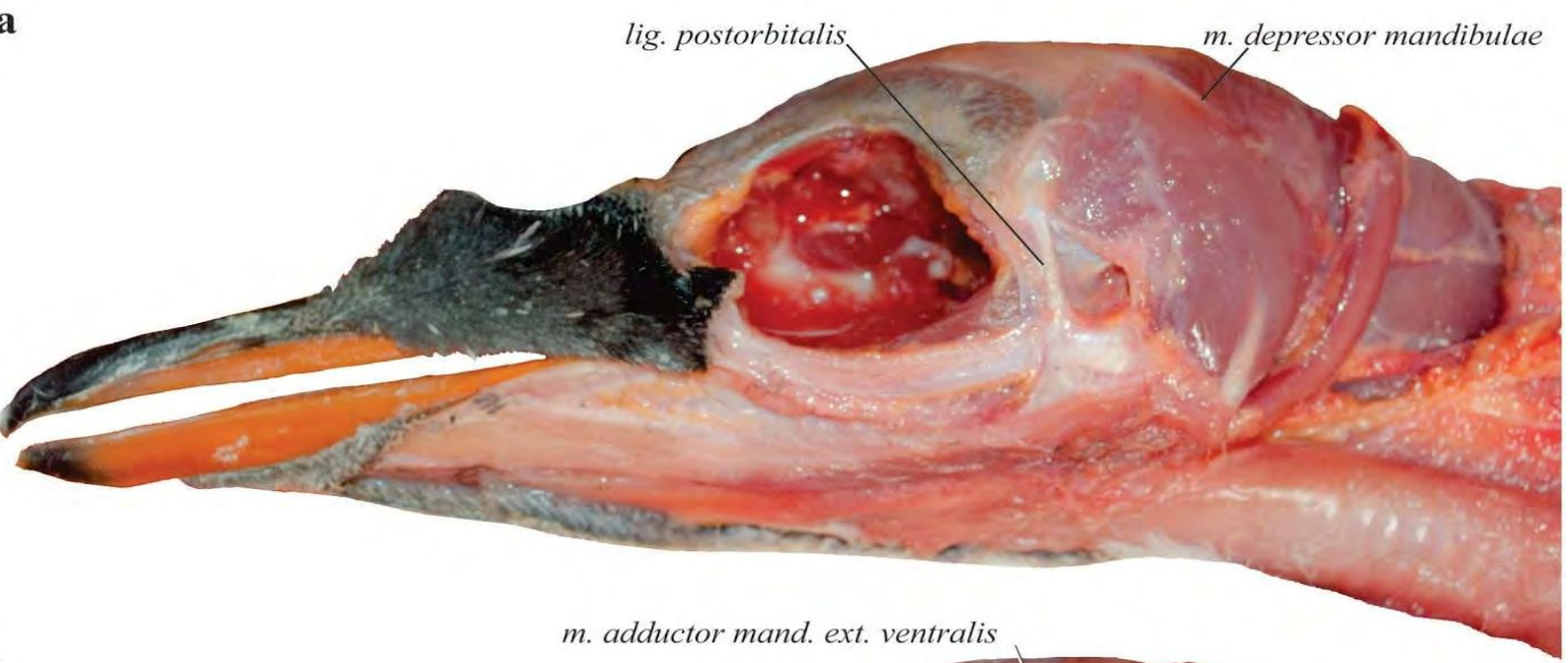

$\mathbf{b}$

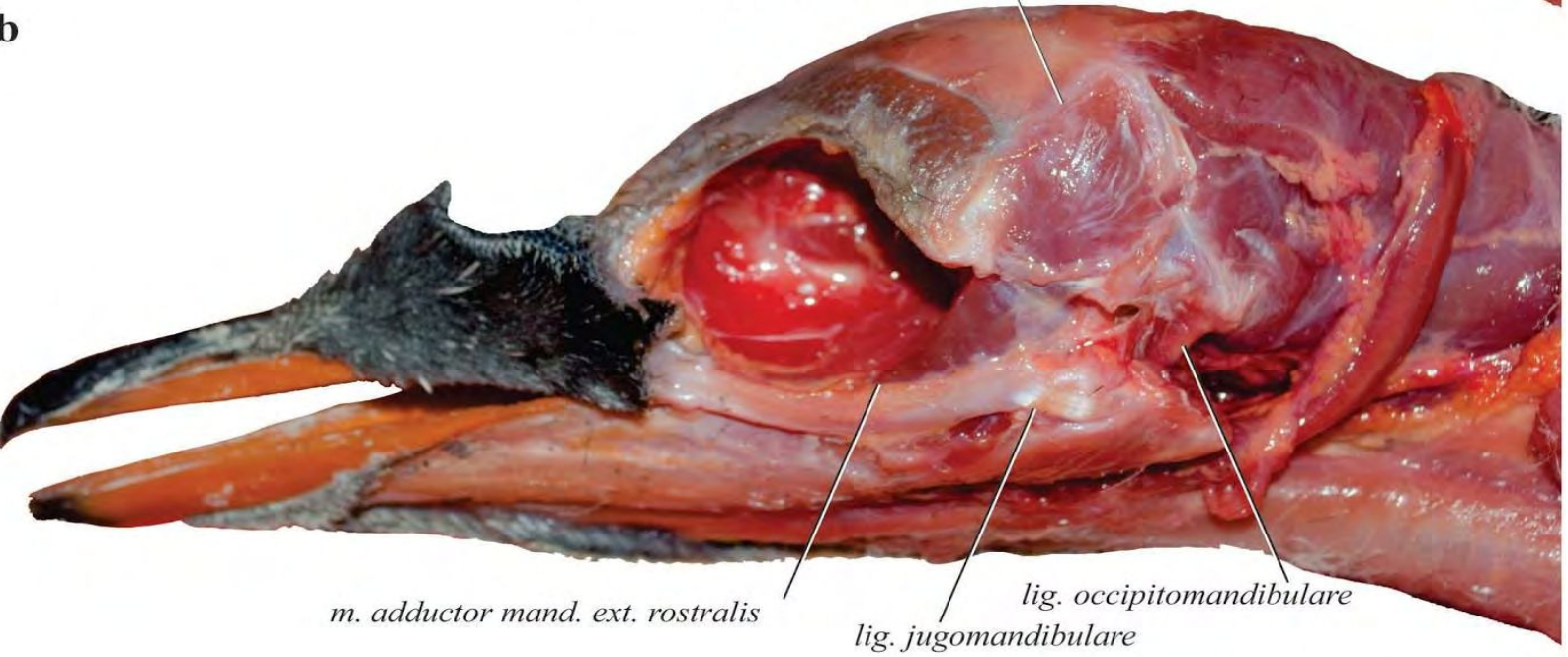

lig. jugomandibulare

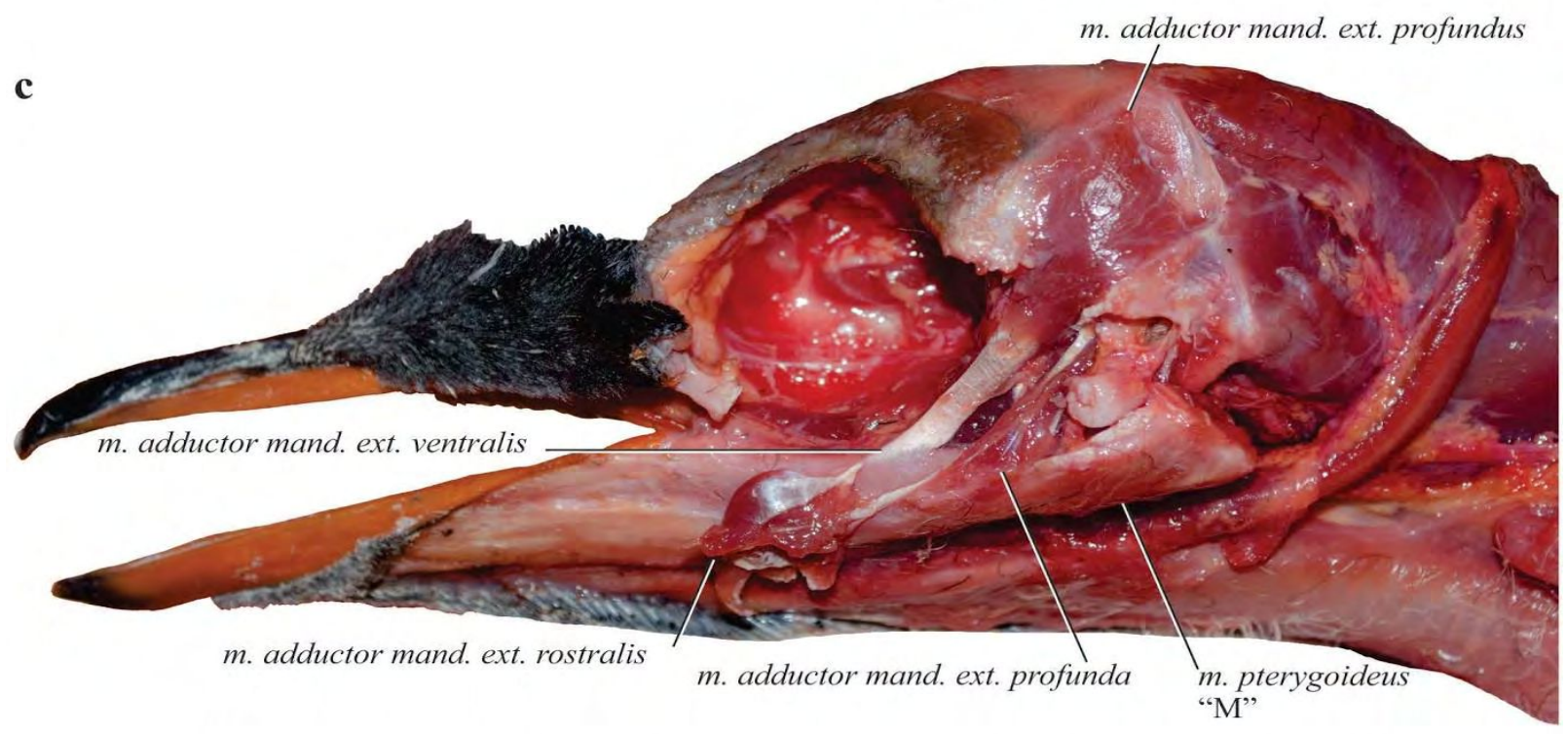

Figura 1 Disecciones musculares del cráneo de un pichón emplumando de Pygoscelis papua. Abreviaciones: ext., externus; lig., ligamentum; mand., mandibularis; m., musculus. 
Inserción

Inserta en el proceso coronoides. En Pygoscelis lo hace por medio de una aponeurosis fuerte, mientras que en Spheniscus lo hace mediante un tendón.

Comentarios

Es la más conspicua de las tres partes. En pichones de Pygoscelis, en los cuales los huesos no se encontraban fusionados, se pudo observar que el os parietale delimita perfectamente el origen de esta pars. Lakjer (1926) lo denominó como medialis, mientras que es reconocido como parte M para Zusi (1975).

\section{M. adductor mandibulae externus pars profunda}

Origen Es a través de un tendón sobre una cresta del proceso ótico del cuadrado (tuberculum subcapitulare según Elzanowski, 2013 según Degrange et al., 2018), y carnoso alrededor del tubérculo sobre la línea media del cuerpo del cuadrado, una parte, incluso, conecta con el meato auditivo (Fig. 1c). Sus fibras corren anteroventralmente hasta su punto de inserción pero en ángulo mayor que las dos anteriores partes.

Inserción De las tres partes, es la que posee la inserción más posterior en la mandíbula. Inserta de manera carnosa en la porción lateral de la mandíbula desde el inicio de la región articular (anterior a la cotyla lateralis) hasta el proceso coronoides (en P. papua no llega hasta el coronoides, va ventralmente hasta la altura del coronoides (Fig. 1c). Posee además un tendón que corre interno entre las fibras e inserta adyacente a la articulación mandibular (al menos en $P$. papua).

Pareciera que este músculo tiene dos facies. Una que origina en el proceso orbital del cuadrado más anteriormente y que inserta más lateral y posteriormente, y la otra que tendría su origen más posterior y dorsal, sobre el eje del cuadrado en el proceso ótico de éste, y una inserción más extensa 
a lo largo de la mandíbula sobre el proceso coronoides hasta el límite anterior de la rama mandibular y la región articular. Sin embargo, Zusi (1975) describe la inserción de este músculo en el proceso ótico del cuadrado. Esta pars es nombrada como caudalis por Lakjer (1926), y parte B Zusi (1975).

\section{M. pseudotemporalis superficialis}

Origen Es carnoso sobre el os laterosphenoidale, en una superficie flanqueada posteriormente por el meato auditivo y el inicio de la fossa temporalis, y lateralmente por el proc. postorbitale, más precisamente en el area muscularis aspera lateral a la inserción del protractor cuadrado. En Spheniscus tiene un tendón que inserta en una "escama" que sobresale del área, el resto de la inserción es carnosa. Las fibras de este músculo corren anteroventralmente.

Inserción La inserción es tendinosa sobre el tuberculum pseudotemporale.

Comentarios

Su función es la de cerrar la mandíbula y brindar estabilidad en los movimientos laterales.

\section{Capa profunda}

M. pseudotemporalis profundus, m. protractor quadrati, m. protractor pterygoidei, y m. pterygoideus.

\section{M. pseudotemporalis profundus}

Origen Se extiende carnosamente por toda la línea ventral del proc. orbitalis del cuadrado. Sus fibras se dirigen anteroventralmente hasta la inserción, y en la porción más posterior terminan corriendo prácticamente en ángulo recto a 
la mandíbula (Fig. 2a, b).

Inserción

La inserción es carnosa en la fossa aditus canalis mandibulae en todas las especies estudiadas.

Comentarios

Su función involubra el cierre de la mandíbula en simultáneo con el pico (Baumel, 1993).

\section{M. protractor quadrati}

Origen Se origina carnosamente en el area muscularis aspera del os laterosphenoidale, entre la inserción del $m$. pseudotemporalis superficialis y el $m$. protractor pterygoidei (que se describe más adelante). Sus fibras corren ventro-lateralmente hacia el cuadrado (Fig. 2b).

Inserción La inserción es carnosa sobre la línea dorsal del proc. orbital del cuadrado.

Comentarios Este músculo mueve el cuadrado dorsoanteriormente, elevando el pico (Zusi, 1975).

\section{M. protractor pterygoidei}

Origen Como se mencionó con anterioridad, origina en el area muscularis aspera del os laterosphenoidale carnosamente y adyacente a la placa basitemporal, $\mathrm{y}$ ventral al origen del $m$. protractor quadrati. Sus fibras corren ventralmente.

Inserción Inserta carnosamente sobre el pterigoides.

Comentarios $\quad$ Mueve el pterigoides dorsoanteriormente, elevando el pico (Zusi, 1975). 
a
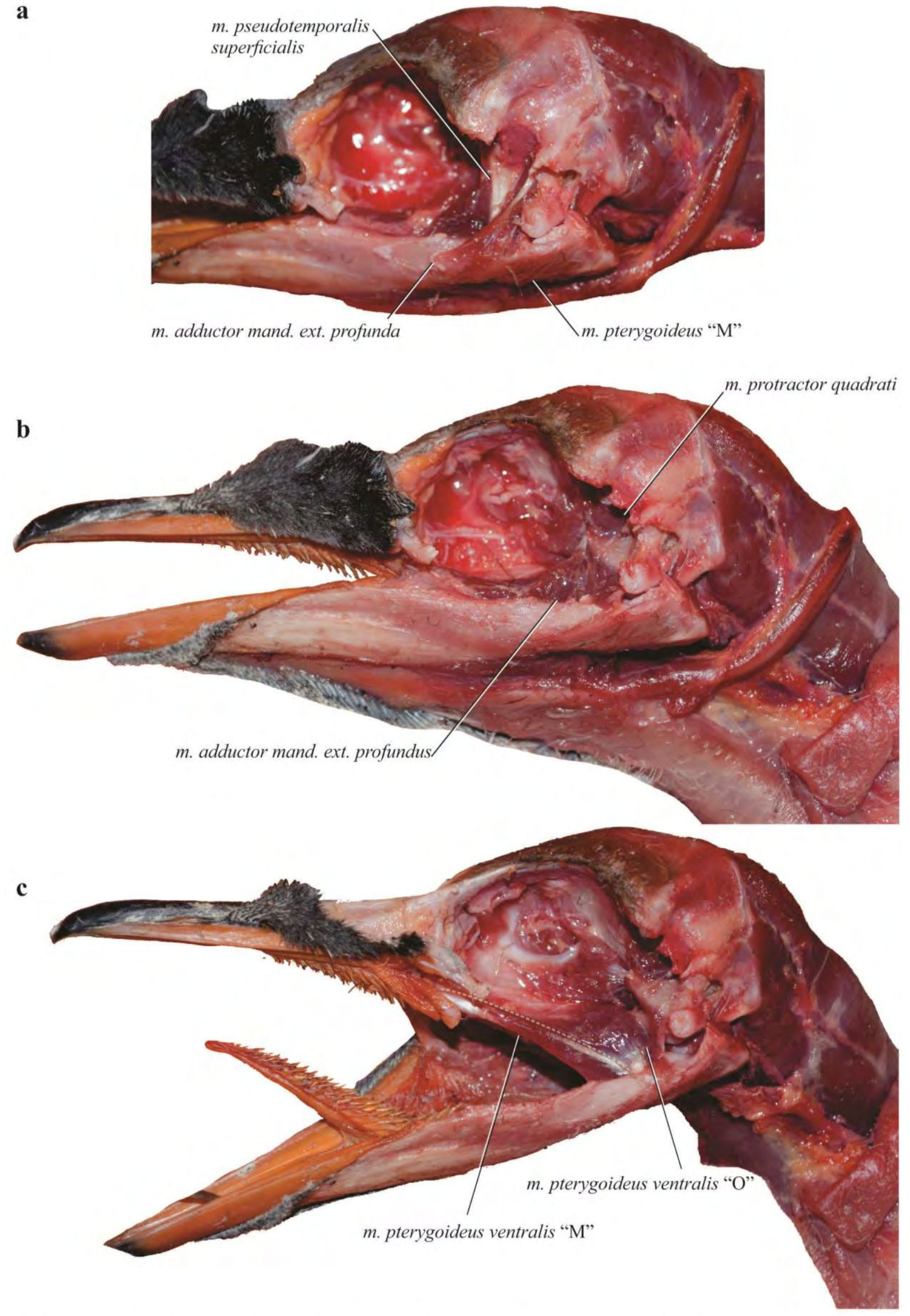

Figura 2 Disecciones musculares del cráneo de un pichón emplumando de Pygoscelis papua. Abreviaciones: ext., externus; mand., mandibularis; $m$., musculus. 


\section{M. pterygoideus}

Zusi (1975) diferencia tres partes, que identifica con las letras M, N y O, una de las cuales (la pars $\mathrm{O}$ ) se diferencia en parte ventromedial y parte dorsolateral. Este músculo es el más robusto y pesado de todos los músculos craneales. En este caso se seguirala nomenclatura de Zusi (1975) para evitar confusiones entre los sinónimos de las diferentes pars de este músculo. En Nomina Anatomica Avium (Baumel, 1993) se lo diferencia en ventral y dorsal. Esta serie de músculos actúan en el cierre del pico, a la vez que elevan la mandíbula (Baumel, 1993) y actuaría junto con el $m$. adductor mandibulae externus como los principales actores en la fuerza de mordida. También se ha propuesto que particularmente la pars O esté involucrada con el arqueamiento de la mandíbula inferior (Zusi 1975, y referencias allí citadas). Debido a la complejidad de este músculo, el origen e inserción será descrito por separado para cada una de sus partes.

\section{M. pterygoideus, Pars $M$}

Origen El origen es carnoso sobre la porción dorsal y el borde lateroposterior de los palatinos en vista ventral. En el pichón de P. papua se observó un tendón en la parte lateral de los palatinos. Las fibras musculares corren posteroventralmente (Fig. 2c).

Inserción

Inserta mediante un tendón en el tuberculum ubicado sobre la cresta ventral de la mandíbula (se ve también en pichones de Pygoscelis adelia y $P$. papua, aunque débilmente en el de $P$. papua). La inserción continúa posteriormente a lo largo de la cresta ventral de la mandíbula (vista ventral) hasta la punta más posterior del processus retroarticularis.

\section{M. pterygoideus, Pars $N$}

Origen $\overline{\mathrm{Su} \text { origen es carnoso sobre la depresión ventral del palatino. Sus fibras se }}$ dirigen posteroventralmente hasta la inserción. 
Inserción

El músculo inserta mediante una aponeurosis sobre la mandíbula, en la porción más anterior y medial del processus medialis.

\section{M. pterygoideus, Pars $O$ dorsolateral}

Origen Se origina carnosamente en la porción dorsal del pterigoides. Sus fibras se dirigen postero-ventralmente hacia el área de inserción (Fig. 2c).

Inserción Se inserta en la mandíbula, en la depresión medial a la cresta ventral mandibular y anterior a otra cresta que separa esta superficie de inserción con el proc. medialis mandibulae. Anteriormente, esta depresión está delimitada por la fossa aditus canalis mandibularis. La inserción es inmediatamente posterior a la parte $\mathrm{M}$.

M. pterygoideus, Pars $\mathrm{O}$, ventromedialis

Origen Sobre la porción ventromedial del pterigoides. Sus fibras corren posteroventralmente hasta la inserción.

Inserción $\overline{\text { En la porción anterior del proc. medialis mandibulae. Está adherido a la }}$ pars $\mathrm{N}$ del $m$. pterygoideus.

\section{Ligamentos}

Si bien la musculatura es la encargada de las fuerzas ejercidas en el movimiento del pico y la mandíbula, tal como se ha detallado en la introducción de este capítulo, los ligamentos presentes en este complejo cumplen un rol no menos importante.

Ligamentum postorbitalis (Fig. 1a), uno de los ligamentos más robustos de la articulación cráneo-mandibular. Este ligamento une el proceso postorbital del cráneo con la mandíbula anterior a la articulación mandibular. El ligamento postorbitalis actúa como punto de anclaje extra de la mandíbula con el cráneo y por lo tanto produce que, contracción del $m$. 
depressor mandibulae mediante, la porción de la mandíbula anterior al ligamento pivote hacia abajo, mientras que la porción posterior al ligamento lo haga hacia arriba (Zusi 1975). En las disecciones se observa que el ligamento postorbitalis es más robusto en Spheniscus y Eudyptes que en Pygoscelis.

Ligamentum jugomandibulare (Fig. 1b), origina en la porción caudolateral de la barra jugal, para insertar en el proc. lateralis de la mandíbula.

Ligamentum occipitomandibulare (Fig. 2a), es el más robusto que se origina en el proceso escamoso posterior a la tuba auditiva y corre anteroventralmente hacia su inserción en la línea más anterior del proc. retroarticularis. Precisamente, inmediatamente posterior al punto más posterior de la cotyla medialis inserta el ligamento.

\section{RESULTADOS: ANÁLISIS CRÁNEO}

\section{Configuración del cráneo, vista dorsal}

\section{Alometría}

La variación de forma explicada por el tamaño fue de un 5,7805\% ( $\mathrm{p}=0,0007)$, por lo que concluimos que, aunque bajo, existe un efecto alométrico en la variación de la forma. Por este motivo los análisis se realizaron en forma paralela con las coordenadas de procrustes originales, y con los datos corregidos por los residuos de la regresión.

\section{Análisis de componentes principales}

En general, y para todas la configuraciones, a lo largo del PC1 (Ver Tabla con porcentajes de variación explicados para los primeros tres componentes) los individuos de Spheniscus se agrupan hacia los valores positivos, mientras que los individuos de Pygoscelis lo hacen hacia los valores negativos (Fig. 3). Eudyptes se encuentra en los valores intermedios junto con Eudyptula, Megadyptes y Aptenodytes. 

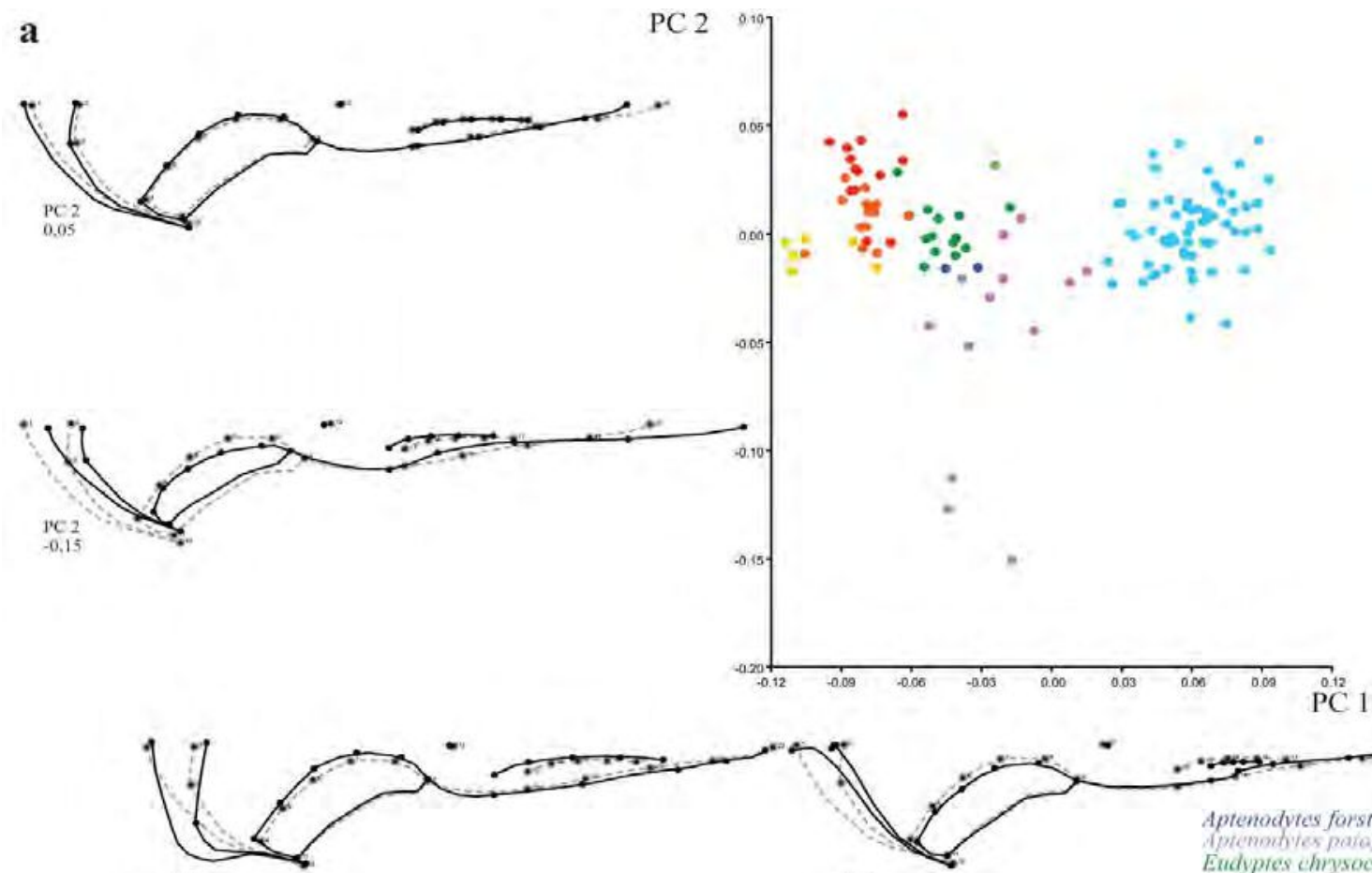

$\mathrm{PC}, 1$
$-0,1$

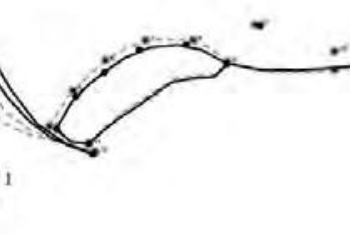

Aptenodves forstert

Aptemmotes parasenien. Endyptes chrysocome

Eudypinda minor

Madrynornis mirandus Madrynornis mirandu
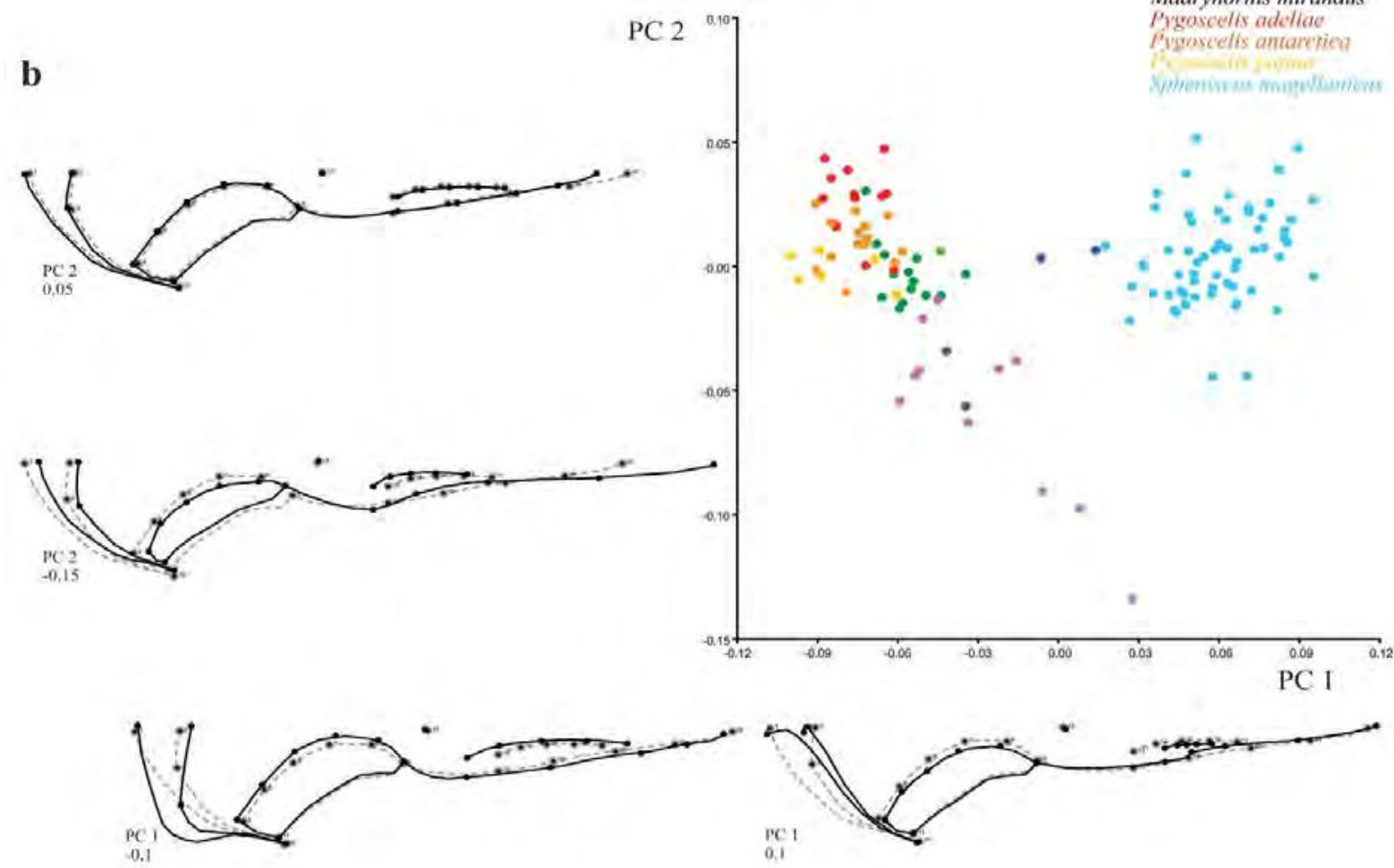

Figura 3. Análisis de componente principales de la configuración del cráneo en vista dorsal. Gráficos de dispersión de los primeros dos PC con el cambio de forma para los valores extremos de cada PC a., datos originales; $\mathbf{b}$., valores corregidos. Las lineas grises punteadas representan la forma promedio mientras que las negras representan los valores extremos de cada PC. 
El PC2 (Fig. 3) separa a Aptenodytes patagonicus de las demás especies. Además, para los individuos de Pygoscelis vemos un gradiente entre las especies en el cual los especímenes de P. papua se ubican en los valores negativos bajos, P. antarctica en los valores neutros y $P$. adeliae hacia los positivos bajos. Entre los análisis de datos crudos y residuales las mayores diferencias encontradas residen en que para el análisis con residuales Eudyptes se solapa con Pygoscelis, al mismo tiempo que Aptenodytes patagonicus se acerca más a Spheniscus en el PC1 (Fig. 3).

Tabla Porcentajes de variación explicada por los primeros tres componentes principales, para el PCA del cráneo en vista dorsal del conjunto de datos originales y corregidos.

\begin{tabular}{|c|c|c|}
\hline & \% Variación-Originales & \% Variación-Corregidos \\
\hline PC1 & , & , \\
\hline $\mathrm{PC} 2$ & , & , \\
\hline PC3 & , & , \\
\hline
\end{tabular}

La variación de forma para el PC1 (Fig. 3) está dada por la extensión medial de la fosa temporal, la proyección medial de la fosa glandular nasal y, por ende, el ancho de los frontales, y la extensión de las narinas. Para los valores positivos (Spheniscus), la fosa temporal llega hasta el plano medial, mientras que para los valores negativos su extensión medial se ve mucho más disminuida. La fosa glandular es menos curva y se encuentra menos desarrollada hacia los valores negativos del gráfico de dispersión, con respecto a los valores positivos. Por último, para este PC, las narinas están menos extendidas anteroposteriormente para los valores positivos (Spheniscus) con respecto a las demás formas. El PC2 explica la variación dada por el tamaño relativo del cráneo con respecto al pico, quedando $A$. patagonicus alejado de las demás especies hacia los valores negativos en donde se aprecia un desarrollo del largo del pico mucho mayor que del cráneo. Además la forma explicada hacia los valores negativos da cuenta de un pico más grácil, mientras que los valores positivos 
tendrían picos más robustos. La fosa glandular presenta una forma más delgada mediolateralmente en los especímenes ubicados hacia los valores negativos.

\section{Categorías de hábitos alimenticios: Análisis multivariado de la varianza}

El MANOVA arrojó un valor de Wilk's Lambda bajo con ambos conjuntos de datos (Tabla ). Por esta razón desestimamos que las diferencias entre grupos estén dadas al azar. Encontramos que las mayores distancias se dieron entre los grupos piscívoros-crustacívoros, mientras que las menores distancias se encontraron entre los crustacívoros-generalistas.

Tabla Análisis multivariante de la varianza (MANOVA) del cráneo en vista dorsal, valores de Wilks' $\lambda$, y distancias de Mahalanobis (D ) entre grupos con sus correspondientes valores de $\mathrm{p}$ asociados. Resultados para el conjunto de datos originales y corregidos.

\begin{tabular}{|c|c|c|c|c|c|}
\hline & & \multicolumn{2}{|c|}{ Datos Originales } & \multicolumn{2}{|c|}{ Datos corregidos } \\
\hline \multicolumn{2}{|c|}{ Wilks' $\lambda$} & \multicolumn{2}{|c|}{, } & \multicolumn{2}{|c|}{, } \\
\hline \multicolumn{2}{|l|}{$\mathrm{p}$} & \multicolumn{2}{|r|}{, } & \multicolumn{2}{|c|}{, } \\
\hline \multirow{3}{*}{$\mathrm{D}$} & & generalista & crustacívoro & generalista & crustacívoro \\
\hline & & \multicolumn{2}{|r|}{, } & \multirow{2}{*}{\multicolumn{2}{|c|}{, }} \\
\hline & piscívoro & \multicolumn{2}{|l|}{, } & & \\
\hline \multirow{2}{*}{$\mathrm{p}$} & generalista & & , & & , \\
\hline & piscívoro & , & , & , & , \\
\hline
\end{tabular}




\section{Categorías de hábitos alimenticios: Análisis de variación canónica}

Para los CVA de ambos conjuntos de datos, los grupos más cercanos resultaron ser los de crustacívoros-generalistas, y la distancia mayor se vio entre los piscívoroscrustacívoros (Tabla ).

Tabla Análisis de variación canónica (CVA) del cráneo en vista dorsal, porcentajes de variación para los dos primeros ejes de variación canónica, y distancias de Mahalanobis (D ) entre grupos con sus correspondientes valores de $\mathrm{p}$ asociados. Resultados para el conjunto de datos originales y corregidos.

\begin{tabular}{|c|c|c|c|c|c|}
\hline & & \multicolumn{2}{|c|}{ Datos Originales } & \multicolumn{2}{|c|}{ Datos Corregidos } \\
\hline CV $1 \%$ & & & , & & \\
\hline \multicolumn{2}{|l|}{ CV $2 \%$} & \multicolumn{2}{|c|}{, } & \multicolumn{2}{|c|}{, } \\
\hline \multirow{3}{*}{$\mathrm{D}$} & & generalista & crustacívoro & generalista & crustacívoro \\
\hline & & & , & & , \\
\hline & piscívoro & , & & , & \\
\hline \multirow{2}{*}{ p } & generalista & & , & & , \\
\hline & piscívoro & , & , & , & , \\
\hline
\end{tabular}

Tanto para el análisis con datos crudos como para el análisis con residuales, el CV1 (Fig. 4) separa los piscívoros de los crustacívoros. Los generalistas quedaron en medio de ambos grupos.

El CV1 (Fig. 4) señala los siguientes caracteres como las diferencias más notables entre los piscívoros y los crustacívoros: la amplitud anteroposterior de la narina (reducida en las formas piscívoras), el ángulo de la crista nuchalis transversa (convergente con la 

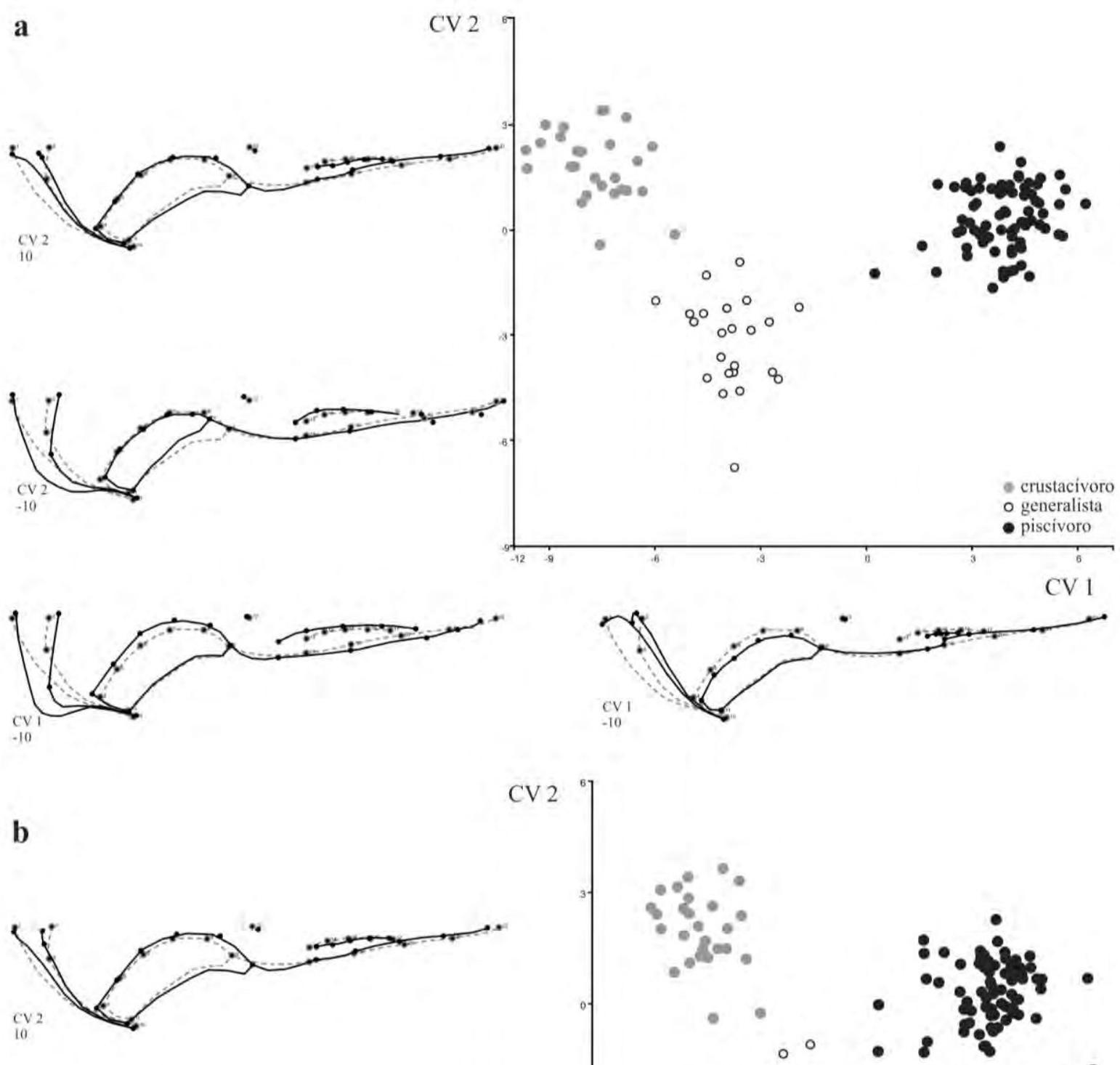

CV 2
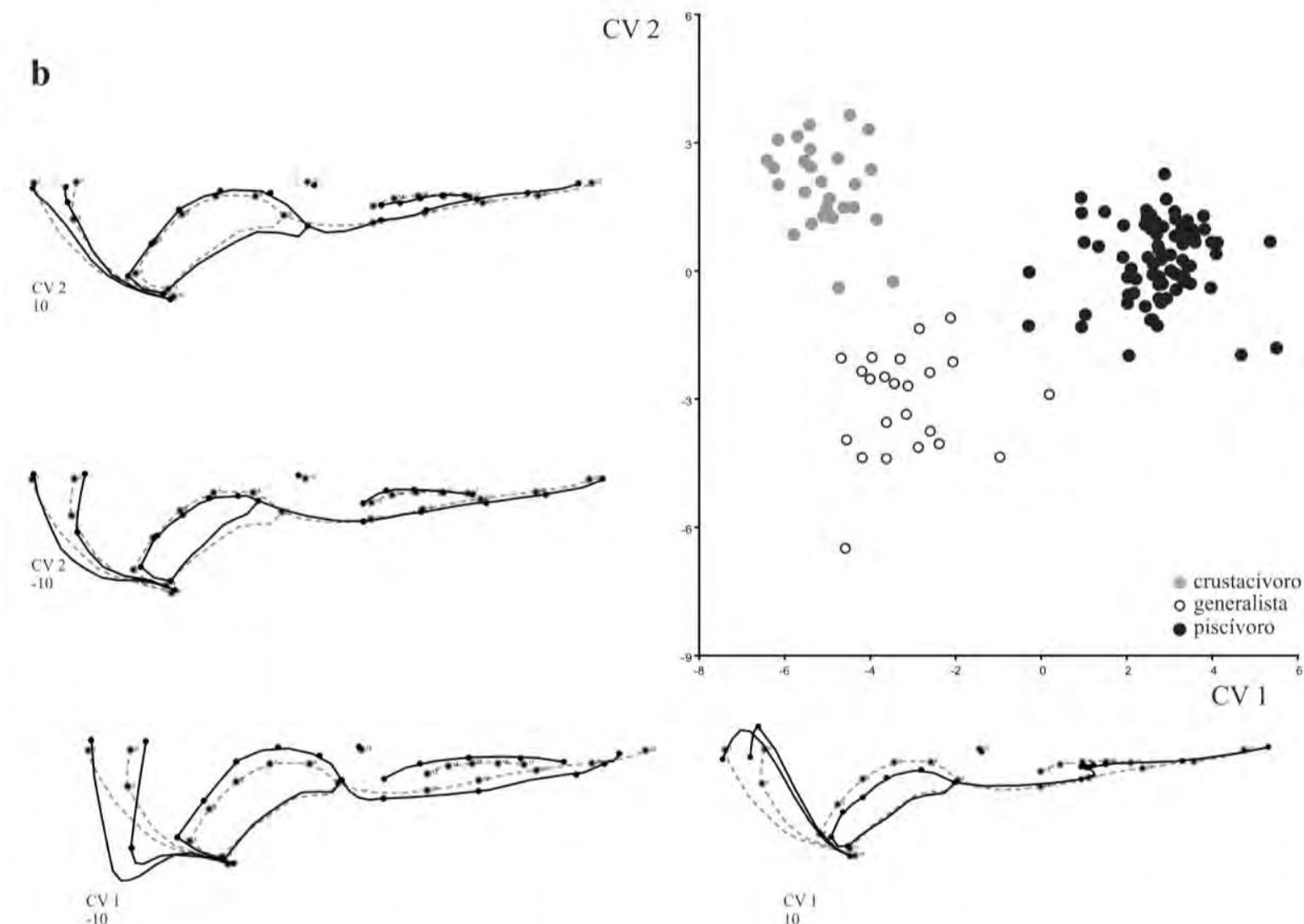

Figura 4 Gráficos de dispersión de los primeros dos $\mathrm{CV}$ de la configuración del cráneo en vista dorsal con el cambio de forma para los valores magnificados de cada CV para a, datos originales; b, datos corregidos. Las líneas grises punteadas representan la forma promedio mientras que las negras representan los valores extremos de cada PC. 
prominentia cerebellaris en las formas piscívoras), la extensión de la fossa temporalis (mayor en las formas piscívoras), y la mayor extensión del pico con respecto a la caja craneana (mayor en las formas piscívoras). En el CV2 (Fig. 4), la mayor variación se ve en el surco de la glándula nasal, en el largo relativo de la bóveda con respecto al pico y en la extensión de la fosa temporal. Para las formas especialistas, la glándula nasal se dispone más paralela al plano sagital, la bóveda craneana posee un tamaño mayor relativo, el pico tiene una longitud relativa menor que las formas generalistas y unas narinas cuyo margen sería paralelo al plano sagital mientras que las formas generalistas, las narinas son más curvas en vista dorsal, y el pico es más largo en relación a la caja craneana.

\section{Configuración de la caja craneana, vista dorsal}

\section{Alometría}

El tamaño explicó un $1,6725 \%$ de la variación en forma para esta configuración y no resultó significativa $(\mathrm{p}=0,1105)$. Por esta razón, en este caso los resultados no se mostrarán por duplicado para los dos sets de datos, y solo se describirán con los datos originales de las coordenadas de procrustes.

\section{Análisis de componentes principales}

Como se observó en el PC 1 (Tabla ) para la configuración anterior, los individuos de Spheniscus se ubicaron hacia los valores positivos mientras el resto de los especímenes de las diferentes especies lo hicieron hacia los valores negativos (Fig. 5). Hacia los negativos extremos se encuentran Pygoscelis, y más hacia los valores neutrales, Eudyptes, Eudyptula, Megayptes y Aptenodytes. Madrynornis mirandus se ubica junto con este grupo. Para el PC2, vemos a Eudyptes hacia los valores positivos extremos, y a Megadyptes y Madrynornis hacia los negativos. Los individuos de las restantes especies se encuentran esparcidos a lo largo del componente. 


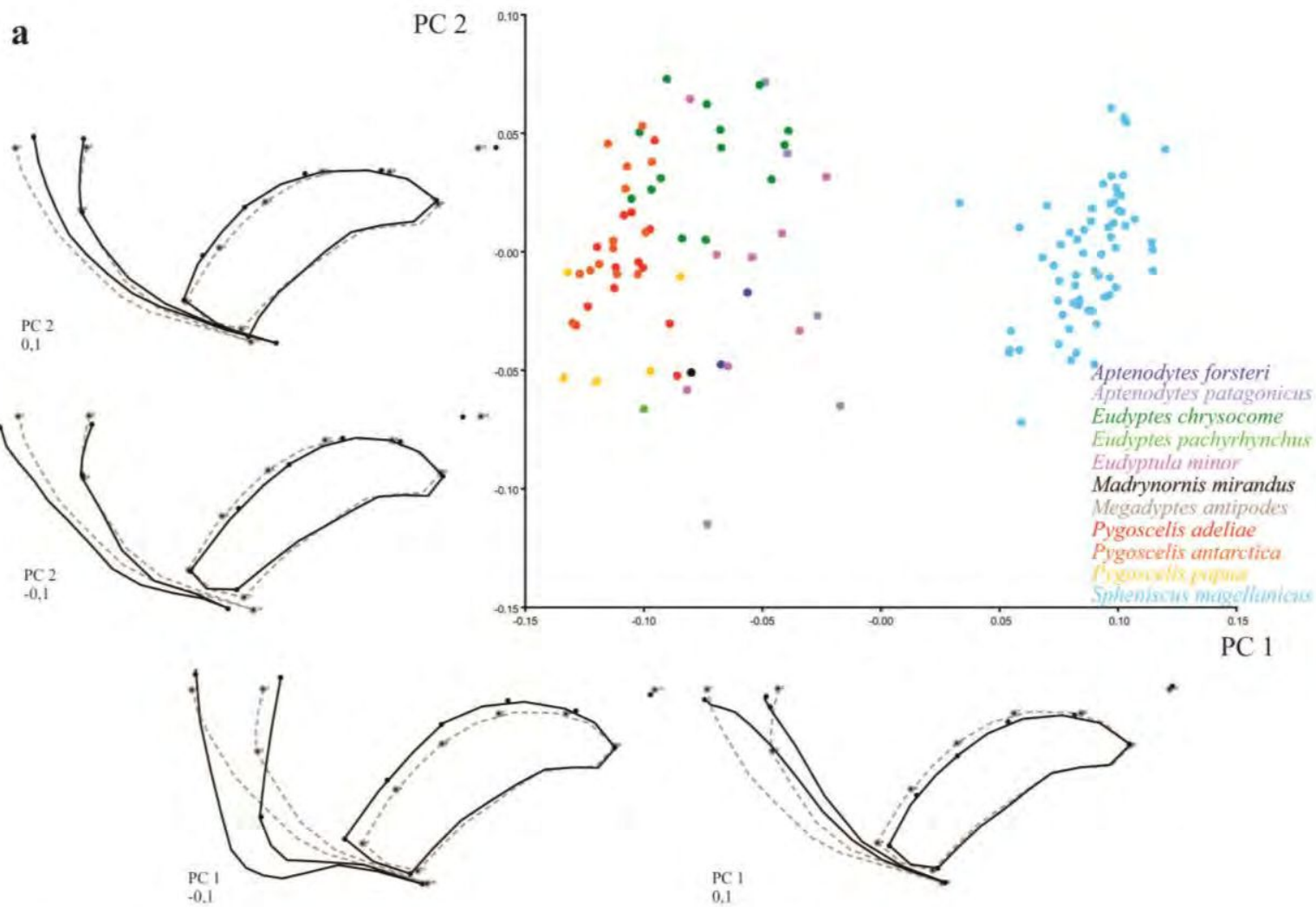

b
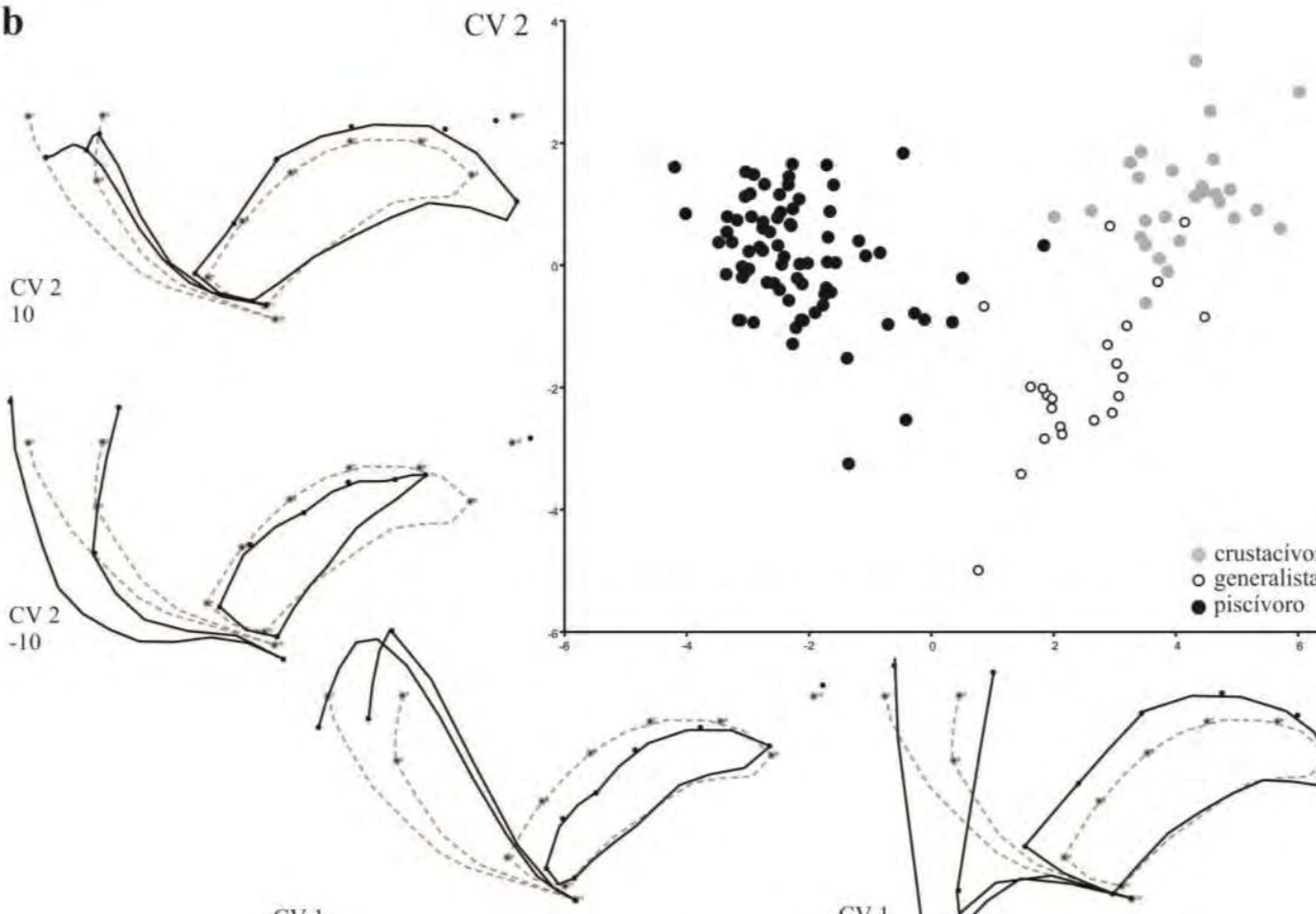

CV 1

CV 1

10

Figura 5 Análisis de la configuración de la caja craneana en vista dorsal. a, análisis de componentes principales, gráficos de dispersión de los primeros dos PC con el cambio de forma para los valores extremos de cada PC; $\mathbf{b}$, análisis de variación canónica, gráficos de dispersión de los primeros dos CV con el cambio de forma para los valores magnificados de cada CV. Las líneas grises punteadas representan la forma promedio mientras que las negras representan los valores extremos de cada PC. 


\begin{tabular}{ll|} 
& \% Variación \\
\hline $\mathrm{PC} 1$ &, \\
$\mathrm{PC} 2$ &, \\
$\mathrm{PC} 3$ &, \\
\hline
\end{tabular}

Tabla Porcentajes de variación explicada por los primeros tres componentes principales, para el PCA del cráneo posterior en vista dorsal del conjunto de datos originales.

La variación de forma para el PC1 (ver Fig. 5) es la misma descrita para el análisis anterior (Ver Configuración del cráneo, vista dorsal: Análisis de componentes principales), mientras que algunas variaciones se observan en el PC 2. Para los valores negativos, la prominentia cerebellaris es más prominente y la fosa de la glándula nasal es más estilizada.

\section{Categorías de hábitos alimenticios: Análisis multivariado de la varianza}

El MANOVA arrojó un valor de Wilk's Lambda bajo (Wilk's $\lambda=, \quad, \quad \mathrm{p}<0,0001$ ), lo que no permite desestimar que las diferencias entre las categorías estén dadas al azar. Siendo, una vez más, las mayores distancias entre los crustacívoros y los piscívoros, seguido por los piscívoros generalistas, y habiéndose hallado como los más cercanos entre sí a los grupos de los crustacívoros y generalistas (Tabla ).

\section{Datos originales}

\section{Wilks' $\lambda$}

$$
\mathrm{p}
$$

\begin{tabular}{|c|c|c|c|}
\hline \multirow{3}{*}{$\mathrm{D}$} & & generalista & crustacívoro \\
\hline & generalista & \multirow[b]{2}{*}{, } & \multirow[t]{2}{*}{, } \\
\hline & piscívoro & & \\
\hline \multirow{2}{*}{$\mathrm{p}$} & generalista & & , \\
\hline & piscívoro & , & , \\
\hline
\end{tabular}

Tabla Análisis multivariante de la varianza (MANOVA) del cráneo posterior en vista dorsal, valores de Wilks' $\lambda$, y distancias de Mahalanobis (D) entre grupos con sus correspondientes valores de $\mathrm{p}$ asociados. Resultados para el conjunto de datos originales. 


\section{Categorías de hábitos alimenticios: Análisis de variación canónica}

Los grupos más cercanos resultaron ser los de crustacívoros-generalistas (Tabla ), y las mayores distancias se hallaron entre los grupos de los piscívoros-crustacívoros. Los resultados en cuanto a la diferenciación morfológica de los grupos son muy similares a los que se obtuvieron para la configuración completa del cráneo en vista dorsal (Ver Fig. 5).

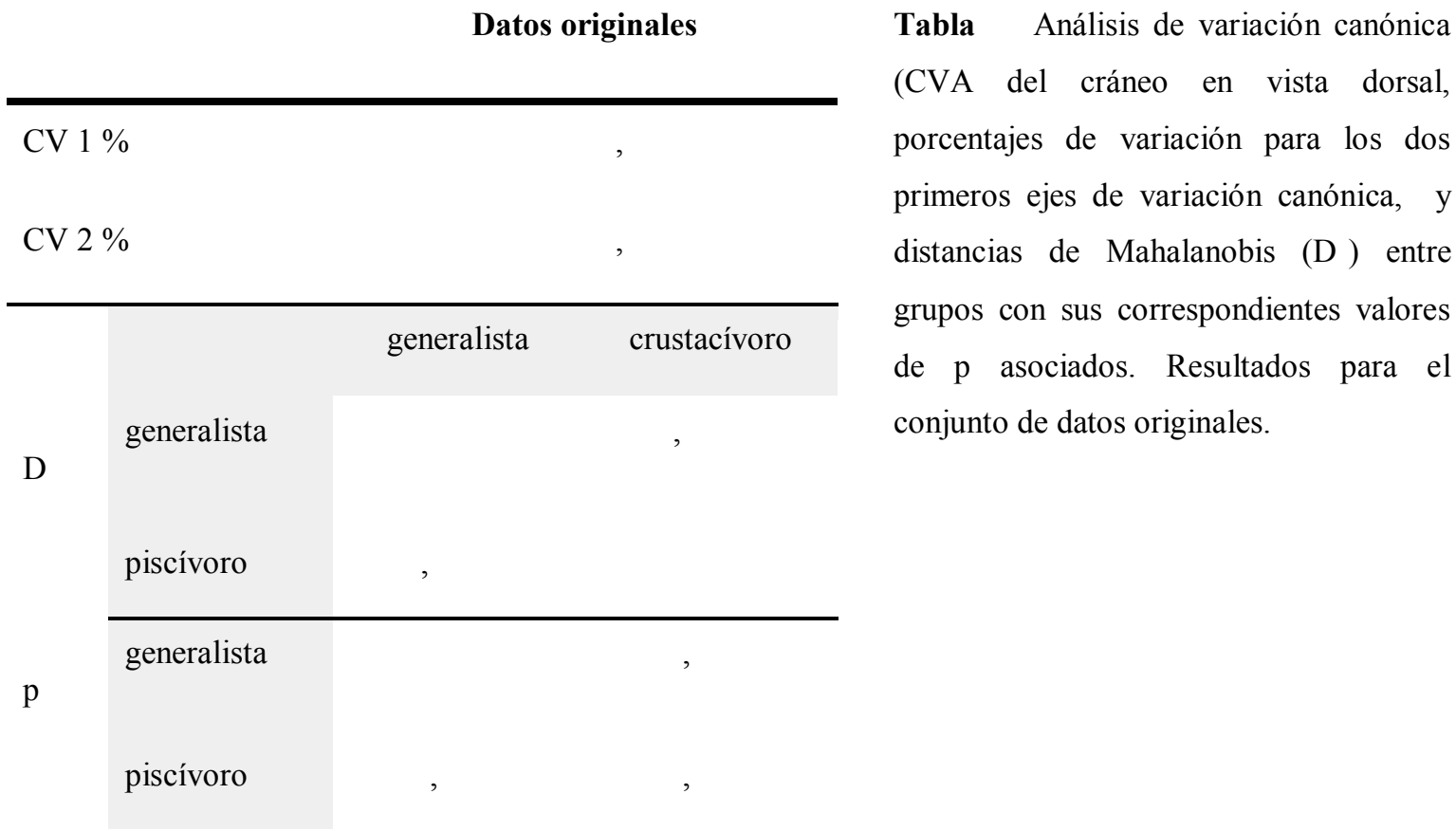

\section{Configuración del pico, vista dorsal}

\section{Alometría}

En este caso, el tamaño explicó un 44,7041\% (p<0,0001) de la variación en forma, un porcentaje muy alto.

\section{Análisis de componentes principales}

En la figura 6 se presentan los gráficos de dispersión para los primeros dos componentes principales (Ver Tabla ) para los análisis de los datos crudos y los residuales. 

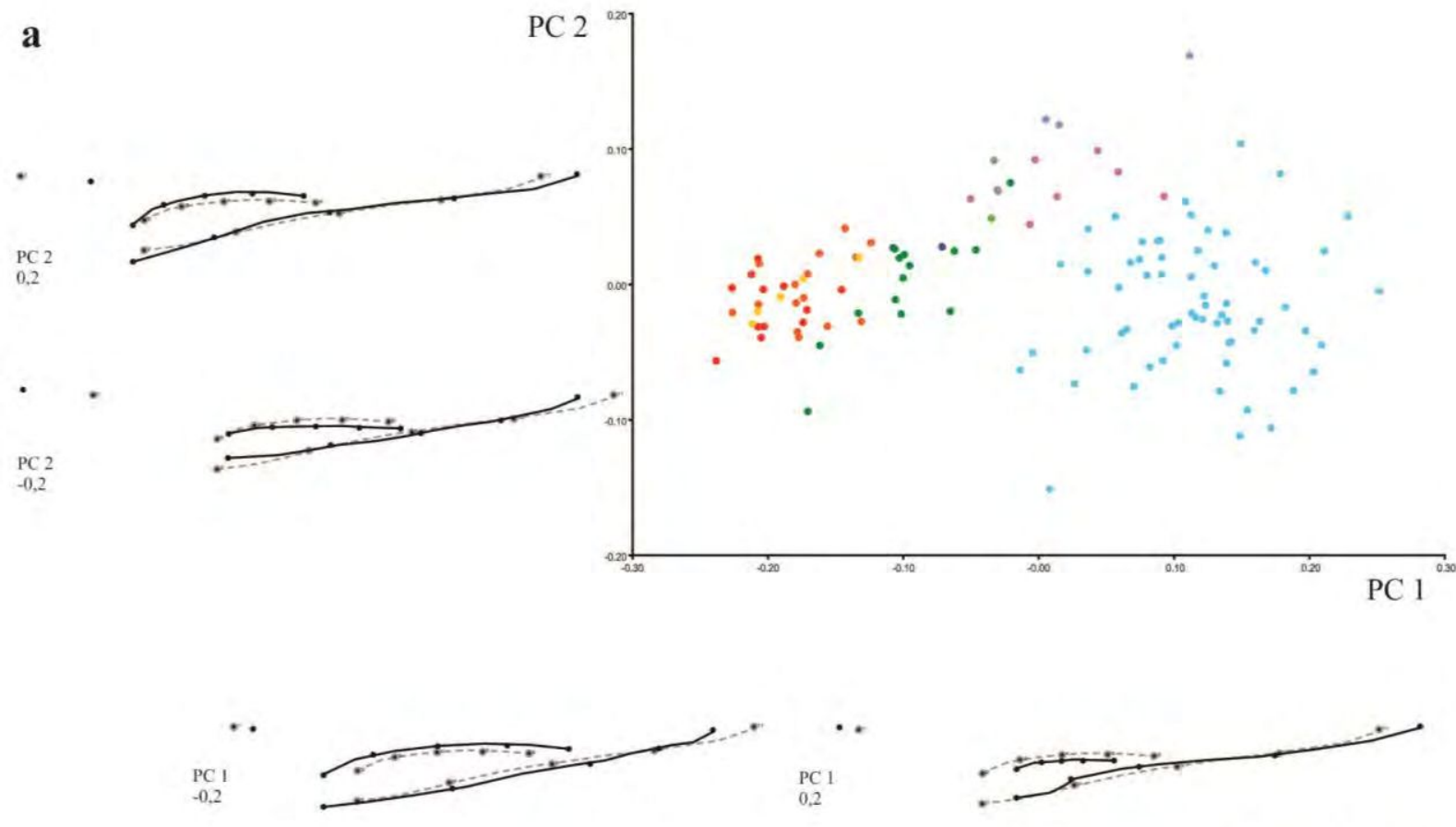

Aptenodytes forsteri Aptenodytes patagonicus Eudyptes chrysocome Eudyptes pachyrhynchus Eudyptula minor Megadyples antipodes Pygoscelis adeliae Pygoscelis antarctica

b

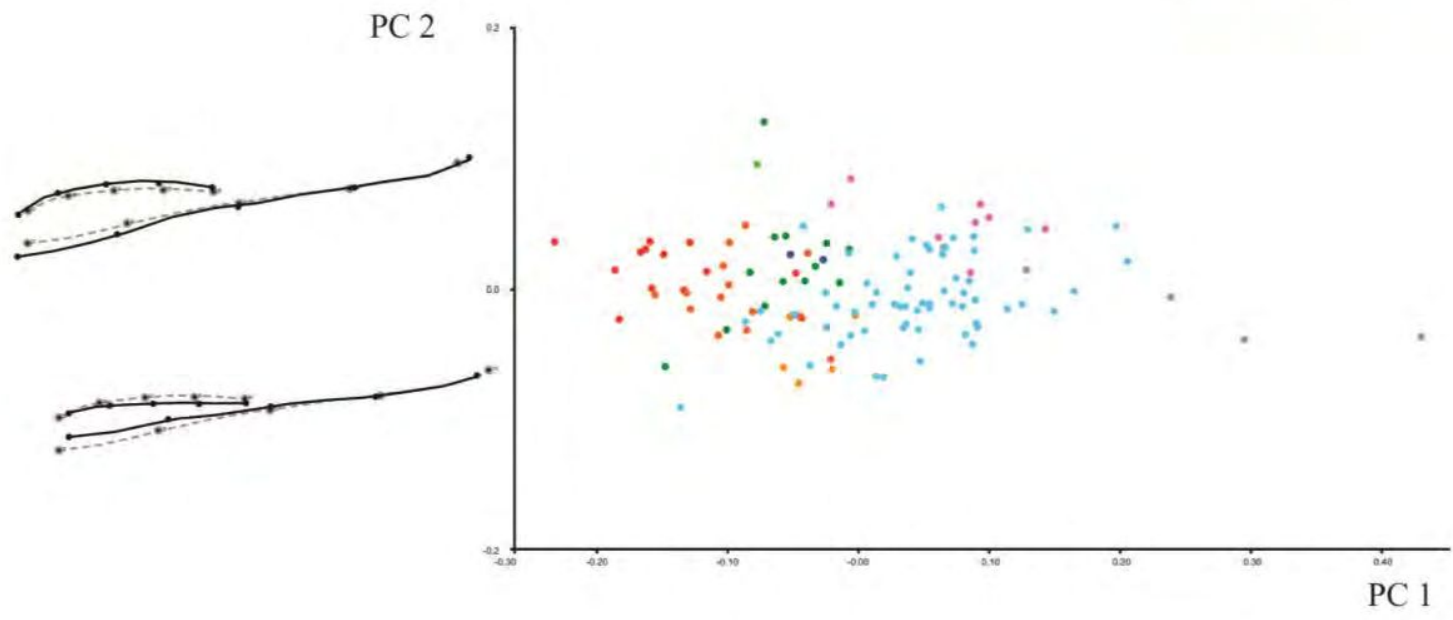

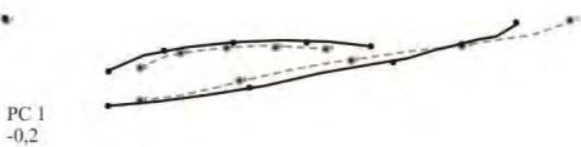

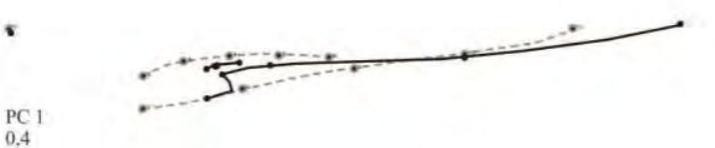

Figura 6 Análisis de componentes principales de la configuración del pico en vista dorsal. Gráficos de dispersión de los primeros dos PC con el cambio de forma para los valores extremos de cada PC para a, datos originales; $\mathbf{b}$, datos corregidos. Las líneas grises punteadas representan la forma promedio mientras que las negras representan los valores extremos de cada PC. 
Recordemos que para este análisis el tamaño explicó más del cuarenta por ciento del cambio de forma.

Tabla Porcentajes de variación explicada por los primeros tres componentes principales, para el PCA del pico en vista dorsal para el conjunto de datos originales y corregidos.

\begin{tabular}{ll|c}
\multicolumn{2}{c|}{$\begin{array}{c}\text { \% Variación-Originales } \\
\text { PC Variación-Corregidos }\end{array}$} \\
\hline PC2 &, \\
PC3 &, &, \\
\hline
\end{tabular}

En rangos generales en ambos PCA, los individuos de Aptenodytes patagonicus, Eudyptula, y Spheniscus se agrupan hacia los valores negativos, mientras que Aptenodytes forsteri, Eudyptes chrysocome, E. pachyrhynchus, y Megadyptes antipodes quedan en valores neutrales (el último más cercano a Spheniscus), y Pygoscelis hacia los valores positivos extremos. Cuando se corrige el análisis eliminando el efecto alométrico, se genera un gradiente de distribución a lo largo del primer componente (Fig. 6a.). Esto resulta por demás interesante, dado que Pygoscelis antarctica y P. adelia (los pingüinos que se alimentan casi de un $100 \%$ en krill) quedan juntos ubicados en los valores positivos extremos. Siguiendo este gradiente de alimentación encontramos a especímenes de Aptenodytes forsteri, Eudyptes chrysocome, E. pachyrhynchus y P. papua, todos clasificados para este trabajo como generalistas. Por último encontramos hacia los valores positivos a especímenes clasificados como piscívoros para este trabajo (Spheniscus, Eudyptula, y Megadyptes), quedando Aptenodytes patagonicus en los valores positivos más extremos de este rango.

\section{Categorías de hábitos alimenticios: Análisis multivariado de la varianza}

El MANOVA arrojó un valor de Wilk's Lambda bajo para los datos crudos, mientras que para los valores residuales el valor fue mucho más alto, aunque todavía bajo (Ver tabla

). Las distancias mayores encontradas fueron diferentes para ambos conjuntos de datos. En el caso del MANOVA de los datos crudos, la mayor distancia hallada resultó entre los grupos 
crustacívoros y piscívoros, seguida por los grupos piscívoros generalistas. Mientras que para los datos residuales las mayores distancias encontradas fueron entre los grupos crustacívoros y generalistas, seguido por los piscívoros-crustacívoros, y quedando como los grupos más cercano los piscívoros y generalistas.

Tabla Análisis multivariante de la varianza (MANOVA) del pico en vista dorsal, valores de Wilks' $\lambda$, y distancias de Mahalanobis (D) entre grupos con sus correspondientes valores de $\mathrm{p}$ asociados. Resultados para el conjunto de datos originales y corregidos.

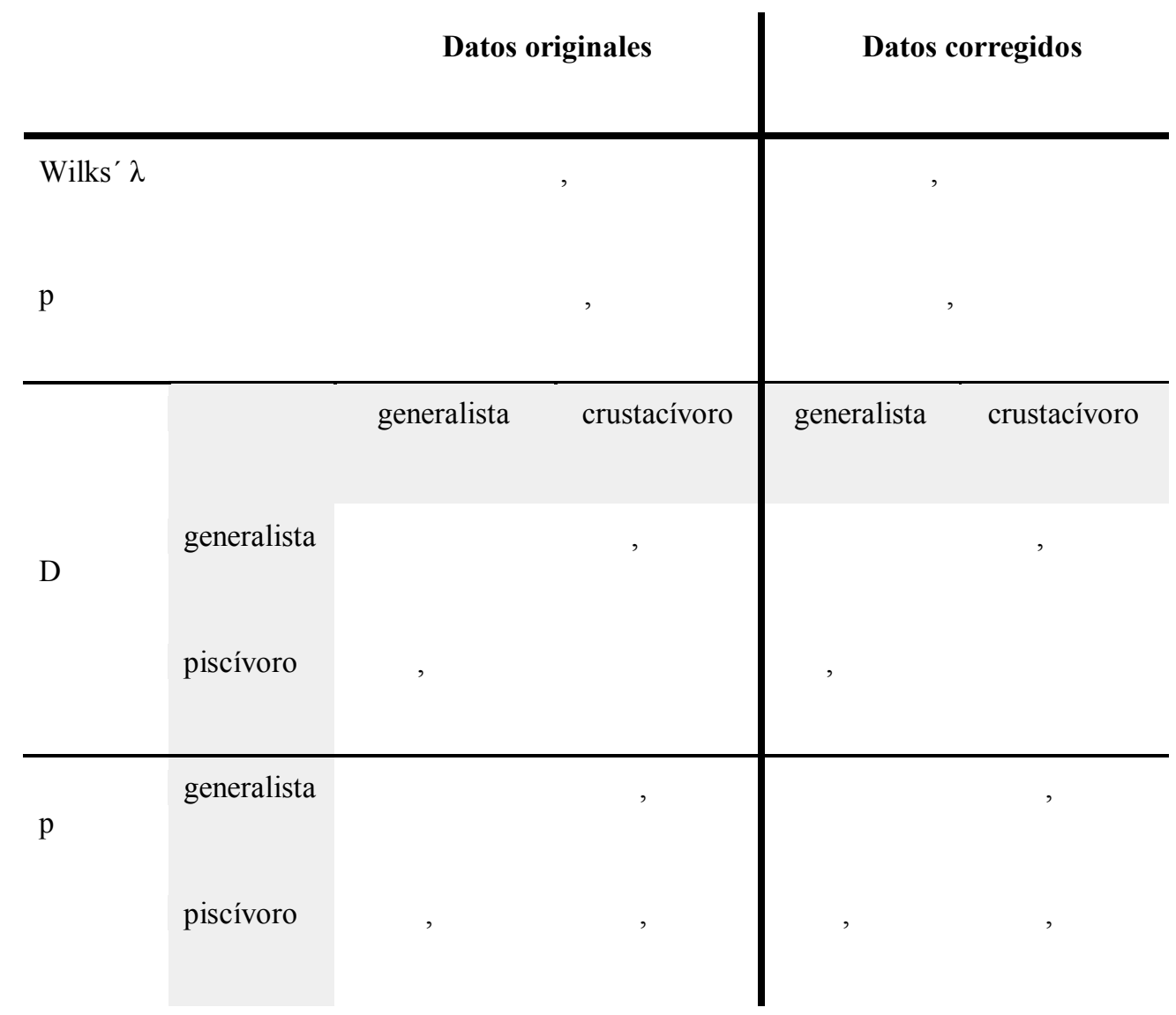

\section{Categorías de hábitos alimenticios: Análisis de variación canónica}

Las distancias de Mahalanobis (D ) calculadas entre los tres grupos dieron resultados dispares para los dos conjuntos de datos (ver Tabla ). Para el conjunto de datos crudos, las mayores distancias resultaron para el grupo de los crustacívoros-piscívoros, seguido de los piscívoros generalistas, quedando los grupos de los crustacívoros-generalistas como los más cercanos. Mientras que para los datos residuales, las distancias mayores halladas resultaron entre los grupos de los crustacívoros-generalistas, seguidas de los curstacívoros piscívoros, y por último los de los piscívoros-generalistas. 
Tabla Análisis de variación canónica (CVA) del pico en vista dorsal, porcentajes de variación para los dos primeros ejes de variación canónica, y distancias de Mahalanobis (D) entre grupos con sus correspondientes valores de $\mathrm{p}$ asociados. Resultados para el conjunto de datos originales y corregidos.

\begin{tabular}{|c|c|c|c|c|c|}
\hline & & \multicolumn{2}{|c|}{ Datos originales } & \multicolumn{2}{|c|}{ Datos corregidos } \\
\hline \multicolumn{2}{|c|}{ CV $1 \%$} & \multicolumn{2}{|r|}{, } & \multicolumn{2}{|c|}{, } \\
\hline \multicolumn{2}{|c|}{ CV $2 \%$} & \multicolumn{2}{|r|}{, } & \multicolumn{2}{|l|}{, } \\
\hline \multirow{3}{*}{$\mathrm{D}$} & & generalista & crustacívoro & generalista & crustacívoro \\
\hline & generalista & \multirow{2}{*}{\multicolumn{2}{|c|}{, }} & \multirow{2}{*}{\multicolumn{2}{|c|}{, }} \\
\hline & piscívoro & & & & \\
\hline \multirow{2}{*}{$\mathrm{p}$} & generalista & & , & & , \\
\hline & piscívoro & , & , & , & $<$ \\
\hline
\end{tabular}

Para el CVA de los datos crudos (Fig. 7), el CV1 separa a los piscívoros de los crustacívoros quedando en el medio los generalistas, una situación similar se da para el mismo análisis de los datos residuales, con la diferencia que en este último, los generalistas quedan junto con los piscívoros para este CV. En ambos análisis, el CV2 separa los generalistas de los especialistas.

En cuanto a las diferencias de formas maximizadas que nos permiten separar grupos, encontramos que para ambos análisis el CV1 encuentra diferencias similares. Los valores negativos donde se agrupan los piscívoros (y en el caso de los residuales, también los generalistas) poseen picos más elongados y narinas poco visibles en vista dorsal (Fig. 7). Mientras que el grupo crustacívoro presenta el caso contrario, con picos robustos, anchos, y narinas extendidas antero posteriormente. 


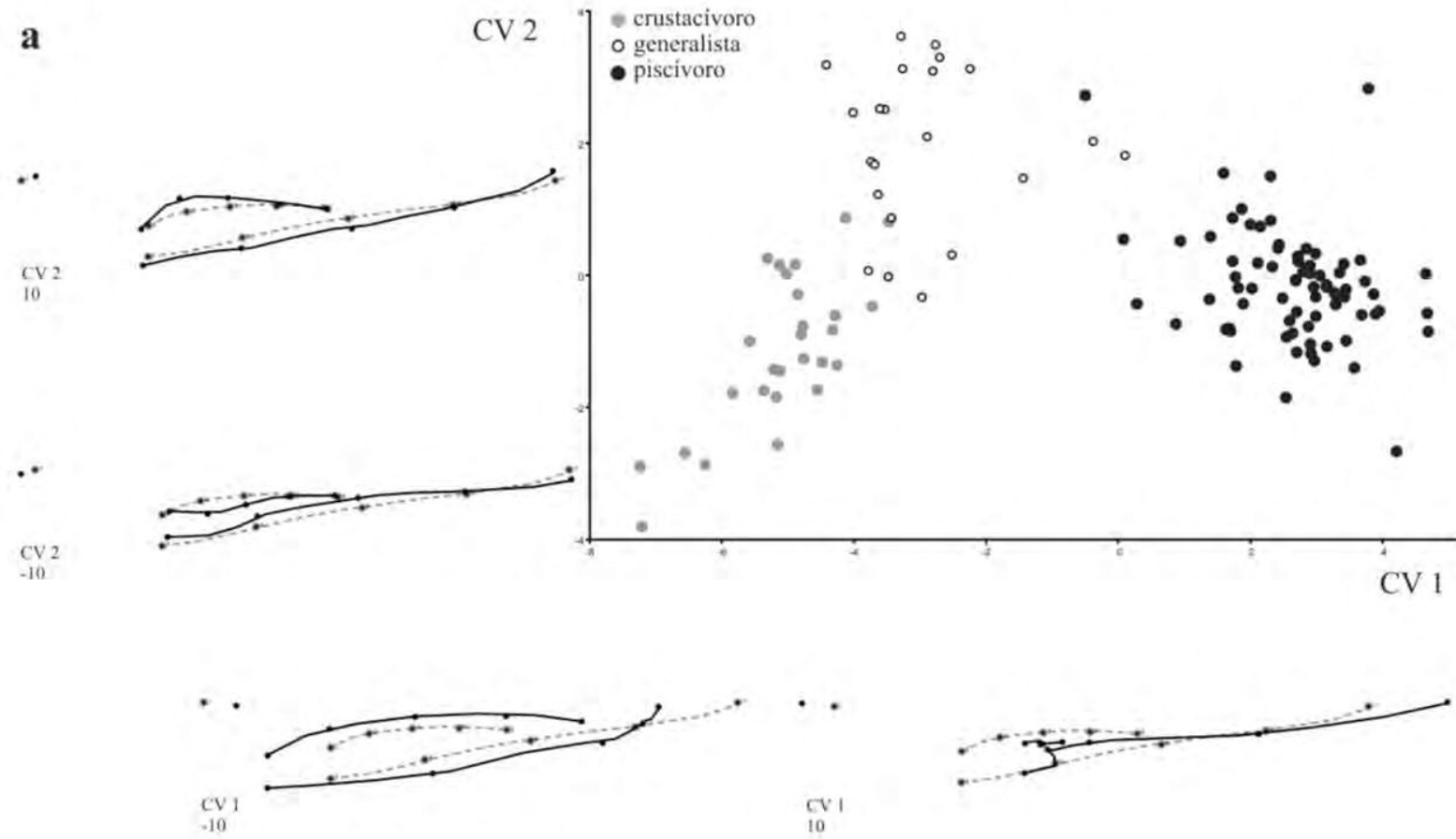

b
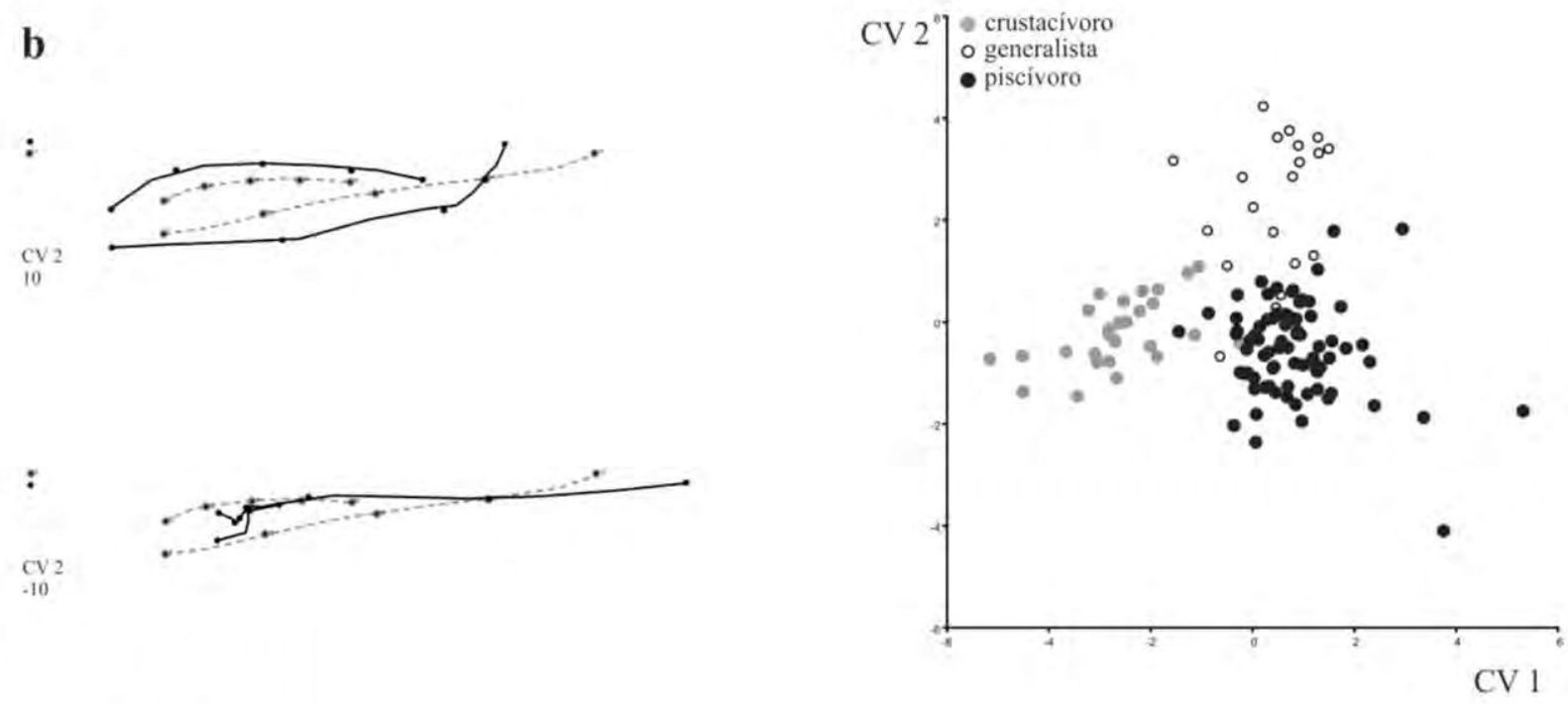

$\mathrm{CV} 1$

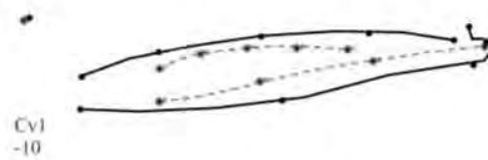

Figura 7 Gráficos de dispersión de los primeros dos $\mathrm{CV}$ de la configuración del pico en vista dorsal, con el cambio de forma para los valores magnificados de cada $\mathrm{CV}$ para $\mathbf{a}$, datos originales; $\mathbf{b}$, datos corregidos. Las líneas grises punteadas representan la forma promedio mientras que las negras representan los valores extremos de cada PC. 
Para el CV2, las diferencias principales se centran en la curvatura del pico y la narina. Las formas generalistas poseen el punto mayor de curvatura de la narina posteriormente, mientras que esta curvatura no está tan marcada en las formas especialistas. El pico, tendría una curvatura convexa en su extensión lateral en las formas generalistas, mientras que para las formas especialistas presentaría una curvatura cóncava en la sección media del pico, generando un margen en "s"

\section{RESULTADOS: ANÁLISIS MANDÍBULA}

\section{Configuración de la mandíbula vista dorsal}

\section{Alometría}

Para esta configuración, el tamaño explicó el 9,9369\% ( $\mathrm{p}<0,001)$, es decir que existe un efecto alométrico en la variación de forma, por lo que a continuación los resultados de los PCA, MANOVA y CVA serán presentados con los datos originales y los corregidos por el efecto alométrico.

\section{Análisis de componentes principales}

Se observa en los gráficos de dispersión para el PC1 (Ver Tabla con porcentajes de variación por PC) que Spheniscus se agrupa hacia los valores positivos, y todos los demás pingüinos hacia los valores neutrales y negativos (Fig. 8). Eudyptes, Megadyptes y Eudyptula se ubican más hacia los valores neutrales, mientras que Pygoscelis y Aptenodytes se encuentran hacia los valores negativos. Para el PC2, Aptenodytes se agrupa hacia los valores positivos extremos, Eudyptes hacia los valores negativos, y Pygoscelis, Spheniscus y Megadyptes en los valores neutros. La posición de Eudyptula en el gráfico de dispersión varía para el análisis de datos crudos y residuales, ubicándose en valores neutrales para el análisis con datos crudos y hacia los valores positivos junto con Aptenodytes para los análisis con datos residuales. Madrynornis se ubica en los valores neutrales para ambos componentes, quedando cercano a Eudyptes. 
a
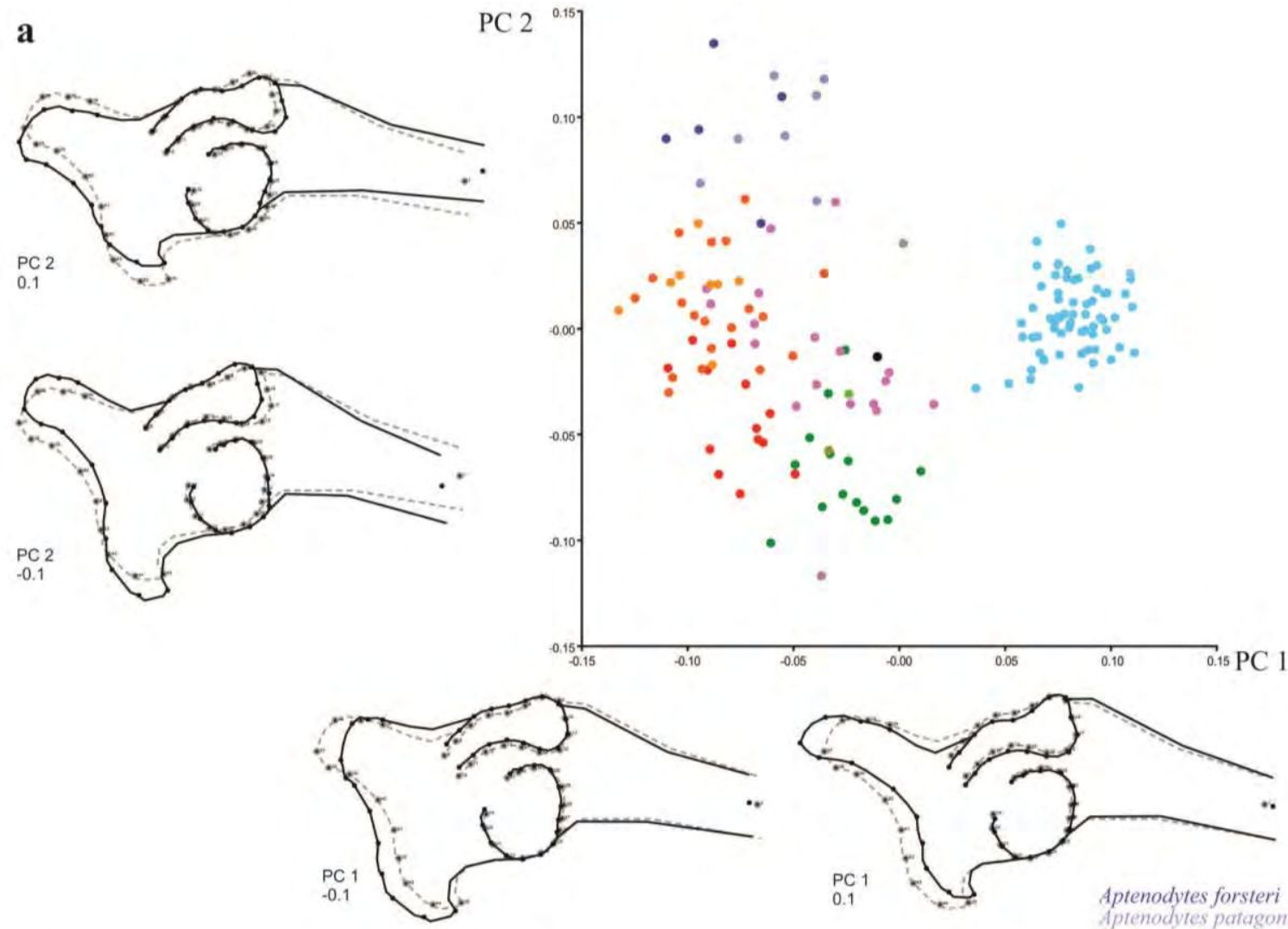

Aplenodytes forsteri Eudvptes chrysocome Eudvptes pachyrhunchus
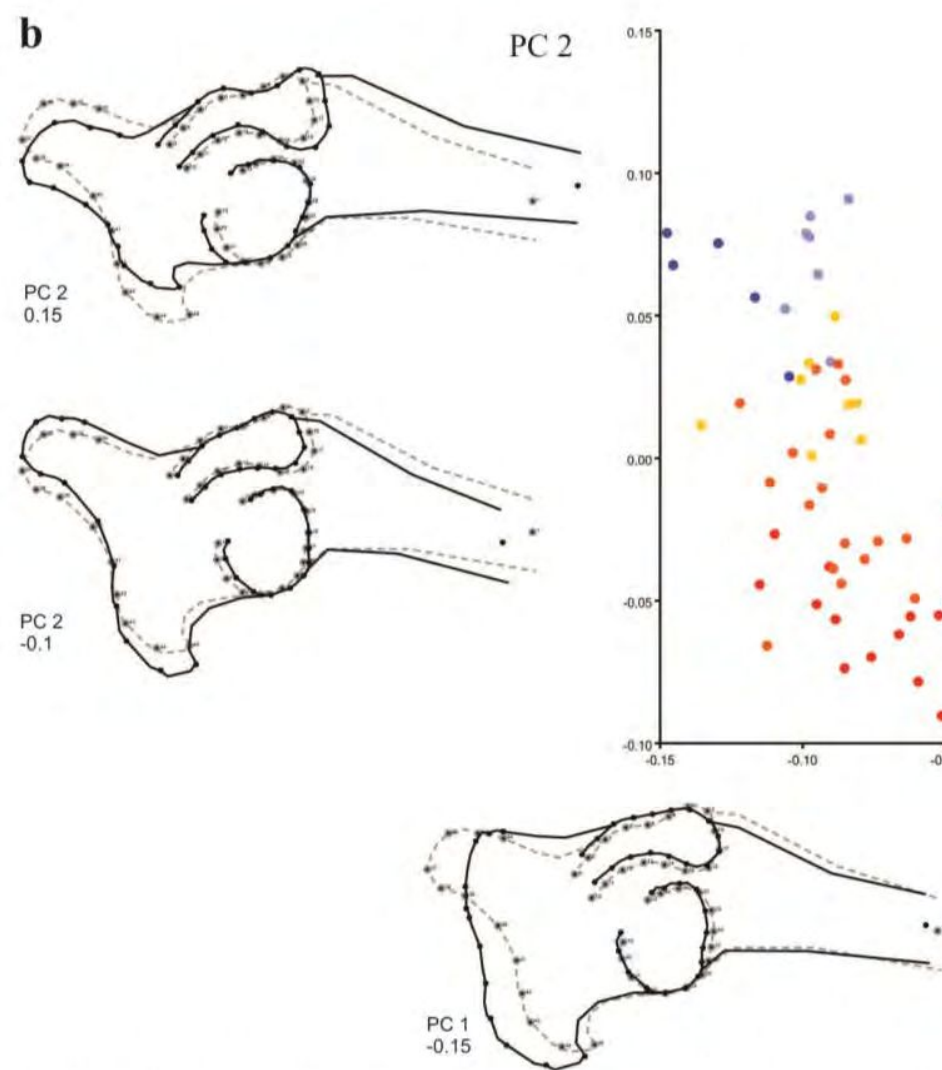

Eudyptula minor Madrynornis mirandus Megadyples antipode Pygoscelis adeliae Pygoscelis antarctica 
Tabla Porcentajes de variación explicada por los primeros tres componentes principales, para el PCA de la mandíbula en vista dorsal del conjunto de datos originales y corregidos.

\begin{tabular}{l|c}
\multicolumn{1}{l|}{$\begin{array}{c}\text { \% Variación-Originales } \\
\text { PC1 }\end{array}$} &, \\
\hline $\mathrm{PC} 2$ &, \\
$\mathrm{PC} 3$ &, \\
\hline
\end{tabular}

La variación en forma explicada por el PC1 (Fig. 8) da cuenta de la forma del proc. retroarticularis, que es delgado y alargado para los individuos que caen hacia los valores positivos del gráfico de dispersión (Spheniscus). En las formas opuestas (Pygoscelis), el proc. retroarticularis es corto y ancho. El proc. coronoideus se encuentra levemente más alejado de la articulación para los individuos que se ubican en los valores positivos extremos (Spheniscus) en comparación con los de los valores negativos (Pygoscelis). El proc. medialis mandibulae es, en comparación con la superficie articular, menos robusto en las formas cercanas a Spheniscus que a Pygoscelis. Por último se observa una separación marcada entre la cotyla caudalis y la $c$. lateralis en los individuos ubicados hacia los valores positivos (Spheniscus), mientras que las formas encontradas en los valores negativos presentan un ancho homogéneo de la cotyla caudalis y c. lateralis, que se encuentran sutilmente divididas. Por último, las morfologías halladas hacia los valores positivos del PC1 presentan proporciones cuadrangulares, mientras que las ubicadas hacia los valores negativos presentan un ancho relativo de la articulación mayor al largo.

El PC2 ubica a los individuos de Aptenodytes en los valores positivos, pasando por Spheniscus, Pygoscelis, Eudyptula, Megadyptes, Madrynornis, y por último los Eudyptes hacia los valores negativos. Las formas ubicadas hacia los valores positivos extremos (Aptenodytes) poseen una c. caudalis que se angosta antes de ensancharse para formar la $c$. lateralis. Mientras que para los valores negativos la $c$. caudalis se ensancha paulatinamente hasta formar la $c$. lateralis. 


\section{Categorías de hábitos alimenticios: Análisis multivariado de la varianza}

El MANOVA arrojó un valor de Wilk's Lambda bajo (Tabla ) para el conjunto de datos completos, por lo que confirmamos que las diferencias entre grupos no estarían dadas por azar. Las mayores distancias encontradas fueron entre los grupos piscívoroscrustacívoros, seguidos del grupo piscívoros-generalistas, y por último los grupos más cercanos resultaron los de los crustacívoros-generalistas.

Tabla Análisis multivariante de la varianza (MANOVA) de la mandíbula en vista dorsal, valores de Wilks' $\lambda$, y distancias de Mahalanobis (D) entre grupos con sus correspondientes valores de $\mathrm{p}$ asociados. Resultados para el conjunto de datos originales y corregidos.

\begin{tabular}{|c|c|c|c|c|c|}
\hline & & \multicolumn{2}{|c|}{ Datos originales } & \multicolumn{2}{|c|}{ Datos corregidos } \\
\hline \multicolumn{2}{|c|}{ Wilks' $\lambda$} & & & \multicolumn{2}{|c|}{, } \\
\hline \multicolumn{2}{|l|}{$\mathrm{p}$} & \multicolumn{2}{|r|}{, } & \multicolumn{2}{|c|}{, } \\
\hline \multirow{3}{*}{$\mathrm{D}$} & & generalista & crustacívoro & generalista & crustacívoro \\
\hline & & & , & \multirow{2}{*}{\multicolumn{2}{|c|}{, }} \\
\hline & piscívoro & , & & & \\
\hline \multirow{2}{*}{$\mathrm{p}$} & generalista & & , & & , \\
\hline & piscívoro & , & , & , & , \\
\hline
\end{tabular}

\section{Categorías de hábitos alimenticios: Análisis de variación canónica}

Para ambos conjuntos de datos, los grupos que resultaron más distantes fueron los de los crustacívoros-piscívoros (Tabla ). Los grupos de los piscívoros-generalistas resultaron ser los segundos en mayor distancia, y los grupos más cercanos fueron los crustacívorosgeneralistas. 


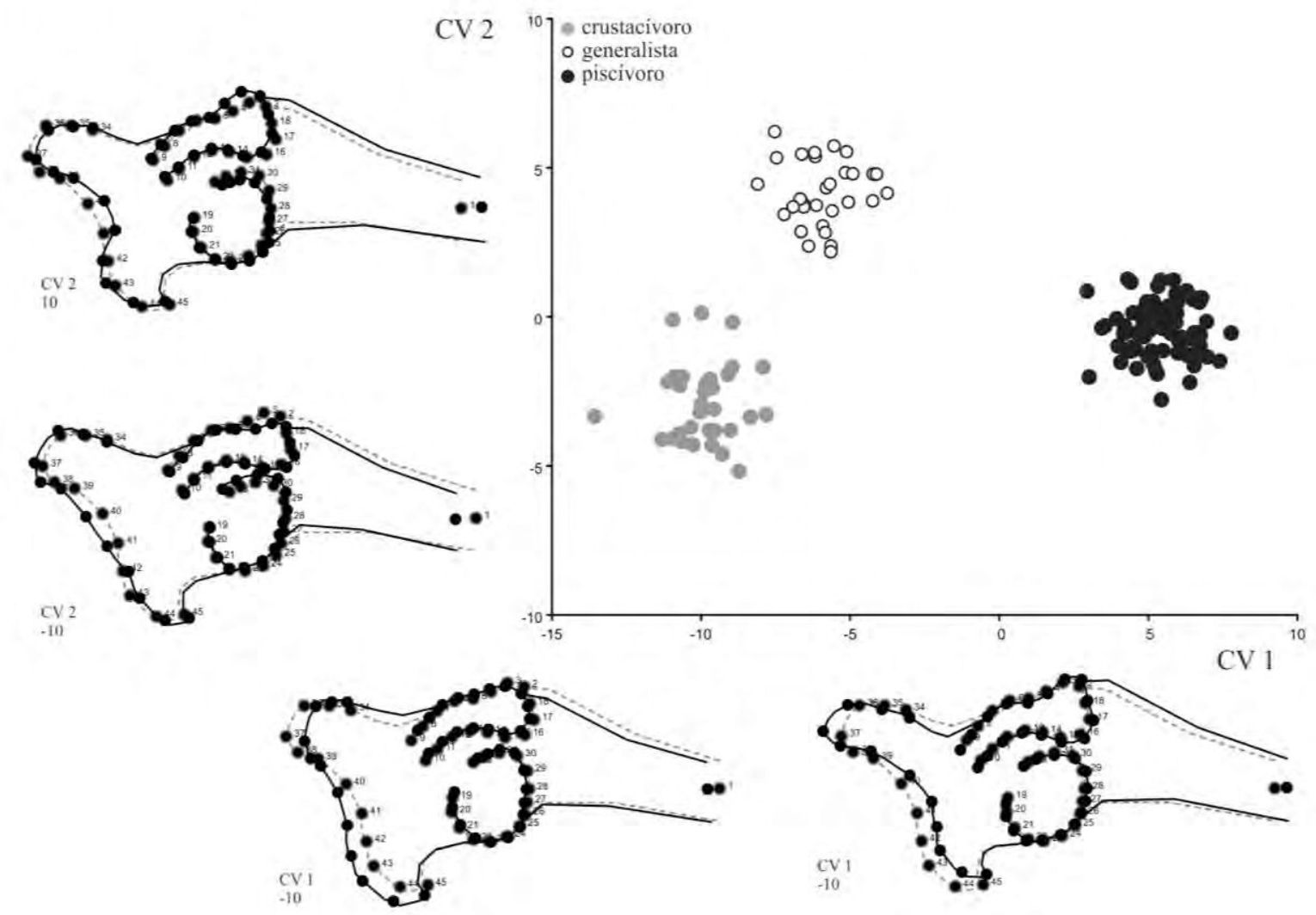

b
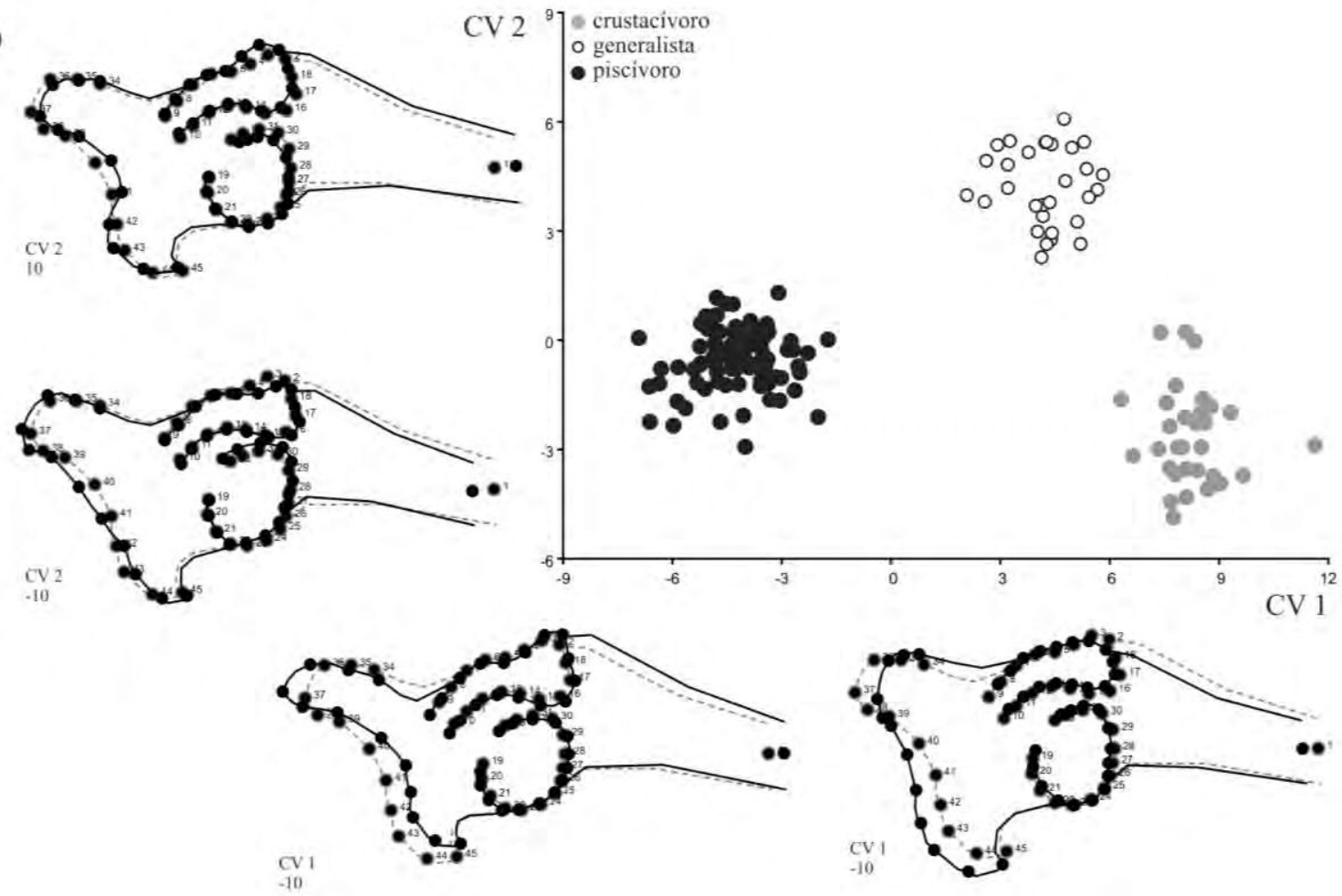

Figura 9 Análisis de variación canónica de la mandibula en vista dorsal. Gráficos de dispersión de los primeros dos $\mathrm{CV}$, con el cambio de forma para los valores magnificados de cada $\mathrm{CV}$ para $\mathbf{a}$, datos crudos; $\mathbf{b}$, valores residuales. Las líneas grises punteadas representan la forma promedio mientras que las negras representan los valores extremos de cada CV. 
Tabla Análisis de variación canónica (CVA) de la mandíbula en vista dorsal, porcentajes de variación para los primeros dos primeros ejes de variación canónica, y distancias de Mahalanobis (D ) entre grupos con sus correspondientes valores de $\mathrm{p}$ asociados. Resultados para el conjunto de datos originales $\mathrm{y}$ corregidos.

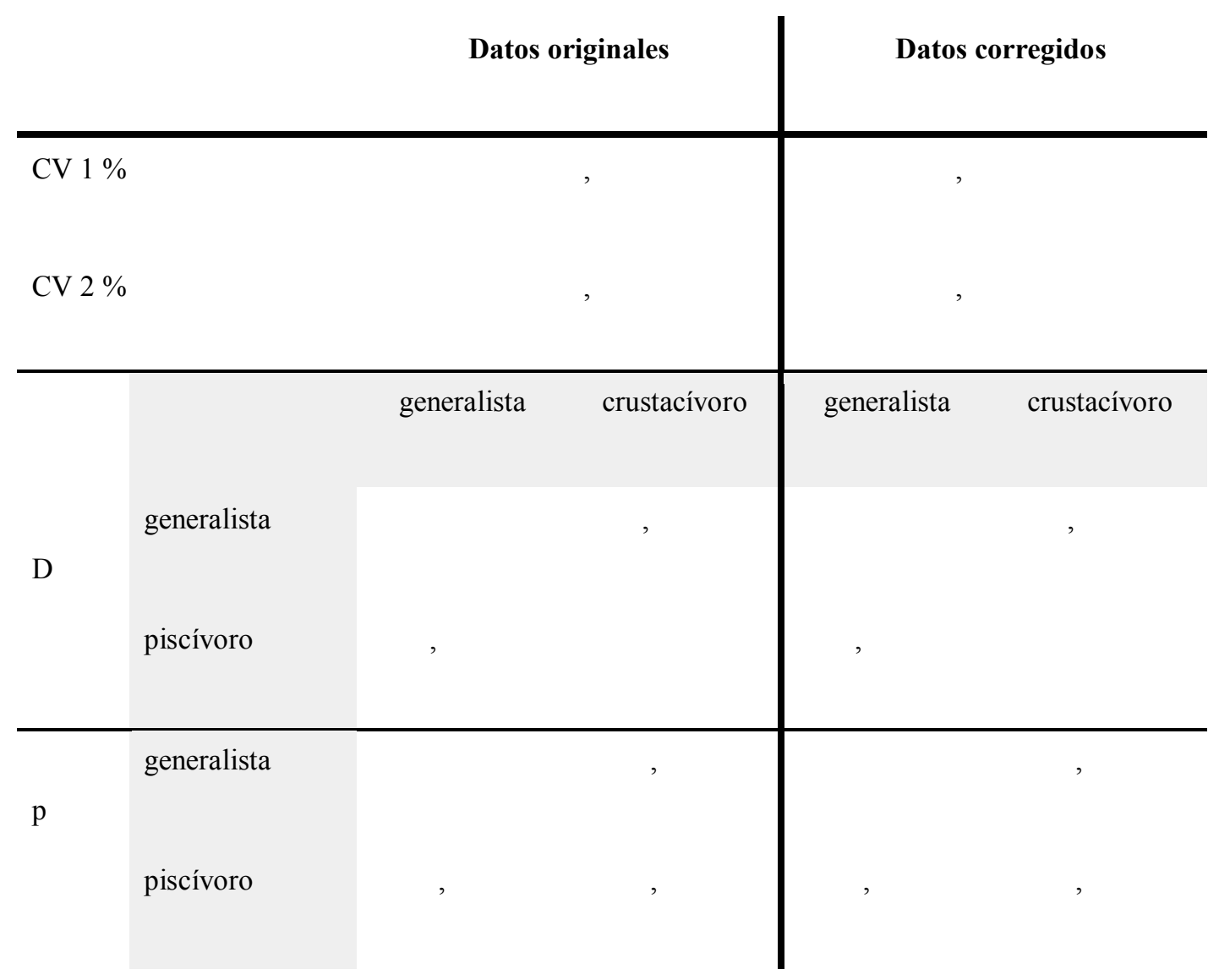

Los piscívoros son separados de los crustacívoros por el $\mathrm{CV}^{3}$ (Fig. 9). Los generalistas quedaron en medio de ambos grupos en el análisis de datos completos aunque cercanos a los crustacívoros. El CV2 separa los generalistas de los especialistas.

En cuanto a la variación de forma explicada por los primeros dos CV (Fig. 9), se destaca lo siguiente: El CV1 explica la variación entre grupos mayormente debido a las características del proc. retroarticularis, la cotyla lateralis, y el proc. coronoideus. Los valores positivos, donde encontramos a los grupos piscívoros presentan una morfología en la cual el proc. retroarticularis es angosto y alargado, mientras que en las formas crustacívoras, es comparativamente más corto y ancho. El proc. medialis mandibulae es en relación entre ambos grupos, más grácil y más curvado en las formas piscívoras, mientras que en las especies crustacívoras presenta una morfología más robusta. La cotyla lateralis presenta un

\footnotetext{
${ }^{3}$ Los valores del CV 1 se encuentran invertidos para el CVA con valores residuales.
} 
ensanchamiento lateromedial mayor en las formas piscívoras, mientras que en las formas crustacívoras es más redondeada. Un angostamiento entre la cotyla caudalis y la c. lateralis se observa en las formas piscívoras, mientras que en las formas crustacívoras la diferenciación entre ambas no es tan notoria. Por último, el proc. coronoideus se encuentra más alejado de la articulación para las formas piscívoras.

El CV2, el cual diferencia los grupos generalistas de los especialistas, describe las diferencias más notorias relacionadas con el ancho de la cotyla medialis y de la c. lateralis y la forma del margen lateral del proc. retroarticularis. Las formas generalistas presentan un mayor ancho en la cotyla lateralis, una c. medialis más redondeada, y un margen medial del proc. retroarticularis curvado. Mientras que las formas especialistas, y sobre todo las crustacívoras, tendrían una cotyla lateralis más angosta, y un menor ancho de la rama mandibular respecto de los generalistas, además de un margen medial del proc. retroarticularis recto.

\section{DISCUSIÓN Y CONCLUSIONES}

Los análisis obtenidos resultaron concluyentes en que existe una correlación entre la variación de la forma del cráneo y la mandíbula con las categorías alimentarias asignadas en esta tesis. Las diferencias entre las categorías propuestas residen en la amplitud y largo de las narinas, el ángulo de la crista nuchalis transversa, el surco de la glándula nasal y en el largo relativo de la bóveda craneana con respecto al pico. Las características morfológicas que Zusi (1975) relaciona con los hábitos alimenticios de los pingüinos quedarían cuantitativamente confirmadas en el presente estudio.

El processus postorbitalis resulta de gran importancia en el movimiento de la mandíbula y no puede ser ignorado. Como han postulado diversos autores (Bock, 1960; Zusi

; Bock, 1999), la porción mandibular posterior a este ligamento que incluye la articulación mandibular es empujada hacia arriba y hacia delante por el $\mathrm{m}$. depressor mandibulae, esto se ve reflejado en un movimiento necesario hacia adelante por parte del cuadrado que a su vez provoca una retracción del pico. Entonces, la condición de Spheniscus magellanicus que incluye un lig. postorbitalis robusto junto con un $m$. depressor mandibulae más desarrollado, con un brazo de palanca de entrada mayor, como se observó tanto en las 
disecciones musculares como en los resultados de los análisis morfo-geométricos, nos indicaría que esta especie (y probablemente todas las de Spheniscus si tomamos nota de las medidas angulares tomadas por Zusi 1975 para Spheniscus demersus) tendría una mayor fuerza de apertura tanto mandibular como del pico y un ángulo mayor de apertura de la boca. Esto se relaciona con un mayor tamaño de presas (Zusi, 1975).

Los resultados también mostraron una relación del largo del pico con respecto al tamaño de la caja craneana, mayor para Aptenodytes patagonicus con respecto al resto de las especies analizadas, relación que también se observa en los CVA para los piscívoros, que presentan picos más largos y gráciles. Esta condición se evidencia a simple vista y concuerda con lo expuesto por Zusi (1975), quien propone un gradiente con respecto a esta relación (largo del pico con respecto al ancho caja craneana). De esta manera, queda Aptenodytes con un pico desproporcionadamente largo, seguido de Spheniscus y P. papua, E. chrysolophus y Megadyptes. $P$. adelia y $P$. antarctica son los que presentan los picos relativamente más cortos (Zusi, 1975). En el presente análisis hemos corroborado cuantitativamente esta relación, aunque con leves modificaciones. Megadyptes queda más cercano a la condición de P. patagonicus (pingüinos rey), mientras que A. forsteri (emperador) sorprendentemente se aleja de su congénere, quedando cercano a Eudyptes. Eudyptula minor no fue tenido en cuenta por Zusi (1975), y nuestro estudio lo encontró cercano a A. forsteri en esta relación cráneo-pico. Esto resulta interesante porque a simple vista el largo pico del emperador es notorio y de antemano se hubiese hipotetizado que tanto A. forsteri (pingüino emperador) como A. patagonicus (pingüino rey) deberían salir más próximos entre sí en los análisis. Picos más largos están relacionados con un mayor alcance o mayor movilidad de las mandíbulas (Zusi, 1975), lo cual a su vez se refleja en el tipo de presa.

Vale la pena destacar aquí los resultados de la configuración del pico para el PCA de datos corregidos, en donde se obtuvo un extraordinario gradiente morfoecológico para el PC1. Este ordenamiento es coincidente con el tipo de alimentación, desde los más extremos crustacívoros (P. antarctica, P. adeliae), pasando por todos generalistas (en orden de más crustacívoro a más piscívoro y de ubicación en PC 1 de negativo a positivo, $E$. pachyrrynchus; E.chrysocome; P. papua; A. forsteri); hasta llegar a los piscívoros (incluyendo a lo que se alimentan de cefalópodos por el tipo de captura que conlleva) Eudyptula minor, Spheniscus magellanicus, Megadyptes antipodes; hasta el más extremo piscívoro como A. patagonicus (pingüino rey). Este resultado refuerza el postulado general de que el pico es un indicador indudable del tipo de dieta y del tipo de presa a capturar, 
incluido el tipo de hábito de forrajeo (Zusi, 1975; Lederer, 1984; Proctor \& Lynch 1993; Feduccia, 1999).

El grado de desarrollo muscular y su relación con la caja craneana se vieron reflejados en los resultados de los análisis morfo-geométricos y durante las disecciones musculares. Spheniscus magellanicus resultó ser el que tendría una mayor fuerza de mordida, necesaria para atrapar presas de gran tamaño y con altas velocidades de nado. Dos estrategias de caza diferentes, en relación a los morfotipos cráneo-mandibulares, se desprenden de los resultados presentados para las formas piscívoras. Por un lado, especímenes con un pico largo, de mayor alcance, y mayor velocidad de cierre, como en Aptenodytes patagonicus (pingüino rey), y por otro lado, una fuerza de mordida evidenciada por el desarrollo de una fosa temporal profunda y ensanchada (ver también e.g., Zusi, 1975; Acosta Hospitaleche, 2009), como en Spheniscus magellanicus. La condición descrita para el pico y la fosa temporal se encuentran en ambas formas, pero una predomina sobre la otra en cada caso.

En cuanto a la mandíbula, las formas piscívoras se distinguen por el proc. retroarticularis angosto y alargado, con un origen del $\mathrm{m}$. depressor mandibulae y el $\mathrm{m}$. pterygoideus extendido, lo cual aumenta el brazo de palanca de entrada e incrementa la fuerza resultante de salida, la cotyla lateralis ensanchada lateralmente, y el angostamiento a nivel de la unión de la cotyla caudalis y la c. lateralis. Esto indica la presencia de músculos más eficientes para la apertura del pico y la mandíbula, y una mayor estabilidad a nivel de la articulación mandibular con el cuadrado.

Los resultados corroboran cuantitativamente muchas de las propuestas de Zusi (1975), como la relación entre picos robustos y cortos en comparación al cráneo como indicativo de una lengua bien desarrollada que empuja el krill más rápidamente al esófago, o fuerzas de mordida menor en formas de pingüinos que se alimentan de presas pequeñas fáciles de atrapar. Esta condición aparece de manera contraria a la de los pingüinos piscívoros (incluido cefalópodos como presa), que deben resistir mayores presiones al capturar sus presas que son de mayor tamaño, y más complejas de atrapar. En este último caso, picos más largos que poseen una mayor movilidad y alcance, una mayor estabilidad mandibular, una mayor fuerza y velocidad de mordida y de apertura del pico y mandíbula, están íntimamente relacionadas con el hábito alimenticio. 


\section{IV}

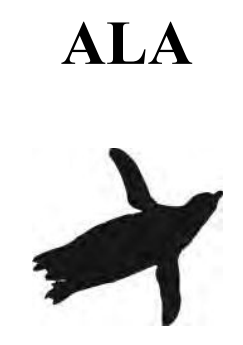

\section{INTRODUCCIÓN}

\section{Adaptaciones osteomusculares del ala y cintura pectoral}

Los pingüinos son eficaces buceadores y se propulsan mediante sus alas, generando lo que muchos llaman, vuelo subacuático (Bannasch, 1994; Ksepka \& Ando, 2011). Durante el buceo, y debido al denso medio en el cual se mueven, los pingüinos generan empuje durante el golpe hacia abajo y hacia arriba del ala (Clark \& Bemis, 1979). Lo que se evidencia en el grado de desarrollo no sólo de los músculos pectorales (adducción del ala), sino del $m$. supracoracoideus (músculo de elevación del ala). Este músculo presenta un gran desarrollo en comparación con el $m$. pectoralis semejante sólo a los colibríes (Bannasch, 1994 y bibliografía allí citada). Poseen alas reducidas en área y en longitud (Clark \& Bemis, 1979), y un muy limitado movimiento en las articulaciones del ala (Shufeldt, 1901; Raikow et al., 1988). El cóndilo ulnar del húmero está reducido (Ksepka et al， ） , al igual que los principales músculos de extensión del ala ( $m$. triceps brachii) que poseen largos tendones íntimamente asociados a los sesamoideos del codo (Haidr \& Acosta Hospitaleche, 2017; Vargas et al., 2017), lo que genera una superficie muy estable para el empuje del agua.

A diferencia de lo que ocurre con el cráneo, no hay suficientes estudios hechos que muestren la relación entre los elementos esqueletales del ala, el tipo de nado, y las presas que potencialmente puedan capturar asociadas a ese nado. Pero sí existen estudios de cinemática del ala, articulación humeral (Bannasch, 1986b; 1994), movimientos bajo el agua de pingüinos (e.g. Clark \& Bemis, 1975), musculatura alar (Schreiweis, 1982), y de proporciones alares y morfometría clásica (Livezey, 1989), entre otros. 
La cintura escapular está formada por una escápula larga y muy ancha, notablemente diferente a la de las aves voladoras que es en forma de espada. El coracoides es una estructura robusta dentro del complejo que presenta una característica facies articularis sternalis curvada. La fúrcula, también robusta, es curva, aplanada mediolateralmente y alta en la articulación con la escápula y coracoides afinandose hacia la unión de ambas clavículas. El esternón es largo y ancho, llegando a cubrir gran parte de la zona abdominal, que se hipotetiza protege los intestinos de los posibles golpes durante la salida del agua (Sladen, 1958; Bannasch, 1986), la quilla es grande y de forma triangular. Por último el húmero, al igual que los restantes elementos del ala, es corto, denso y dorsoventralmente aplanado. Su diáfisis es relativamente recta en las formas actuales (posee una forma sigmoidea en los pingüinos del Eoceno).

La forma aplanada de los huesos del ala, junto a la reducción en tendones de músculos extensores del ala, el gran desarrollo de huesos sesamoideos en el codo generando una articulación en máxima extensión y estable (Haidr \& Acosta Hospitaleche, 2017; Vargas et al., 2017), la reducción de la mayoría de los músculos intrínsecos del ala en tendones, y la densidad de plumas en forma de escamas, forman una superficie altamente eficiente en el empuje del agua durante el buceo. El plano de golpe es perpendicular al eje longitudinal. El ala transmite fuerzas subiguales durante su abducción y adducción y actúa como un hidrodeslizador ubicado con un ángulo de ataque positivo (supinación) en addución, y un ángulo negativo (pronación) en abducción (Clark \& Bemis, 1979). A diferencia de las especies de mayor tamaño donde las velocidades serían más constantes, en las especies más pequeñas un aumento en velocidad sería producto de un aleteo más largo (Clark \& Bemis, 1979), y por otro lado para alcanzar las mismas velocidades un pingüino más chico debiera realizar más aleteos que uno grande (Bannasch, 1994). Además, pingüinos de gran tamaño, como el pingüino rey, podrían realizar movimientos complejos, y presentan incluso una gran flexión espinal en comparación a otras especies (Clark \& Bemis, 1979) con alas de mayor área para contrarrestar el arrastre (Bannasch, 1994).

En cuanto a la articulación húmero-glenoidea, la superficie elipsoidal de la cara articular del húmero daría como resultado una rotación excéntrica en dos ejes (Bannasch, 1994). La cavidad glenoidea se encuentra formada por la facies articularis humeralis del coracoides y escápula, y el ligamentum coracoscapulare interosseum que une ambas facies (Bannasch, 1994). Tanto el extremo más proximal de la facies articularis humeralis de la escápula, y el ligamentum acrocoracohumerale, dan soporte al húmero e impiden que éste se 
desplace posteriormente. El ligamentum acrocoracohumerale origina en el lateral del proceso acrocoracoideo e inserta en el sulcus ligamentosus transverso del húmero. El ligamentum scapulohumerale limita la pronación de un posible deslizamiento anterior de la cabeza humeral (Bannasch, 1994). En posición de pronación (posición en la cual está el ala al ser adducida), el lig. acrocoracohumerale da soporte extra al húmero. La supinación se ve limitada por el lig. coracohumerale y el lig. scapulohumerale (Bannasch, 1994). La única otra articulación en la cintura escapular con cierto grado de movimiento es la del coracoides con el esternón, cuyo movimiento se da sobre su eje longitudinal con respecto al esternón (Bannasch, 1986b; 1994). Tanto la fúrcula como la escápula carecen de la posibilidad de movimiento con respecto al coracoides. Los músculos involucrados en el movimiento del ala se originan en el esternón, en la escápula, en el coracoides, en la fúrcula, y en las membranas y ligamentos que unen todos estos elementos. Todos estos músculos insertan, a excepción del m. tríceps brachii scapularis, en el húmero.

El estudio de las inserciones en el húmero resulta de interés y puede brindarnos información valiosa sobre el posible grado de desarrollo de los músculos. Si bien todos los elementos de la cintura pectoral fueron estudiados a lo largo de la tesis, en los análisis de morfometría geométrica sólo se incluyeron los coracoides. Al intentar analizar las escápulas y las clavículas, surgieron imposibilidades metodológicas intrínsecas a estos elementos que al prepararse para su ingreso en las colecciones, tienden a sufrir importantes deformaciones que interfieren con los resultados. También se analizaron los húmeros, y los esternones.

\section{Objetivos}

El objetivo del presente capítulo es el de determinar las diferencias morfo-anatómicas del ala y cintura pectoral entre los pingüinos piscívoros, crustacívoros y generalistas. 


\section{MATERIALES}

Para el presente capítulo se utilizaron especímenes de pingüinos que conservaran esqueletos completos o, al menos, casi completos, los cuales fueron obtenidos de las colecciones visitadas que se detallan en el Capítulo II. Para los análisis de morfometría geométrica, las configuraciones contaron con un $\mathrm{n}$ diferente, dependiendo de la disponibilidad de material o del error en la toma de las fotografías. En el Anexo I, se encuentran las tablas detallando los especímenes utilizados para los análisis de cada configuración.

Los materiales utilizados durante las disecciones musculares son los citados en el Capítulo II. Las especies incluidas fueron: Pygoscelis adelia (en su mayoría), P. papua, Spheniscus magellanicus y Eudyptes chrysocome. El pesado de los músculos se realizó para 21 individuos pertenecientes a tres especies, P. adeliae, P. papua y Spheniscus magellanicus (Tabla ), de acuerdo a la disponibilidad de materiales.

\section{MÉTODOS}

Para las descripciones, los músculos fueron agrupados en cinco capas siguiendo el orden de aparición. La primera incluyó a los músculos subcutáneos, la segunda al musculus latissimus dorsi, $m$. pectoralis thoracica y $m$. brachialis; la tercera al $m$. triceps scapularis, $m$. propatagialis y $m$. supracoracoides; la cuarta al $m$. deltoides minor, $m$. deltoides major, $m$. triceps humeralis, al m. scapulohumeralis caudalis; y finalmente la quinta, al $m$. coracobrachialis caudalis, $m$. subcoracoides y al $m$. subscapularis.

Los músculos seleccionados para el pesado y posterior análisis fueron el $m$. pectoralis thoracica y el $m$. supracoracoides, por ser los músculos más conspicuos y por estar directamente relacionados con la elevación y adducción del ala. Si bien se intentó pesar todos los músculos, en la práctica, la correcta extracción de los músculos en los pichones resultó inviable en la mayoría de los casos. La razón de esto fue la consistencia de los músculos, su tamaño y fragilidad. Se realizaron regresiones entre los pesos y el culmen de los especímenes 
para evaluar su variación a lo largo de la ontogenia. El culmen fue utilizado como un proxy del tamaño del animal.

Para los análisis de morfometría geométrica se definieron siete configuraciones, dos para el húmero (Tablas 1 y 2), tres para el coracoides (Tablas , y ), y dos para el esternón (Tablas y ).

Tabla 1 Configuración de landmarks del húmero en vista dorsal, número de landmarks y definición.

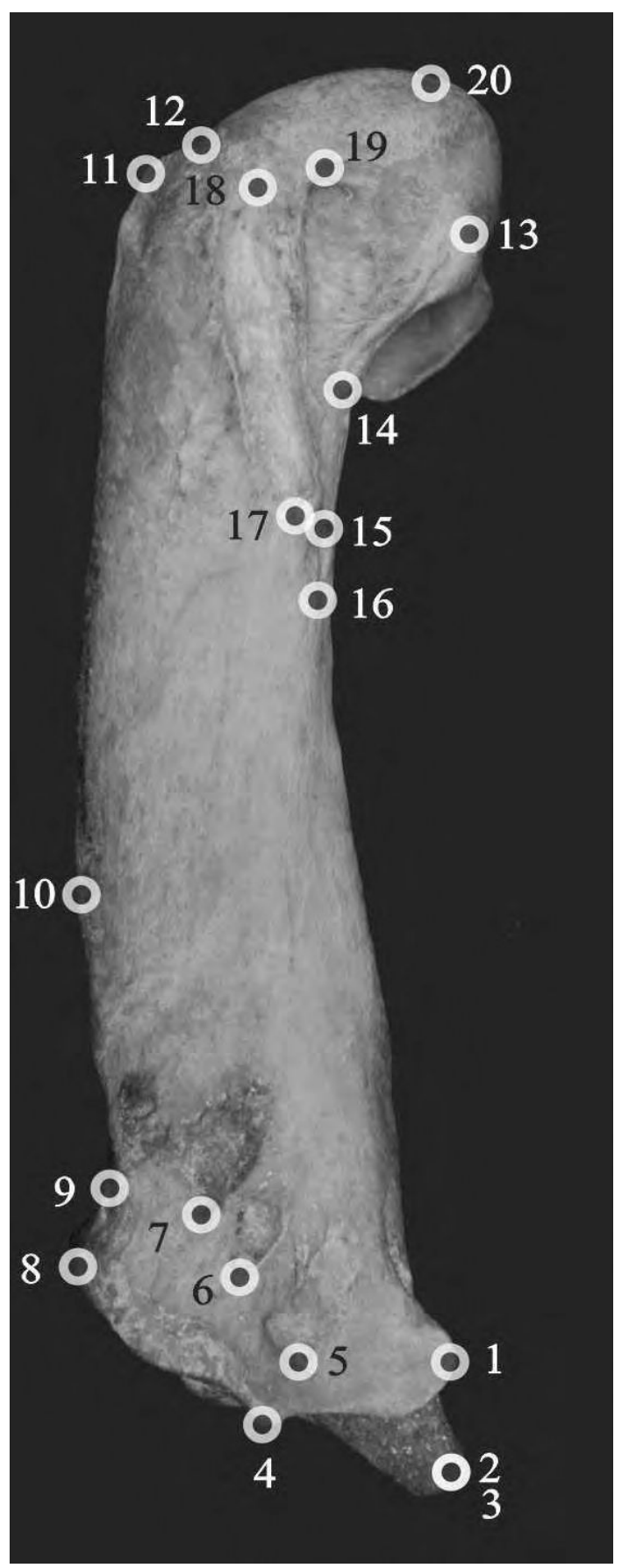

\begin{tabular}{|c|c|}
\hline$L m k$ & Nombre \\
\hline & cresta troclear dorsal \\
\hline & cresta troclear medial \\
\hline & processus flexorius \\
\hline & epicondylus dorsalis \\
\hline & extensor metacarpi ulnaris \\
\hline & extensor digitorum communis \\
\hline & supinator \\
\hline & condylus dorsalis \\
\hline & comienzo del condylus dorsalis \\
\hline & angulus preaxialis \\
\hline & tuberculum dorsale \\
\hline & borde anterior del caput humeri \\
\hline- & impressio m. coracobrachialis caudalis \\
\hline- & impressio m. latissimus dorsi \\
\hline- & impressio m. supracoracoideus \\
\hline & fossa tricipitalis secundaria \\
\hline
\end{tabular}


Tabla 2 Configuración de landmarks del húmero en vista ventral, número de landmarks y definición

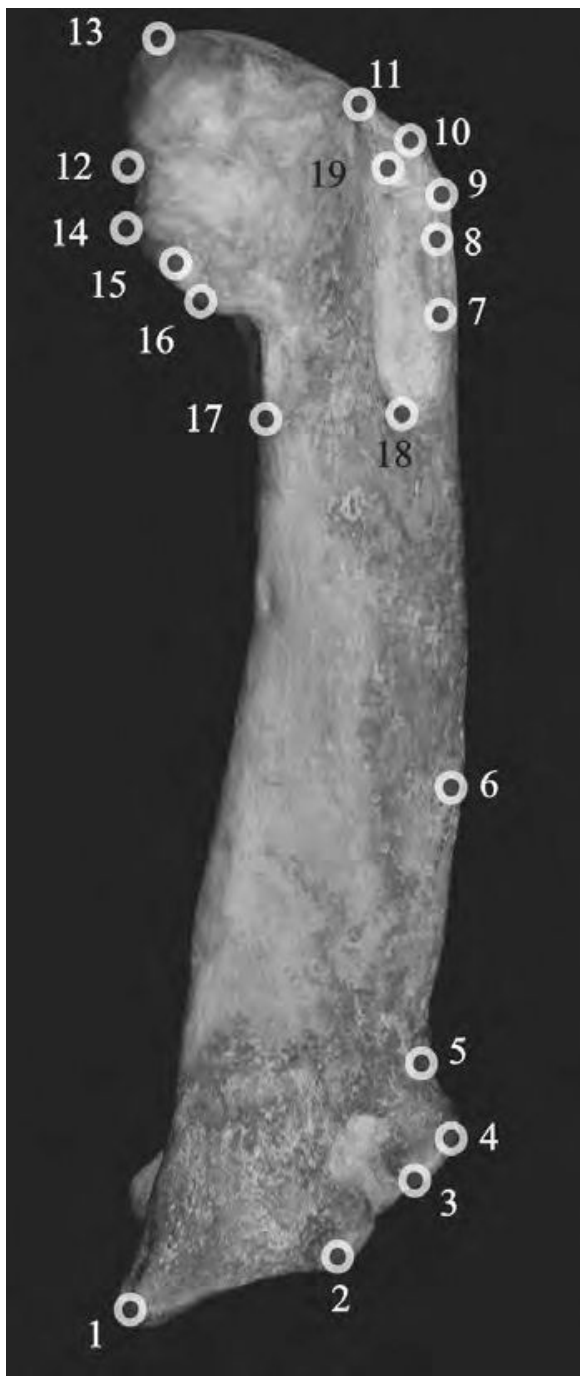

$\begin{array}{ll}\text { Lmk } & \text { Nombre } \\ & \text { processus flexorius } \\ & \text { condylus ventralis } \\ \text { - } & \text { condylus dorsalis } \\ \text { inicio de condylus dorsalis } \\ \text { angulus preaxialis } \\ \text { impressio m. propatagialis } \\ \text { - } \quad \begin{array}{l}\text { extremo anterior y posterior de } \\ \text { caput humeri }\end{array} \\ \text { caput humeri, punto más saliente } \\ \text { impressio m. pectoralis thoracica } \\ \text { tuberculum ventrale } \\ \text { fosa sobre tuberculum ventrale }\end{array}$

Tabla 3 Configuración de landmarks del coracoides en vista esternal, número de landmarks y definición.

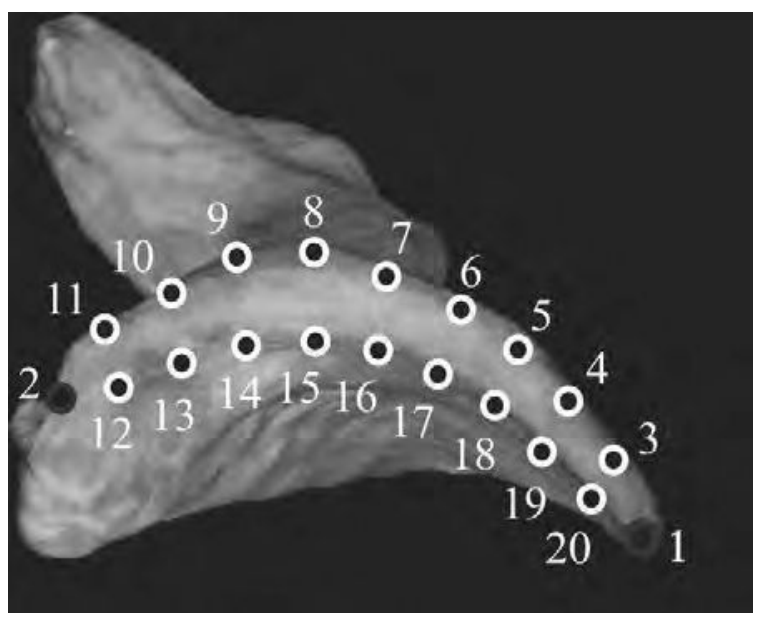

\section{Lmk Nombre}

\begin{tabular}{l}
\hline $\begin{array}{l}\text { extremo lateral de facies articularis } \\
\text { sternalis }\end{array}$ \\
extremo medial de facies articularis \\
sternalis \\
semilandmarks sobre línea ventral de \\
facies articularis sternalis \\
semilandmarks sobre línea dorsal de \\
facies articularis sternalis
\end{tabular}


Tabla 4 Configuración de landmarks del coracoides en vista dorsal, número de landmarks y definición.

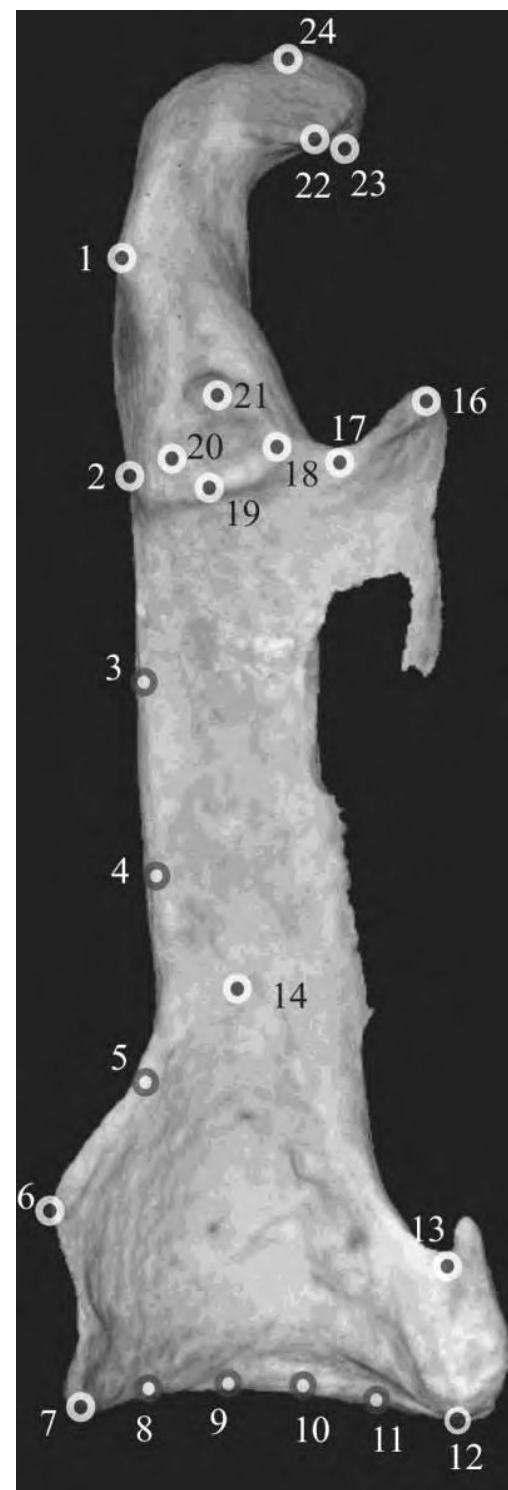

\begin{tabular}{ll} 
Lmk & Nombre \\
\hline$-\quad$ & fossa articularis humeralis \\
$-\quad$ & semilandmarks margen lateral \\
& punto más saliente del proc. lateralis \\
& facies articularis sternalis, extremo lateral y \\
medial & semilandmarks sobre facies sternalis articularis \\
& muesca distal del margen medial \\
& punto más proximal de la impressio m. \\
sternocoracoidei
\end{tabular}

extremo más proximal del proc.acrocoracoideus 
Tabla 5 Configuración de landmarks del coracoides en vista ventral, número de landmarks y definición.

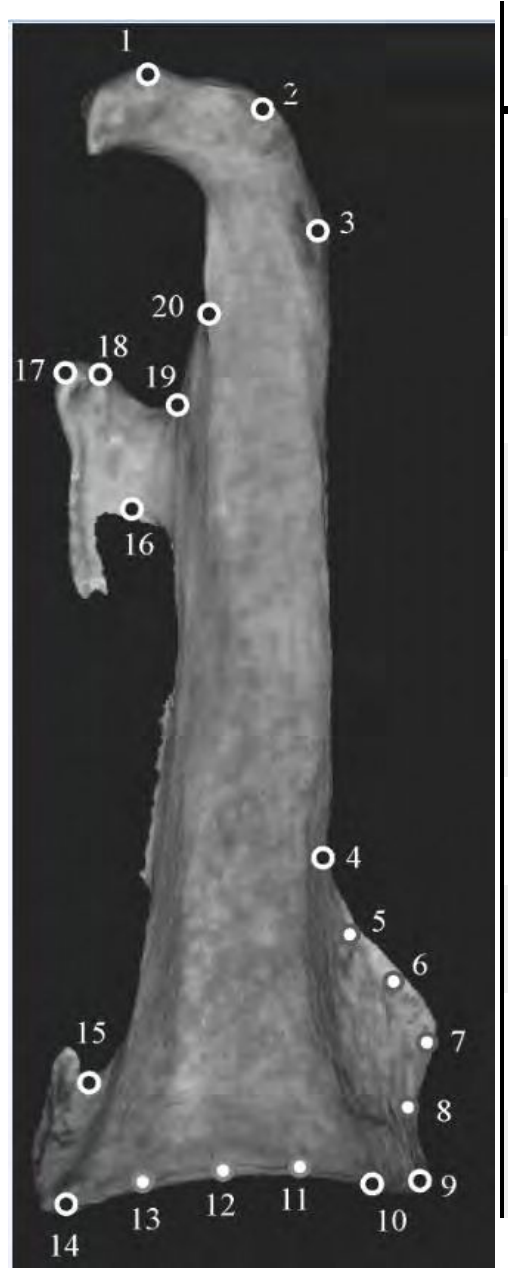

\begin{tabular}{|ll}
\hline Lmk & Nombre \\
\hline$-\quad$ & proc. acrocoracoideus \\
& $\begin{array}{l}\text { punto más saliente de la fossa articularis } \\
\text { humeralis }\end{array}$ \\
& inicio del proc. lateralis \\
& semilandmarks sobre proc. lateralis \\
& final de proc. lateralis \\
- & $\begin{array}{l}\text { facies articularis sternalis, extremo lateral y } \\
\text { medial }\end{array}$ \\
& semilandmarks sobre facies articularis sternalis \\
- & sulcus supracoracoideus \\
& muesca distal del margen medial \\
&
\end{tabular}

Tabla 6 Configuración de landmarks del esternón en vista lateral, número de landmarks y definición.

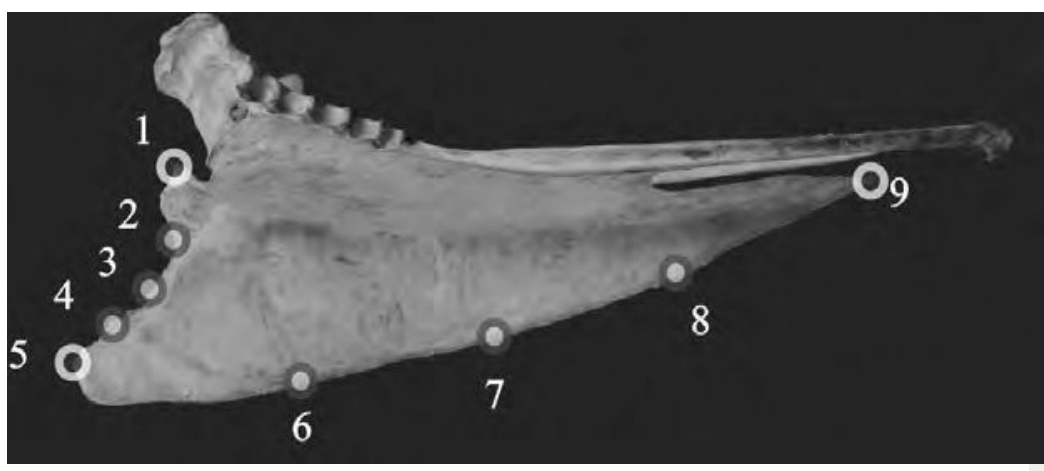

\begin{tabular}{ll} 
Lmk & Nombre \\
\hline & spina externa \\
- & contorno entre 1 y 5 \\
& apex carinae \\
- & carina sterni, contorno
\end{tabular}

extremo de la trabecula mediana 
Tabla 7 Configuración de landmarks del esternón en vista ventral, número de landmarks y definición.

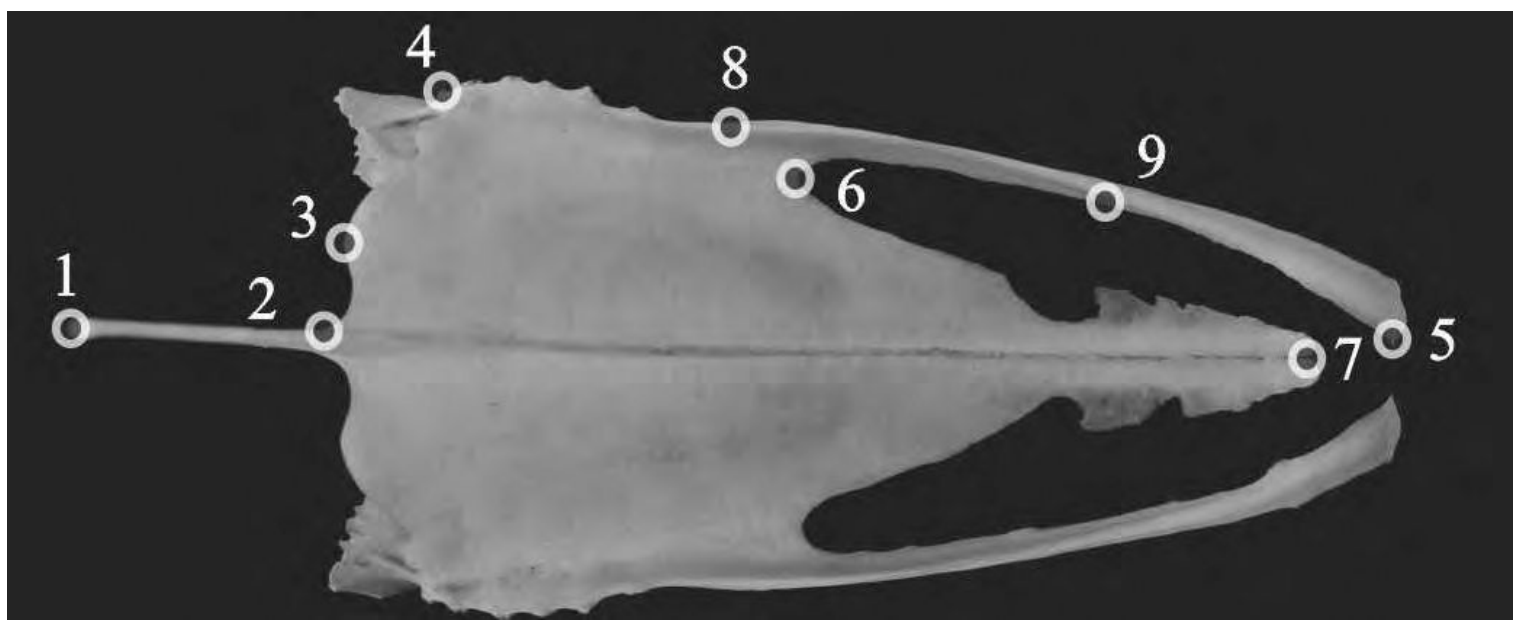

Lmk Nombre

apex carinae

unión más anterior del corpus sterni con con la carina

punto de mayor protrusión del margen anterior del corpus

primer processus articularis sternocostalis

extremo mediocaudal de la trabecula lateralis

punto más anterior de la incisura lateralis

extremo de la trabecula mediana

cresta de inserción de la porción caudolateral del $m$. pectoralis thoracica, extremo lateral y medial

A partir de estas configuraciones (Tablas 1 a 7) se realizaron una serie de análisis en el programa Morpho J. En primera medida, se analizó si existía un efecto alométrico en la variación de forma, lo cual se hizo a partir de una regresión entre las coordenadas de procrustes y el tamaño del centroide de la configuración. De existir un efecto alométrico se procedió a realizar los análisis por duplicado, es decir por un lado con los datos originales de las coordenadas de procrustes, y por el otro, con los datos corregidos de los residuos obtenidos de la regresión. Luego se exploraron los datos de los diferentes especímenes a estudiar y su distribución en el morfoespacio a través de un análisis de componentes principales (PCA). Como se quería estudiar la relación entre la morfología de las diferentes configuraciones con las categorías dietarias de cada especie de pinguino (Ver en Tabla 2 del Capítulo II), se realizó un análisis multivariante de la varianza (MANOVA) para corroborar 
que las diferencias entre las categorías fuesen significativas. Por último, para calcular las distancias morfológicas entre las categorías dietarias, y estudiar la variación de forma entre las categorías se realizó un análisis de variación canónica (CVA). Para más detalles de los diferentes análisis ver el Capítulo II.

\section{RESULTADOS: MIOLOGÍA COMPARADA}

\section{Miología comparada}

Se describe de manera comparativa la musculatura involucrada en los movimientos de ala de Pygoscelis y Spheniscus, principalmente. Entre las muestras se incluyen además, individuos adultos y pichones de Pygoscelis adeliae, pichones de P. papua, adultos y juveniles de Spheniscus magellanicus, y un adulto y un juvenil de Eudyptes chrysolophus con el fin de ampliar el marco descriptivo.

\section{Primera Capa}

\section{Músculos Subcutáneos}

En la región torácica se observaron dos pares de músculos subcutáneos, estos paquetes son anchos y planos, el primero se ubica antero-ventralmente en el flanco.

Origen El paquete ventral de músculos se origina en la piel, a nivel de la línea media de la escápula, inmediatamente posterior a su parte más caudal. Las fibras contactan la inserción del $m$. latissimus dorsi metapatagialis y corren cráneo-dorsalmente. El paquete posterior origina en la región pélvica.

Inserción La inserción se encuentra cercanamente relacionada con el tendón del $m$. 
pectoralis thoracica. Posterior a este paquete muscular hay un segundo músculo cuyas fibras van desde la región pélvica hacia la abdominal.

\section{Comentarios Aunque los músculos subcutáneos no tengan participación en los movimientos del ala, dan forma al cuerpo, y por contracción podrían proveer una conformación más hidrodinámica al animal. Schreiweis (1982) describe al más ventral de estos músculos subcutáneos como parte del $\mathrm{m}$. pectoralis pars subcutanea abdominalis.}

\section{Segunda capa}

Musculus latissimus dorsi, $m$. pectoralis thoracica y $m$. brachialis.

\section{M. latissimus dorsi}

Nuestras observaciones concuerdan con las de Schreiweis (1982) en cuanto a la división de este músculo en tres partes: cranialis, metapatagialis, y caudalis. El m. latissimus dorsi cranialis es un músculo plano y expandido de forma cuadrangular. Este músculo actúa como elevador del ala, y participa en los movimientos de pronación. La descripción general, así como el detalle del origen e inserción, será realizada independientemente para cada pars.

\section{Latissimus dorsi cranialis}

Es un músculo plano y ancho a lo largo de toda su inserción, cuyas fibras van convergiendo hacia su punto de inserción, generando una forma general triangular (Fig. 1). 


\section{Origen}

Posee un origen aponeurótico en la apófisis neural de la porción caudal de la primera a la quinta vértebra torácica. Según Schreiweis (1982) el origen anterior se extendería hasta la última vértebra cervical, esto no pudo observarse durante nuestras disecciones. Sus fibras corren desde su porción craneal, media y caudal, ventrocaudalmente, ventralmente, y ventrocranealmente, respectivamente.

\section{Inserción}

Se inserta mediante un robusto tendón que atraviesa una polea fibrosa (la cual está unida a la escápula a una cicatriz fuertemente marcada en el húmero, que yace algunos pocos milímetros distal a la cresta caudal de la fossa tricipitalis).

\section{Comentarios}

Este músculo desarrolla en Pygoscelis una lengua accesoria (slip) que se adhiere a la porción distal del $m$. triceps scapularis dorsalis y a la porción más proximal de su tendón (descrito también para Aptenodytes por Schreiweis, 1982). Esta lengua accesoria podría fortalecer la efectividad de esta porción muscular como elevador del ala (Bannasch, 1986b). Dado que esta estructura se encuentra presente en Pygoscelis y Aptenodytes, y está ausente en Spheniscus y Eudyptes, resulta muy probable que tampoco haya estado desarrollada en Madrynornis, que se encuentra filogenéticamente más próximo a estos últimos géneros. Un mapeo más completo de este carácter podría contribuir a generar una hipótesis más robusta en este sentido, lo cual escapa a los objetivos del presente estudio, pero será testeado en un futuro cercano. La polea por donde pasan los tendones del $m$. latissimus dorsi es descrito como único en pingüinos por Schreiweis 


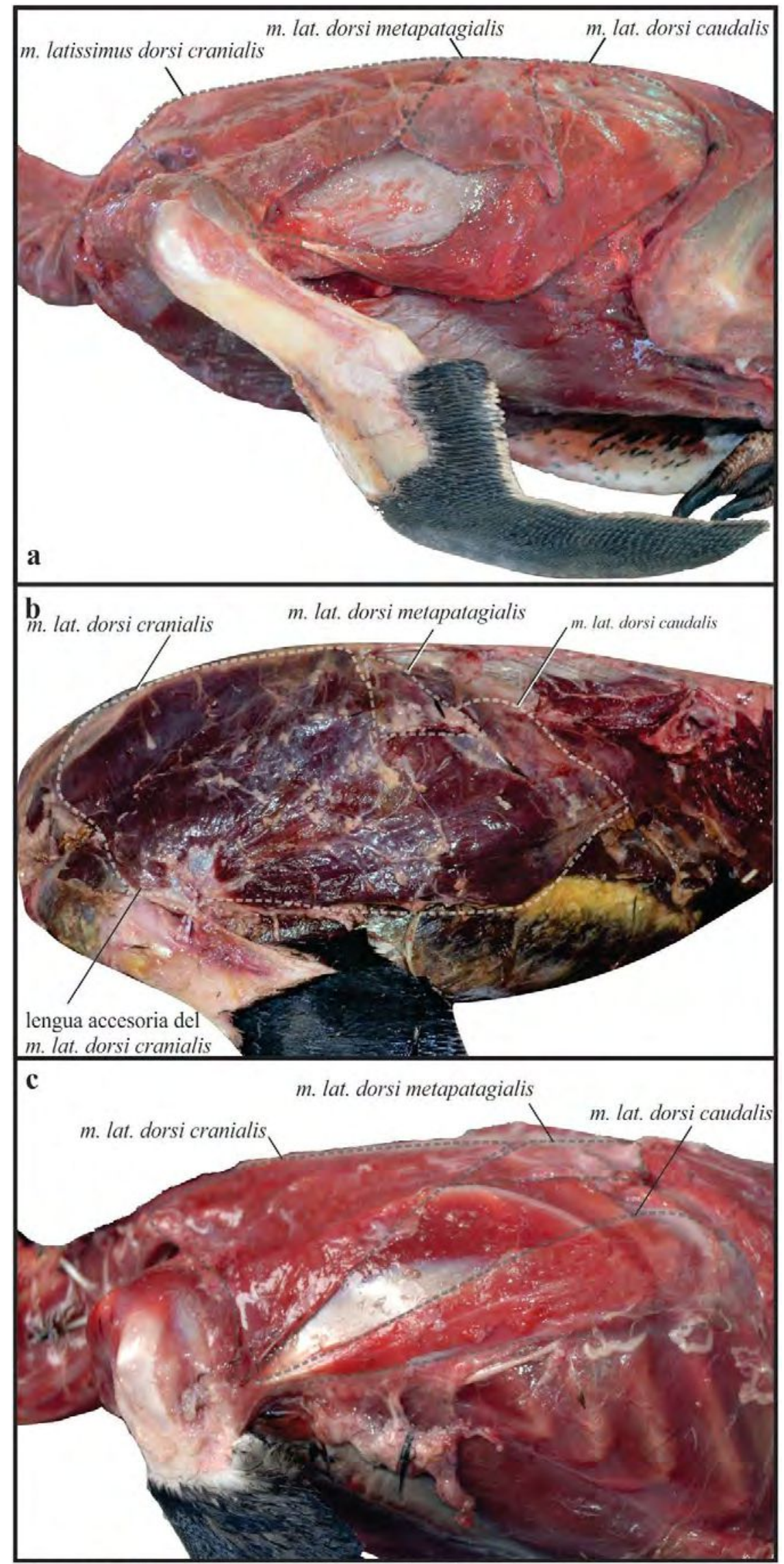

Figura 1 Primera capa muscular, se visualizan el $m$. latissimus dorsi en a, adulto de Spheniscus magellanicus; $\mathbf{b}$, adulto de Pygoscelis adeliae; c, juvenil de Eudyptes chrysocome. Abreviaciones: lat., latissimus. 


\section{M. latissim us dorsi metapatagialis}

Este músculo plano presenta una forma trapezoidal, manteniendo prácticamente el mismo ancho desde su origen hasta su inserción (Fig. 1).

Origen Este músculo origina aponeuróticamente al nivel de la sexta vértebra torácica. Sus fibras se extienden posteroventralmente.

Inserción

Se inserta carnosamente sobre la piel hacia el margen dorsal de la extremitas caudalis scapulae.

Comentarios

Es un músculo corto. En Spheniscus, este músculo es más ancho que en Pygoscelis y se extiende más ventralmente. Sus fibras están cercanas a las del $m$. latissimus dorsi cranialis, eso hace que la separación de ambos durante la disección resulte dificultosa. Schreiweis (1982) describe el origen como proveniente de las espinas dorsales de las vértebras 4, 5, y 6 para Eudyptes, esto pudo ser corroborado durante disecciones propias en Eudyptes.

\section{Latissimus dorsi caudalis}

Este músculo es delgado, como una lámina, al igual que las demás divisiones del $\mathrm{m}$. latissimus dorsi, y presenta forma de lágrima (Fig. 1).

Origen Tiene un origen amplio con una larga y ancha, aunque delicada, aponeurosis que se une a las espinas neurales de las últimas vértebras torácicas y las primeras sacras (sólo pudo observarse en Pygoscelis adeliae), la línea ventral de la lamina preacetabularis ilii, llegando hasta la porción anterior del corpus ischii illium y la región pélvica. Sus fibras corren cranealmente hacia el húmero. Schreiweis (1982) describe un origen en el margen inferior del ilion y los músculos abdominales. 
dorsi cranialis, ambos tendones se encuentran parcialmente unidos cerca de su inserción.

Comentarios

Este músculo es plano, y en Spheniscus permanece como un músculo independiente. En Pygoscelis adeliae, su margen anterior está fusionado con el $m$. latissimus dorsi cranialis (característica también descrita para Aptenodytes por Schreiweis, 1982), mientras que en Spheniscus magellanicus y Eudyptes existe una amplia brecha entre ambos. Este músculo actúa en la supinación y la adducción del ala.

\section{M. pectoralis thoracica}

Es un músculo robusto que está compuesto por tres subdivisiones: una clavicular, una caudolateral y una medial (Fig. 2).

Origen La pars clavicular se origina en una pequeña porción de la membrana sternocoracoclavicularis, y en la superficie lateral de scapus clavicularis. Sus fibras corren caudo-lateralmente hacia su inserción tendinosa en el húmero.

La pars medial es la más superficial y la de mayor tamaño, se origina carnosamente en el $m$. supracoracoidei y en el margen de la carina sterni. Sus fibras corren cráneo-lateralmente.

La pars caudolateral se origina en la trabecula caudolateralis del esternón. Sus fibras corren cráneo-lateralmente (en ángulo más cerrado que en el caso de la división medial) hacia una fuerte inserción tendinosa en la impressio m. pectoralis thoracica del húmero.

Inserción

El tendón de la porción clavicular se inserta cranealmente en la impressio m. pectoralis thoracica del húmero, y superficial al tendón del resto del músculo en Spheniscus.

La porción medial se inserta carnosamente en la subdivisión clavicular y 
caudolateral cercano a la inserción de los tendones de ambas subdivisiones en el húmero. Schreiweis (1982) describe para la pars medial una inserción conjunta con la división caudolateral en un tendón común.

El tendón de la porción caudolateral se inserta en la impressio m. pectoralis thoracica.

Comentarios

En Pygoscelis existe una extensión membranosa hacia la intumescencia humeri que no fue observada en Spheniscus. El $m$. pectoralis thoracica es antagonista del $m$. supracoracoideus y actúa en el empuje hacia abajo.

\section{M. brachialis}

Origen Este músculo se origina en la fossa brachialis, ubicada en el margen laterodistal del húmero (Fig. 3b).

Inserción

Se inserta de manera carnosa en la porción proximal del radio (Fig. 3b).

Comentarios

Schreiweis (1982) describe para Spheniscus magellanicus, entre otros pingüinos, un slip que había sido previamente notado por Schoepss (1829) y que se desprende del $m$. brachialis y se inserta mediante un tendón corto en el borde radial y proximal de la ulna. Schreiweis (1982) discute que esto sería evidencia de que este músculo es realmente homólogo al $\mathrm{m}$. brachialis de otras aves, el cual ha modificado su punto de inserción debido a la compresión dorsoventral del ala que sufren todos los pingüinos como parte de las adaptaciones al buceo. Se describe como flexor del antebrachium (Schreweis, 1982). 


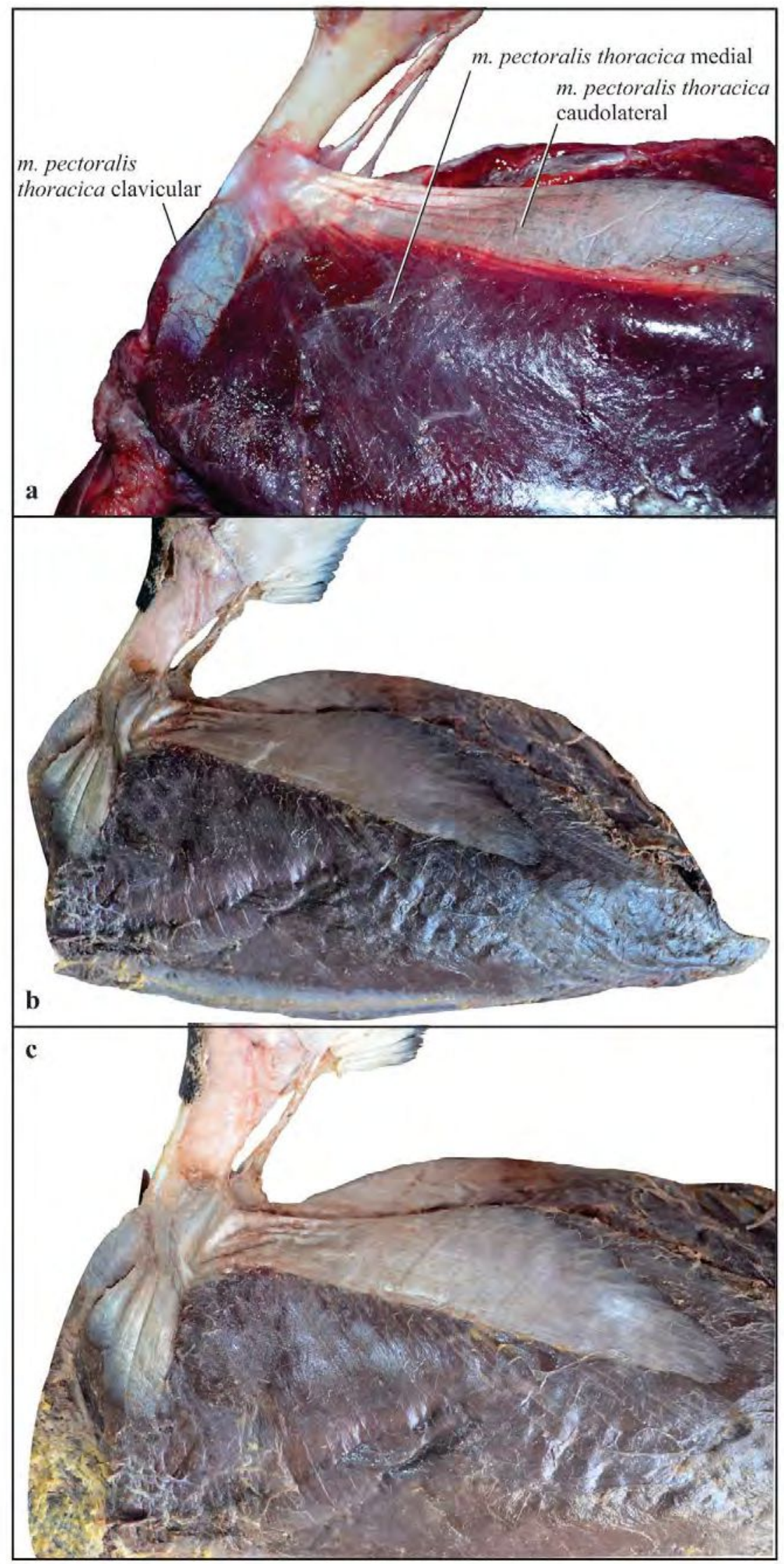

Figura 2 Segunda capa muscular, vista lateroventral en a, adulto de Spheniscus magellanicus; b, c, adulto de Pygoscelis adeliae. Abreviaciones: memb., membrana; m., musculus. 


\section{Músculos de la tercera capa}

M. triceps scapularis, m. propatagialis, y m. supracoracoides

\section{M. triceps brachii scapularis}

Este músculo posee dos cabezas, una dorsal y una ventral.

Origen $\overline{\text { La cabeza dorsal se origina carnosa del processus articularis clavicularis }}$ (facies articularis acrocoracoidea en Baumel, 1993) de la fúrcula, la porción proximal de la cara dorsal del ligamentum coracoescapularis, del acromion escapular, y de la porción medial del scapus claviculae. Sus fibras corren sobre los músculos del hombro hacia el olécranon (Fig. 3a, 4).

El origen de la cabeza ventral es sobre el margen lateral de la escápula, inmediatamente proximal al punto de inserción de la polea por donde pasa el m. latissimus dorsi.

Inserción

Tanto la cabeza dorsal como la ventral se unen en un tendón común a la altura del inicio de la fossa tricipitalis, que corre a lo largo de toda la extensión de la diáfisis del húmero. Se fusiona al sesamoideo ulnae caudal que pasa por el sulcus scapulotricipitalis y finalmente se une al mayor y más ventral de los dos os. sesamoideums (patella ulnaris in Furbringer, 1888) para finalmente insertarse en la ulna.

Comentarios

Está mucho más desarrollado que la cabeza ventral y converge en el mismo tendón. Es un músculo más robusto en Pygoscelis que en Spheniscus.

\section{M. propatagialis}

De acuerdo con Schreiweis (1982), este músculo posee una subdivisión en una capa profunda y una capa superficial en todos los pingüinos, exceptuando Pygoscelis antarctica, P. adeliae, y Eudyptula. Por el contrario, durante las disecciones encontramos esta 
subdivisión presente también en $P$. adeliae con tendones y origen independientes y separados por una fascia. Por el contrario, no se encontraron estas divisiones en Spheniscus magellanicus.

Origen $\overline{\text { La capa superficial es la de mayor tamaño, se origina carnosamente en la }}$ cicatriz oval del proc. acrocoracoideus del coracoides, y en el ápice craneodorsal de la fúrcula. La capa más profunda tiene un origen tendinoso en la extremitas omalis coracoidei.

Inserción Se inserta en la crista deltopectoralis (crista propatagialis). La inserción se extiende a lo largo de todo el margen lateral del húmero hacia el radio (Fig. 3a y 4). La capa más profunda se inserta con su tendón alrededor del tuberculum dorsale.

Comentarios

El $m$. propatagialis mueve el ala hacia adelante y está involucrado en la pronación.

\section{M. supracoracoideus}

Es un músculo bipennado con un vientre y tendón robusto, cuyo vientre se dispone por debajo del $m$. pectoralis thoracica (Fig. 3 b, c, d).

Origen $\overline{\text { Es carnoso en el corpus sternalis, la mayor parte de la carina sterni, en la }}$ superficie ventral del corpus coracoideus, el margo internus de la fúrcula, y la membrana sternocoracoclavicularis. En Spheniscus el origen es además aponeurótico sobre el sulcus que corre a lo largo del margo costalis sternalis, y además, en contraposición a Pygoscelis, no llega hasta la membranae incisurarum. Sus fibras musculares convergen en un tendón robusto, y ancho en forma de cinta que pasa por el foramen triosseum hacia su inserción en el húmero. 


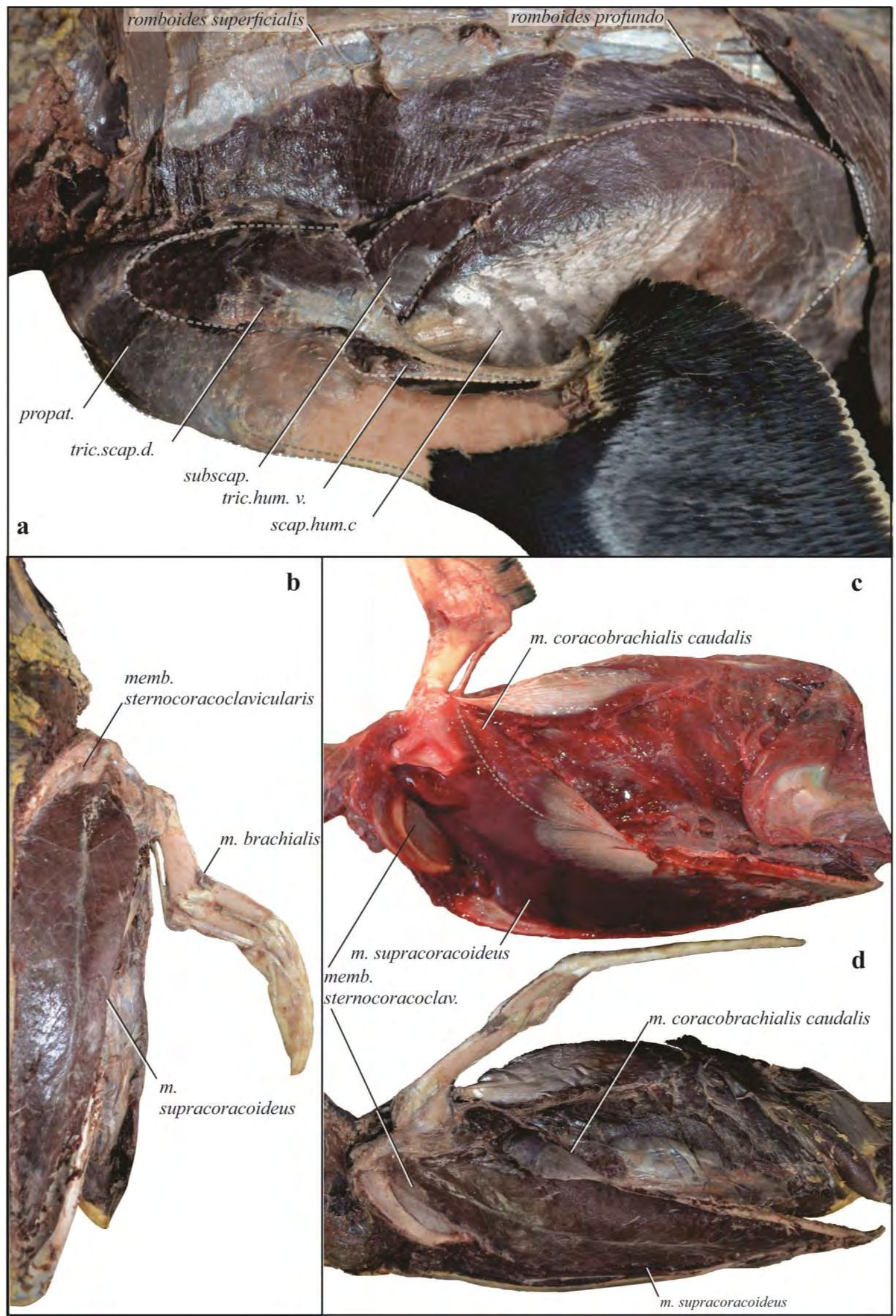

Figura 3 a, segunda capa muscular en adulto de Pygoscelis adeliae; $\mathbf{b}, \mathbf{c}, \mathbf{d}$, tercera capa muscular en un adulto de Spheniscus magellanicus en vista lateral y en un adulto de Pygoscelis adeliae en vista ventral y lateral. Abreviaciones: memb., membrana; m., musculus. 
Inserción

Se inserta a través del tendón al cual convergen sus fibras (ver más arriba), sobre una cicatriz oblonga ubicada en la cara dorsal del húmero, cercana a la cabeza humeral. Esta marca constituye la cicatriz muscular de mayor tamaño del húmero. Su forma y ubicación relativa varía entre especies (Ver resultados morfogeométricos, en este mismo capítulo).

Comentarios

Su desarrollo depende de la osificación de los huesos a los que se relaciona, al igual que en el caso de $m$. pectoralis thoracica y del $m$. scapulohumeralis caudalis, por lo que está comparativamente poco desarrollado en pichones y juveniles. El $\mathrm{m}$. supracoracoideus actúa en el movimiento ascendente del ala (eleva el ala) y es antagonista del $m$. pectoralis thoracica. En el inicio del movimiento lleva el ala a una posición de supinación, y luego asciende (Bannasch, 1986b).

\section{Músculos de la cuarta capa}

M. deltoides minor, m. deltoides major, m. triceps humeralis, y m. scapulohumeralis caudalis.

\section{M. deltoides minor}

Origen Es en la porción caudal de la cara dorsal del ligamento sternocoracoclavicular y del lig. coracoescapularis, y en el proceso acromial de la escápula. La porción más robusta del músculo se desarrolla cerca del origen, sus fibras pasan por el foramen triosseum y siguen distalmente hasta el húmero (Fig. 5b).

Inserción Se une al tuberculum dorsale en el húmero (Fig. 5b).

Comentarios Este músculo de dos cabezas, está mucho más desarrollado que el $\mathrm{m}$. deltoides major. Su función es la de elevar el ala, al mismo tiempo que favorece la supinación de la cabeza humeral. 

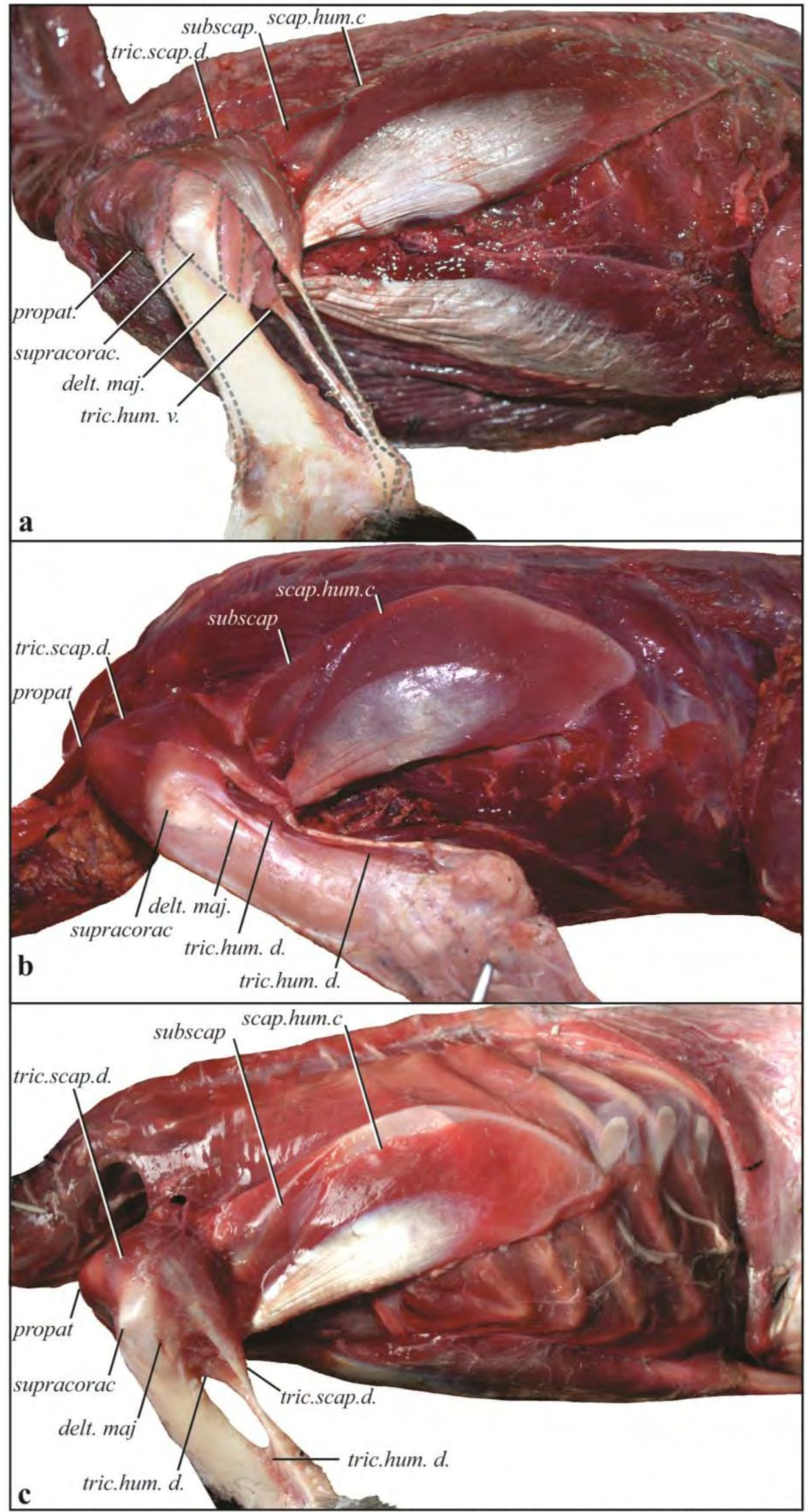

Figura 4 Tercera capa muscular en a, adulto de Spheniscus magellanicus; b, pichón emplumando de Pygoscelis papua; c, juvenil de Eudyptes chrysocome. Abreviaciones: delt. maj., deltoides major; tric.scap.d., triceps scapularis dorsalis; propat., propatagialis; scap.hum. c, scapulohumeralis caudalis; subscap., subscapularis; supracorac., supracoracoideus; tric.scap.d., triceps scapularis dorsalis; tric.hum. d., triceps humeralis dorsalis; tric.hum. v, triceps humeralis ventralis. 


\section{M. deltoides major}

Origen Este músculo delgado y triangular se origina en el margen dorsal del ligamento coracoescapular y en el ápice del proc. acrocoracoideus del coracoides. Sus fibras corren caudoventralmente hacia su inserción (Fig. 4).

Inserción

Se inserta en el húmero entre el $m$. latissimus dorsi y el $m$. supracoracoidei.

Comentarios

Está pobremente desarrollado y tiene poca influencia en los movimientos del ala.

\section{M. triceps brachii humeralis}

Está constituido por dos cabezas, una ventral y una dorsal (Fig. 3a y 4).

Origen La cabeza ventral se origina dentro de la fossa tricipitalis, y su vientre ocupa todo el volumen de la fosa. Aproximadamente a la altura del foramen vascular presente en el margen medial del húmero, las fibras confluyen en dos tendones que aparecen unidos como uno. Durante las disecciones encontramos que tanto en Spheniscus como en Pygoscelis esta cabeza muscular estaba separada en dos partes por una fascia. Cada una de estas divisiones confluye en un tendón diferente (aunque externamente ambos aparecen unidos). Cada división se origina en uno de los compartimientos de la fossa tricipitalis, que en todos los pingüinos actuales es bipartita. Estos dos tendones a su vez se unen con el del $m$. triceps scapularis, condición no descrita previamente por Schreiweis (1982), quien los describe a los tres como con un solo tendón. Este tendón continúa unido al sesamoideo dorsal del codo (el más pequeño) en ese punto, pasando por el sulcus humerotricipitalis. Tanto este sesamoideo como aquel al cual se une el $m$. triceps scapularis, son osificaciones de los tendones y actúan como un cierre osteológico de la articulación del codo (Bannasch, 1986a). 
Por otro lado, el origen de la cabeza dorsal del $m$. triceps humeralis es carnoso e inmediatamente distal a la fossa tricipitalis, cercano al foramen vascular del margen medial del húmero. El músculo continúa adherido distalmente al margen posterior del húmero.

Inserción

La cabeza ventral se inserta en el olécranon de la ulna, mientras que la cabeza dorsal se inserta en el sesamoideo del $m$. triceps scapularis carnosamente, junto al $m$. triceps scapularis.

Comentarios

Aunque la cabeza ventral del $\mathrm{m}$. triceps humeralis está poco desarrollada, sus tendones y huesos sesamoideos asociados estabilizan el codo. Al tirar de la cabeza ventral del músculo, los sesamoideos permanecen firmemente unidos a la articulación, haciéndola más rígida y evitando la rotación de los elementos del zeugopodio.

La cabeza dorsal presenta diferencias de desarrollo entre ambos géneros. El vientre muscular se encuentra localizado más distalmente en Spheniscus magellanicus, mientras que en Pygoscelis adeliae, el músculo completo es más robusto y su ancho es más constante a lo largo de su extensión.

\section{M. scapulohumeralis caudalis}

Origen Se origina en el corpus scapularis (el cual no se encuentra completamente osificado en pichones y juveniles), inmediatamente posterior a la cicatriz de inserción del m. subscapularis (Fig. 3a y 4). En adultos de Pygoscelis adeliae, el músculo se extiende más ventralmente que el corpus scapularis.

Inserción Se une a la crista bicipitalis mediante un tendón robusto.

Comentarios $\overline{\text { Es un músculo grande, proporcionalmente más voluminoso en adultos que }}$ en pichones. Mueve el ala en dirección caudal y dorsalmente. 


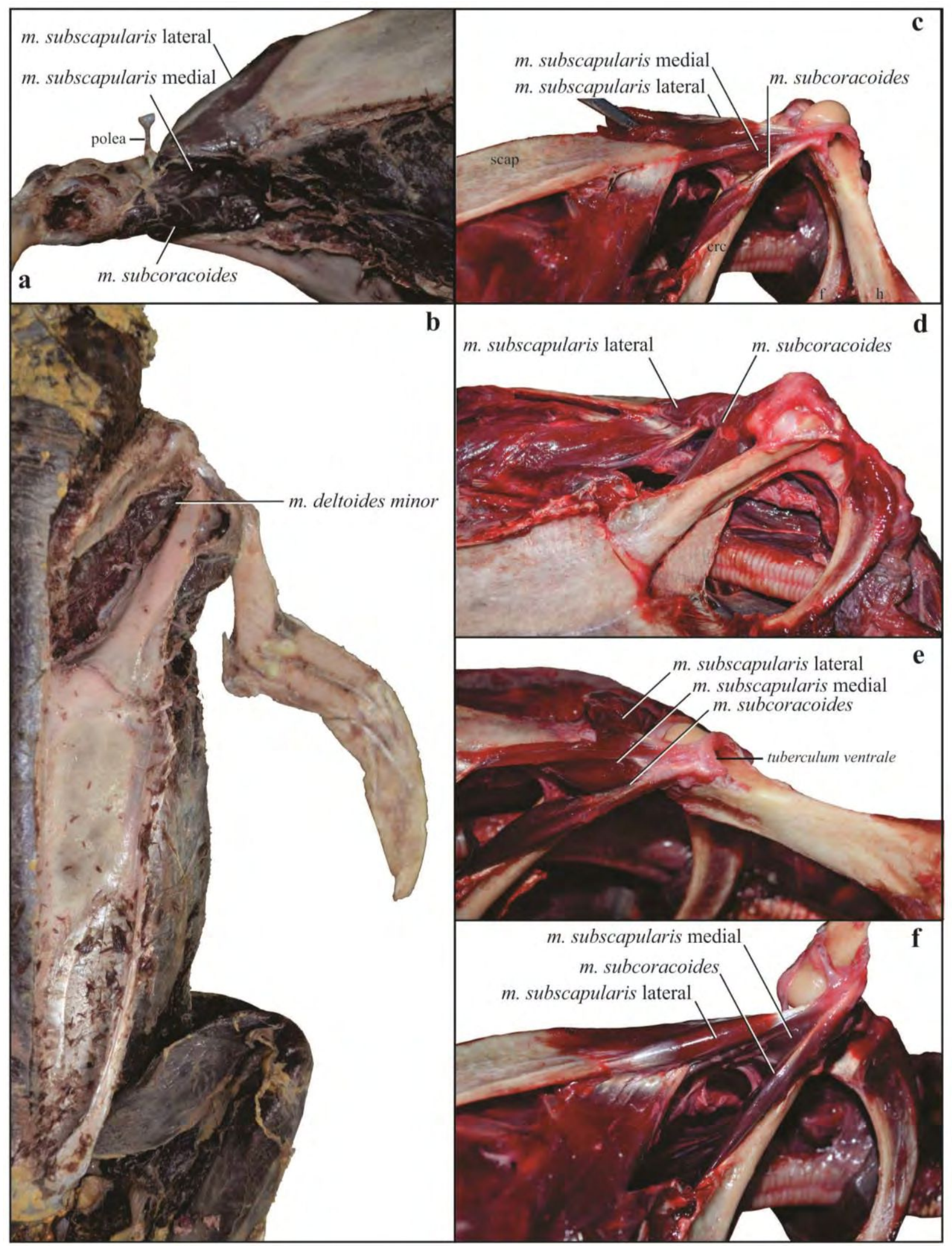

Figura 5 a, b, cuarta capa muscular en adulto de Pygoscelis adeliae, vista lateroposterior y ventral; $\mathbf{c}, \mathbf{d}, \mathbf{e}$, y f, quinta capa muscular, en adulto de Spheniscus magellanicus en vista ventrolateral. Abreviaciones:f, fúrcula; h, húmero; crc, coracoides; esc, escápula; m., musculus. 


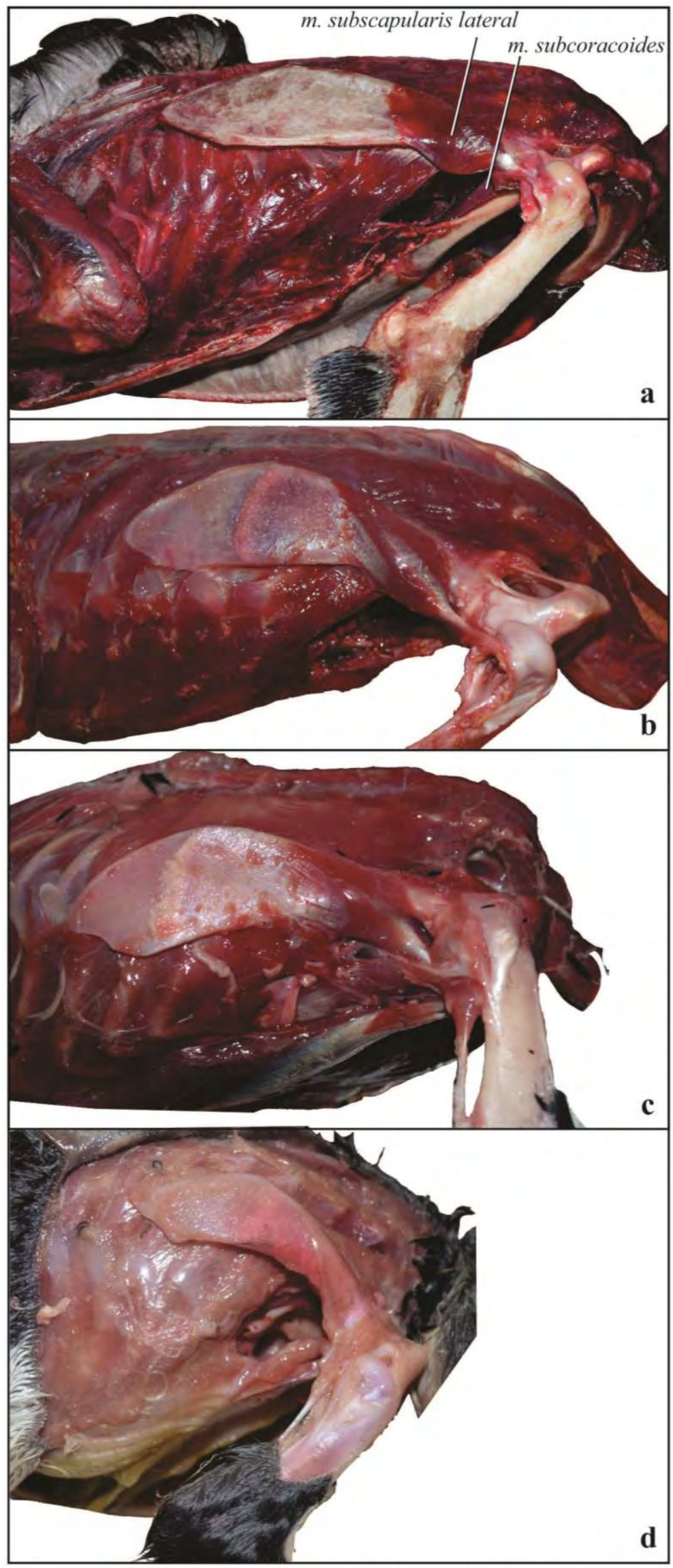

Figura 6 Quinta capa muscular en a, adulto de Spheniscus magellanicus; b, pichón emplumando de Pygoscelis papua; c, juvenil de Eudyptes chrysocome; d, pichón de pocas semanas de P. papua. Abreviaciones: m., musculus. 


\section{Músculo de la quinta capa}

M. coracobrachialis caudalis, m. subscapularis, y m. subcoracoides.

\section{Coracobrachialis caudalis}

Origen El músculo origina carnosamente en el processus lateralis coracoidei, en el processus craniolateralis del esternón, a la altura de las tres primeras costillas del esternón (de manera aponeurótica en Spheniscus), y en la porción lateral del m. supracoracoideus.

Inserción

Se inserta mediante un tendón en el margo caudalis que delimita la fossa tricipitalis del húmero (Fig. 3c, d).

Comentarios

Este músculo actúa empujando el ala ventrocaudalmente, y participa en los movimientos de supinación.

\section{Subscapularis}

Este músculo posee dos cabezas, una medial y otra lateral (Fig. 5 y 6).

Origen La cabeza medial se origina carnosamente en la línea media de la cara ventral de la membrana que une el proc. acromialis (escápula) y el proc. acrocoracoides (coracoides) y de la porción proximal de la escápula. Sus fibras corren caudolateralmente hacia su inserción en el húmero.

La cabeza lateral se origina carnosamente en la superficie anterior de la cresta de la facies lateralis del corpus scapularis, desarrollando, además, un origen aponeurótico hacia el margen ventral del margen de esta cresta. Sus fibras corren craneoventralmente y se fusionan con aquellas de la cabeza medial.

Inserción Ambas cabezas se insertan en conjunto en la incisura capitis cerca del tuberculum ventralis (húmero). Esta incisura actúa, además como una polea 
para el paso del músculo, y es más profunda en Spheniscus que en Pygoscelis. Si bien se fusiona parcialmente al $\mathrm{m}$. subcoracoides, se puede identificar su tendón y lugar de inserción independiente.

Comentarios

De acuerdo con Bannasch (1986a), la cabeza lateral de este músculo eleva la cabeza del húmero en la cavidad articular. Ambos tienen un componente de fuerza medial y aportan la pronación necesaria que antecede al movimiento de abducción del ala (Bannasch, 1986b).

\section{Subcoracoides}

Origen Se origina carnosamente desde la superficie dorsal de la spina sternalis, a medial en la membrana sternoclavicularis (Fig. 5 y 6).

Inserción $\mathrm{Su}$ inserción es tendinosa en la fosa del tuberculum ventralis. Este tendón está fuertemente adherido a la cápsula articular adyacente. Schreiweis (1982) observa que esta inserción es mediante un tendón corto y robusto al m. subscapularis en el extremo proximal de la cresta bicipital del húmero. Como se detalló anteriormente al describir el $m$. subscapularis, ambos tendones pudieron ser separados durante la disección.

No fue posible separar los tendones del $m$. subcoracoides y $m$. subscapularis en los pichones, así como tampoco en pichones emplumados de $P$. adelia. Este músculo limita la supinación, junto con el subcoracoideus (Bannasch, 1986b). 


\section{ANÁLISIS DE LOS PESOS DE LOS MÚSCULOS}

El peso de los dos principales músculos en el vuelo subacuático involucrados en la elevación del ala como lo es el $m$. supracoracoideus, y en el descenso y empuje del agua como lo es el $m$. pectoralis thoracica fueron evaluados para una serie ontogenética (Tabla ) del pingüino adelia (Pygoscelis adeliae).

Tabla Individuos diseccionados con músculos pesados. En negrita, los especímenes utilizados en la regresión. Abreviaciones: h, hembra; m, macho; m., musculus; pect, pectoralis thoracica; suprac, supracoracoideus.

\begin{tabular}{|c|c|c|c|c|c|c|c|c|}
\hline$n^{\circ}$ & Especie & Procedencia & sexo & edad & $\begin{array}{l}\text { culmen } \\
(\mathbf{m m})\end{array}$ & $\begin{array}{c}\text { masa } \\
\text { corporal }\end{array}$ & $\begin{array}{c}\text { m. pect } \\
\text { (g) }\end{array}$ & $\begin{array}{l}\text { m. suprac } \\
\text { (g) }\end{array}$ \\
\hline & Pygoscelis adeliae & Antártida & $?$ & pichón & , & , & , & , \\
\hline & Pygoscelis adeliae & Antártida & $?$ & pichón & , & , & , & , \\
\hline & Pygoscelis adeliae & Antártida & $?$ & pichón & , & , & , & , \\
\hline & Pygoscelis adeliae & Antártida & $?$ & pichón & , & , & , & , \\
\hline & Pygoscelis adeliae & Antártida & $?$ & pichón & , & , & , & , \\
\hline & Pygoscelis adeliae & Antártida & $\mathrm{m} ?$ & pichón & , & , & , & , \\
\hline & Pygoscelis adeliae & Antártida & $\mathrm{h}$ & $\begin{array}{l}\text { pichón } \\
\text { guardería }\end{array}$ & & , & , & $?$ \\
\hline & Pygoscelis adeliae & Antártida & $?$ & $\begin{array}{c}\text { pichón } \\
\text { emplumado }\end{array}$ & , & & , & , \\
\hline & Pygoscelis adeliae & Antártida & $?$ & adulto & , & & , & , \\
\hline & Pygoscelis adeliae & Antártida & $\mathrm{m} ?$ & adulto & , & & , & , \\
\hline & Pygoscelis adeliae & Antártida & $\mathrm{m}$ & adulto & , & & , & , \\
\hline & Pygoscelis adeliae & Antártida & $\mathrm{m}$ & adulto & , & & , & , \\
\hline
\end{tabular}




\begin{tabular}{|c|c|c|c|c|c|c|c|}
\hline Pygoscelis adeliae & Antártida & $?$ & adulto & , & & & , \\
\hline Pygoscelis adeliae & Antártida & $\mathrm{m}$ & adulto & , & & & , \\
\hline Pygoscelis papua & Antártida & $?$ & pichón & , & , & , & , \\
\hline Pygoscelis papua & Antártida & $\mathrm{m} ?$ & pichón & , & , & , & , \\
\hline Pygoscelis papua & Antártida & $\mathrm{h}$ ? & pichón & , & , & , & , \\
\hline Pygoscelis papua & Antártida & $?$ & $\begin{array}{l}\text { pichón } \\
\text { guardería }\end{array}$ & & & $?$ & $?$ \\
\hline Pygoscelis papua & Antártida & $\mathrm{m} ?$ & $\begin{array}{l}\text { pichón } \\
\text { guardería }\end{array}$ & , & & $?$ & $?$ \\
\hline Pygoscelis papua & Antártida & $?$ & $\begin{array}{l}\text { pichón } \\
\text { emplumando } \\
\text { (36 días) }\end{array}$ & , & & , & , \\
\hline $\begin{array}{l}\text { Spheniscus } \\
\text { magellanicus }\end{array}$ & Chubut & $\mathrm{m}$ & adulto & & $?$ & , & , \\
\hline
\end{tabular}

Las regresiones entre los pesos de estos dos músculos con respecto al largo del culmen, valor proxy utilizado para indicar el tamaño relativo del individuo (Ver tabla ), muestra una recta de crecimiento similar para ambos músculos, aunque para el $\mathrm{m}$. pectoralis thoracica (Fig. 7), el aumento en peso es mucho mayor al del $m$. supracoracoideus (Fig. 7). Se observa un aumento abrupto de peso para ambos músculos entre pichón en guardería y adulto. Lamentablemente no pudieron muestrearse juveniles, pero creemos que este aumento en peso muscular se dé probablemente en los primeros meses del estadío juvenil. Para los adultos, notamos que en casi todos los especímenes los pesos de ambos músculos se encuentran por encima de la recta. Observamos que el individuo 8 que corresponde a un pichón emplumado volantón (Tabla , Fig. 7) cae muy por debajo de la recta en ambas regresiones. Este dato, aunque interesante, podría resultar en un outlier debido a que fue encontrado muerto al momento en que partían los últimos volantones de la colonia, por lo que su muerte (sumado al dato del bajo peso corporal) podría estar dada por una alimentación deficiente o a una eclosión tardía, y podría estar muy por fuera del promedio para pichones de esa edad. 
a

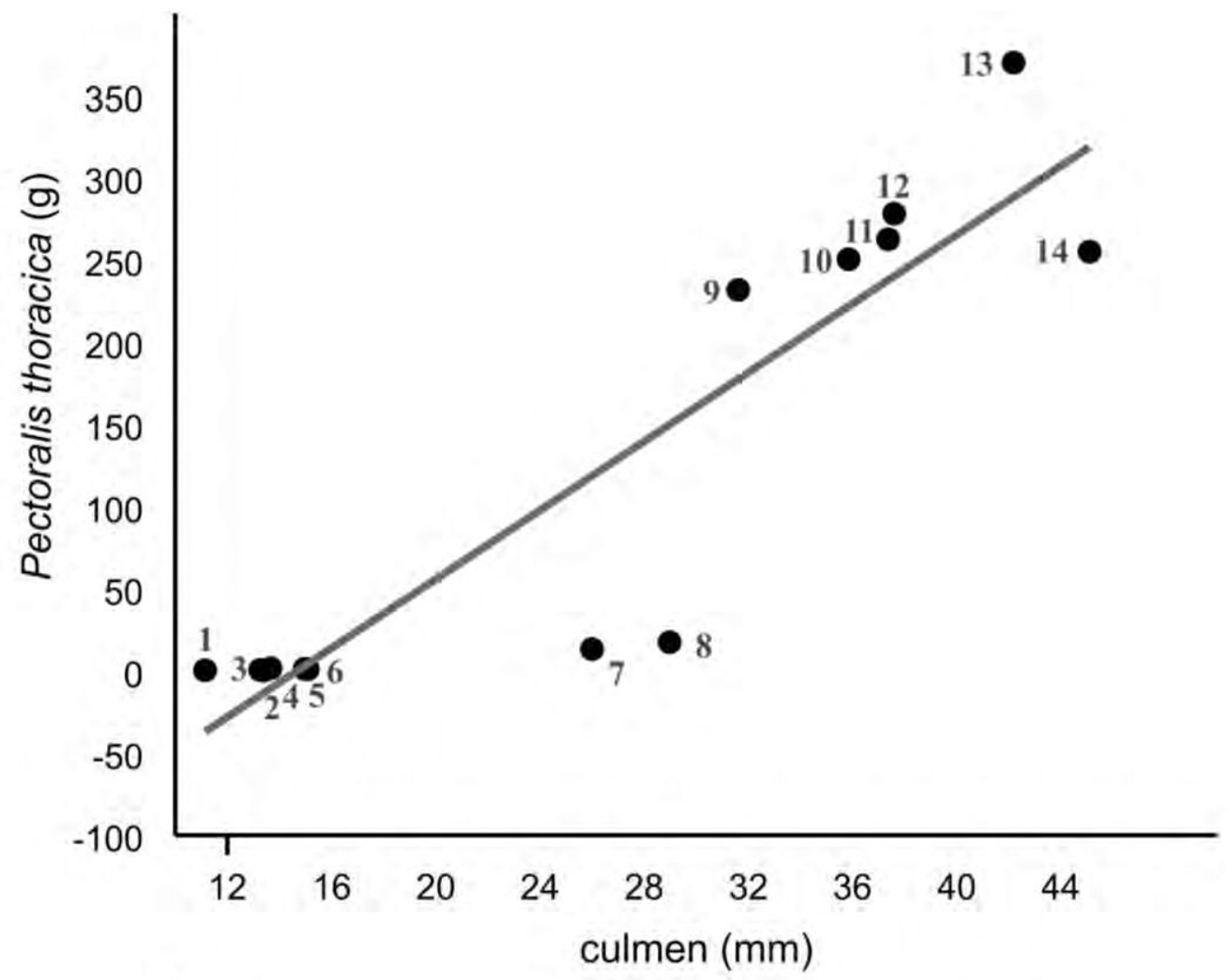

b

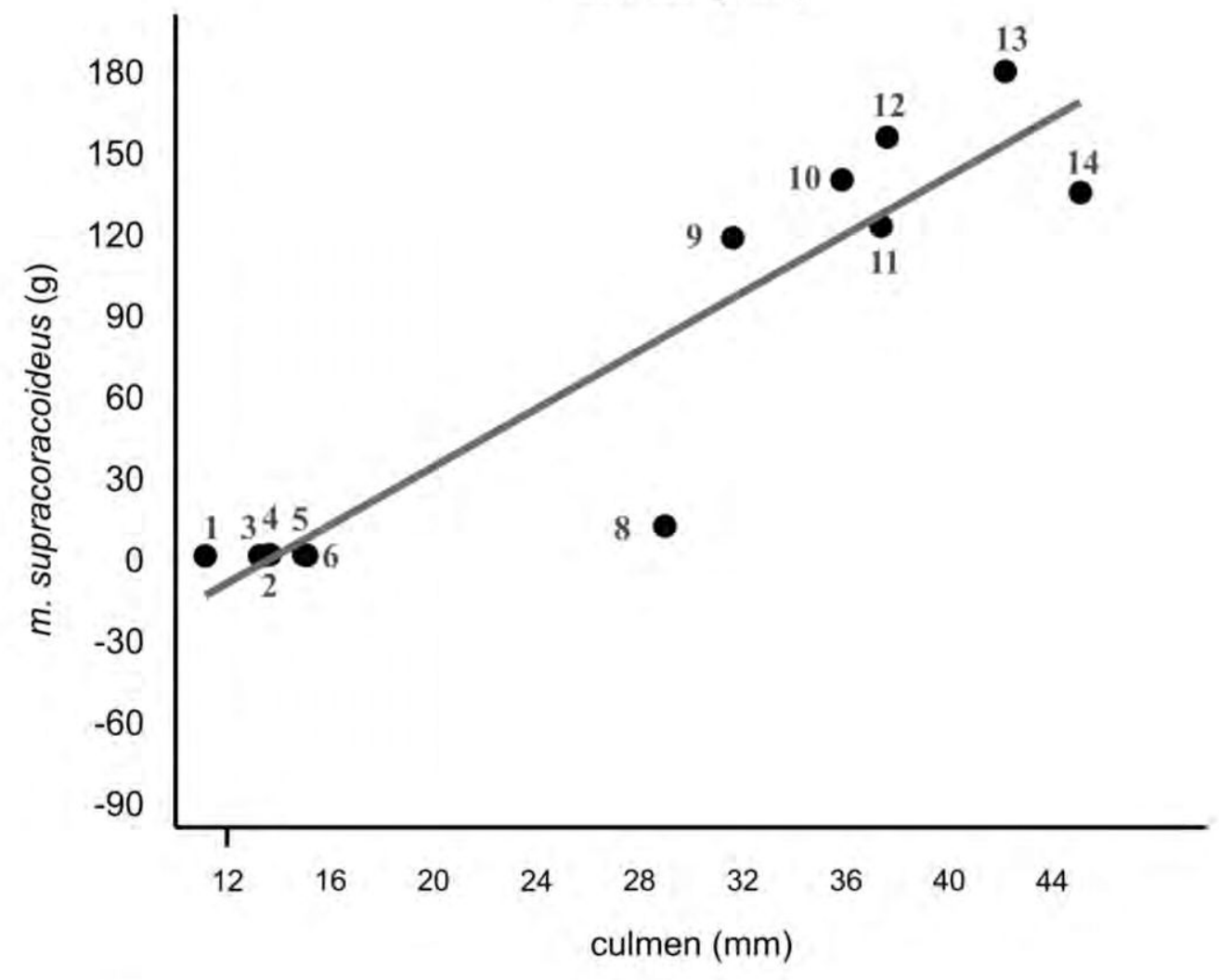

Figura 7 Modelo lineal bivariado entre el culmen y del peso de a, el $m$. pectoralis thoracica; $\mathbf{b}$, el $m$. supracoracoideus. 
Tabla Resultado de la regresión de los pesos musculares en individuos de Pygoscelis adeliae de diferentes edades. Los valores fueron normalizados.

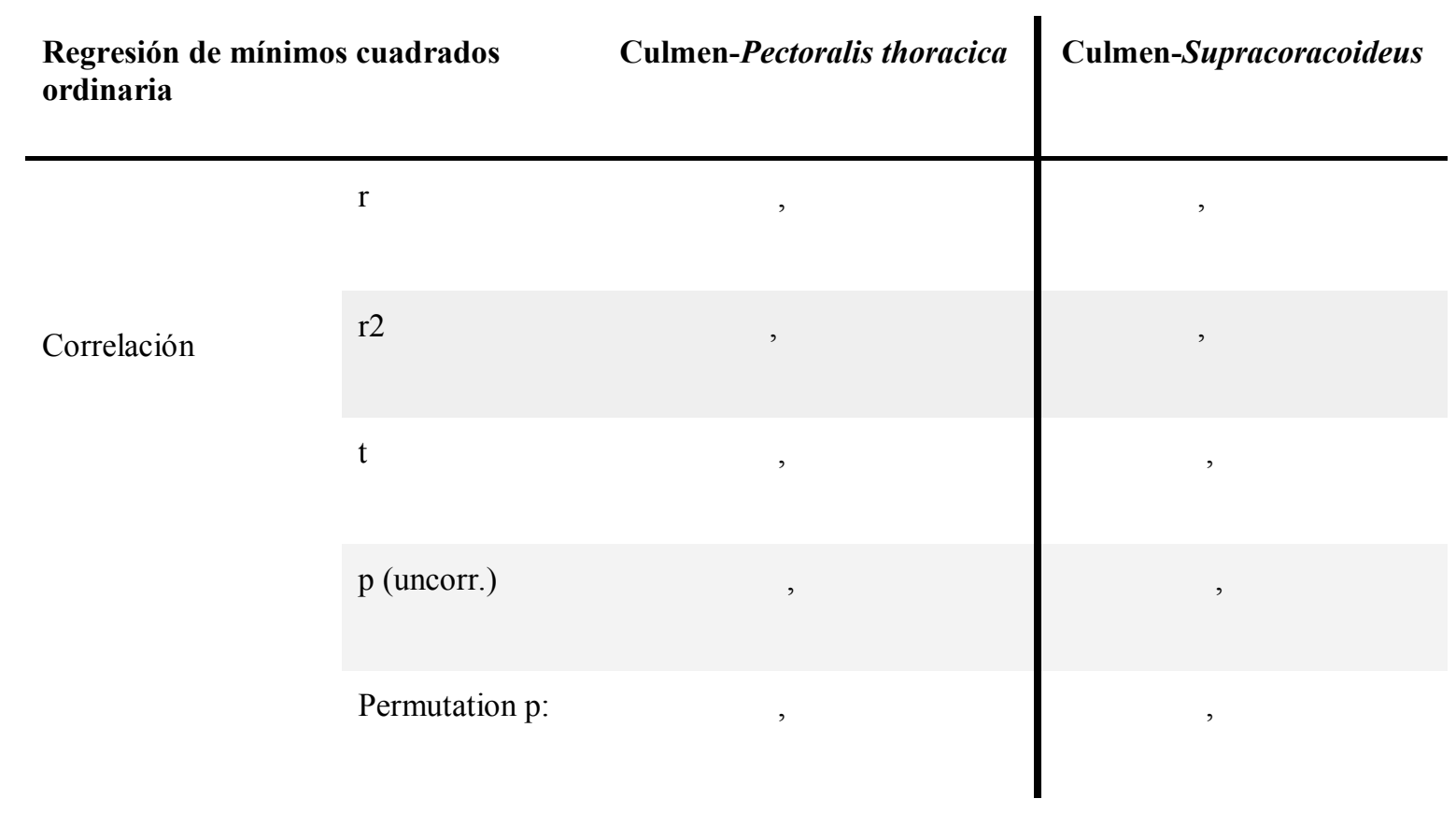

RESULTADOS: ANÁLISIS HÚMERO

\section{CONFIGURACIÓN DEL HÚMERO VISTA DORSAL}

\section{Alometría}

La regresión arrojó como resultado que un 10,7759\% de la variación de la forma se encuentra explicada por el tamaño $(p<0,0001)$.

\section{Análisis de componentes principales}

Se realizó un PCA con los datos crudos y uno con los datos residuales debido a que la variación de forma explicada resultó significativa (Ver Configuración del húmero: vista dorsal, Alometría en este mismo capítulo), donde se encontró que los primeros tres componentes principales explicaron más del 48\% de la variación (Tabla ). 
a
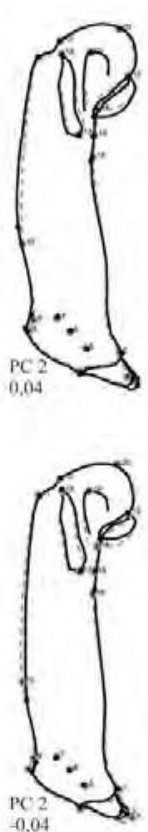

b

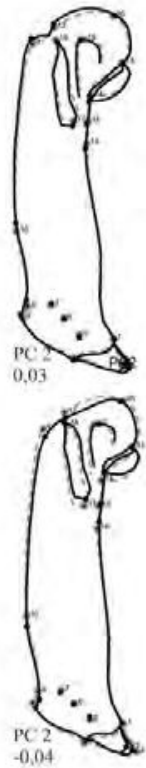

PC 2

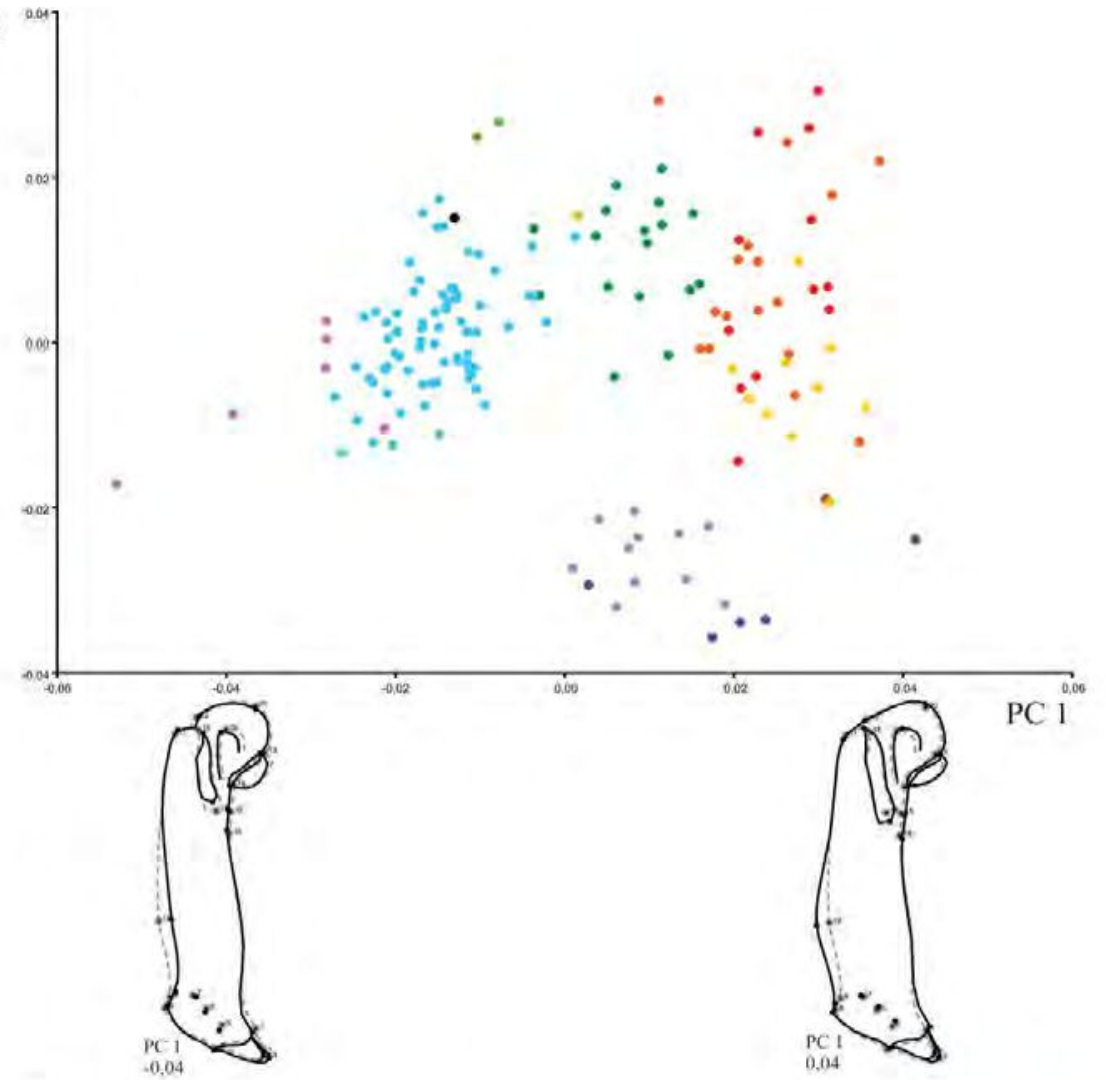

$\mathrm{PC} 2^{\circ}$

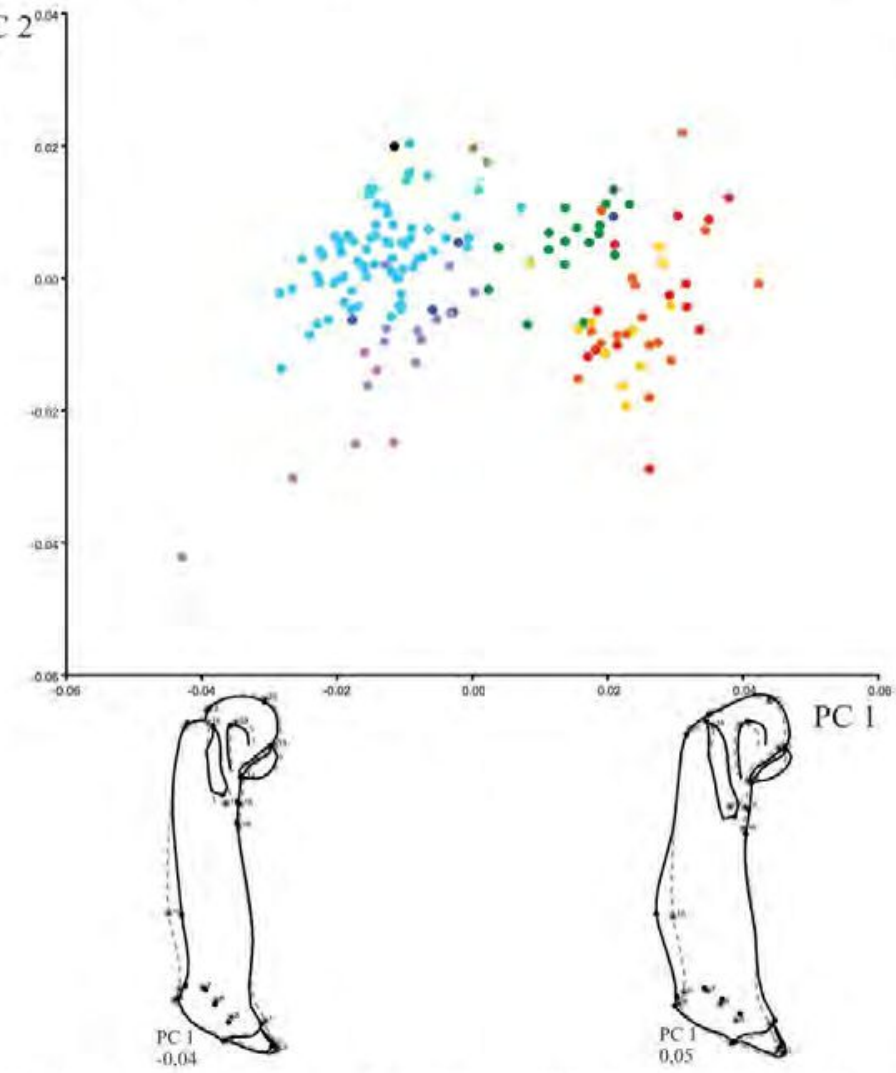

Aptenodytes forsteri iptenodytes patagonitews Euchpres chrysocome Eudyptes chrysolophins Eudyples pachorhanchus Eudypinle minor. Madrynornis mirandus Pygoscelis adeliae Pvosecelis antarctice

Sohoniocte mayclanticus

Figura 8 Análisis de componentes principales de la configuración del húmero en vista dorsal. Gráficos de dispersión de los primeros dos PC con el cambio de forma para los valores extremos de cada PC para a, datos originales; $\mathbf{b}$, datos corregidos. Las líneas grises punteadas representan la forma promedio mientras que las negras representan los valores extremos de cada PC. 
Tabla Porcentajes de variación explicada por los primeros tres componentes principales, para el PCA del conjunto de datos originales y corregidos.

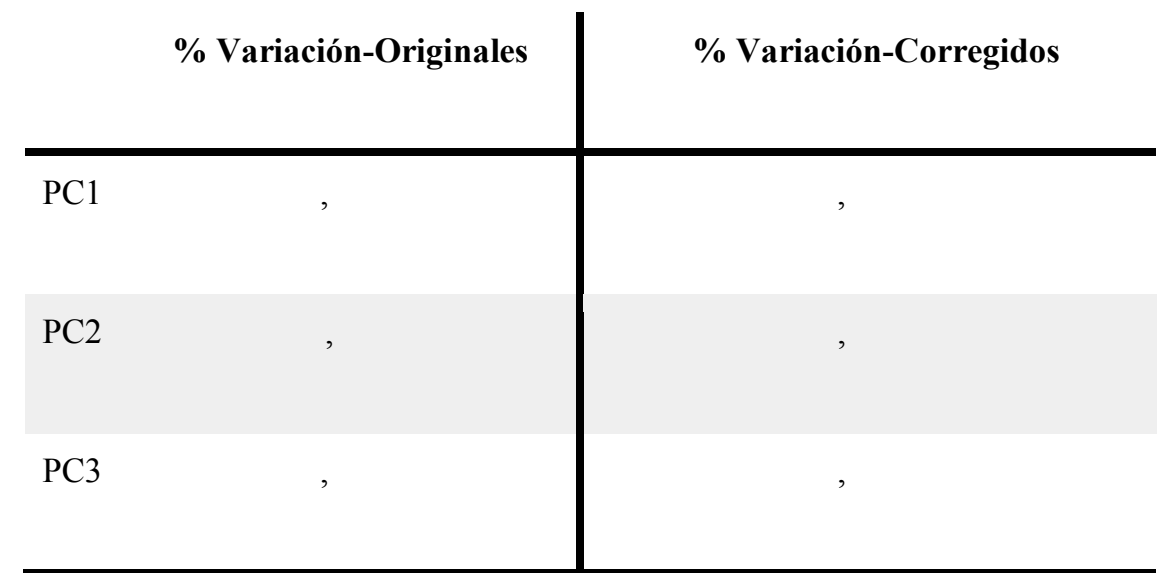

En el PCA de datos crudos, el PC1 agrupa a los especímenes de Pygoscelis hacia los valores positivos, en los valores intermedios a Eudyptes y Aptenodytes, hacia los valores negativos a Spheniscus y Madrynornis, y con valores más extremos aun sitúa a Eudyptula también en los valores negativos (Fig. 8). El PC2 para el mismo análisis agrupa a Pygoscelis, Eudyptes, Madrynornis, Eudyptula y Spheniscus hacia los valores positivos y neutros, y a Aptenodytes hacia los negativos. Dentro del primer grupo, Pygoscelis es el que abarca el mayor rango de variación en el PC1, desde los valores positivos más extremos hacia valores negativos bajos. Madrynornis tiende a ubicarse hacia los valores positivos más extremos (PC1), Spheniscus y Eudyptes se ubican en los valores positivos y neutrales, y Eudyptula en los valores neutrales tendiendo a los negativos.

Para la presente configuración, se vio una variación considerable del PCA para los datos residuales. El PC1 del PCA de datos residuales agrupa hacia los valores positivos a Pygoscelis, en los neutrales a Eudyptes, y hacia los negativos a Spheniscus, Eudyptula, Aptenodytes y Madrynornis (Fig. 8). El PC2 agrupa de una manera similar a Pygoscelis, Spheniscus y Eudyptes, mientras que Madrynornis se desplaza hacia los positivos más extremos al mismo tiempo que Aptenodytes se mueve hacia los valores neutros y Eudyptula hacia los negativos más extremos. Quedando entonces, Spheniscus más cercano a Eudyptula, Aptenodytes y Madrynornis. 
La variación de forma en el PC1 para los dos análisis resultaron muy similares y se explican juntos. El cambio mayor se visualiza en el angulus preaxialis, el cual es marcado, protruyente y levemente más distal hacia los valores donde de agrupa Pygoscelis (Fig. 8). El tuberculum dorsale se encuentra alejado del caput humeri, a la vez que este último se encuentra más externo también para los valores positivos (Pygoscelis). La cicatriz de inserción del $\mathrm{m}$. coracobrachialis caudalis ubicado en el margen caudal de la fossa tricipitalis es más corto para las formas que se encuentran hacia los valores positivos, a diferencia de la cicatriz de inserción del $m$. supracoracoideus que se encuentra más extendido, y oblicuamente orientado respecto a la diáfisis para los mismos valores. La cresta troclear caudal se proyecta proximal y medialmente hacia los valores positivos, las cicatrices del extensor metacarpi ulnaris (e. met. ul.), extensor digitorum communis (e. dig. com), y el supinator (sup) (de acuerdo a la terminología propuesta por Schreiweis, 1982) forman un ángulo más agudo con la diáfisis, y el condylus dorsalis es más bajo en los valores positivos. Los valores negativos presentan una cicatriz para este músculo más corta y paralela a la diáfisis. La variación de forma encontrada para el PC2 en los dos análisis fue mayor que para el PC1. Para el PCA de datos crudos, la mayor variación se encuentra en el angulus preaxialis el cual está mucho más desplazado hacia el centro de la diáfisis para los valores positivos. Para esos mismos valores, se observa una inserción del $m$. coracobrachialis caudalis más extendida, un leve desplazamiento distal de la inserción del $\mathrm{m}$. latissimus dorsi, la cresta troclear cranial (proc. flexorius) distalmente más extendida y un condylus dorsalis levemente más desarrollado. Las formas hacia los valores negativos del PC2 presentan el tuberculum dorsale más pronunciado, y el inicio del caput humeri más desplazado proximalmente. El resto de la variación de forma coincide con la observada para el análisis con los datos crudos. La variación de forma para ambos análisis resultó similar, no así la distribución de los individuos. Resulta razonable que Aptenodytes sea el que presenta gran variación en su distribución ya que son especies considerablemente de mayor tamaño al resto.

\section{Categorías de hábitos alimenticios: Análisis multivariante de la varianza}

El MANOVA con los PC de las coordenadas de procrustes de los datos originales, y los obtenidos a partir de los residuales de la regresión dieron como resultado un valor de Wilk's Lambda bajo, por lo cual las diferencias entre grupos no serían debidas al azar. Las distancias de Mahalanobis ubicaron a los grupos crustacívoro-generalista como los más 
cercanos (ver Tabla ), los grupos piscívoros-generalistas quedaron a una distancia intermedia, mientras que los crustacívoros-piscívoros fueron hallados como los más lejanos (Tabla ).

Tabla Análisis multivariante de la varianza (MANOVA) del húmero en vista dorsal, valores de Wilks' $\lambda$, y distancias de Mahalanobis entre grupos con sus correspondientes valores de $\mathrm{p}$ asociados. Resultados para el conjunto de datos originales y corregidos.

\begin{tabular}{|c|c|c|c|c|c|}
\hline & & \multicolumn{2}{|c|}{ Originales } & \multicolumn{2}{|c|}{ Corregidos } \\
\hline \multicolumn{2}{|c|}{ Wilks' $\lambda$} & \multicolumn{2}{|c|}{, } & \multicolumn{2}{|c|}{, } \\
\hline \multicolumn{2}{|l|}{$\mathrm{p}$} & \multicolumn{2}{|c|}{, } & \multicolumn{2}{|c|}{, } \\
\hline \multirow{3}{*}{ D } & & generalista & crustacívoro & generalista & crustacívoro \\
\hline & & & , & \multirow{2}{*}{\multicolumn{2}{|c|}{, }} \\
\hline & piscívoro & , & & & \\
\hline \multirow{2}{*}{$\mathrm{p}$} & generalista & & , & & $<$, \\
\hline & piscívoro & , & , & , & , \\
\hline
\end{tabular}

\section{Categorías de hábitos alimenticios: Análisis de Variación Canónica}

La menor distancia se halló para los grupos crustacívoro-generalista en los dos Análisis de Variación Canónica (CVA) realizados (Tabla ). La mayor distancia resultó ser entre los grupos crustacívoro-piscívoro, mientras que la distancia intermedia se halló entre los grupos piscívoros-generalistas. 
Tabla Análisis de variación canónica (CVA) del húmero en vista dorsal, porcentajes de variación para los dos primeros ejes de variación canónica, y distancias de Mahalanobis (D ) entre grupos con sus correspondientes valores de $\mathrm{p}$ asociados. Resultados para el conjunto de datos originales y corregidos.

\begin{tabular}{|c|c|c|c|c|c|}
\hline & & \multicolumn{2}{|c|}{ Originales } & \multicolumn{2}{|c|}{ Corregidos } \\
\hline \multicolumn{2}{|c|}{ CV $1 \%$} & \multicolumn{2}{|c|}{, } & \multicolumn{2}{|c|}{, } \\
\hline \multicolumn{2}{|c|}{ CV $2 \%$} & \multicolumn{2}{|c|}{, } & \multicolumn{2}{|c|}{, } \\
\hline \multirow{3}{*}{$\mathrm{D}$} & & generalista & crustacívoro & generalista & crustacívoro \\
\hline & & & , & \multirow{2}{*}{\multicolumn{2}{|c|}{, }} \\
\hline & piscívoro & , & & & \\
\hline \multirow{2}{*}{$\mathrm{p}$} & generalista & & , & & , \\
\hline & piscívoro & , & , & , & , \\
\hline
\end{tabular}

Tanto para el CVA de datos crudos de las coordenadas de procrustes como para el CVA de los datos corregidos por el efecto alométrico, el CV1 separa exitosamente el grupo crustacívoro (Pygoscelis adeliae, P. antarctica) de los piscívoros (Aptenodytes patagonicus, Eudyptula, Spheniscus) (Fig. 9). El grupo generalista (A. forsteri, Eudyptes, P. papua), en cambio, queda entre medio de los dos grupos. En tanto que el CV2 separa a los grupos especialistas de los generalistas.

La variación de forma para el CV1 explicada en ambos análisis (datos crudos y residuales) y que diferencia los piscívoros de los crustacívoros es muy similar aunque más exacerbada para el conjuntos de datos residuales (Fig. 9). En este CV se observa que la variación de forma explica para las formas piscívoras un angulus preaxialis curvado hacia dentro, un tuberculum dorsale ubicado más proximalmente, un caput humeri menos protruyente, una cicatriz de inserción del $m$. coracobrachialis caudalis más corta, la fossa 
a

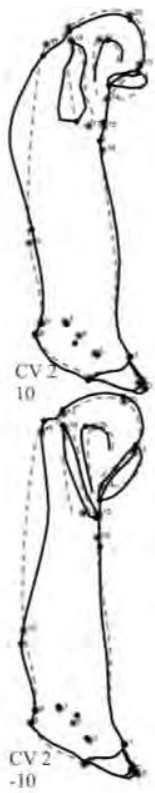

b
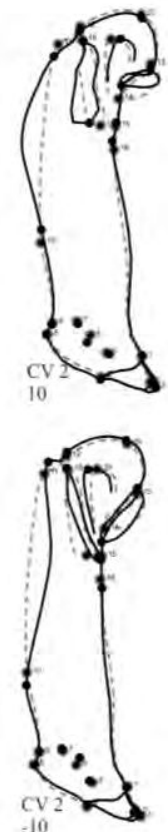
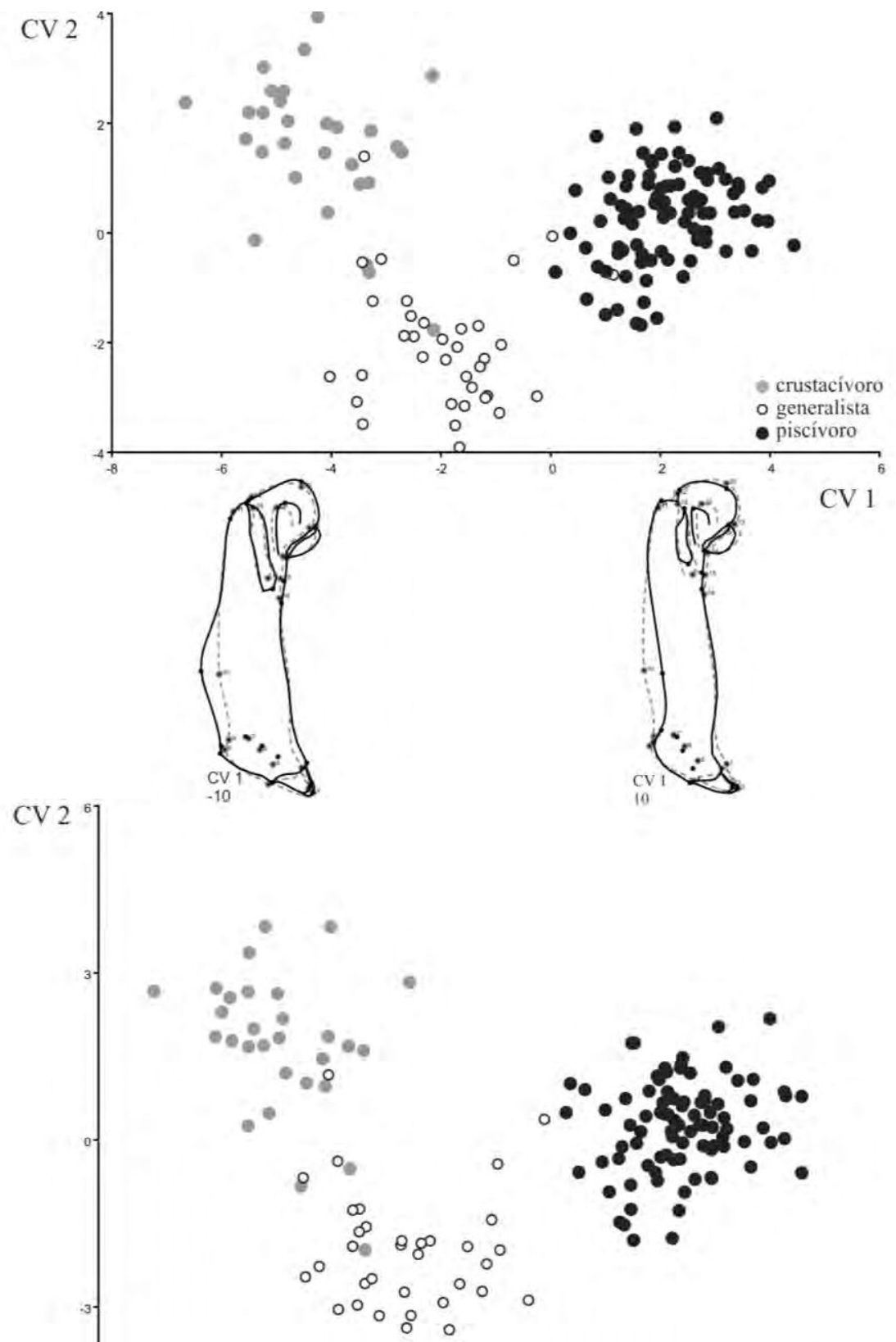

$\circ$

- crustacivoro generalista - piscivoro

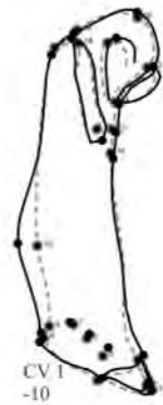

CV 1

Figura 9 Gráficos de dispersión de los primeros dos $\mathrm{CV}$ de la configuración del húmero en vista dorsal, con el cambio de forma para los valores magnificados de cada $\mathrm{CV}$ para $\mathbf{a}$, datos originales; $\mathbf{b}$, datos corregidos. Las líneas grises punteadas representan la forma promedio mientras que las negras representan los valores extremos de cada PC. 
tricipitalis secundaria se ubica cercana a la cicatriz del $m$. supracoracoides, el cual es más corto y se dispone más paralelamente. Siguiendo, las crestas trocleares se encuentran poco protruidas, los extensor metacarpi ulnaris, extensor digitorum communis, y el supinator se ubican escalonados, siendo el extensor metacarpi ulnaris el más lejano a diáfisis. Por último, en las formas piscívoras, los cóndilos que articulan con el radio y la ulna tienden también a estar más paralelos a la diáfisis, y el cóndilo dorsal es más alto.

Por otro lado, el CV1 para los valores que agrupan los crustacívoros explica una morfología con tuberculum dorsale más distante del caput humeri cuyo extremo más protruido se aleja medioproximalmente de la configuración y la cicatriz del $\mathrm{m}$. coracobrachialis caudalis es más larga (Fig. 9). Estas características contribuyen a una robustez general mayor de la cabeza humeral para estos grupos. Además, el CV1 caracteriza al grupo crustacívoro con una cicatriz del $\mathrm{m}$. latissimus dorsi levemente más oblicua respecto al margen medial del húmero, las crestas trocleares son protuberantes, los extensor metacarpi ulnaris, extensor digitorum communis, y el supinator se encuentran ubicados paralelos con respecto a los cóndilos de articulación. El cóndilo dorsal es más alto para estas formas y el angulus preaxialis se encuentra más desarrollado y anguloso. La morfología general de estas formas es más robusta.

En el CV2, la diferencia en forma está dada por el tuberculum dorsale que es más cercano al caput humeri para los valores del grupo generalista, la cicatriz del $\mathrm{m}$. coracobrachialis caudalis se encuentra más extendida para los generalistas mientras que es más corto para los valores de los grupos especialistas, la inserción del m. latissimus dorsi está más alejada de la cabeza humeral para los grupos generalistas, mientras que la del $\mathrm{m}$. latissimus dorsi se encuentra más alejada de la cabeza humeral (Fig. 9). La inserción del $m$. supracoracoideus está más extendida aunque es más delgada para los generalistas, el extensor digitorum communis se encuentra comparativamente más proximal que el extensor metacarpi ulnaris y el supinator en los generalistas, y el angulus preaxialis se encuentra más distal también para este grupo. 


\section{CONFIGURACIÓN DEL HÚMERO VISTA VENTRAL}

\section{Alometría}

La regresión dio como resultado que para el conjunto de datos completo, el tamaño explica un 7,0530\% $(\mathrm{p}<0,0001)$ de la variación.

\section{Análisis de componentes principales}

Dado que existe un efecto alométrico, cada uno de los análisis de esta sección se realizó tanto para los datos originales como para los corregidos con los residuos. La Tabla indica los porcentajes de la variación explicado por los primeros tres componentes principales para los dos PCA.

Tabla Porcentajes de variación explicada por los primeros tres componentes principales, para el PCA del húmero en vista ventral del conjunto de datos originales y corregidos.

\begin{tabular}{l|l|l} 
& \% Variación-Originales & \% Variación-Corregidos \\
\hline PC1 & &, \\
\hline PC2 &, \\
\hline &, \\
\hline
\end{tabular}

Para ambos PCA, Pygoscelis se agrupa hacia los valores positivos del PC1, a la vez que Spheniscus se agrupa hacia los valores negativos, junto con Madrynornis (Fig. 10). Eudyptes se ubica con valores intermedios entre ambos grupos. La mayor diferencia se observa, como se ha notado para los anteriores análisis, con Aptenodytes y Eudyptula, que son los dos géneros en que se da la mayor variación de tamaño, siendo Aptenodytes los 
b

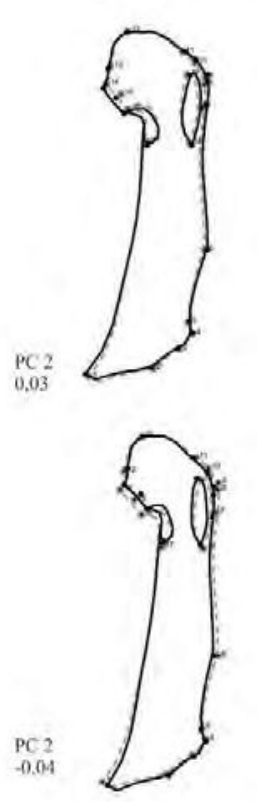

PC 2

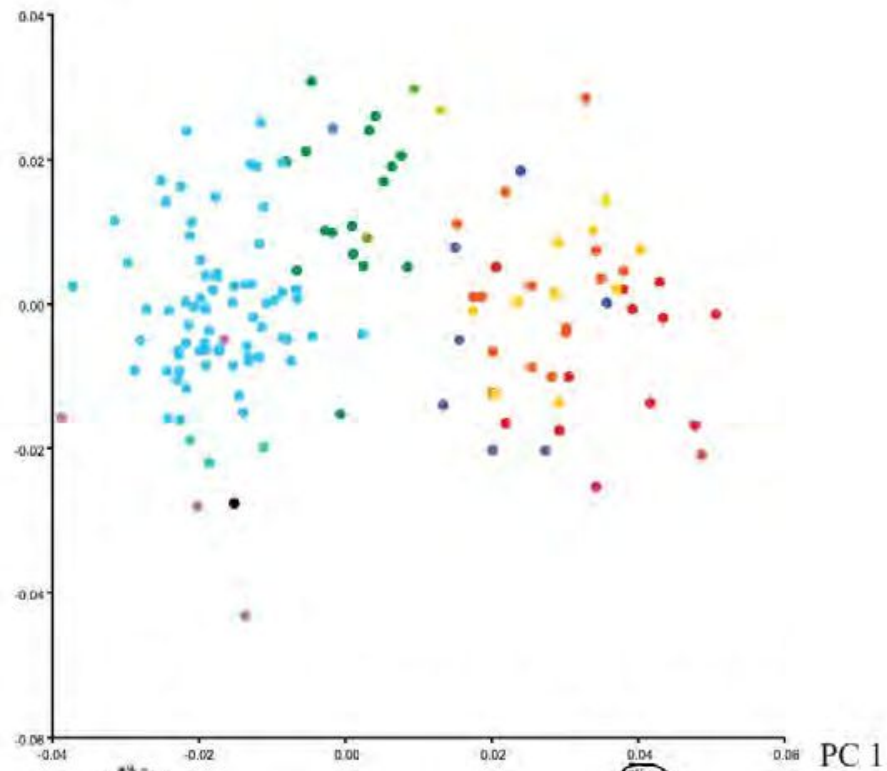

PC 2

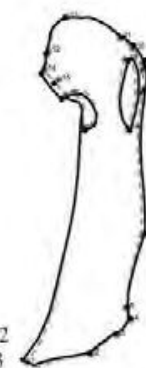

$\mathrm{PC}$
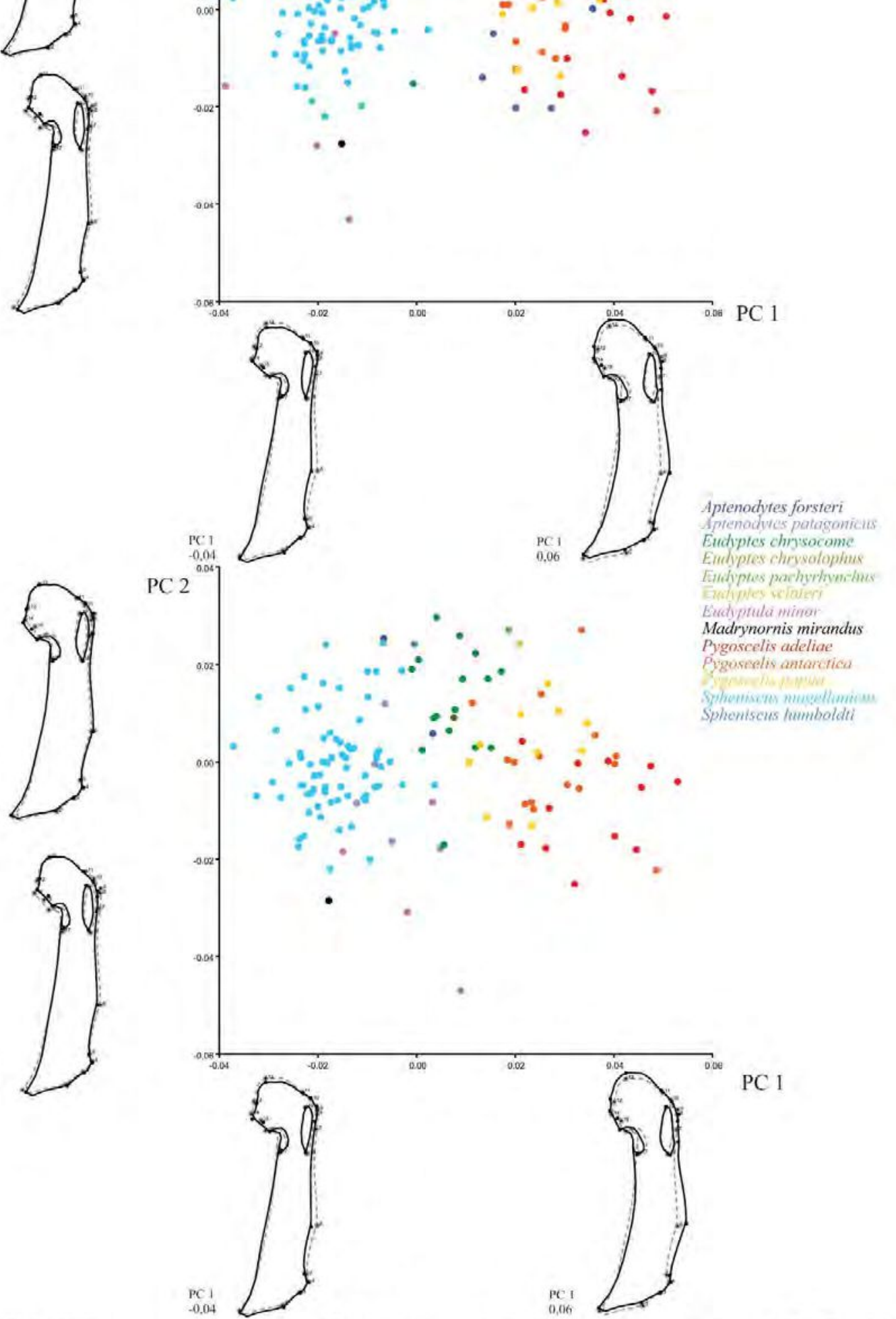

Figura 10 Análisis de componentes principales de la configuración del húmero en vista ventral. Gráficos de dispersión de los primeros dos PC con el cambio de forma para los valores extremos de cada PC para a, datos originales; $\mathbf{b}$, datos corregidos. Las lineas grises punteadas representan la forma promedio mientras que las negras representan los valores extremos de cada PC. 
pingüinos más grandes y Eudyptula los pingüinos más pequeños. Para el PCA de los datos crudos, Aptenodytes se agrupa con Pygoscelis (aunque hacia los valores positivos bajos), y Eudyptula junto a Spheniscus (Fig. 10). Para los valores residuales, en cambio, los individuos de ambos géneros se ubican en los valores negativos bajos del PC1 junto a Spheniscus. A lo largo del PC2, Eudyptes se ubica hacia los valores positivos y Eudyptula hacia los valores negativos. Pygoscelis papua se ubica más próximo a los valores negativos y Madrynornis mirandus, en ambos análisis, hace lo propio hacia los valores negativos extremos. El resto de los individuos se disponen en un amplio rango del componente.

La variación de forma para los dos primeros PC fue muy similar en los dos análisis (Fig. 10). Hacia los valores positivos del PC1, donde se ubican los individuos de Pygoscelis, se agrupan formas con una cabeza humeral más desarrollada, que se proyecta proximalmente. Por el contrario, hacia los valores negativos, los individuos poseen una cabeza más redondeada y menos protruyente. La línea de inserción del $m$. deltoides minor se encuentra alejada de la cabeza en los individuos situados hacia los valores positivos y se dispone paralela a la diáfisis, mientras que para los valores negativos se encuentra en ángulo a la misma. La inserción del $m$. propatagialis es más elongada y se ubica distalmente con respecto a los valores negativos. El angulus preaxialis está más desarrollado y se extiende lateralmente en las formas de los valores positivos. Distalmente, el cóndilo dorsal es más bajo hacia los valores positivos y la articulación con el radio y ulna tiende a ser más paralelo a la diáfisis hacia los valores positivos que hacia los valores negativos. La crista bicipitalis (lugar de inserción del m. scapulohumeralis caudalis) está más extendida y se ubica más medial hacia los valores positivos. Para el PC2, la mayor variación se encontró para el tubérculo ventral, el cual se aleja de la configuración general de la cabeza humeral para los valores positivos donde se ubica Eudyptes.

\section{Categorías de hábitos alimenticios: Análisis multivariante de la varianza}

Las diferencias entre las categorías dietarias resultaron significativas. El grupo con mayores distancias para el conjunto de datos completos resultó el de los piscívoros con los crustacívoros para ambos MANOVA (Tabla ). De la misma manera, las menores distancias se encontraron para crustacívoros-generalistas. 
Tabla Análisis multivariante de la varianza (MANOVA) del húmero en vista ventral, valores de Wilks' $\lambda$, y distancias de Mahalanobis (D) entre grupos con sus correspondientes valores de $p$ asociados. Resultados para el conjunto de datos originales y corregidos.

\begin{tabular}{|c|c|c|c|c|c|}
\hline & & \multicolumn{2}{|c|}{ Originales } & \multicolumn{2}{|c|}{ Corregidos } \\
\hline \multicolumn{2}{|c|}{ Wilks' $\lambda$} & \multicolumn{2}{|c|}{, } & \multicolumn{2}{|c|}{, } \\
\hline \multirow[t]{2}{*}{$\mathrm{p}$} & & \multicolumn{2}{|r|}{, } & \multicolumn{2}{|r|}{, } \\
\hline & & generalista & crustacívoro & generalista & crustacívoro \\
\hline \multirow{2}{*}{ D } & generalista & & , & \multirow{2}{*}{\multicolumn{2}{|c|}{, }} \\
\hline & piscívoro & , & & & \\
\hline \multirow{2}{*}{$\mathrm{p}$} & generalista & & , & & , \\
\hline & piscívoro & , & , & , & , \\
\hline
\end{tabular}

\section{Categorías de hábitos alimenticios: Análisis de variación canónica}

El CVA ubicó como grupos más cercanos al de crustacívoros-generalistas en los dos casos, mientras que los grupos más alejados resultaron ser los de piscívoros-generalistas, quedando los grupos piscívoros-crustacívoros con distancias intermedias (Tabla ).

Tabla Análisis de variación canónica (CVA) del húmero en vista ventral, porcentajes de variación para los dos primeros ejes de variación canónica, y distancias de Mahalanobis (D) entre grupos con sus correspondientes valores de $\mathrm{p}$ asociados. Resultados para el conjunto de datos originales y corregidos.

\begin{tabular}{|c|c|c|}
\hline & Originales & Corregidos \\
\hline CV $1 \%$ & , & , \\
\hline CV $2 \%$ & , & , \\
\hline
\end{tabular}




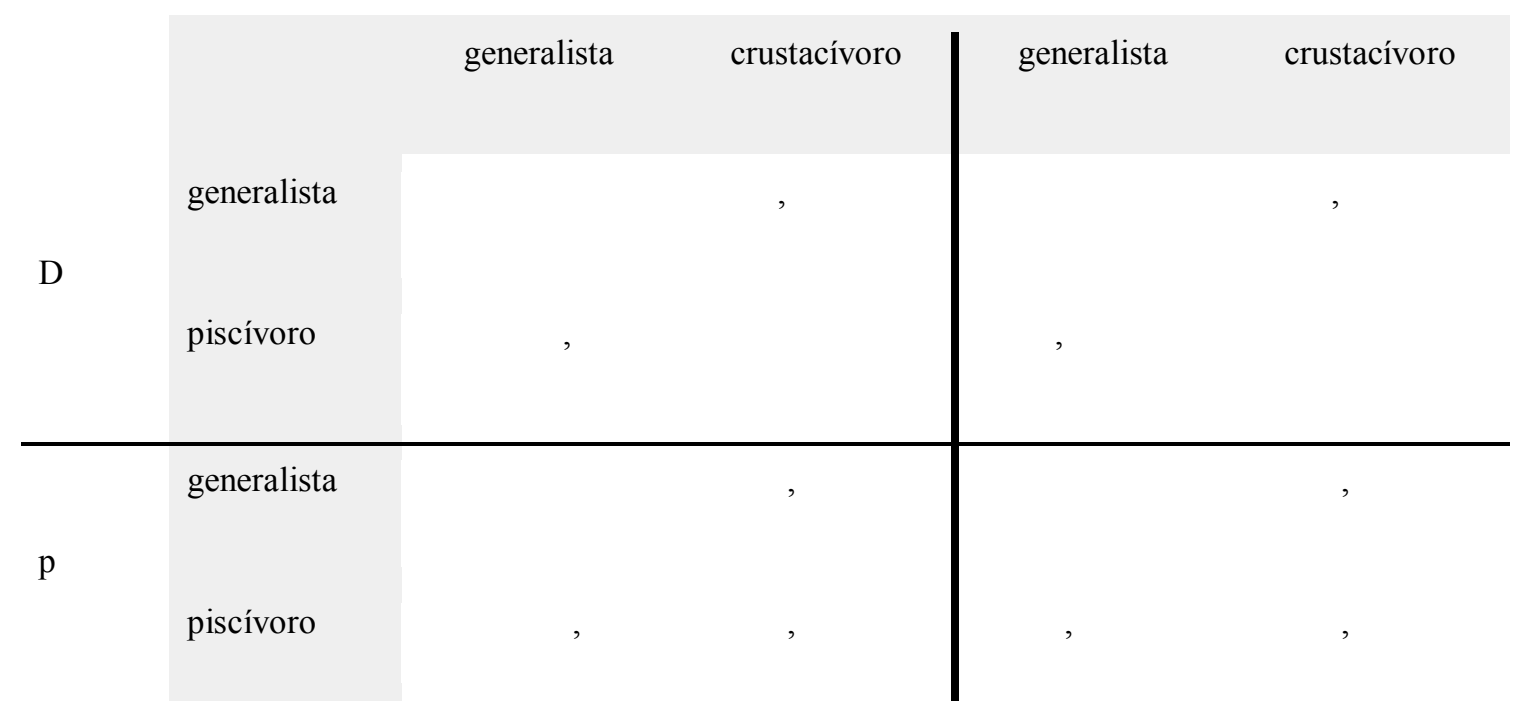

En ambos análisis, el CV1 separa los piscívoros de los crustacívoros (Fig. 11). Para este mismo eje los generalistas quedan entre medio de ambos grupos aunque más cercanos a los crustacívoros. El CV2 separa, en ambos análisis, los grupos especialistas de los generalistas como en la mayoría de los análisis antes detallados.

En el CV1 vemos que la variación de forma es similar en ambos análisis ${ }^{4}$. Los grupos piscívoros poseen formas gráciles, condición que hemos observado en otras vistas del húmero y en otros huesos para este grupo (Fig. 11). En el CV1, además, se observa que la cabeza humeral se encuentra reducida en las formas piscívoras, mientras que en las formas crustacívoras tienden a estar más protruidas. Por otro lado, las cicatrices de inserción del $m$. deltoides minor (tuberculum dorsale) y del $\mathrm{m}$. propatagialis están menos extendidas en las formas piscívoras que en las crustacívoras. La crista bicipitalis (lugar de inserción del $m$. scapulohumeralis caudalis) se encuentra también más extendida en las formas crustacívoras. La incisura capitis es más ancha en los pingüinos piscívoros, la disposición de los landmarks en esta zona también indicaría que es más profunda para las formas piscívoras que para las crustacívoras. Esta incisura actúa como polea y como sitio de inserción para el $m$. subscapularis. En cuanto a la diáfisis, el análisis indica que las formas piscívoras presentan una diáfisis angosta, con una leve tendencia a curvarse medialmente, y un angulus preaxialis poco desarrollado. Las formas crustacívoras presentan un ancho de diáfisis mayor con un angulus preaxialis más desarrollado y una tendencia a curvarse lateralmente. En cuanto a la epífisis distal, el condylus dorsalis es más alto en las formas piscívoras que en las crustacívoras. La articulación es más perpendicular a la diáfisis en los crustacívoros que en los piscívoros.

\footnotetext{
${ }^{4}$ El CV 2 está invertido para el CVA de los residuales.
} 
a

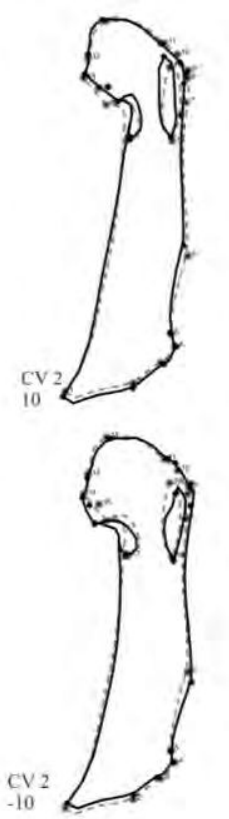

b

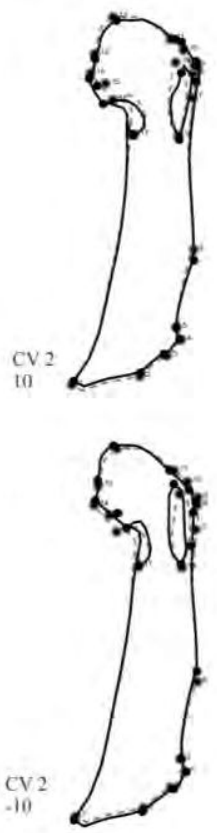

b
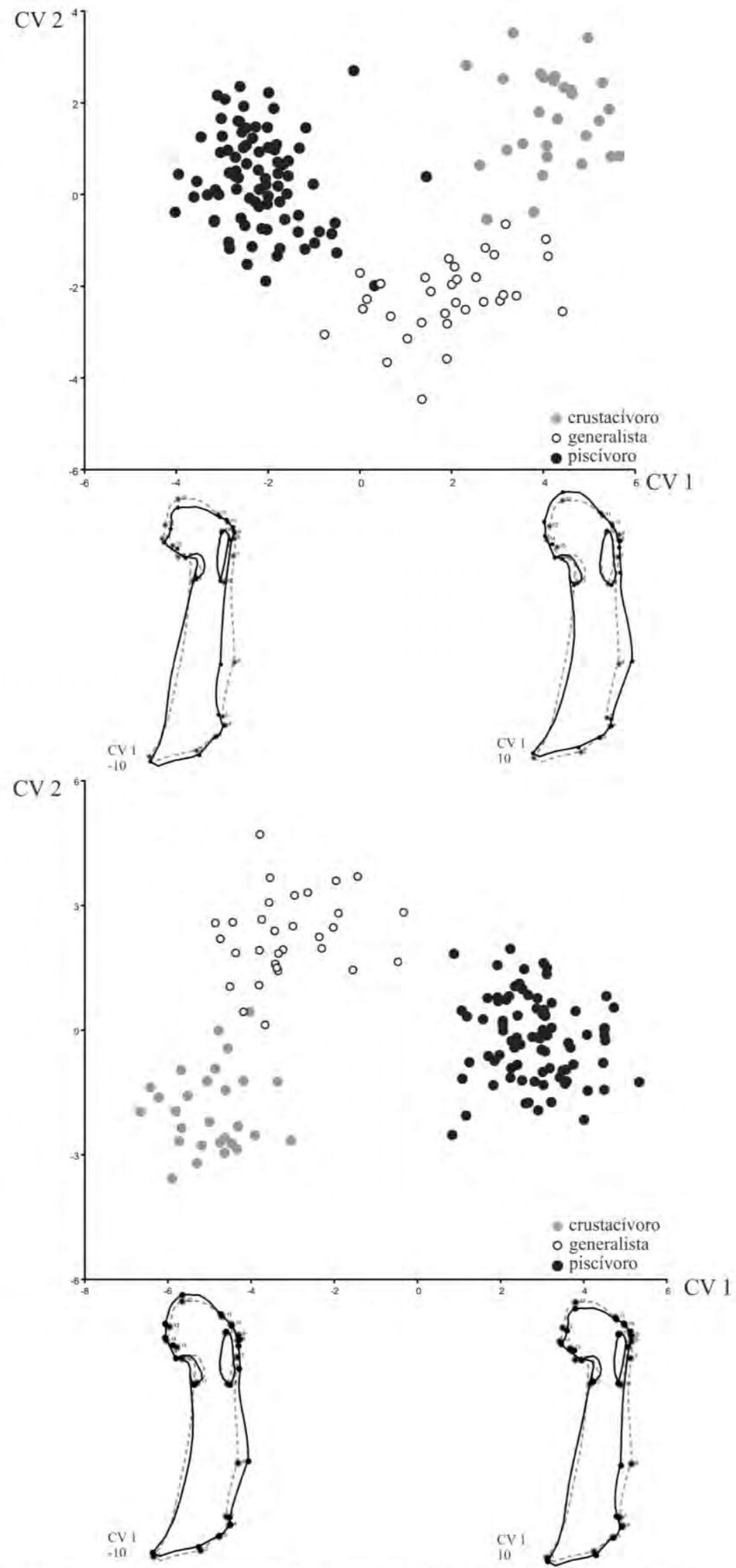

Figura 11 Gráficos de dispersión de los primeros dos CV de la configuración del húmero en vista ventral, con el cambio de forma para los valores magnificados de cada CV para $\mathbf{a}$, datos originales; $\mathbf{b}$, datos corregidos. Las líneas grises punteadas representan la forma promedio mientras que las negras representan los valores extremos de cada PC. 
En el CV2, la variación de forma también es similar para los dos análisis (Fig. 11). La mayor variación se encontraría a la altura del angulus preaxialis, el cual es más cercano a la epífisis distal en las formas generalistas. Esta condición también se observó en el análisis de la vista caudal del húmero. Además, tanto la cicatriz de inserción del $\mathrm{m}$. deltoides minor, como la del m. propatagialis están más alejadas de la articulación con la cintura escapular en las formas especialistas.

\section{DISCUSIÓN INTEGRAL DE LOS ANÁLISIS DEL HÚMERO}

Tanto el MANOVA como el CVA nos confirman que las morfologías de las categorías dietarias presentan diferencias significativas y pueden ser usadas para describir la variación de forma en los grupos. Encontramos, entonces, que las morfologías relacionadas a un hábito de vida piscívoro presentan formas más gráciles, característica que coincide con la condición observada en el coracoides (ver Resultados: análisis del coracoides, a continuación). En el húmero, la diáfisis es recta y angosta, mientras que las formas crustacívoras poseen morfologías más robustas. Formas gráciles permitirían una más ágil maniobrabilidad a grandes velocidades y ante presas rápidas.

El tuberculum dorsale (sitio de inserción del $m$. deltoides minor) está situado más cercano al caput humeri en las formas piscívoras que en las crustacívoras. Esta configuración reduce el brazo de palanca de entrada para este músculo, por lo que fuerzas de igual magnitud generarían fuerzas resultantes menores para la condición de brazo de palanca corto, de todas maneras este músculo como también el $m$. deltoides major se encuentran muy reducidos en pingüinos. También en las formas piscívoras, la fossa tricipitalis secundaria estaría más cerca a la inserción del m. supracoracoideus, esta fosa es lugar de inserción del ligamento scapulohumeral dorsal (Bannasch, 1986b). Esta configuración podría resultar más estable teniendo un origen más anterior del ligamento que limite el movimiento anterior y la pronación de la cabeza del húmero. En las formas piscívoras, la inserción del $\mathrm{m}$. supracoracoides se encuentra paralela a la diáfisis y la cicatriz es además más corta que en las formas crustacívoras. En estos últimos, las crestas trocleares más protruidas hacen que los huesos sesamoideos y los tendones de los m. triceps scapularis y humeralis ventralis queden más alejados del cuerpo del hueso. La situación contraria se encuentra en los piscívoros, que tendrían tanto los tendones como lo huesos sesamoideos más integrados al húmero, haciendo 
más estable la articulación estilopodio-zeugopodio. El extensor metacarpi ulnaris, el extensor digitorum communis, y el supinator, que también estabilizan esta articulación al empujar el agua, pero en el plano caudo-craneal, presentan una disposición diferente. Las estrategias morfofuncionales para estabilizar cráneocaudalmente la articulación estilopodio-zeugopodio son estructuralmente diferentes en Pygoscelis y Spheniscus. En las formas piscívoras como Spheniscus, el extensor metacarpi ulnaris, y el extensor digitorum communis, en menor medida, están más alejados de la epífisis distal. Esto indica que los tendones que allí se originan poseen una mayor longitud con respecto a los de las formas crustacívoras. En Pygoscelis y otros crustacívoros, en cambio, los tendones son más cortos ya que se encuentran más cercanos al extremo distal del húmero. Estos tendones se encuentran además más distanciados entre sí que en los piscívoros, ya que la epífisis distal del húmero es proporcionalmente más ancha en los crustacívoros.

Si bien el cóndilo dorsal es el único cóndilo que fue representado por un landmark, observamos en los análisis que en las formas piscívoras está más elevado proximalmente con respecto a los demás elementos distales. Esta condición podría indicar una articulación que forme un ángulo más agudo con respecto a la diáfisis en las formas piscívoras (esto es congruente con las observaciones a ojo desnudo) que podría traducirse en un estado de flexión del ala mayor en las formas piscívoras.

En las formas generalistas, las cicatrices de inserción de algunos músculos, tales como el $m$. supracoracoideus o el $m$. coracobrachialis caudalis, son más extensas. Por otro lado, la cicatriz del $m$. latissimus dorsi estaría más alejada de la cabeza del húmero, aumentando el brazo de palanca. 


\section{RESULTADOS: ANÁLISIS CORACOIDES}

\section{CONFIGURACIÓN DEL CORACOIDES EN VISTA ESTERNAL}

\section{Alometría}

La regresión entre coordenadas de procrustes y el logaritmo del tamaño del centroide dio como resultado que un 4,2689\% de la variación de la forma se encuentra predicho por el tamaño. Las permutaciones arrojaron un valor significativo $(\mathrm{p}=0,0002)$.

Aunque bajo, se observa un valor significativo del efecto alométrico en la variación de forma. Por consiguiente, se realizaron los análisis de componentes principales (PCA) con las coordenadas de procrustes originales y con los residuos de la regresión para explorar las diferencias entre estos resultados.

\section{Análisis de componentes principales}

Se realizó un PCA exploratorio con los datos crudos y residuales. La Tabla muestra los porcentajes explicados de la variación para los primeros tres componentes.

Tabla Porcentajes de variación explicada por los primeros tres componentes principales, para el PCA del coracoides en vista esternal del conjunto de datos originales y corregidos.

\begin{tabular}{|c|c|c|}
\hline & $\%$ Variación-datos originales & \% Variación-datos corregidos \\
\hline $\mathrm{PC} 1$ & , & , \\
\hline PC2 & , & , \\
\hline PC3 & , & , \\
\hline
\end{tabular}


$\mathbf{a}$
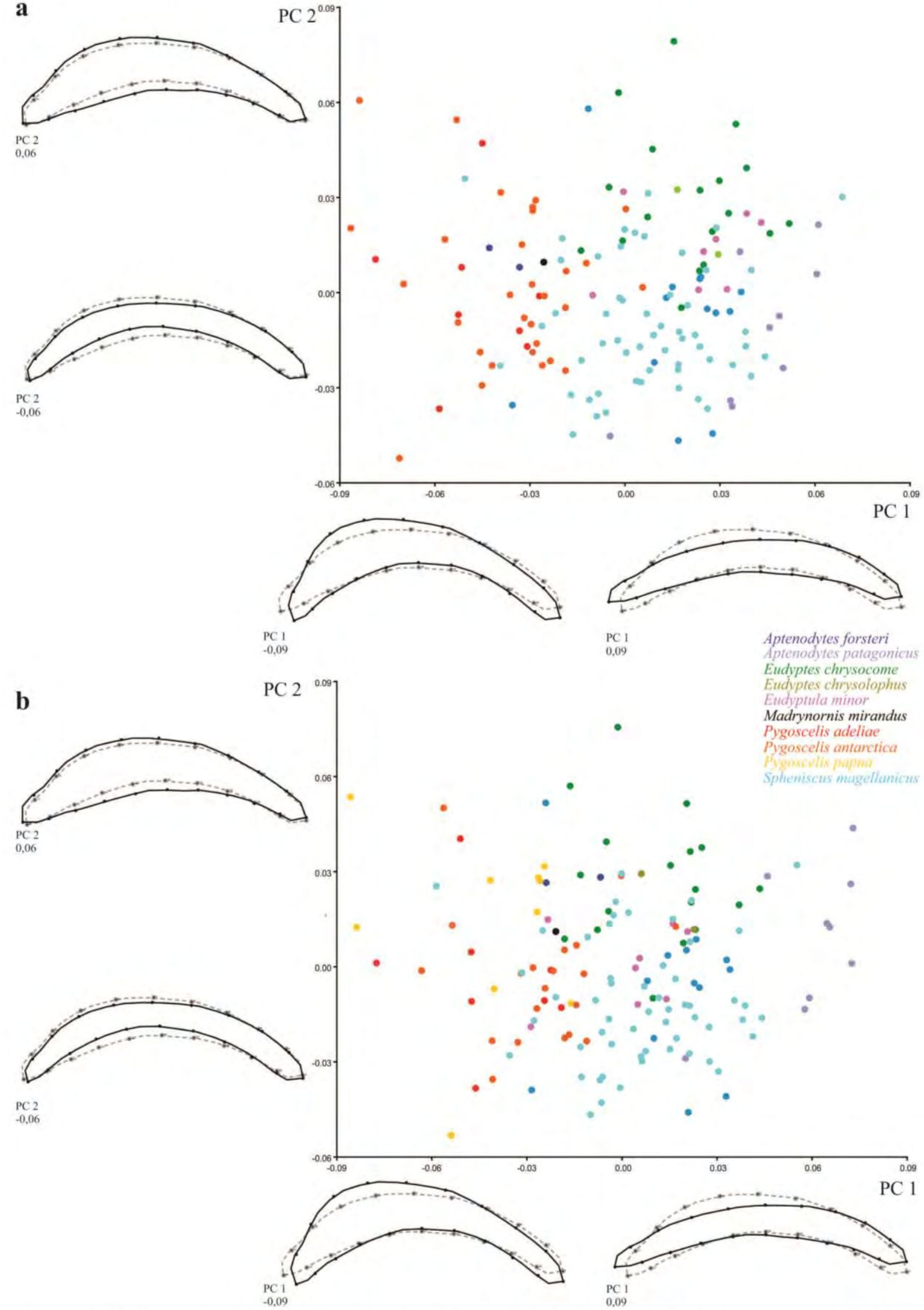

Figura 12 Análisis de componentes principales de la configuración del coracoides en vista esternal. Gráficos de dispersión de los primeros dos PC con el cambio de forma para los valores extremos de cada PC para a, datos crudos; $\mathbf{b}$, valores residuales. Las líneas grises punteadas representan la forma promedio mientras que las negras representan los valores extremos de cada PC. 
El primer componente principal distribuye a los individuos de Pygoscelis y Aptenodytes forsteri hacia los valores negativos, mientras que hacia los valores positivos nos encontramos con especímenes de Spheniscus, Eudyptes, Eudyptula y Aptenodytes patagonicus (Fig. 12). Spheniscus queda más cerca al grupo de Pygoscelis, mientras que Aptenodytes patagonicus queda ubicado hacia los valores positivos más extremos. Madrynornis mirandus se encuentra en el límite entre Spheniscus y Pygoscelis. El segundo PC nos separa a Eudyptes hacia los valores positivos más extremos, a Eudyptula en la mitad del rango y Aptenodytes, Spheniscus y Pygoscelis hacia los valores negativos (Fig. 12). Si bien la mayor cantidad de especímenes de Pygoscelis tiende a los valores negativos, su rango es más amplio y algunos individuos se encuentran en el mismo rango que Eudyptes para este componente. Madrynornis mirandus se ubica hacia los valores neutros, por debajo de Eudyptes. El tercer componente ubica tanto a Pygoscelis como a Spheniscus en un amplio rango a lo largo del eje, y deja a Aptenodytes y Eudyptula más cercano a los valores negativos, y a Eudyptes tendiendo a los valores positivos más extremos.

Cuando eliminamos la variación vinculada con el efecto alométrico, el gráfico de dispersión con los primeros dos componentes principales presenta algunas sutiles variaciones. En el primer componente, los especímenes de Aptenodytes forsteri aparecen más cerca de los individuos de Spheniscus ubicados hacia los valores más negativos, y Aptenodytes patagonicus se agrupa hacia los valores positivos más extremos alejándose aún más de Spheniscus y de los demás especímenes en general (Fig. 12). El resto de los grupos no varía su posición, al igual que Madrynornis. El segundo componente principal, por su parte, aleja a Eudyptula del grupo de Eudyptes, al mismo tiempo Aptenodytes patagonicus se aproxima a Eudyptes.

La variación de forma, tanto para el PCA realizado a partir de las coordenadas de procrustes como a partir de los residuales de la regresión, fue similar para los primeros componentes. La mayor variación de forma se registró para los landmarks 1 y 2 (los extremos de la facies articularis sternalis) y semilandmarks 7, 8 y 9 (la porción más medial del margen ventral de mayor curvatura). Para los valores positivos más extremos, podemos ver una forma general de la articulación que resulta homogénea en altura y poco curvada. La situación es contraria para los valores negativos, en los cuales se encuentra el grupo de Pygoscelis, para los cuales el primer componente explica una variación tendiente a formas más robustas en la sección centro-medial de la articulación, con una curvatura pronunciada (Fig. 12). Para el 
segundo componente, los valores positivos extremos, donde se localizan los especímenes de Eudyptes, observamos un engrosamiento del cuerpo de la articulación.

A modo de resumen, podemos decir entonces que el primer componente nos separa en principio las especies que se alimentan más específicamente de crustáceos (Pygoscelis, Aptenodytes forsteri), por un lado, y aquellas más piscívoras por el otro (Spheniscus, Eudyptula, Aptenodytes patagonicus). Si bien Eudyptes (pingüino de dieta generalista) se acerca a este segundo grupo, el segundo PC lo separa notablemente de todos los demás grupos que son más especialistas. Acompañado de esto, la variación de forma indica, para el primer componente, que los valores más cercanos a Pygoscelis presentan formas más robustas, con un arqueamiento más pronunciado de la facies articularis sternalis, y un engrosamiento de la superficie más medial, mientras que los valores positivos más extremos (más cercanos a Spheniscus y Aptenodytes patagonica) poseen formas que incluyen una altura constante y una menor curvatura de la facies articularis sternalis. En cuanto al gráfico de dispersión y al posicionamiento de los diferentes individuos en ambos PCA, notamos que las mayores diferencias se observan para los individuos de las especies de mayor y menor porte como lo son Aptenodytes forsteri y A. patagonicus por un lado, y Eudyptula por el otro.

\section{Categorías de hábitos alimenticios: Análisis multivariante de la varianza}

Al realizar el MANOVA de los 10 primeros componentes principales, se encontró que el Wilks' $\lambda$ fue bajo y significativo (Tabla ), las distancias de Mahalanobis ubicaron más cercanos a los grupos piscívoro-generalistas, y a los piscívoros y curstacívoros como los más lejanos entre sí (Tabla ).

Tabla Análisis multivariante de la varianza (MANOVA) del coracoides en vista esternal, valores de Wilks' $\lambda$, y distancias de Mahalanobis (D) entre grupos con sus correspondientes valores de $p$ asociados. Resultados para el conjunto de datos originales y corregidos.

\begin{tabular}{|c|c|c|}
\hline & Datos originales & Datos corregidos \\
\hline Wilks' $\lambda$ & , & , \\
\hline $\mathrm{p}$ & , & , \\
\hline
\end{tabular}




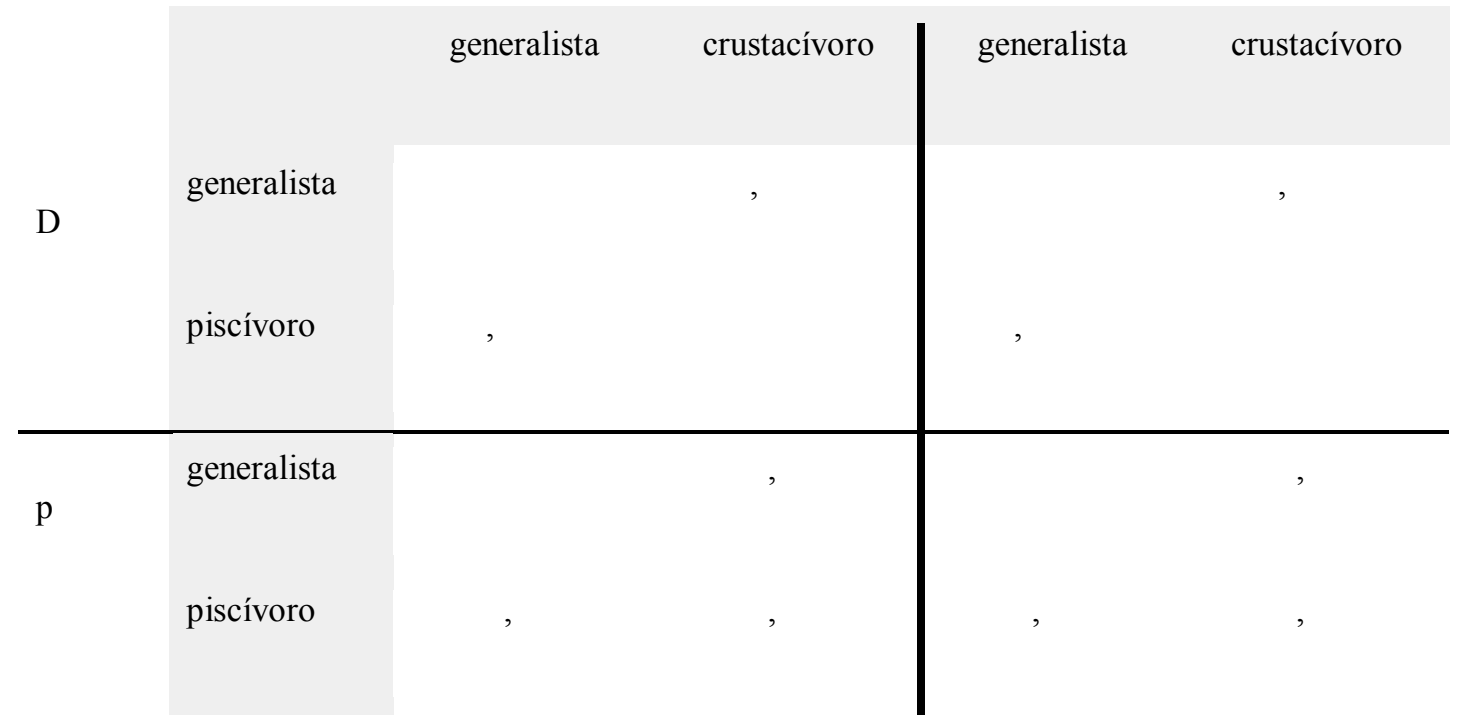

\section{Categorías de hábitos alimenticios: Análisis de variación canónica}

Se realizaron dos análisis de variación canónica (CVA) para maximizar las diferencias entre los grupos de la categoría dieta, uno para los datos crudos, y otros con los residuales de la regresión. Como resultado se obtuvo que el primer eje ${ }^{5}$ de variación canónica (CV) explica el 69,835\% (62,963\% para el CVA con los residuales) de la variación total y es el que nos separa a los crustacívoros (Pygoscelis antarctica, $P$. adeliae), y generalistas (Pygoscelis papua, Aptenodytes forsteri, Eudyptes chrysocome, E. chrysoplophus) de los piscívoros (Spheniscus magellanicus, Aptenodytes patagonicus, Eudyptula minor). El segundo CV (30,165\% para los datos originales, 37,037\% para los residuales) separa a los grupos más generalistas de los especialistas (crustacívoros y piscívoros).

En ambos análisis las distancias de Mahalanobis ubicaron como más cercano al grupo piscívoro del generalista, y como más lejano a los grupos crustacívoros y piscívoros, quedando los grupos de los crustacívoros y los generalistas a una distancia intermedia (Tabla ) .

\footnotetext{
${ }^{5}$ El CV 2 está invertido para el CVA de los residuales.
} 
Tabla Análisis de variación canónica. (CVA) del coracoides en vista esternal, porcentajes de variación para los dos primeros ejes de variación canónica, y distancias de Mahalanobis (D ) entre grupos con sus correspondientes valores de $\mathrm{p}$ asociados. Resultados para el conjunto de datos originales y corregidos.

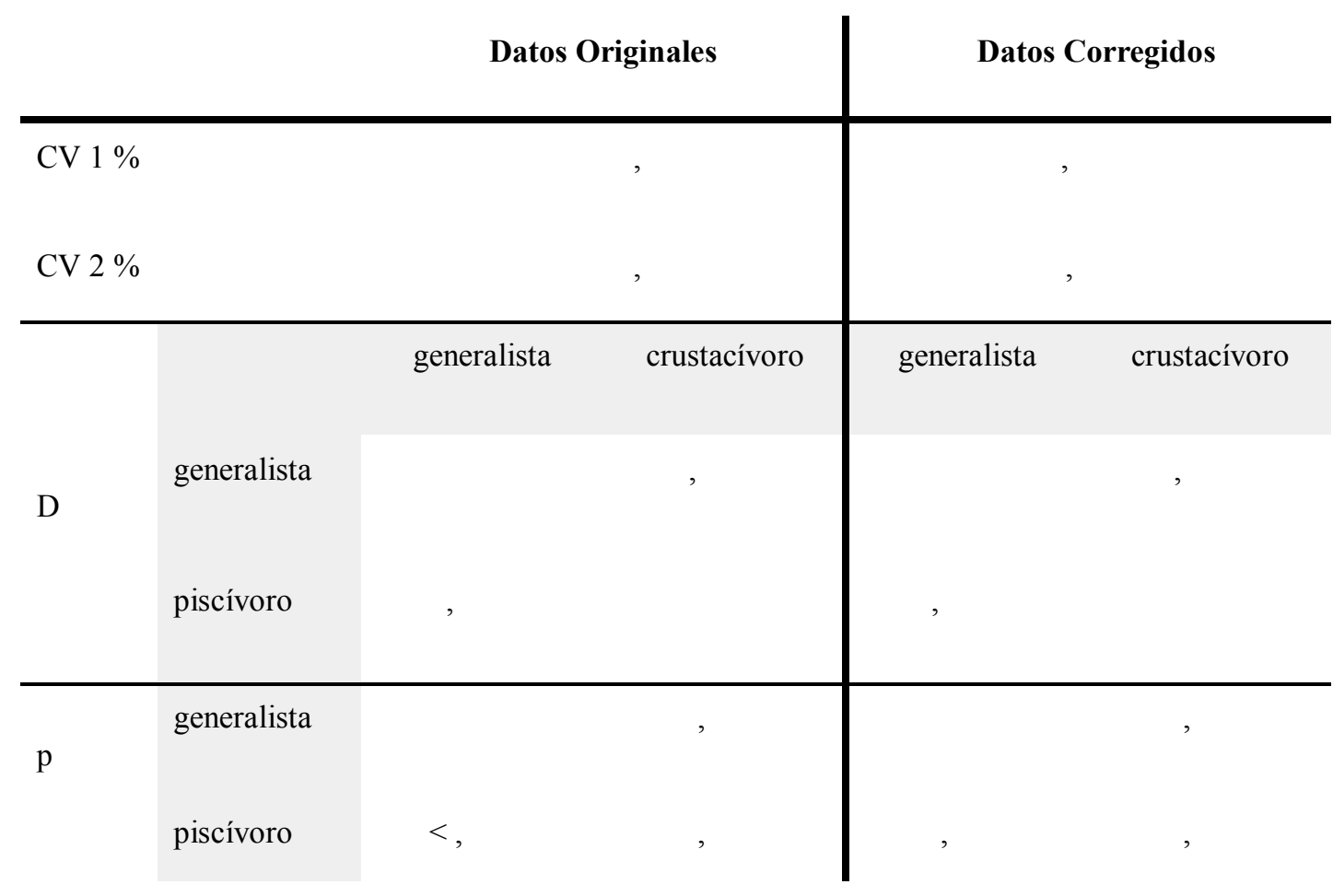

La variación de forma para la primera variante canónica, que nos separa piscívoros de crustacívoros, describe para los piscívoros una articulación que tiende a ser plana, con un ancho dorsoventral homogéneo en toda su extensión aunque un tanto mayor hacia la porción lateral (Fig. 13). Por otro lado, las formas crustacívoras presentan una marcada curvatura, con una protuberancia en la línea ventromedial, que conlleva un ensanchamiento de esa porción de la articulación. Para el segundo eje (el cual separa los grupos especialistas de los generalistas), la variación de forma está dada principalmente por el ancho dorsoventral de la articulación en toda su extensión, y el grado de su curvatura mediolateral. Las formas generalistas tenderían a poseer un grado de curvatura menor y un grosor mayor de la articulación. 


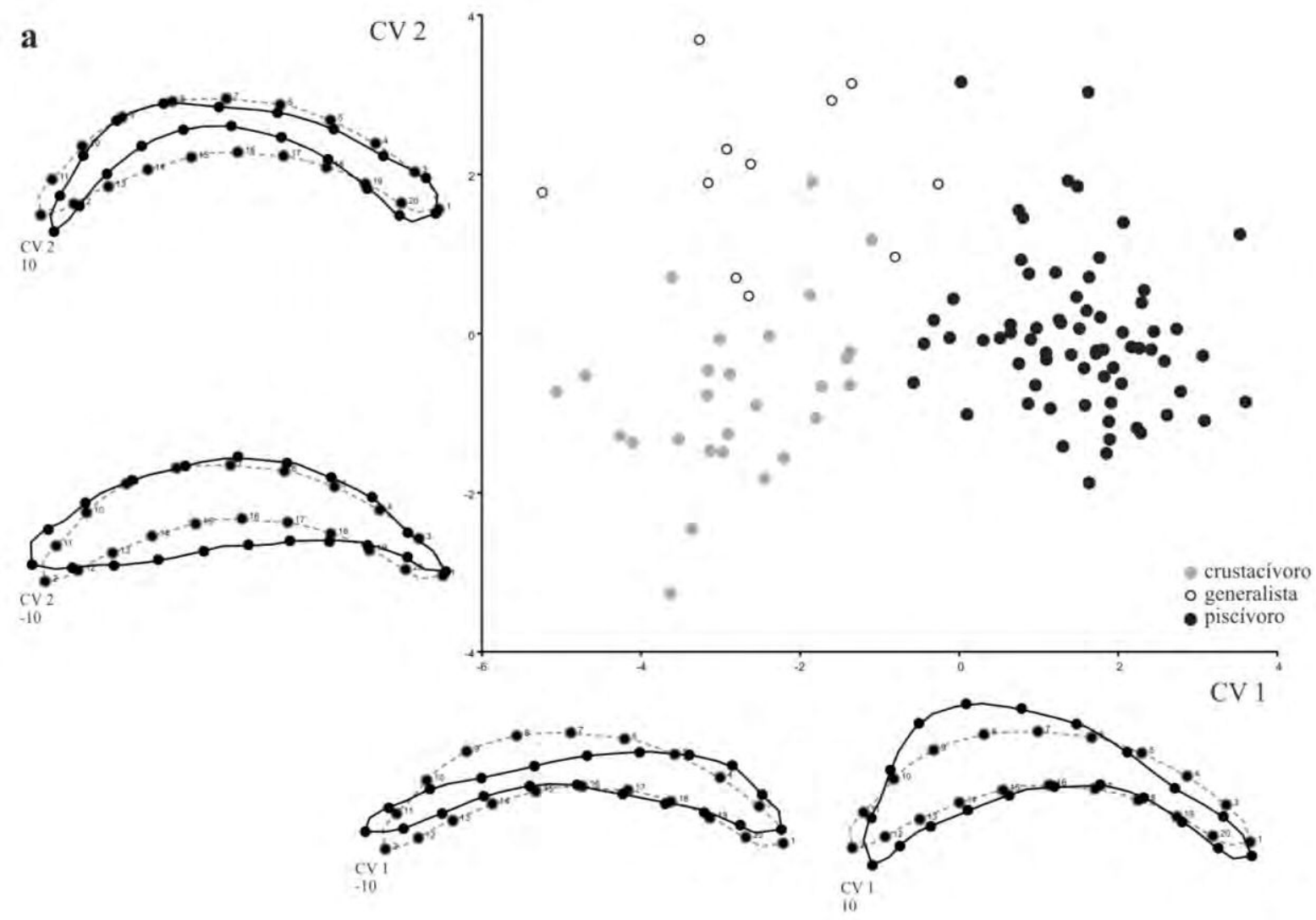

b
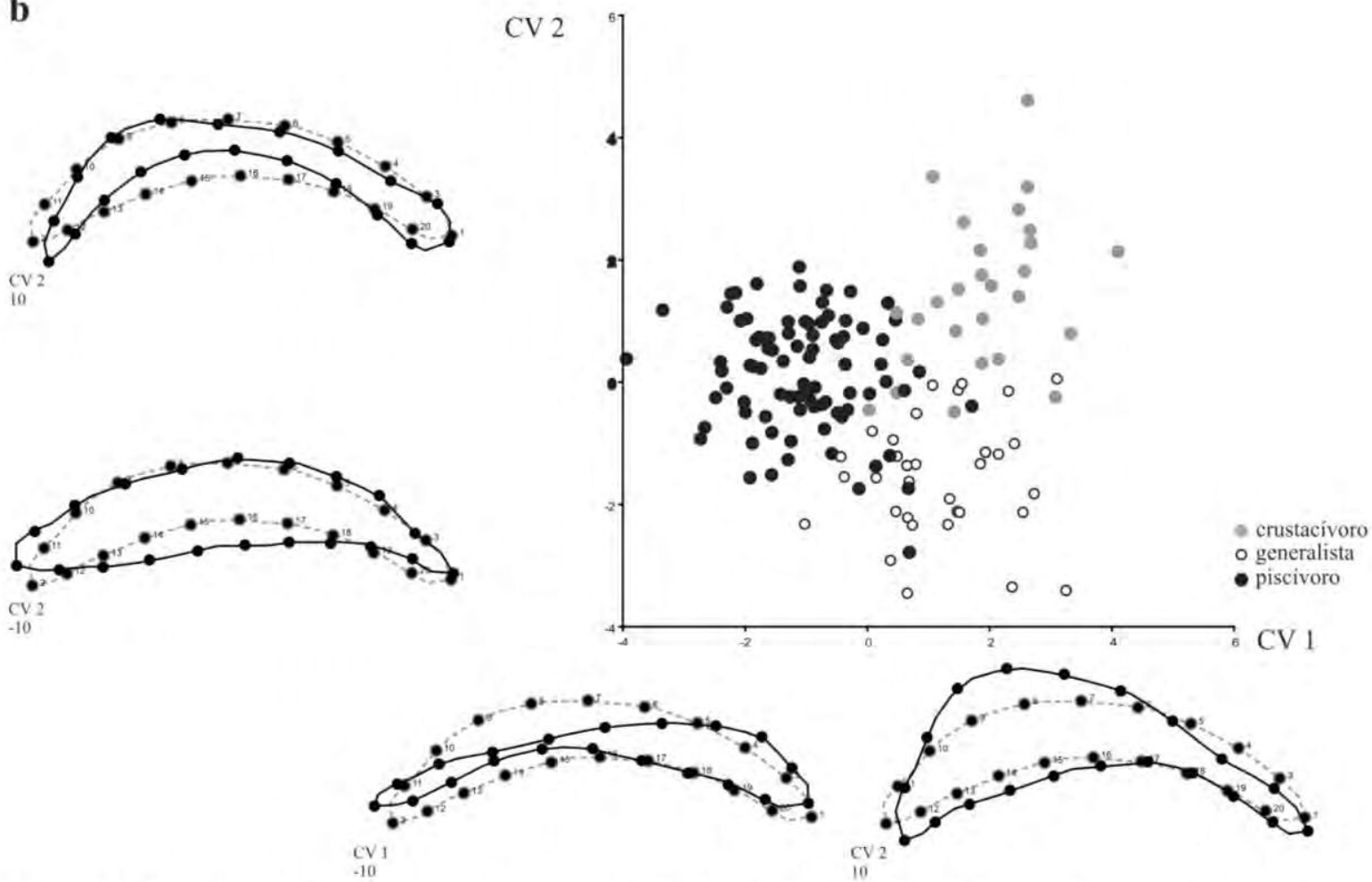

Figura 13 Gráficos de dispersión de los primeros dos CV de la configuración del coracoides en vista esternal, con el cambio de forma para los valores magnificados de cada $\mathrm{CV}$ para a, datos originales; $\mathbf{b}$, datos corregidos. Las líneas grises representan la forma promedio mientras que las negras representan los valores extremos de cada PC. 


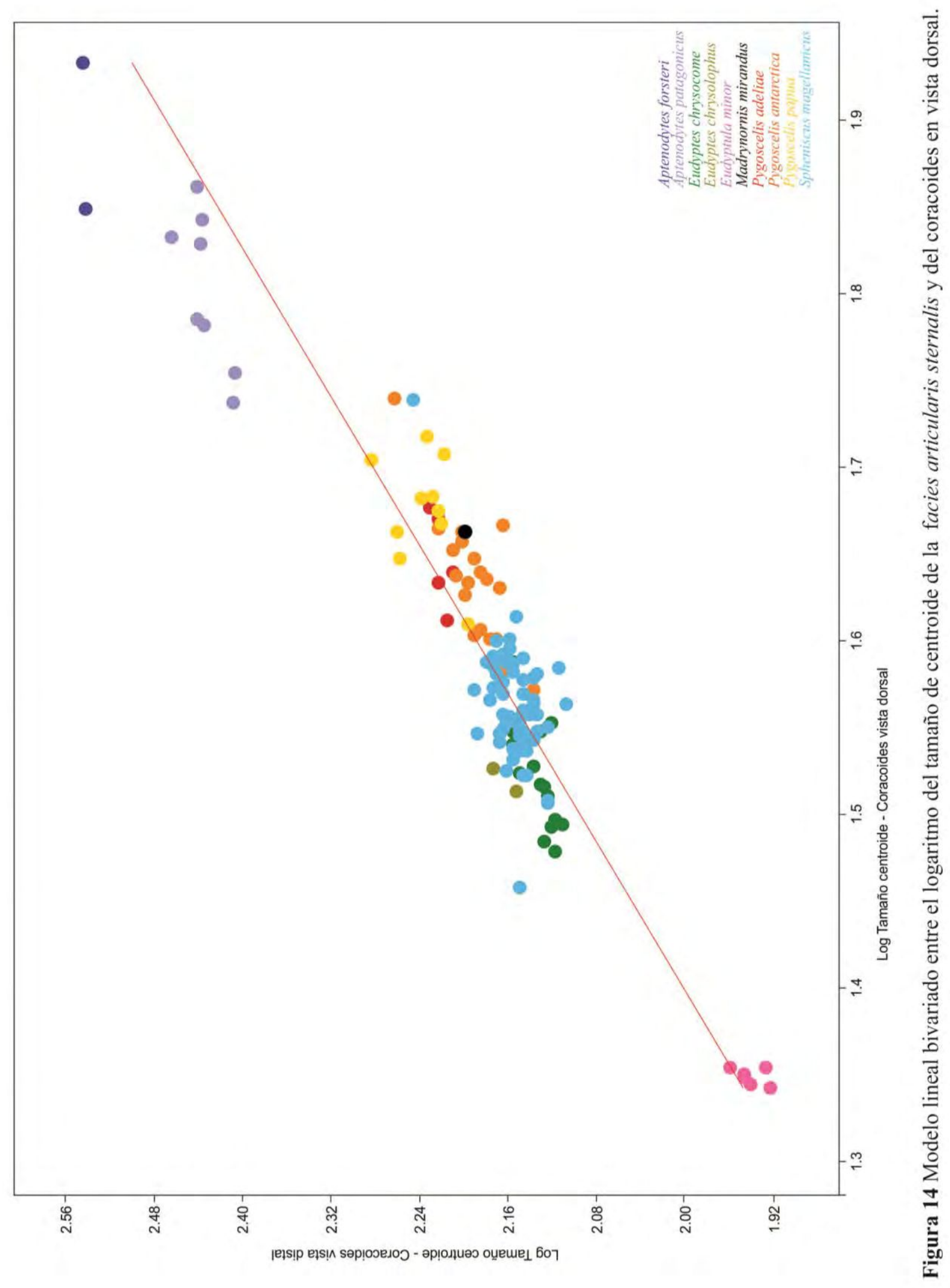




\section{Variación de Tamaño de la Facies articularis sternalis}

La superficie de articulación del coracoides es el punto de anclaje que posee todo el complejo ala/cintura escapular al esternón y por lo tanto al resto del cuerpo. Por esto, su forma y tamaño relativo al cuerpo resultan muy informativos a la hora de analizar las propiedades biomecánicas de la cintura escapular. Una morfología más estable y un tamaño relativo mayor o menor puede brindarnos información acerca del rol específico de la facies articularis sternalis.

La regresión $(r=0,87822, p<0,001)$ entre el logaritmo del tamaño del centroide de la facies y el logaritmo del tamaño del coracoides total (del tamaño del centroide de la configuración de landmarks del coracoides en vista dorsal) muestra que Eudyptes y en menor medida Aptenodytes y Spheniscus presentan un desarrollo relativo menor de la facies articularis sternalis mientras que Eudyptula, Pygoscelis y Madrynornis mirandus presentan un tamaño relativo mayor (Fig. 14).

\section{CONFIGURACIÓN DEL CORACOIDES EN VISTA DORSAL}

\section{Alometría}

La regresión entre las coordenadas de Procrustes y el logaritmo del tamaño del centroide dio como resultado que el tamaño explicaría un 4,4070\% de la variación total de la forma ( $\mathrm{p}<0,0001)$. Dado que esto sugiere que existe un efecto alométrico en la variación de forma, realizamos un PCA exploratorio, teniendo en cuenta tanto los datos originales como los resultados de los residuos de la regresión.

\section{Análisis de componentes principales}

En el gráfico de dispersión del PCA, a lo largo del PC1 (Ver Tabla con porcentajes de variación para los primeros tres PC), los especímenes de Pygoscelis se distribuyen desde los valores neutros hacia los positivos, mientras que hacia los negativos más extremos encontramos a Spheniscus, Eudyptula, Eudyptes y Aptenodytes. Madrynornis mirandus se encuentra incluido junto con los ejemplares de Pygoscelis y más cercano a los valores neutros. Al mismo tiempo, el PC2 separa a Aptenodytes hacia los valores positivos, mientras 
que hacia los neutros encontramos a Eudyptes y Eudyptula. Además, Eudyptula se encuentra cercano a Spheniscus, que se ubica hacia los valores negativos extremos. Los PCA de los valores originales y corregidos presentan una dispersión similar de los puntos en el gráfíco.

Tabla Porcentajes de variación explicada por los primeros tres componentes principales, para el PCA del coracoides en vista dorsal del conjunto de datos originales y corregidos.

\begin{tabular}{l|l|l}
\hline \% Variación-Datos originales & \% Variación- Datos corregidos \\
\hline PC1 &, \\
\hline PC2 &, \\
\hline PC3 &, \\
\hline
\end{tabular}

La variación de forma explicada por los primeros dos componentes no varía entre los PCA de datos originales y corregidos, por lo que se describen juntos. Para los valores positivos del PC1, que es donde se agrupan los individuos de Pygoscelis, encontramos coracoides más robustos, mientras que hacia los valores negativos la morfología general del cuerpo tiende a ser más grácil. Proximalmente, el extremo en forma de gancho del processus acrocoracoideus se encuentra ubicado en el plano longitudinal en aquellos especímenes ubicados hacia el extremo positivo del gráfico, mientras que para los valores negativos, este carácter se encuentra rotado. Hacia el margen medial del coracoides, el processus procoracoideus se ubica protruido proximalmente para los valores negativos (Spheniscus, Aptenodytes, Eudyptes y Eudyptula) con respecto a los valores positivos. La facies articularis sternalis es levemente más cóncava en los especímenes que se ubican hacia los valores negativos del eje. El proc. lateralis está más extendido lateroproximalmente en los especímenes que se sitúan hacia los valores positivos, al mismo tiempo que los landmarks ubicados en el margen lateral se alejan lateralmente en concordancia con una mayor robustez en los especímenes ubicados para estos valores (Pygoscelis). Retomando los datos acerca del extremo proximal del coracoides, puede destacarse que la cotyla scapularis varía su disposición siendo más cuadrangular y distal al processus acrocoracoideus hacia los valores positivos del eje, mientras que es más elongada hacia los valores negativos. 
a

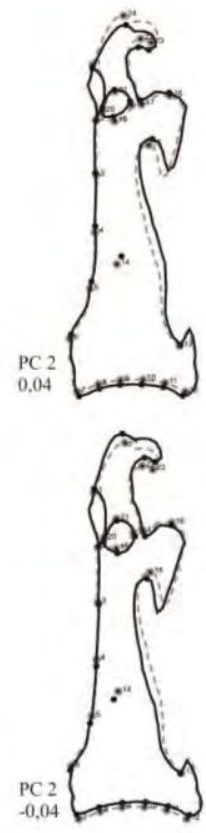

b

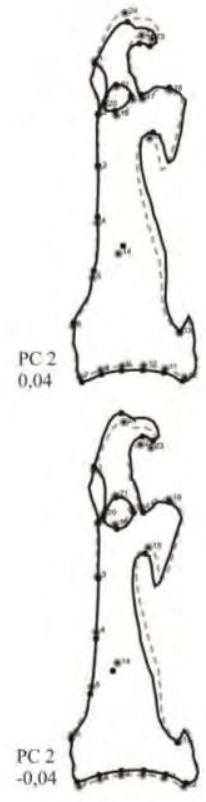

PC 1

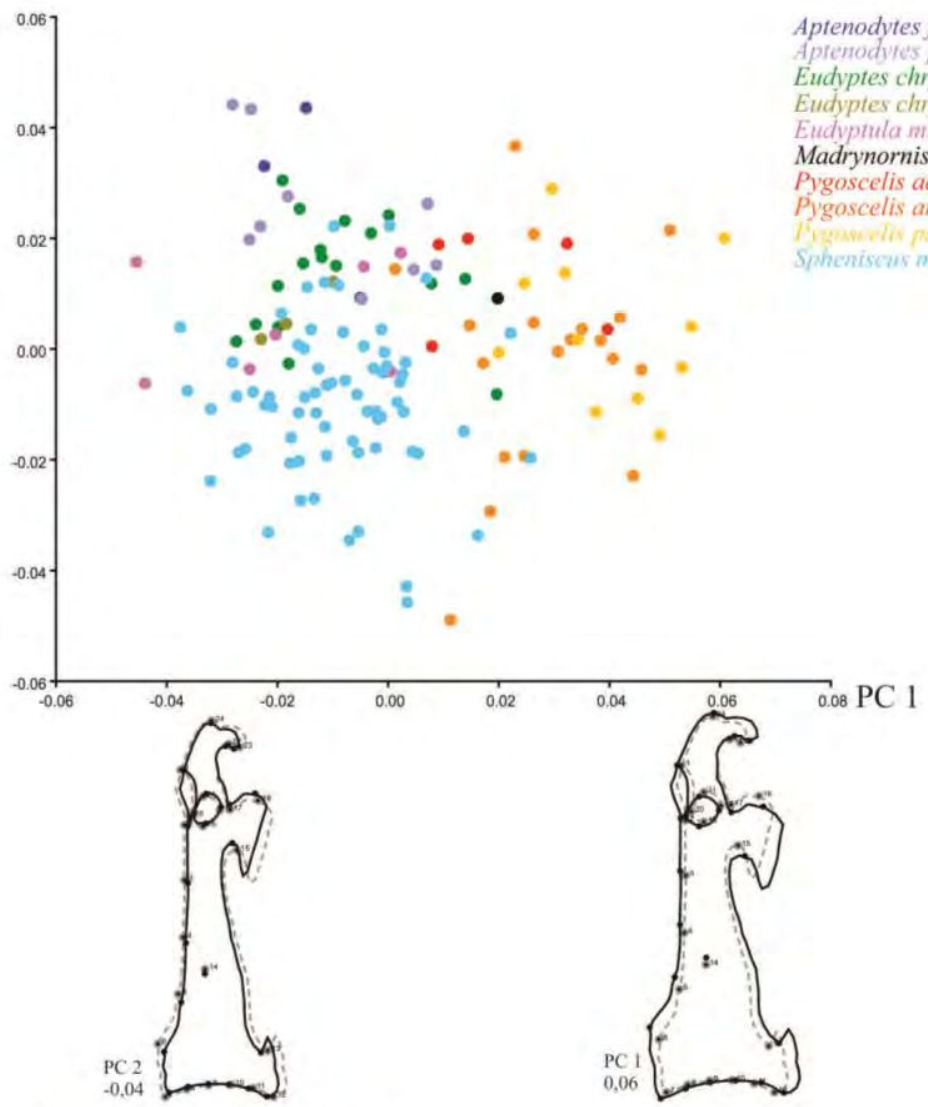

PC 2

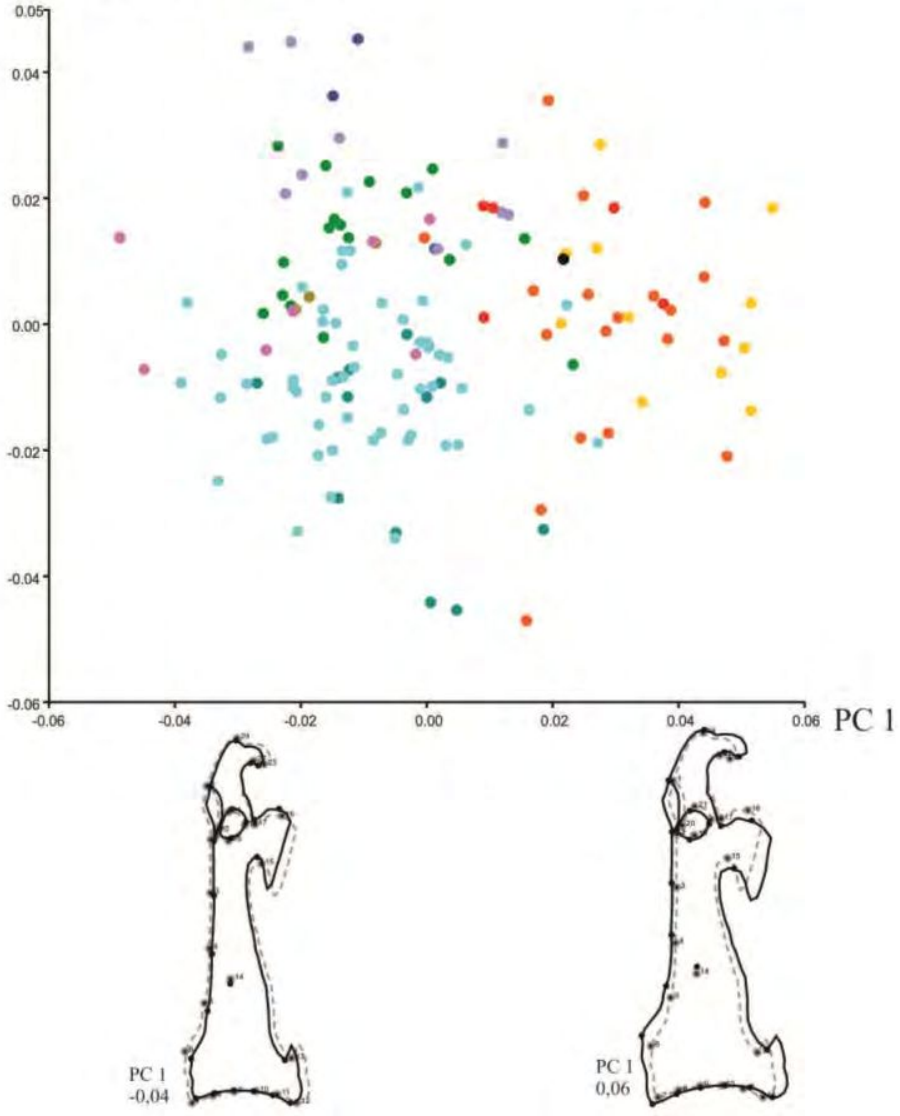

Figura 15 Análisis de componentes principales de la configuración del coracoides en vista dorsal. Gráficos de dispersión de los primeros dos PC con el cambio de forma para los valores extremos de cada PC para a, datos originales; b, datos corregidos. Las líneas grises punteadas representan la forma promedio mientras que las negras, los valores extremos de cada PC. 
Para el segundo componente (PC2), la mayor variación en forma se encuentra en las regiones proximales y distales del coracoides. Hacia los valores positivos se ubica Aptenodytes, en el que los landmarks distales se desplazan alejándose del resto de la configuración, mientras que en el extremo proximal el processus acrocoracoideus se desplaza acortándose la distancia respecto al resto de los landmarks.

En resumen, las distribuciones de ambos PCA fueron similares así también como el cambio de forma explicada por los componentes principales. Se halló que las formas cercanas a Spheniscus son más gráciles y poseen una cotyla scapularis más extendida próximodistalmente, mientras que Pygoscelis presenta una morfología robusta, con una cotyla scapularis más cuadrangular.

\section{Categorías de hábitos alimenticios: Análisis multivariante de la varianza}

Al realizar el MANOVA (10CP) el Wilk's lambda resultó bajo y significativo para ambos análisis aunque el MANOVA de datos residuales resultó más alto. Por tal motivo, rechazamos la hipótesis nula acerca de que las diferencias entre grupos podrían deberse al azar. Las distancias de Mahalanobis resultaron menores para los grupos crustacívorogeneralista en ambos análisis. Para el análisis con datos originales la mayor distancia entre grupos resultó ser entre los piscívoros y los generalistas, mientras que para el MANOVA con datos corregidos resultó ser entre crustacívoros y piscívoros (Tabla ).

Tabla Análisis multivariante de la varianza (MANOVA) del coracoides en vista dorsal, valores de Wilks' $\lambda, y$ distancias de Mahalanobis (D) entre grupos con sus correspondientes valores de $p$ asociados. Resultados para el conjunto de datos originales, y corregidos.

\begin{tabular}{ll|l}
\multicolumn{2}{c|}{ Originales } & \multicolumn{2}{c}{ Corregidos } \\
\hline Wilks' $\lambda$ &, & \\
$\mathrm{p}$ &, & \\
\hline generalista crustacívoro & generalista crustacívoro
\end{tabular}




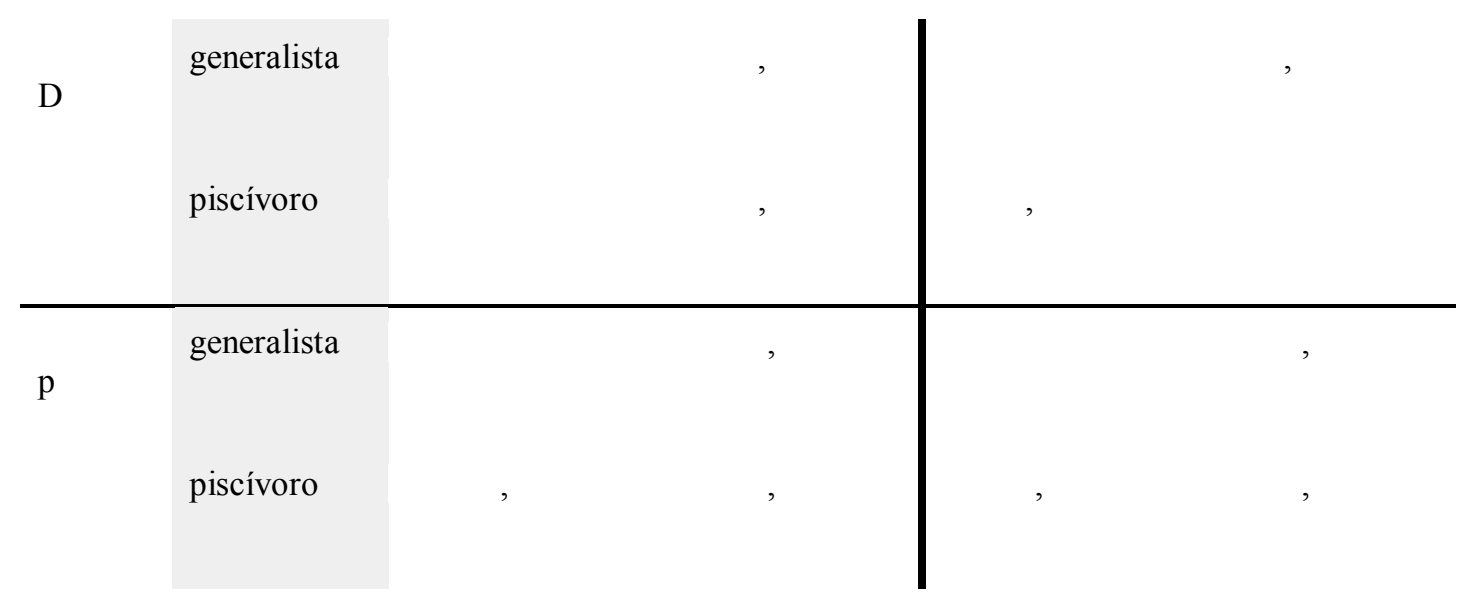

\section{Categorías de hábitos alimenticios: Categoría de análisis de variación canónica}

El CV1 explica más del $80 \%$ de la variación total (Ver Tabla ) y es el que nos separa a los piscívoros (Aptenodyptes patagonicus, Spheniscus magellanicus) de los crustacívoros y generalistas (Aptenodytes forsteri, Eudyptes y Pygoscelis papua). Complementariamente, el CV2 separa a los grupos más especialistas (crustacívoros y piscívoros) de los generalistas.

Tabla Análisis de variación canónica (CVA) del coracoides en vista dorsal, porcentajes de variación para los dos primeros ejes de variación canónica, y distancias de Mahalanobis (D) entre grupos con sus correspondientes valores de $\mathrm{p}$ asociados. Resultados para el conjunto de datos originales, y corregidos.

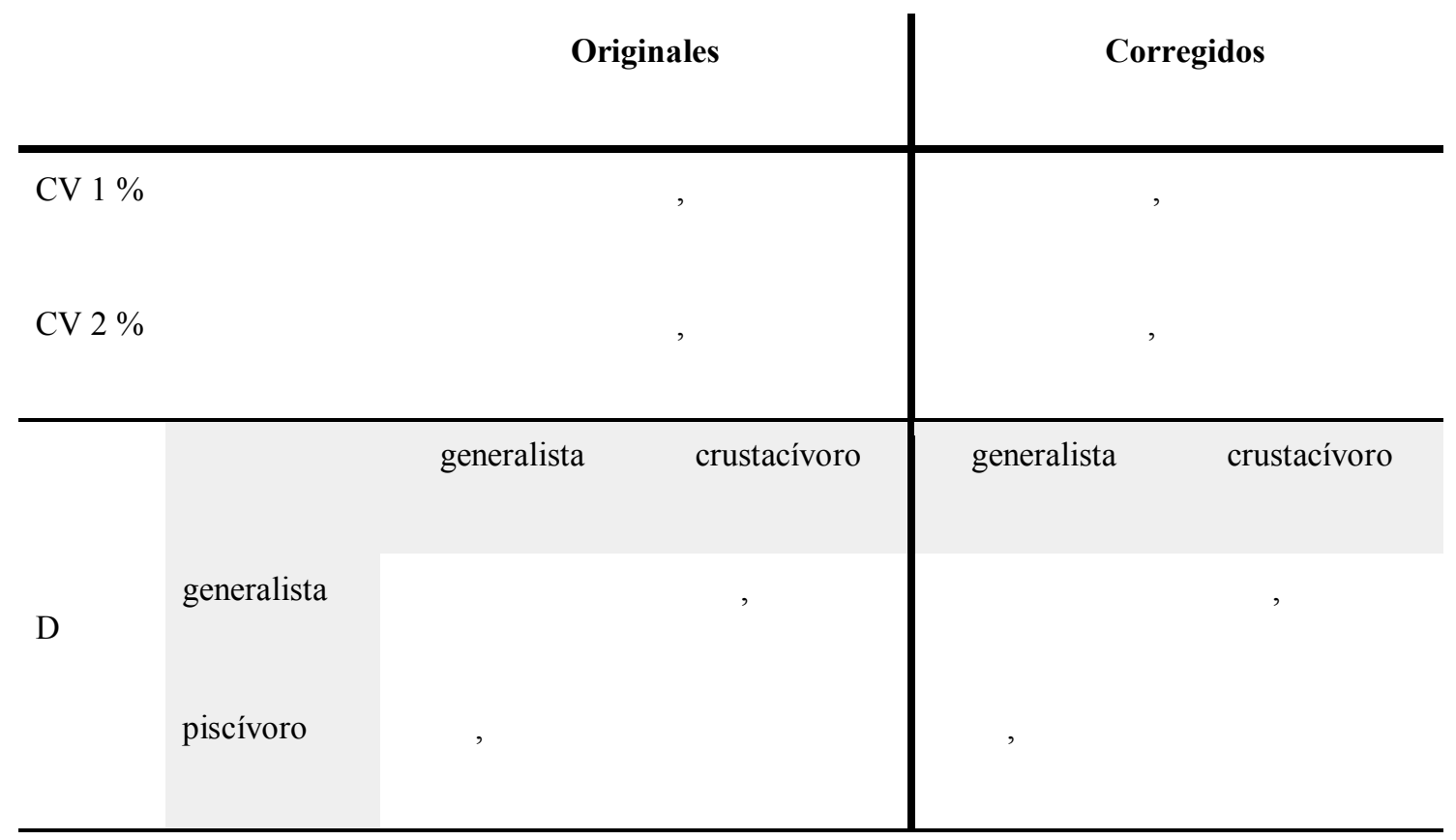




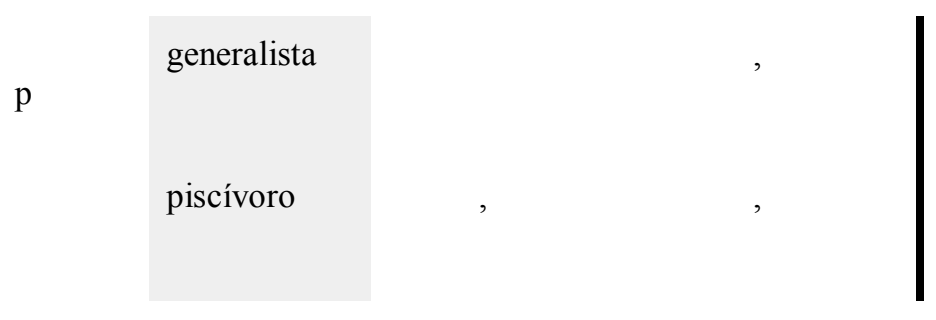

Las D resultaron mayores entre los grupos crustacívoros-piscívoros (Tabla ), seguido por los grupos piscívoros-generalistas y siendo los grupo más cercanos los crustacívoros-generalistas.

El cambio de forma dado a lo largo del CV1 es similar para ambos conjuntos de datos. El grupo formado por los piscívoros se diferencia del resto por tener una forma general más grácil, un processus lateralis más bajo y una cotyla scapularis más elongada próximodistalmente (Fig. 16). Para el CV2 ${ }^{6}$ las formas crustacívoras presentan un ancho del cuerpo del coracoides homogéneo, un processus acrocoracoideus robusto y recto, y un processus lateralis en paralelo con el eje del hueso. Mientras que las formas generalistas se encuentran más asociadas a una morfología grácil, acompañada de un angostamiento progresivo del cuerpo del coracoides hacia la porción proximal, un processus acrocoracoideus inclinado medialmente, y un processus lateralis que se angosta hacia la facies articularis sternalis.

6 El CV 2 está invertido para el CVA de los residuales. 
a
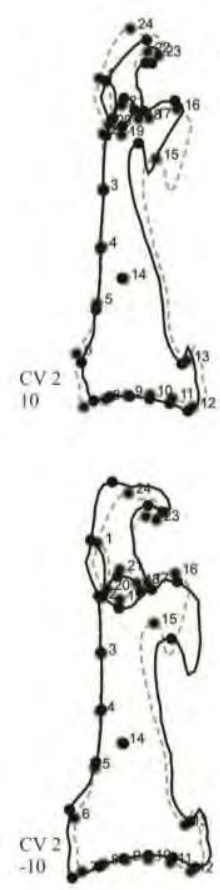

CV 2

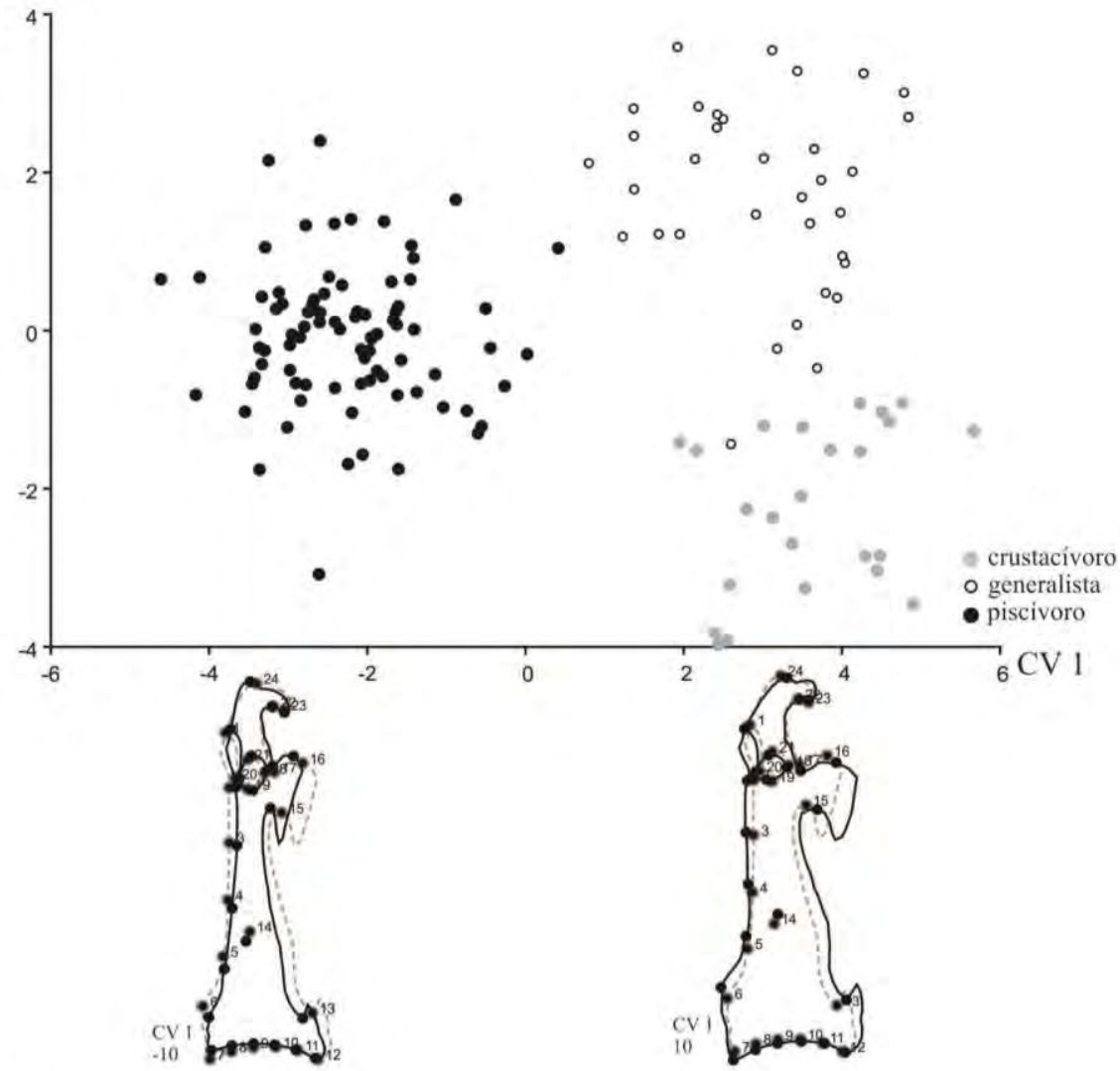

b

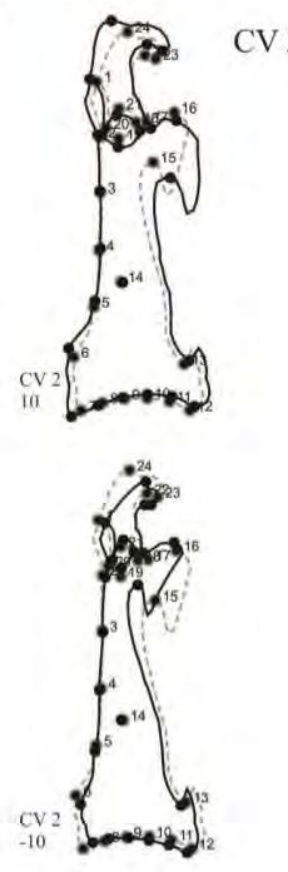

$\mathrm{CV} 2$
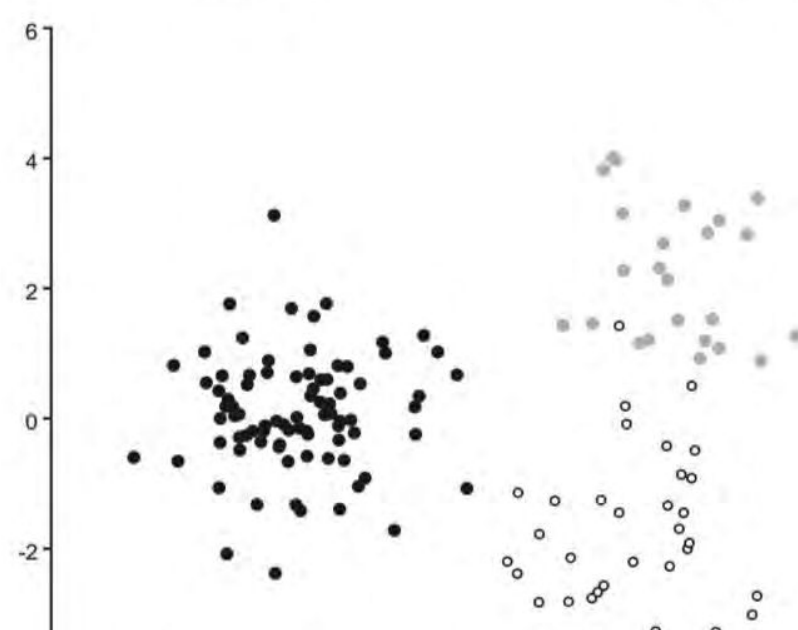

- crustacívoro - generalista CV 1

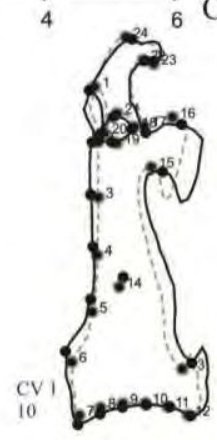

Figura 16 Gráficos de dispersión de los primeros dos CV de la configuración del coracoides en vista dorsal, con el cambio de forma para los valores magnificados de cada $\mathrm{CV}$ para $\mathbf{a}$, datos originales; $\mathbf{b}$, datos crudos. Las líneas grises punteadas representan la forma promedio mientras que las negras representan los valores extremos de cada PC. 


\section{CONFIGURACIÓN DEL CORACOIDES EN VISTA VENTRAL}

\section{Alometría}

La regresión entre las coordenadas de procrustes y el logaritmo del tamaño dio como resultado que un $3,5995 \%(\mathrm{p}=0,0006)$ de la variación fue explicado por el tamaño.

\section{Análisis de componentes principales}

El PC1 (Tabla , para porcentajes de variación explicados por los primeros tres PC), separa a las especies actuales hacia los valores positivos de Madrynornis mirandus que se ubica hacia los negativos. Por su parte, el PC2 separa a Madrynornis mirandus, Spheniscus, Eudyptula y Eudyptes (valores positivos) de Pygoscelis, que se ubica hacia los valores negativos. Hacia los valores neutrales encontramos a Aptenodytes.

Tabla Porcentajes de variación explicada por los primeros tres componentes principales, para el PCA del coracoides en vista ventral del conjunto de datos originales y corregidos

\begin{tabular}{|c|c|c|}
\hline & $\%$ Variación-Originales & $\%$ Variación-Corregidos \\
\hline $\mathrm{PC} 1$ & , & , \\
\hline $\mathrm{PC} 2$ & , & , \\
\hline $\mathrm{PC} 3$ & , & , \\
\hline
\end{tabular}

En cuanto a la variación de forma explicada por el primer componente, se observa que para los valores positivos (pingüinos actuales) la forma de la región distal del coracoides se encuentra más cercana a la epífisis proximal, que es además más angosta (Fig. 17). A su vez, vemos que el sulcus supracoracoideus es más perpendicular al eje y que el proc. acrocoracoideus se ubica más medial en los taxones actuales. Finalmente, la protuberancia de la fossa articularis humeralis se extiende más lateral en los actuales que en Madrynornis. 
a

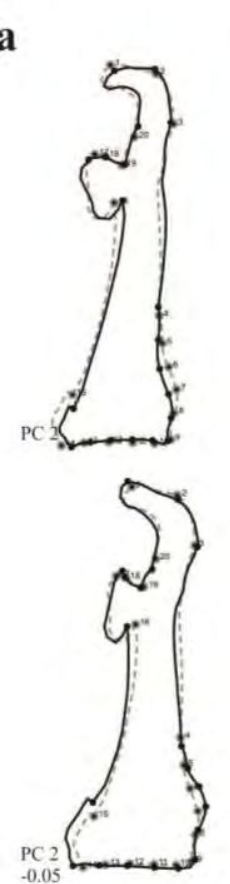

PC $2^{0.05}$

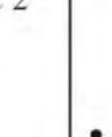

$-0.10$
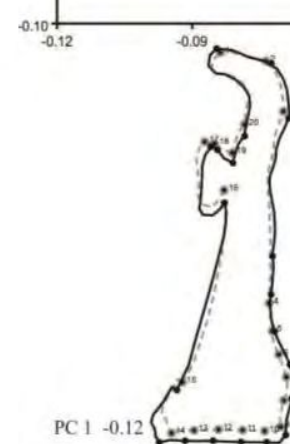

b

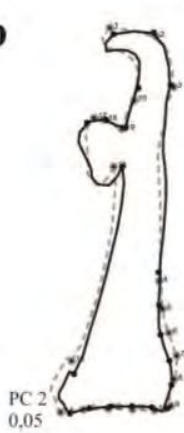

PC $2^{\circ 00}$

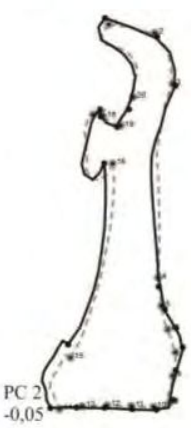

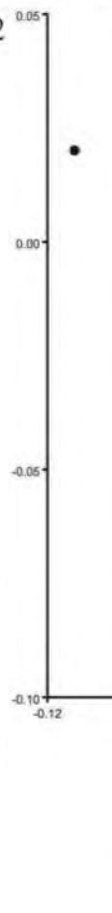

$\mathrm{PCI}-\mathrm{T} \cdot 12$
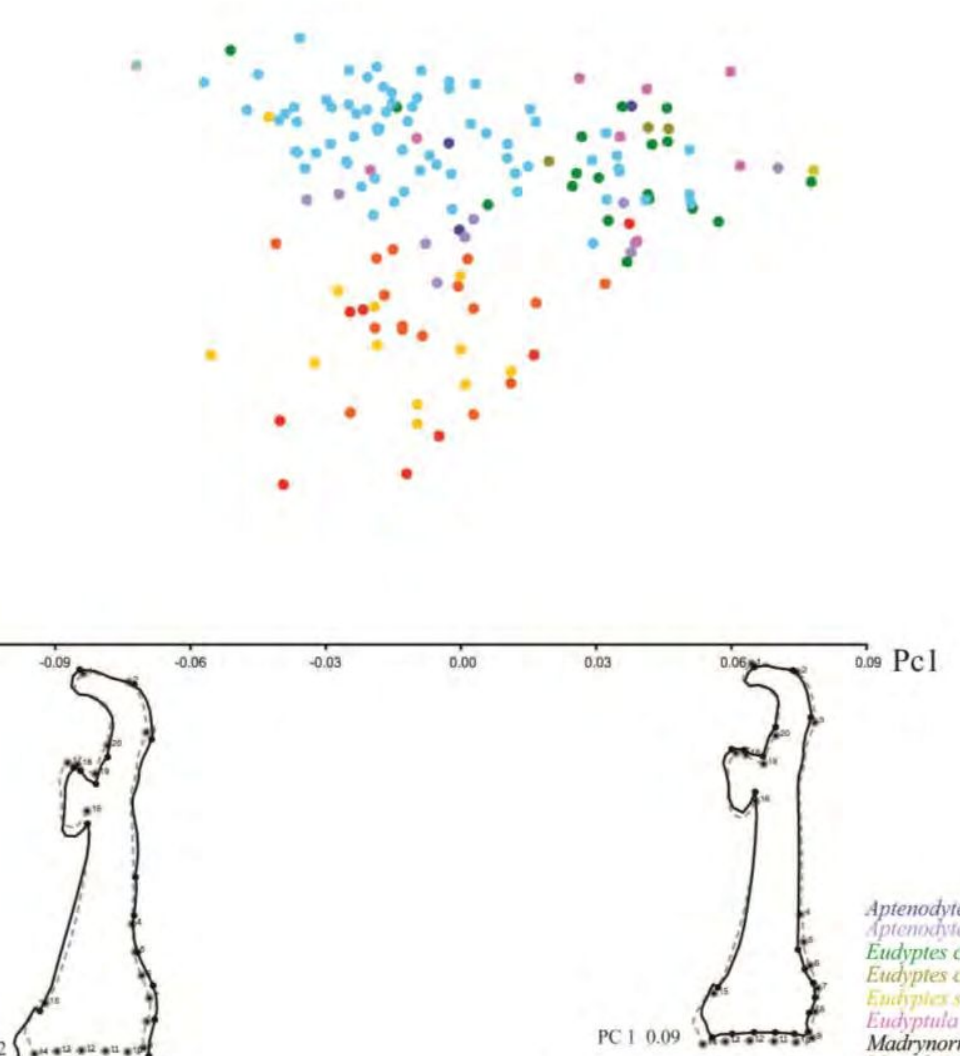
Madrynornis mirandus Pygaseelis odleline Pygoseetis adeliae oscelis antarctica

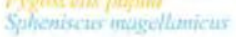

Aptenodytes forsteri 4prenndites patogonicus Eudyptes chrysocome Eudyptes fhrosolophes

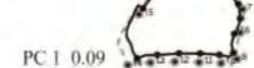

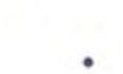

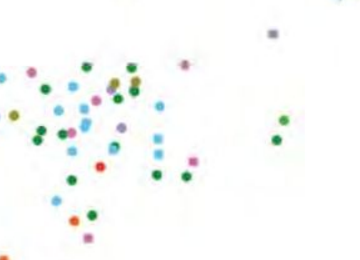

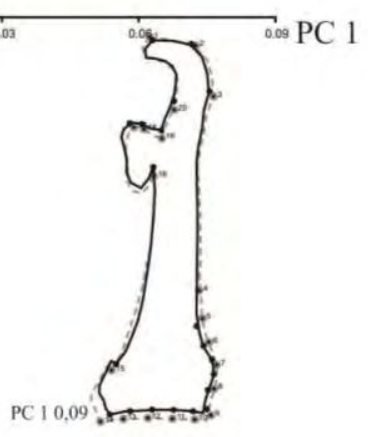

Figura 17 Análisis de componentes principales de la configuración del coracoides en vista ventral. Gráficos de dispersión de los primeros dos PC con el cambio de forma para los valores extremos de cada PC para a, datos originales; $\mathbf{b}$, datos corregidos. Las líneas grises punteadas representan la forma promedio mientras que las negras representan los valores extremos de cada PC. 
Para el PC2 se observa que el ala del proc. lateralis se encuentra más protruida para los valores negativos (Pygoscelis), al mismo tiempo que el angulus medialis se desplaza medialmente. Hacia el extremo proximal, el punto más proximal del foramen $n$. supracoracoideus se ubica medialmente hacia los valores negativos, lo que conlleva un mayor diámetro de la diáfisis, mientras que el proc. acrocoracoideus se desplaza anteoromedialemente para estos valores (Pygoscelis).

\section{Categorías de hábitos alimenticios: Análisis multivariante de la varianza}

El MANOVA dio como resultado un Lambda de Wilk bajo (Tabla ), las distancias de Mahalanobis (D ) calculadas resultaron más cercanas para los grupos piscívoro-generalista mientras que a los piscívoro-crustacívoro como los más lejanos (Tabla ). Por su parte, los grupos crustacívoros-generalistas quedaron a una distancia intermedia.

Tabla Análisis multivariante de la varianza (MANOVA) del coracoides en vista ventral, valores de Wilks' $\lambda$, y distancias de Mahalanobis (D ) entre grupos con sus correspondientes valores de $\mathrm{p}$ asociados. Resultados para el conjunto de datos originales y corregidos

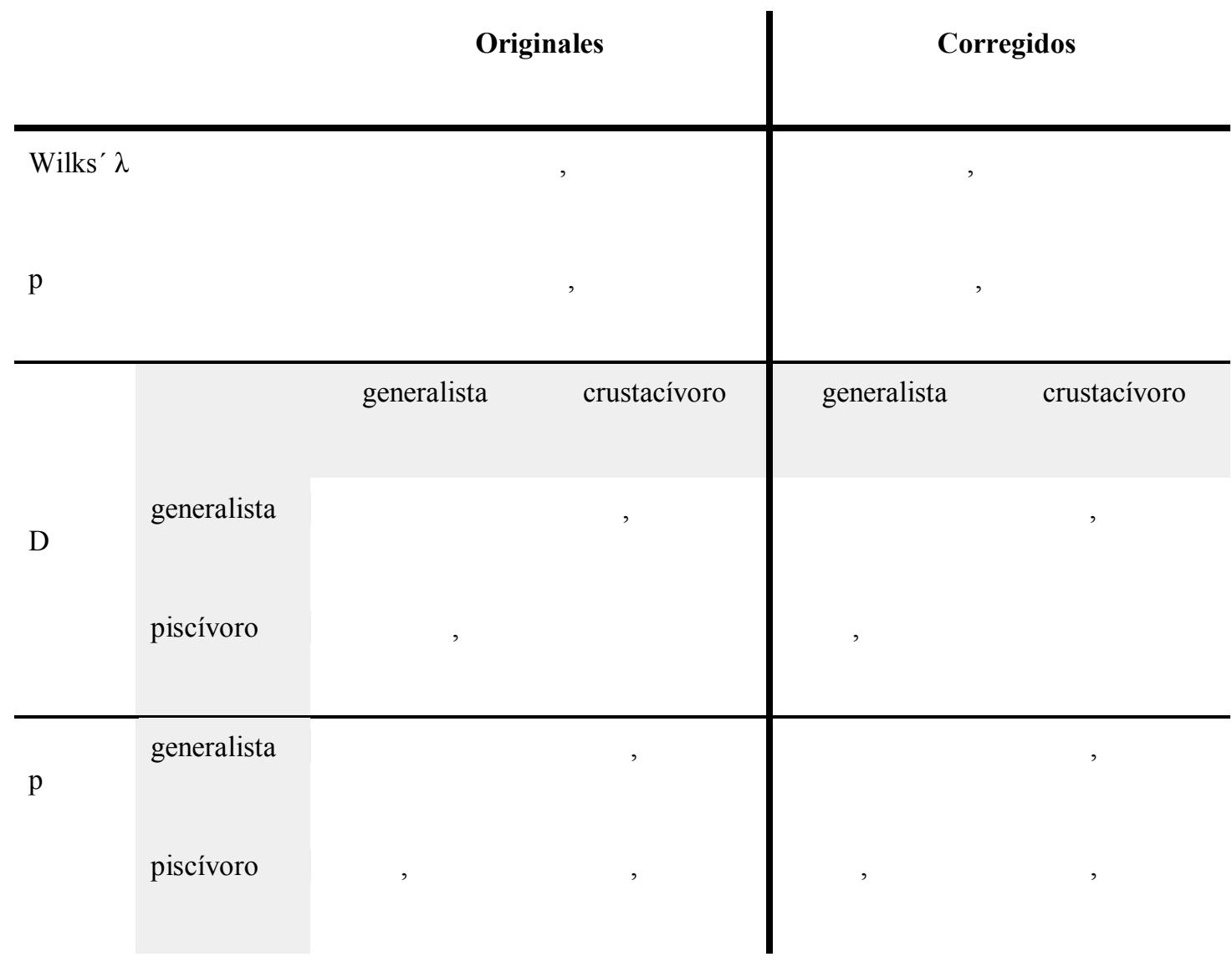




\section{Categorías de hábitos alimenticios: Análisis de variación canónica}

Para ambos CVA las mayores distancias se hallaron entre los grupos piscívoroscrustacívoros (Tabla 2 ). Las distancias entre los demás grupos resultaron en valores similares entre sí. De todas maneras, las menores distancias de Mahalanobis entre grupos para el análisis con datos crudos se hallaron entre los grupos piscívoros-generalistas, mientras que para el análisis con los residuales resultó ser entre los crustacívoros y generalistas (Tabla ) .

Tabla Análisis de variación canónica (CVA) de la configuración del coracoides en vista ventral. Porcentajes de variación para los dos primeros ejes de variación canónica, y distancias de Mahalanobis (D ) entre grupos con sus correspondientes valores de $\mathrm{p}$ asociados. Resultados para el conjunto de datos originales y corregidos.

\begin{tabular}{|c|c|c|c|c|c|}
\hline & & \multicolumn{2}{|c|}{ Originales } & \multicolumn{2}{|c|}{ Corregidos } \\
\hline \multicolumn{2}{|c|}{ CV $1 \%$} & \multicolumn{2}{|c|}{, } & \multicolumn{2}{|c|}{, } \\
\hline \multicolumn{2}{|c|}{ CV $2 \%$} & \multicolumn{2}{|c|}{, } & \multicolumn{2}{|c|}{, } \\
\hline \multirow{3}{*}{ D } & & generalista & crustacívoro & generalista & crustacívoro \\
\hline & generalista & \multirow{2}{*}{\multicolumn{2}{|c|}{, }} & \multirow{2}{*}{\multicolumn{2}{|c|}{, }} \\
\hline & piscívoro & & & & \\
\hline \multirow{2}{*}{$\mathrm{p}$} & generalista & & , & & , \\
\hline & piscívoro & , & , & , & , \\
\hline
\end{tabular}

El CV1 separa el grupo crustacívoros (Pygoscelis adeliae, P. antarctica) de los piscívoros (Aptenodytes patagonicus, Eudyptula, Spheniscus). El grupo generalista queda entre medio de los dos grupos anteriores. Para los dos análisis, el CV2 separa los grupos especialistas (crustacívoros y piscívoros) de los generalistas. 

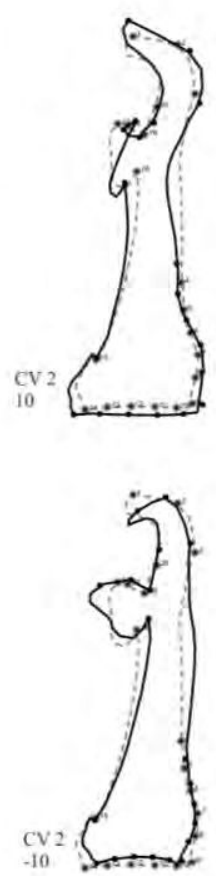

b

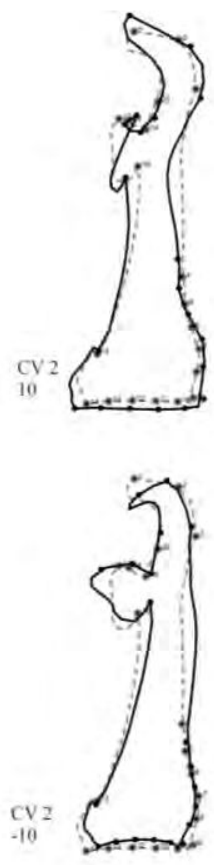

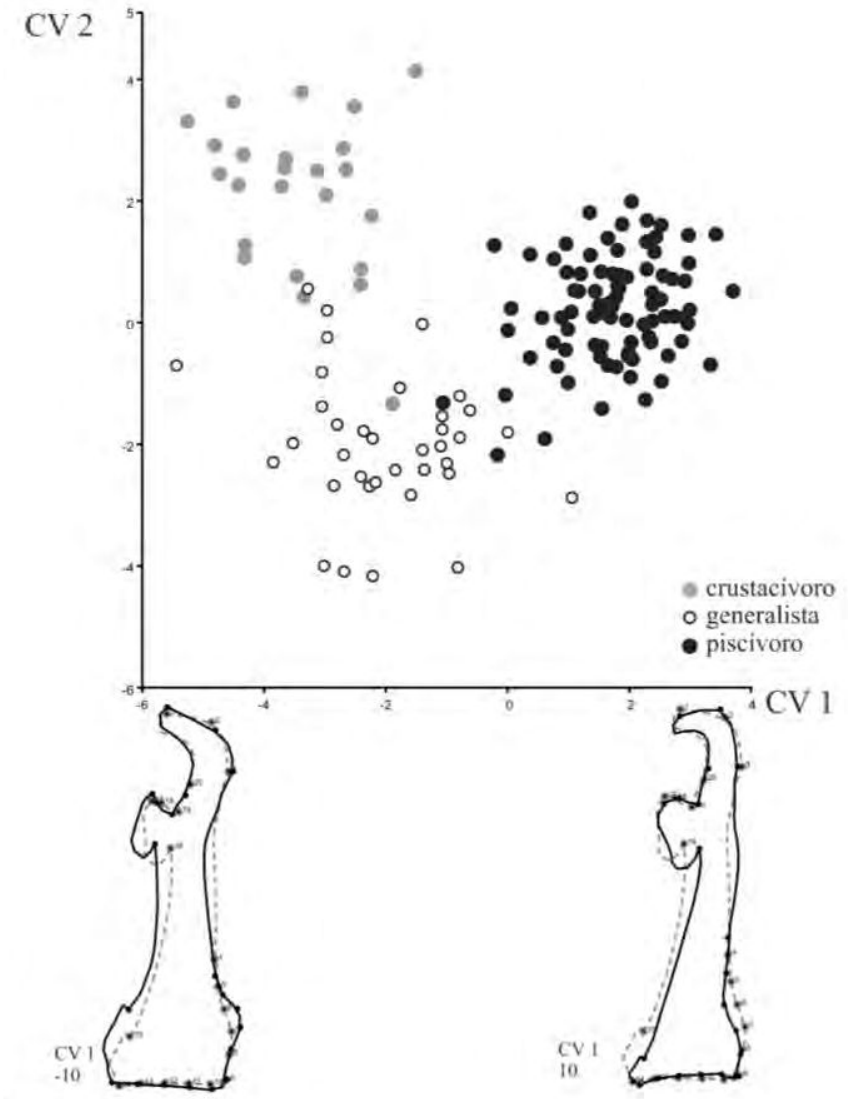

CV 2

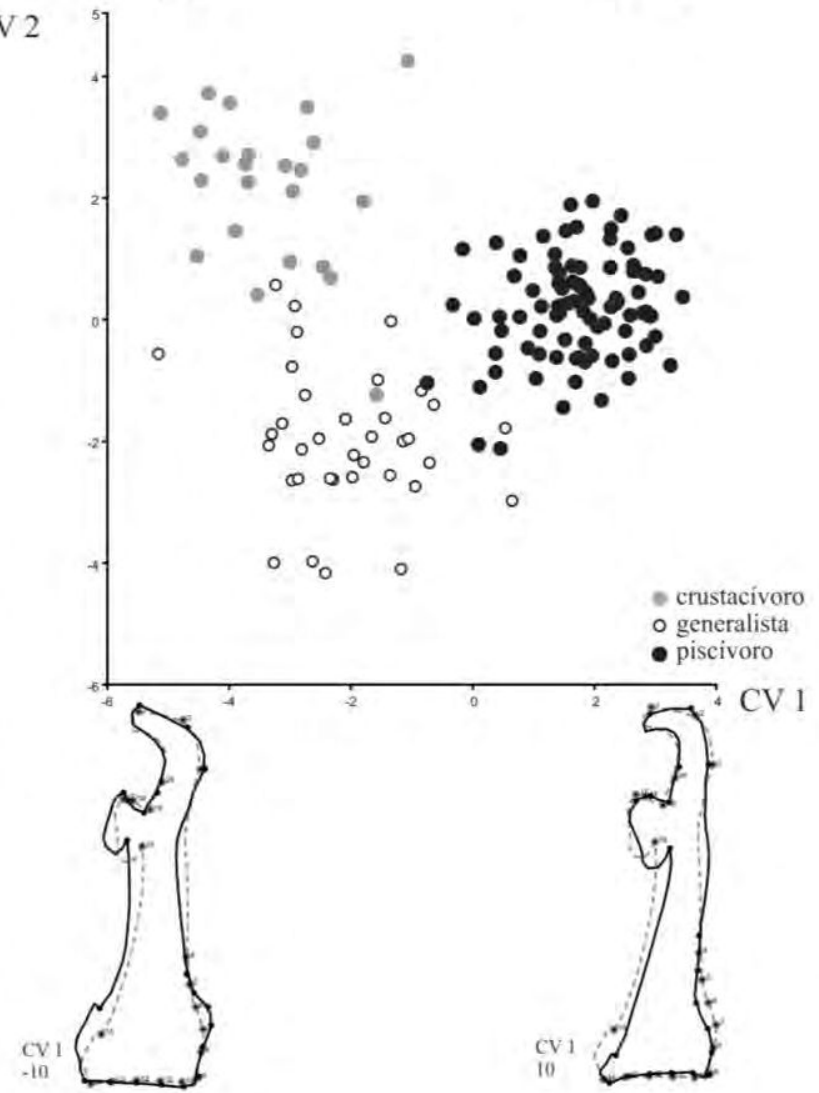

Figura 18 Gráficos de dispersión de los primeros dos CV de la configuración del coracoides en vista ventral, con el cambio de forma para los valores magnificados de cada $\mathrm{CV}$ para a, datos originales; $\mathbf{b}$, datos corregidos. Las líneas grises punteadas representan la forma promedio mientras que las negras representan los valores extremos de cada PC. 
Para el CV1 la variación de forma explicada para ambos análisis, y que diferencia los piscívoros de los crustacívoros, es muy similar. El grupo crustacívoro presenta una forma más robusta, con el proc. lateralis con un ala lateralmente pronunciada (señalada por los landmarks 6 y 7), la muesca distal del margen medial se aleja del borde medial, la diáfisis se ensancha al igual que el sulcus supracoracoideus, la superficie oval de origen del $\mathrm{m}$. propatagialis se angosta, el proc. procoracoideus se desplaza hacia el proc. acrocoracoideus, y su extremo diverge del eje del hueso (Fig. 18). El CV2 muestra un eje de variación de forma en el cual el grupo de los generalistas presenta formas con un proc. procoracoideus más medialmente extendido y con el extremo del proc. acrocoracoideus levemente inclinado hacia el cuerpo del hueso.

\section{DISCUSIÓN INTEGRAL DE LOS ANÁLISIS DEL CORACOIDES}

La facies articularis sternalis, superficie de articulación del coracoides con el esternón, presenta una gran variabilidad a lo largo de la historia evolutiva de los pingüinos (e.g., Marples, 1952; Simpson, 1975; Bannasch, 1994; Acosta Hospitaleche \& Di Carlo, 2010). En los pingüinos Eocenos presenta una característica forma sigmoidea (Acosta Hospitaleche \& Di Carlo, 2010), mientras que a partir del Oligoceno ya se observa la característica forma curvada en " $u$ " que se acentúa en los pingüinos actuales Se caracteriza por ser una estructura robusta dentro del complejo escapular. En nuestro grupo de estudio se observó que la variación de forma para esta estructura es grande. Sus diferencias mayores radican en su altura a lo largo de la facies, y el grado de curvatura medio dorsal. La facies articularis curvada podría hacer frente de manera más eficiente y generar estabilidad en el complejo cintura escapular que se ve expuesto por las fuerzas del $m$. pectoralis thoracica y el m. supracoracoideus (Bannasch, 1994). Por lo que un mayor ángulo de curvatura, como el observado en Pygoscelis, podría estar relacionado con una mayor estabilidad debido a músculos más fuertes y robustos de abducción y adducción del ala.

Por otro lado, para ambas vistas del coracoides, vemos que las formas relacionadas a Spheniscus son más gráciles, con una cotyla scapularis más extendida próximo-distalmente, proc. lateralis bajos, con una cicatriz oval y alargada para el origen del $m$. propatagialis, y con el extremo del proc. acrocoracoides no rotado y formando un ángulo recto con el eje del hueso. Mientras que los grupos crustacívoros poseen una contextura más robusta, con un proc. lateralis más extendido y con un ala lateral más protruida, un sulcus supracoracoides 
más amplio, una superficie oval del proc. acrocoracoides más angosta, y un proc. acrocoracoides ventralmente rotado y formando un ángulo mayor con el hueso.

El tamaño mayor relativo de la facies articularis sternalis, como en Aptenodytes (Fig. 14), aumentaría la superficie de contacto lateromedial con el esternón. Esto genera un punto de contacto más firme y disminuye las posibilidades de deslizamiento entre ambas superficies. Spheniscus tendría una superficie de origen del $m$. propatagialis más elongada. Por otro lado, la morfología relacionada a Pygoscelis y al grupo crustacívoro indica un hueso más robusto con un surco para el paso del $m$. supracoracoideus más marcado, y una superficie de origen más amplia. El $m$. coracobrachialis caudalis también contaría con una superficie de anclaje más amplia para el grupo de Pygoscelis, ya que se origina, en parte, en el proc. lateralis del coracoides.

\section{RESULTADOS: ANÁLISIS ESTERNÓN}

\section{CONFIGURACIÓN DEL ESTERNÓN EN VISTA LATERAL}

\section{Alometría}

Para esta configuración, se obtuvo que el tamaño explica un $16,8776 \%(\mathrm{p}=0,0002)$ de la variación en forma, por lo que existe un efecto alométrico en los datos.

\section{Análisis de componentes principales}

Los agrupamientos no son tan claros para esta configuración, tal vez porque el $n$ es muy pequeño. Para ambos análisis, el PC1 (Tabla con los porcentajes de variación explicada por los primeros tres componentes) agrupa a Spheniscus hacia los valores positivos, mientras hacia el otro extremo encontramos a Pygoscelis. Con valores intermedios se ubican Eudyptes, Madrynornis, Eudyptula y Aptenodytes. Para el análisis con los datos corregidos, Eudyptula se aleja un poco de Spheniscus con respecto al análisis con los datos originales y Aptenodytes patagonicus se dispone más cercanamente a Spheniscus con los valores 
corregidos. Madrynornis mirandus se aleja un poco más de los valores positivos en el análisis de los datos residuales.

Tabla Porcentajes de variación explicada por los primeros tres componentes principales, para el PCA del esternón en vista lateral del conjunto de datos originales de las coordenadas de procrustes, y corregidos.

\begin{tabular}{|c|c|c|}
\hline & \% Variación-Originales & \% Variación-Corregidos \\
\hline PC1 & , & , \\
\hline PC2 & , & , \\
\hline PC3 & , & , \\
\hline
\end{tabular}

La variación de forma para los primeros dos PC fue muy similar en los dos análisis. El PC1 explica una diferencia de forma en la cual los valores positivos, donde encontramos a Spheniscus, presentan una altura mayor de la quilla en relación con su longitud total. La quilla es, en parte, el lugar de inserción del $m$. supracoracoideus, y del $m$. pectoralis thoracica. Para este componente, la variación en forma se concentra en la spina externa rostri y en el apex carinae. Para los valores positivos, donde se encuentra agrupado Spheniscus, la spina externa rostri está más desarrollada que en Pygoscelis, y el apex carinae está más cercano al corpus sterni.

\section{Categorías de hábitos alimenticios: Análisis multivariante de la varianza}

Los valores de Wilks' lambda fueron bajos (Tabla ), aunque más altos que en la mayoría de los anteriores resultados. Las distancias de Mahalanobis no pudieron ser calculadas para los grupos crustacívoros-generalistas para ambos casos. Para los grupos cuyas distancias sí fueron calculadas, resultó que los grupos crustacívoros-piscívoros presentaron las mayores distancias, mientras que los resultados para el grupo piscívoros-generalistas resultaron no significativos. 

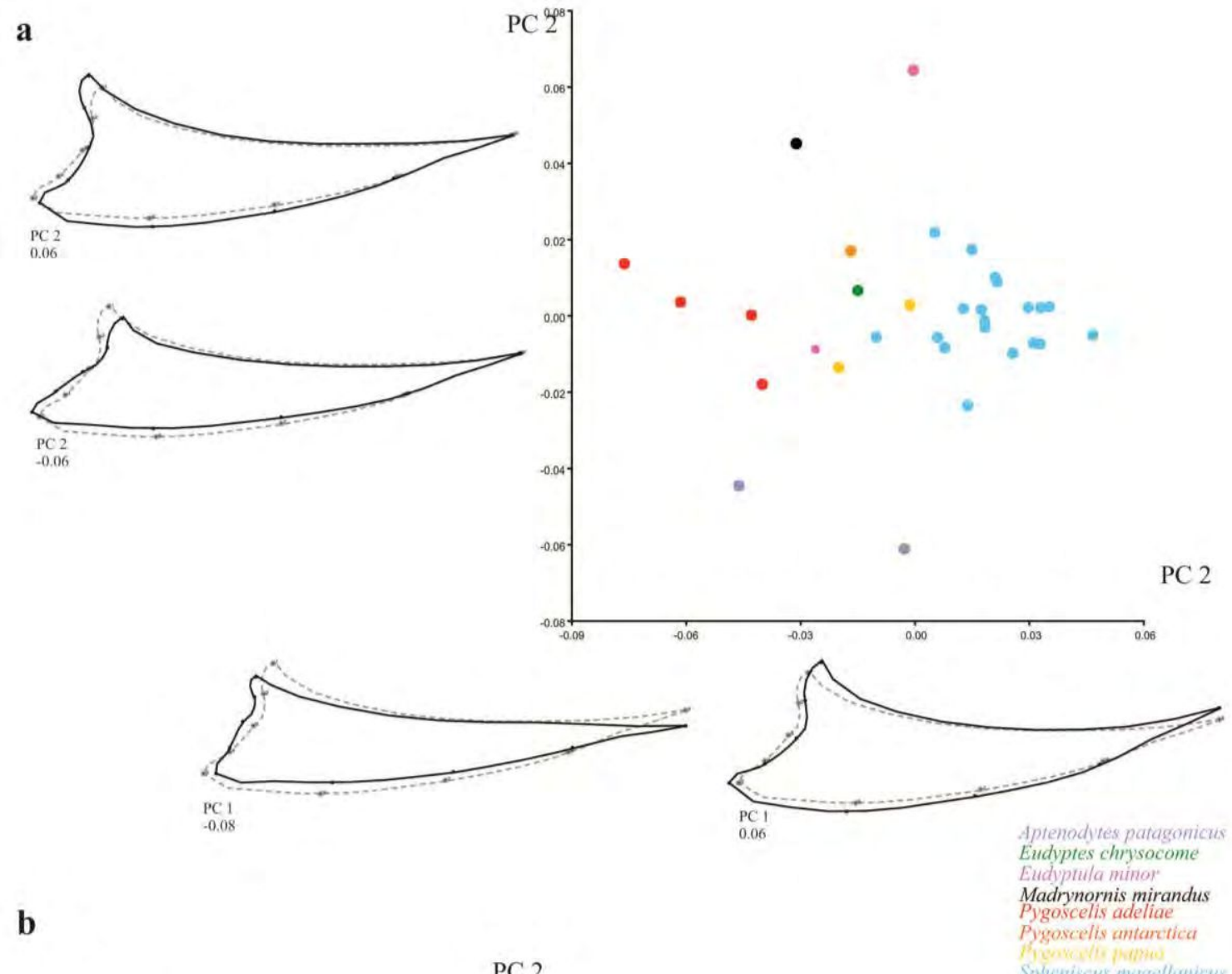

b
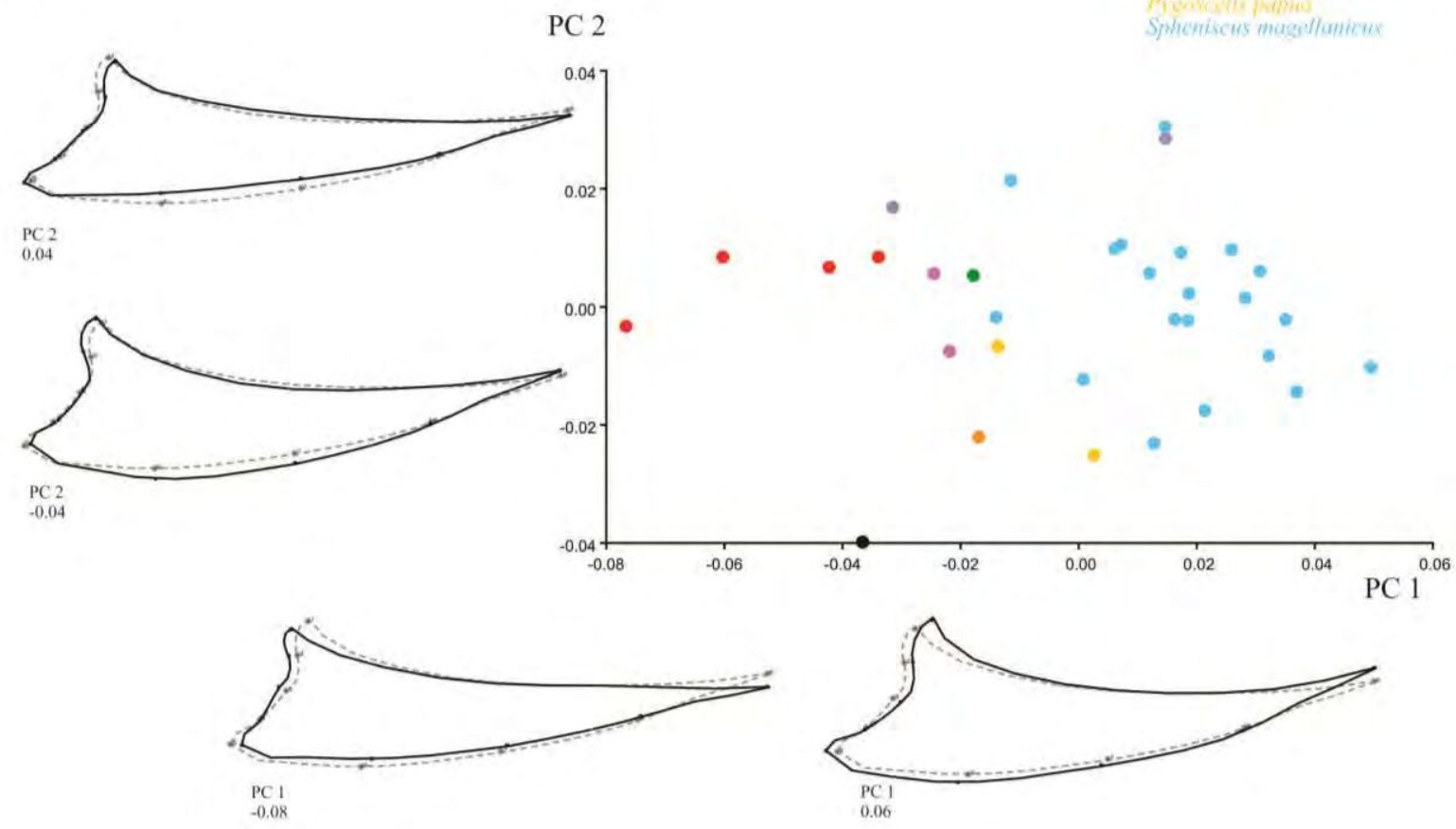

Figura 19 Análisis de componentes principales del esternón en vista lateral. Gráficos de dispersión de los primeros dos PC con el cambio de forma para los valores extremos de cada PC realizados a partir de a, datos originales; b, datos corregidos. Las líneas grises punteadas representan la forma promedio mientras que las negras representan los valores extremos de cada PC. 
Tabla Análisis multivariante de la varianza (MANOVA) de la configuración del esternón en vista lateral. Valores de Wilks' $\lambda$, y distancias de Mahalanobis (D ) entre grupos con sus correspondientes valores de $\mathrm{p}$ asociados. Resultados para el conjunto de datos originales y corregidos.

\begin{tabular}{|c|c|c|c|c|c|}
\hline & & \multicolumn{2}{|c|}{ Originales } & \multicolumn{2}{|c|}{ Corregidos } \\
\hline \multicolumn{2}{|c|}{ Wilks' $\lambda$} & \multicolumn{2}{|c|}{, } & \multicolumn{2}{|c|}{, } \\
\hline \multicolumn{2}{|l|}{$\mathrm{p}$} & \multicolumn{2}{|c|}{$<$} & \multicolumn{2}{|c|}{, } \\
\hline \multirow{3}{*}{$\mathrm{D}$} & & generalista & crustacívoro & generalista & crustacívoro \\
\hline & generalista & \multicolumn{2}{|c|}{ falló } & \multicolumn{2}{|c|}{ falló } \\
\hline & piscívoro & & & & \\
\hline \multirow{2}{*}{$\mathrm{p}$} & generalista & & falló & & falló \\
\hline & piscívoro & , & , & , & , \\
\hline
\end{tabular}

Categorías de hábitos alimenticios: Análisis de variación canónica

Para los análisis de variación canónica tanto de los datos originales como de los corregidos, la mayor distancia encontrada resultó ser entre los piscívoros-crustacívoros (Tabla ). Los grupos más cercanos fueron los crustacívoros-generalistas (Tabla ), y los grupos con distancias intermedias fueron los piscívoros-generalistas (Tabla ).

Tabla Análisis de variación canónica (CVA) de la configuración del esternón en vista lateral. Porcentajes de variación para los dos primeros ejes de variación canónica, y distancias de Mahalanobis (D ) entre grupos con sus correspondientes valores de $\mathrm{p}$ asociados. Resultados para el conjunto de datos originales, y corregidos. 


\begin{tabular}{|c|c|c|c|c|c|}
\hline & & \multicolumn{2}{|c|}{ Originales } & \multicolumn{2}{|c|}{ Corregidos } \\
\hline \multicolumn{2}{|c|}{ CV1 \% } & \multicolumn{2}{|l|}{, } & \multicolumn{2}{|c|}{, } \\
\hline \multicolumn{2}{|c|}{ CV2 \% } & \multicolumn{2}{|l|}{, } & \multicolumn{2}{|c|}{, } \\
\hline \multirow{3}{*}{$\mathrm{D}$} & & generalista & crustacívoro & generalista & crustacívoro \\
\hline & & \multirow{2}{*}{\multicolumn{2}{|c|}{, }} & \multirow{2}{*}{\multicolumn{2}{|c|}{, }} \\
\hline & piscívoro & & & & \\
\hline \multirow{2}{*}{$\mathrm{p}$} & generalista & & , & \multirow{2}{*}{\multicolumn{2}{|c|}{, }} \\
\hline & piscívoro & , & , & & \\
\hline
\end{tabular}

En ambos análisis, el CV1 agrupó por un lado a los piscívoros, por el otro a los crustacívoros, y en el medio a los generalistas. Por su parte, el CV2 separó a los generalistas de los especialistas (Fig. 20).

En cuanto a la variación de la forma, para el CV1 observamos que lo que nos permite separar grupos es la curvatura de la unión de la quilla con el corpus, el desarrollo del apex carinae y de la spina externa rostri. En las formas crustacívoras, el desarrollo del ápice de la quilla (apex carinae) está menos desarrollado, mientras que en los grupos piscívoros, el ápice se proyecta y tiene una forma más puntiaguda. En cuanto a la spina externa rostri, está mucho menos desarrollada en las formas piscívoras que en las crustacívoras. En cuanto al CV2, los grupos se ven separados por la curvatura de la quilla y de la unión de la misma con el corpus sternalis. Las formas especialistas tendrían una quilla y un corpus más recto, mientras que las formas generalistas tendrían una quilla y un corpus más curvados. 
a
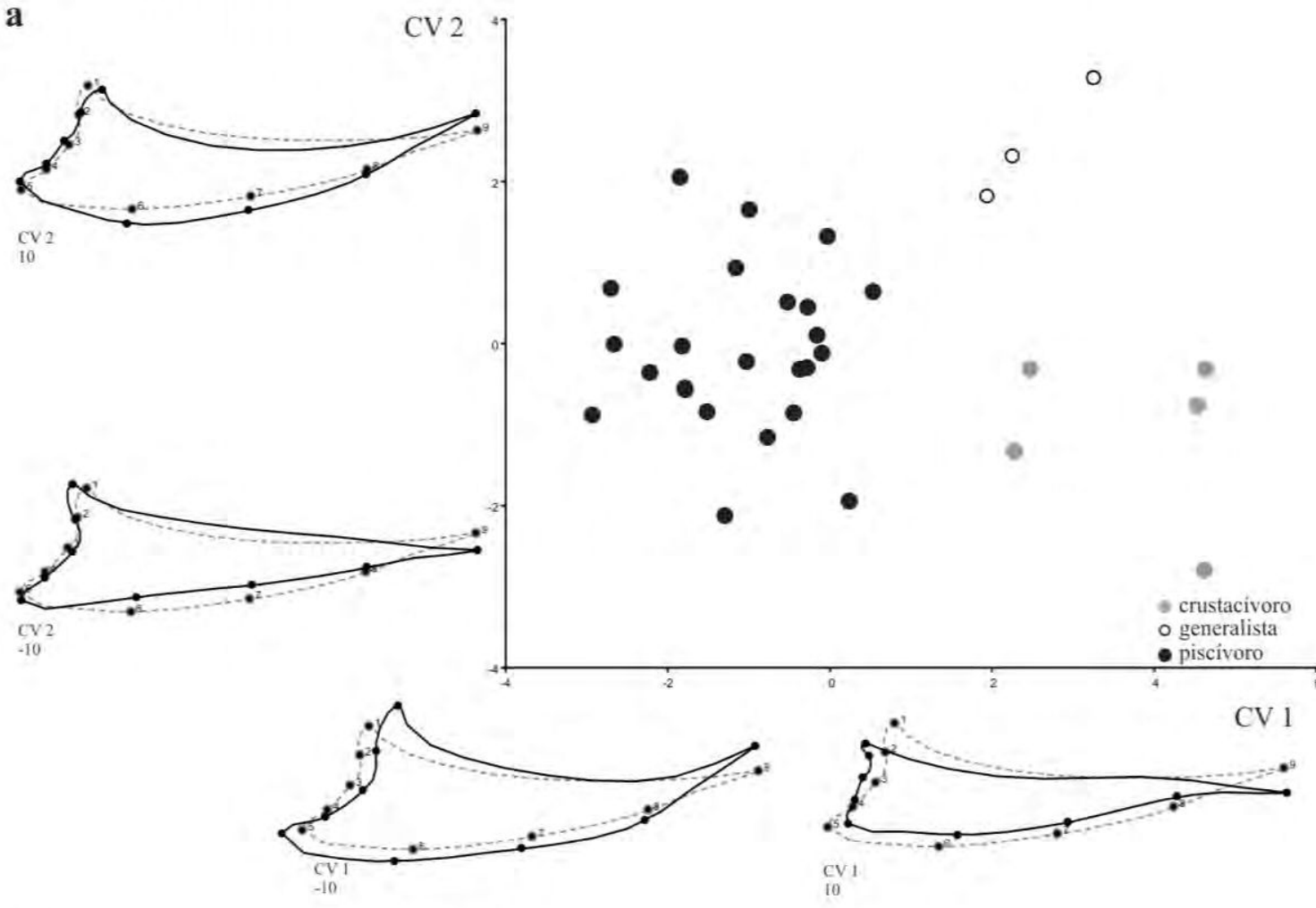

${ }_{10}^{\mathrm{CV}} 1$
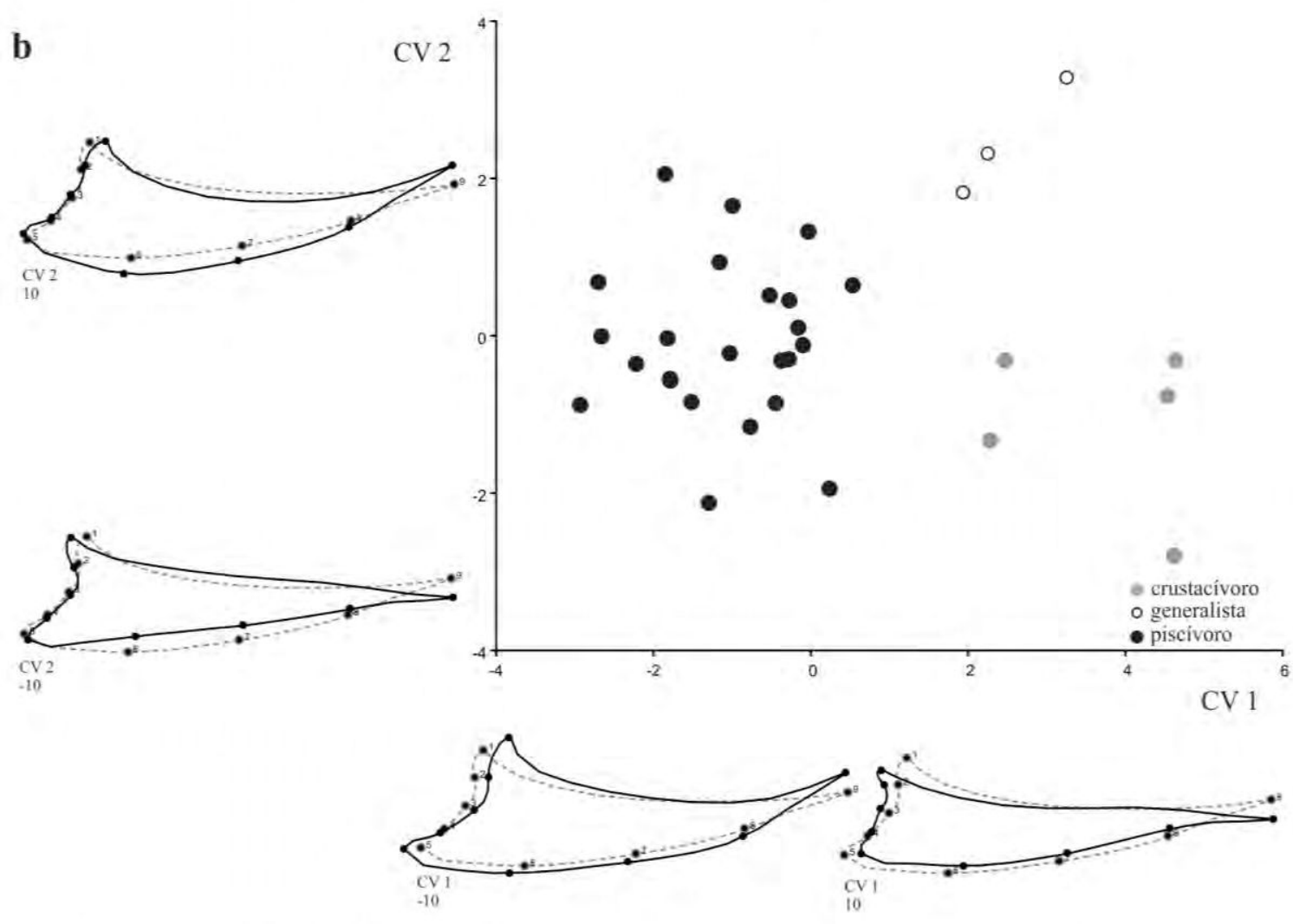

Figura 20 Análisis de variación canónica del esternón en vista lateral. Gráficos de dispersión de los primeros dos $\mathrm{CV}$, con el cambio de forma para los valores magnificados de cada $\mathrm{CV}$ para $\mathbf{a}$, datos originales; $\mathbf{b}$, datos corregidos. Las lineas grises punteadas representan la forma promedio mientras que las negras representan los valores extremos de cada CV. 


\section{CONFIGURACIÓN DEL ESTERNÓN EN VISTA VENTRAL}

\section{Alometría}

Para esta configuración, el tamaño explicó el 13,1529\% ( $\mathrm{p}<0,0001)$ de la variación.

\section{Análisis de componentes principales}

El PC1 (Tabla ) agrupa a Pygoscelis y a Aptenodytes forsteri hacia los valores positivos $^{7}$, mientras que hacia los valores negativos encontramos a Spheniscus. En los valores neutrales se ubicó Eudyptes, y en los valores negativos más bajos a Madrynornis. La mayor variación en la disposición de los puntos en el gráfico de dispersión entre los dos análisis se ve, una vez más, en Aptenodytes y Eudyptula. Para el PCA de datos originales, los individuos de A. patagonicus se agrupan junto con los de Eudyptes y los de A. forsteri con los de Pygoscelis. Mientras que en el PCA de los datos corregidos, tanto A. patagonicus como A. forsteri se ubican más cercanos a Spheniscus. Eudyptula se comporta en los análisis de dos maneras diferentes: para el PCA de datos originales se ordena junto con Spheniscus, mientras que para el de los datos corregidos, se agrupa con Eudyptes. En el PC2 se agrupan hacia los valores positivos los individuos de Aptenodytes y Eudyptula, Madrynornis y parte de los de Eudyptes. Spheniscus y Pygoscelis se encuentran dispersos, tanto hacias los valores positivos como hacia los negativos.

Tabla Porcentajes de variación explicada por los primeros tres componentes principales, para el PCA de la configuración del esternón en vista ventral del conjunto de datos originales, y corregidos.

\begin{tabular}{|c|c|c|}
\hline & \% Variación-Originales & \% Variación-Corregidos \\
\hline $\mathrm{PC} 1$ & , & , \\
\hline PC2 & , & , \\
\hline PC3 & , & , \\
\hline
\end{tabular}

7 Los valores del CV 2 están invertido para el CVA de los residuales. 

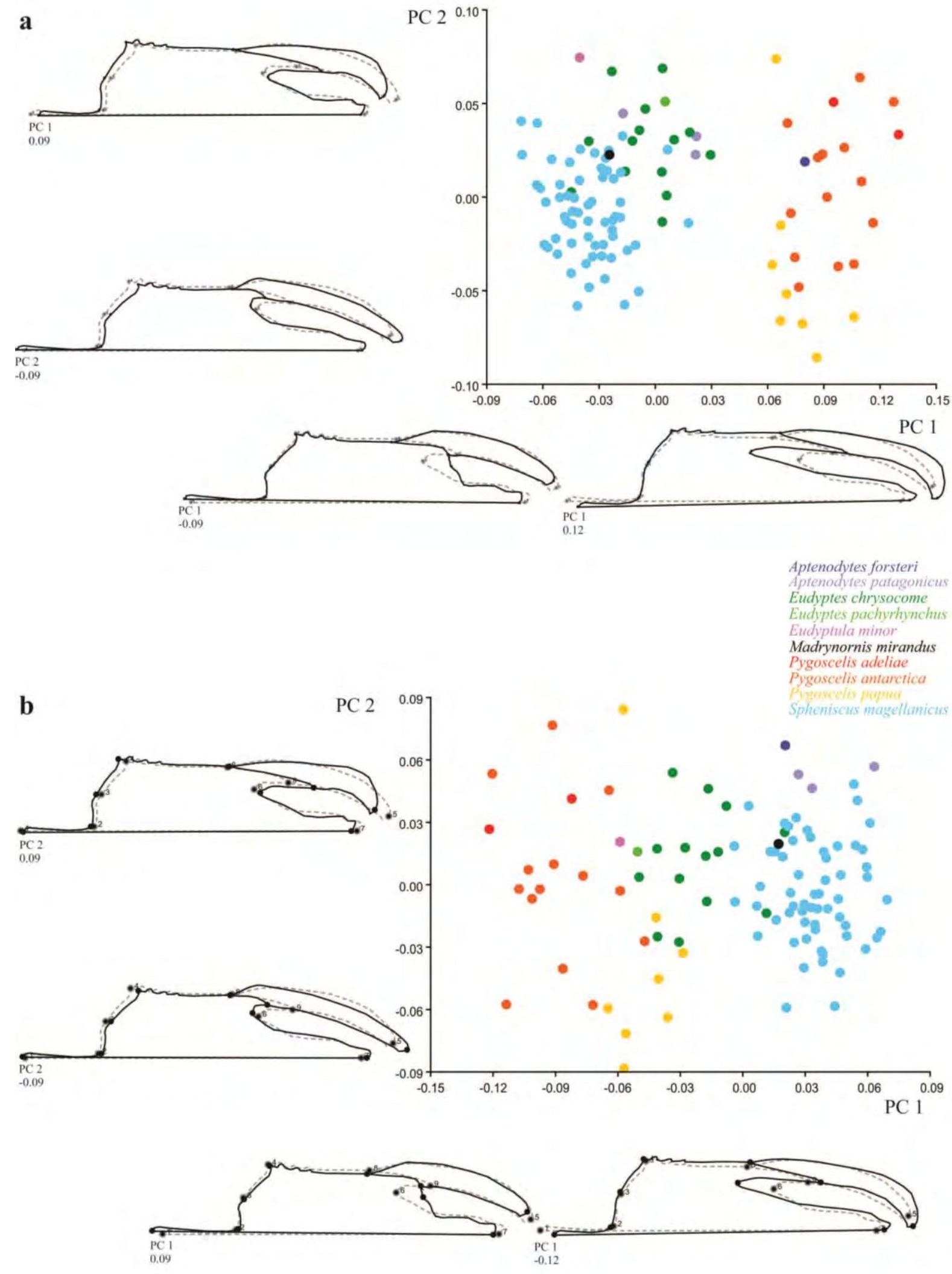

Figura 21 Análisis de componentes principales del esternón en vista ventral. Gráficos de dispersión de los primeros dos PC con el cambio de forma para los valores extremos de cada PC realizados a partir de a, datos originales; $\mathbf{b}$, datos corregidos. Las líneas grises punteadas representan la forma promedio mientras que las negras representan los valores extremos de cada PC. 
La variación de forma para los dos primeros PC fue muy similar en los dos análisis. En el PC1, las mayores diferencias se concentran para el apex carinae, la incisura caudolateralis, la línea en la trabecula caudolateralis (límite caudal del origen del $\mathrm{m}$. supracoracoideus) y la longitud relativa total del corpus y de la trabecula caudolateralis (Fig. 21). Para los valores positivos, encontramos un apex carinae más corto que para los valores negativos donde se agrupa Spheniscus, el extremo craneal de la incisura caudolateralis se extiende cranealmente con respecto a los valores negativos, la línea en la trabecula caudolateralis está también más extendida que en los valores donde se agrupa Spheniscus, la trabecula caudolateralis se extiende hasta un punto más próximo a la línea media en los individuos situados hacia los valores positivos que en los ubicados hacias los negativos. Finalmente, la longitud relativa total del corpus es mayor para los valores donde se agrupa Pygoscelis.

Para el PC2, las diferencias se ven en un acortamiento general del esternón en los individuos situados hacia los valores positivos (donde se agrupa Eudyptes), en la longitud de la línea de la trabecula caudolateralis, que es más corta para los valores negativos que para los positivos (donde se agrupa Eudyptes), y por un desplazamiento anterior de la porción de la articulación de las costillas y el margen craneal del corpus, también para los valores negativos con respecto a los positivos.

\section{Categorías de hábitos alimenticios: Análisis multivariante de la varianza}

El valor de Wilks' lambda fue bajo para ambos análisis (Tabla ). En cuanto a la distancia entre grupos, una vez más, las mayores distancias encontradas resultaron ser entre los crustacívoros y los piscívoros, las intermedias entre los crustacívoros y los generalistas y las menores distancias halladas fueron entre los grupos de los piscívoros y los generalistas (Tabla ).

Tabla Análisis multivariante de la varianza (MANOVA) de la configuración del esternón en vista ventral. Valores de Wilks' $\lambda$, y distancias de Mahalanobis (D) entre grupos con sus correspondientes valores de $\mathrm{p}$ asociados. Resultados para el conjunto de datos originales y corregidos. 


\begin{tabular}{|c|c|c|c|c|c|}
\hline & & \multicolumn{2}{|c|}{ Originales } & \multicolumn{2}{|c|}{ Corregidos } \\
\hline \multicolumn{2}{|c|}{ Wilks' $\lambda$} & \multicolumn{2}{|c|}{, } & \multicolumn{2}{|c|}{, } \\
\hline \multicolumn{2}{|l|}{$\mathrm{p}$} & \multicolumn{2}{|c|}{, } & \multicolumn{2}{|c|}{, } \\
\hline \multirow{3}{*}{$\mathrm{D}$} & & generalista & crustacívoro & generalista & crustacívoro \\
\hline & generalista & & , & & , \\
\hline & piscívoro & , & & , & \\
\hline \multirow{2}{*}{$\mathrm{p}$} & generalista & & , & & , \\
\hline & piscívoro & , & , & , & , \\
\hline
\end{tabular}

\section{Categorías de hábitos alimenticios: Análisis de variación canónica}

Al igual que para el MANOVA, las distancias de Mahalanobis (D ) calculadas para el CVA resultaron como los grupos más lejanos los de los crustacívoros y los piscívoros, seguido de los crustacívoros y generalistas (Tabla ). Por último, los más cercanos fueron los de los piscívoros y los generalistas (Tabla ).

Tabla Análisis de variación canónica (CVA) de la configuración del esternón en vista ventral. Porcentajes de variación para los dos primeros ejes de variación canónica, y distancias de Mahalanobis (D ) entre grupos con sus correspondientes valores de $\mathrm{p}$ asociados. Resultados para el conjunto de datos originales y corregidos.

\begin{tabular}{|c|c|c|}
\hline & Datos Originales & Datos Corregidos \\
\hline CV $1 \%$ & , & , \\
\hline CV $2 \%$ & , & , \\
\hline
\end{tabular}




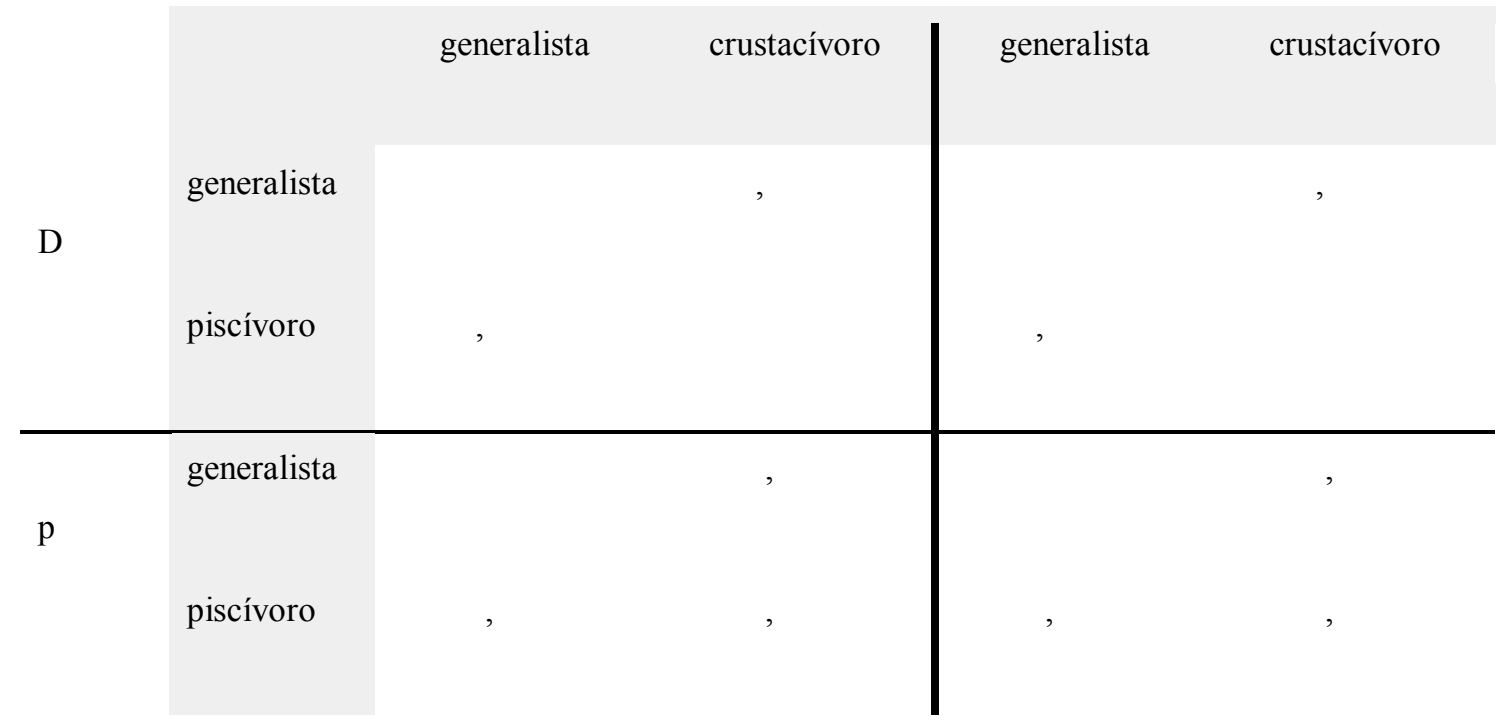

El CV1 para ambos análisis agrupó a los piscívoros separado ampliamente de los crustacívoros, dejando a los generalistas en una posición intermedia. El CV2 nuevamente separó a los generalistas de los especialistas (crustacívoros y piscívoros).

El CV1 explica la diferencia entre grupos principalmente por la longitud de la incisura caudolateralis, para ambos análisis. Para los crustacívoros, la extensión de esta incisura es mucho mayor que para los grupos piscívoros. Otra característica que diferencia a los grupos es la extensión y ancho de la trabecula caudolateralis, la cual es más larga, más ancha y se extiende más medialmente en los crustacívoros que en los pingüinos piscívoros. Además, la extensión de la línea intermuscular de la trabecula caudolateralis es mayor en las formas crustacívoras. La longitud relativa del esternón también es mayor en las formas crustacívoras, aunque la quilla tiene una menor longitud.

Para el CV2, la diferencia principal estaría en el ancho relativo del esternón y de la trabecula lateralis, que en las formas generalistas (A. forsteri, P. papua, Eudyptes) es más ancho que en los grupos especialistas (piscívoros y crustacívoros; A. patagonicus, Spheniscus, $P$. adeliae, P. antarctica y Eudyptula). Otra diferencia reside en la forma del margen anterior del corpus, más redondeado en las formas generalistas y más anguloso en las formas especialistas. 

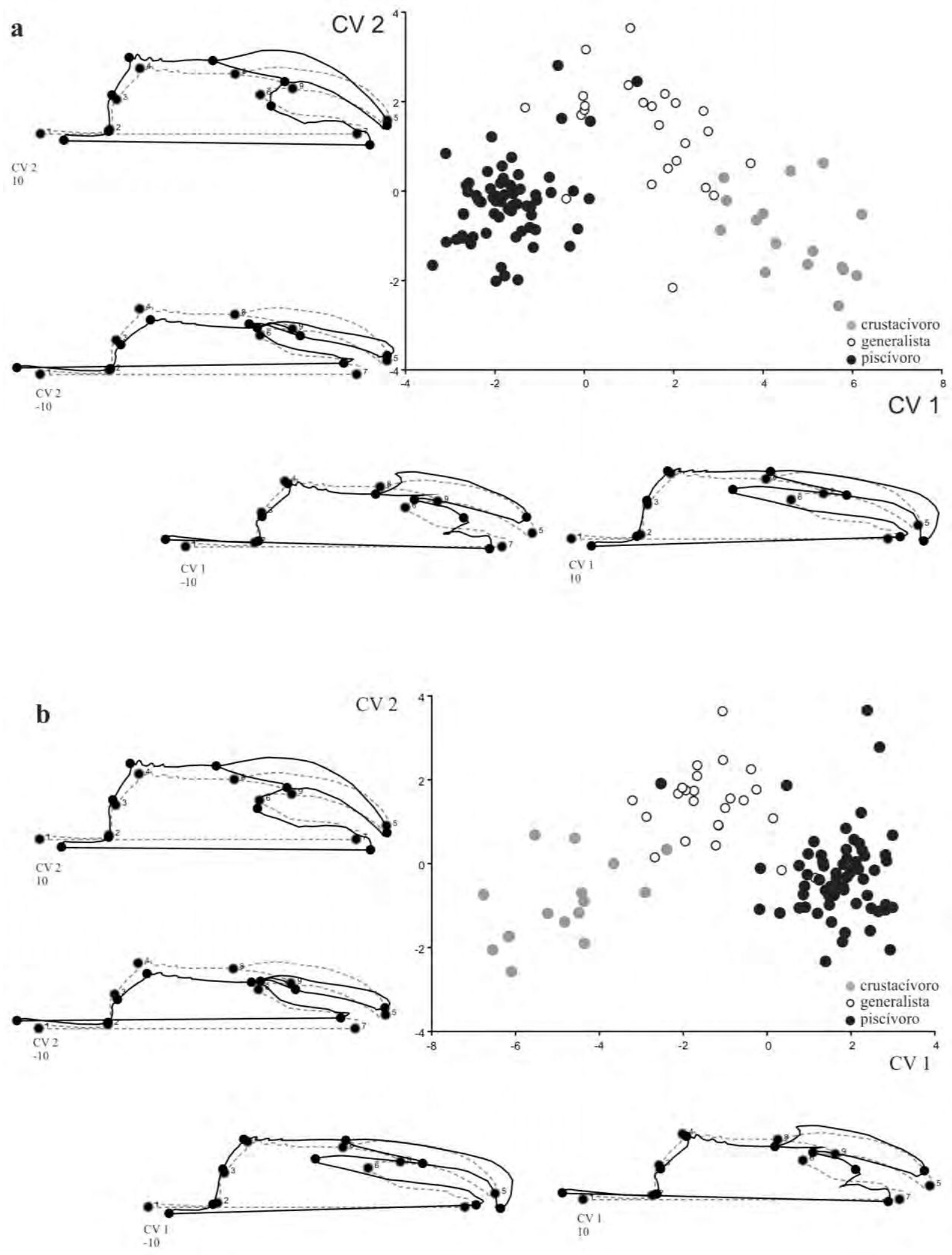

Figura 22 Análisis de variación canónica del esternón en vista lateral. Gráficos de dispersión de los primeros dos $\mathrm{CV}$, con el cambio de forma para los valores magnificados de cada $\mathrm{CV}$ para $\mathbf{a}$, datos originales; $\mathbf{b}$, datos corregidos. Las líneas grises punteadas representan la forma promedio mientras que las negras representan los valores extremos de cada CV. 


\section{DISCUSIÓN INTEGRAL DE LOS ANÁLISIS DEL ESTERNÓN}

Para el esternón, el número total de individuos utilizados en los análisis se vio reducido principalmente para la vista lateral. Al igual que en los resultados de los otros análisis, las formas crustacívoras resultaron más robustas. Una de las características que ayudó a separar grupos fue una incisura caudolateralis abierta y profunda para las formas crustacívoras, lo que implica un área mayor de membrana que conecta porciones del esternón (corpus y trabecula lateralis) en el lugar de origen del m. surpacoracoideus. Además, se encontró en las formas piscívoras una quilla más desarrollada (apex carinae) y en forma puntiaguda. Esta característica acerca el origen del $\mathrm{m}$. pectoralis thoracica al húmero. Las formas crustacívoras presentarían un ancho de la trabecula caudolateralis acompañada de una mayor longitud de la línea intermuscular de la trabecula caudolateralis.

\section{DISCUSIONES Y CONCLUSIÓN}

Las formas crustacívoras, representadas principalmente por Pygoscelis, resultan ser más robustas. Esto es así tanto para las piezas óseas analizadas como para los músculos diseccionados y descritos.

Para los análisis de morfometría geométrica resultó que el tamaño explicó un porcentaje significativo aunque muy bajo para la mayoría de las configuraciones. Los porcentajes de la forma explicada por el tamaño son incluso menores a los encontrados en muchos otros trabajos de aves (Bright et al., 2016; Yamasaki et al., 2018), y más cercanos a lo propuesto por Klingenberg y Marugán Lobón (2013).

Los resultados entre el conjunto de datos originales y corregidos no fueron muy variables. Sólo para Aptenodytes y Eudyptula se vieron las mayores diferencias en cuanto a la ubicación de los especímenes en los PCA, lo cual es de esperarse debido a que representan las formas actuales más grandes y pequeñas que existen entre los pingüinos. 
Las categorías dietarias resultaron significativas para todos los análisis excepto en algunos en los cuales el n final se vio muy reducido. Esto indicaría que las categorías son realmente confiables y que los resultados encontrados en la variación de forma estarían estrechamente relacionados con la función de la misma en los movimientos de persecución y captura de las presas.

Todos los músculos que originan en la cintura escapular e insertan en el húmero convierten al sistema cavidad glenoidea/húmero en una palanca de tercer grado, en la cual las fuerzas necesarias para el movimiento se encuentran entre el fulcro (la articulación del húmero con la cavidad glenoidea) y la resistencia a vencer. Las articulaciones serían más móviles para Spheniscus y, en muchos casos, Spheniscus presentaría brazos de palanca de entrada menores a los presentados en formas crustacívoras cómo Pygoscelis. Por su parte, las grandes fuerzas de los músculos presentes en Pygoscelis estarían estabilizadas por la curvada superficie de la facies articularis sternalis (Bannasch, 1994).

El musculus pectoralis thoracica es el más robusto de los músculos involucrados en el vuelo subacuático (Tabla 8) (Schreiweis, 1982; Bannasch, 1994), característica compartida con el resto de las aves (George \& Berger, 1966). El aumento de volumen a lo largo de su ontogenia se hace abrupto desde los últimos estadios de pichón, al igual que es el caso del $m$. supracoracoideus. Las tres partes de este músculo estarían involucradas en distintas secciones del movimiento durante el aleteo hacia abajo (abducción del ala). La pars clavicularis, la más anterior de todas las partes, sería la encargada de iniciar el movimiento de descenso del ala, al mismo tiempo que limitaría el movimiento posterior del ala (componentes aportadas por las otras dos partes) (Bannasch, 1994). La parte caudolateral y principalmente la medial son las responsables de la fuerza ejercida sobre el ala hacia abajo.

El m. supracoracoideus es un músculo que se encuentra más desarrollado en pingüinos debido a que deben elevar el ala en un medio mucho más denso. Es el principal actor en este movimiento del ala y su origen ocupa gran parte del esternón (ver $M$. supracoracoideus, en Resultados: Disecciones musculares) (Schreiweis, 1982; Bannasch, 1994). Su inserción en el húmero deja, una de las cicatrices más notorias en este hueso. La inclinación, y el grado de desarrollo de la impresión que deja habla de un músculo más robusto y con una disposición de su tendón más oblicua a la diáfisis en Pygoscelis, condición que se repite para las formas crustacívoras. Esto también se condice con lo obtenido para el coracoides, en el cual las formas crustacívoras presentarían un surco para el paso del $\mathrm{m}$. 
supracoracoideus más marcado. Las diferencias en desarrollo de este músculo no han sido tratados por Schreiweis (1982), mientras que Bannasch (1994) compara el m. pectoralis con respecto al $m$. supracoracoideus pero sólo para Pygoscelis antarctica $(1: 1,98)$, y Aptenodytes forsteri $($, )

Si bien los pesos de los músculos nos indican un mayor peso para Pygoscelis que Spheniscus, lamentablemente los datos resultan insuficientes para evaluar cuantitativamente cuáles son las diferencias en peso entre estas dos formas ecomorfológicas extremas de manera fehaciente. Sin embargo, se espera en un futuro cercano contar con más datos al respecto para poder analizarlo con un mayor grado de confianza. 


\section{MODULARIDAD, INTEGRACIÓN Y CORRELACIÓN ENTRE ESTRUCTURAS}

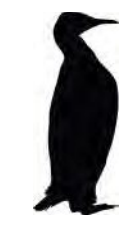

\section{INTRODUCCIÓN}

La morfología del cráneo y de los elementos de la cintura pectoral presentaron un cambio de forma significativo entre las categorías alimentarias señaladas (Ver Capítulo III y IV). Esto significa que es posible caracterizar morfoanatómicamente a las formas piscívoras y a las crustacívoras a partir de los elementos del cráneo, el ala y la cintura pectoral. En esta etapa resulta interesante estudiar si existe una correlación en la variación de los diferentes elementos óseos entre sí. Dos preguntas fundamentales surgen:

1. ¿Existen módulos en el cráneo o se ha desarrollado como una estructura integrada?

2. ¿Existe una tendencia en la variación del cráneo con respecto al ala, y entre el húmero y la cintura pectoral?

La morfometría geométrica cuenta con un amplio número de herramientas para abordar una infinidad de preguntas morfológicas, entre ellas los conceptos de integridad y modularidad. Dos conceptos que están íntimamente ligados entre sí. En este marco, resulta necesario definir algunos conceptos generales.

Klingenberg (2014) define integración como,

“...la tendencia de diferentes rasgos a variar conjuntamente, de manera coordinada, a través de una estructura morfológica o incluso de un organismo completo." 
Entonces, en muchos casos la integración morfológica es tendiente a concentrarse en ciertos complejos específicos que a su vez serían independientes de otros complejos (Klingenberg, 2013). Esta condición da origen entonces a módulos.

La modularidad morfológica implicaría entonces una,

“integración ... compartimentada, con una fuerte integración dentro del módulo y una débil entre módulos" (Klingenberg, 2013).

La modularidad ha sido abordada desde la morfometría geométrica en diferentes trabajos (Klingenberg, 2009; Klingenberg et al, 2010), en peces (Kimmel et al., 2012), salamandras (Ivanović \& Kalezić, ), lagartijas (Sanger et al., 2012), homínidos (Mitteroecker \& Bookstein, 2008; Bruner et al., 2010; Martínez-Abadías et al., 2012; Wellens et al., 2013), y en otros grupos de mamíferos (Klingenberg, et al., 2004; Hallgrímsson et al., 2009; Klingenberg, 2009; Drake \& Klingenberg, 2010; Jamniczky \& Hallgrímsson, ; Jojić et al., 2012; del Castillo et al., 2017). En aves también se ha estudiado la modularidad de ciertas estructuras como el cuello de los pingüinos (Guinard \& Marchand, 2010), entre músculos y estructuras osteológicas craneales en loros (Tokita et al., 2007), y en cráneos desde la morfometría geométrica (en cuervos, Yamasaki et al., 2017; entre todos los órdenes de aves, Klingenberg \& Marugan, 2013).

Estudios recientes vinculan la evolución del cráneo aviano a procesos de pedomorfosis (Bhullar et al., 2012; Bhullar et al., 2016), lo cual se cree que llevaría a una evolución integral del cráneo (Klingenberg \& Marugán Lobón, 2013). De todas maneras, otras presiones adaptativas, entre ellas funcionales, han llevado a indagar sobre posibles cambios diferenciales en las regiones craneales, con resultados negativos (Klingenberg \& Marugán Lobón, 2013). Otros trabajos han hallado porcentajes medios a bajos de variación morfológica explicada por integración, que interpretan como una evolución flexible del pico mediante presiones selectivas puntuales (Yamasaki et al., 2017). Klingenberg y Marugan (2013) abordaron la temática en un estudio que incluyó representantes de todos los órdenes de aves, obteniendo, como se mencionó con anterioridad, que el cráneo varía en las aves como una unidad integrada. Podemos, entonces, evaluar hipótesis de modularidad de diferentes estructuras como el cráneo, y además, de existir, estudiar la covariación de esos módulos, así también como la covariación de diferentes estructuras esqueletales. 
En el presente capítulo evaluamos hipótesis de modularidad del cráneo, incluyendo el pico, que no fue incluido en Klingenberg y Marugan (2013) por presentar alta variabilidad entre sus especies bajo estudio. Además, se estudió si existe, y de qué tipo es, la covariación entre elementos craneales por un lado, y elementos alares por el otro, y a su vez entre el cráneo y el ala. Como se explica en el Capítulo II, los análisis serán duplicados, es decir que se presentarán con los datos originales de coordenadas de procrustes, y los corregidos del efecto alométrico con los residuos de la regresión.

\section{MATERIALES}

La lista de especímenes que se utilizaron para cada conjunto de análisis se encuentra detallada en el Anexo II. Las configuraciones de landmarks que se utilizaron para cada análisis se encuentran especificadas en el texto y son las mismas que se estudiaron en los capítulos III y IV.

\section{MÉTODOS}

En el cráneo se evaluó una hipótesis de modularidad (Fig. 1), que incluyó dos módulos hipotéticos: por un lado a la caja craneana, y por el otro el pico. Se obtuvo un coeficiente RV que nos permitió comparar la hipótesis propuesta con alternativas encontradas al azar. Estos módulos también fueron estudiados mediante un análisis de mínimos cuadrados parciales (PLS).

Esto se realizó con el fin de evaluar patrones de covariación entre cráneo y mandíbula, que podrían brindar información valiosa de estos complejos relacionados con el hábito alimenticio. También se quiso evaluar si realmente estructuras directamente relacionadas con el hábito alimenticio covarían y de qué forma con los elementos directamente relacionados con el buceo, como lo es el húmero, y el coracoides.

Para los análisis de mínimos cuadrados parciales (PLS), las configuraciones que se estudiaron corresponden a preguntas específicas y se limitaron a las siguientes: 
- caja craneana en vista dorsal - mandíbula en vista dorsal

- pico en vista dorsal - mandíbula en vista dorsal

- caja craneana en vista dorsal - húmero en vista dorsal

- húmero en vista dorsal - coracoides en vista dorsal

Los análisis realizados en el presente capítulo fueron llevados a cabo con el software MorphoJ.
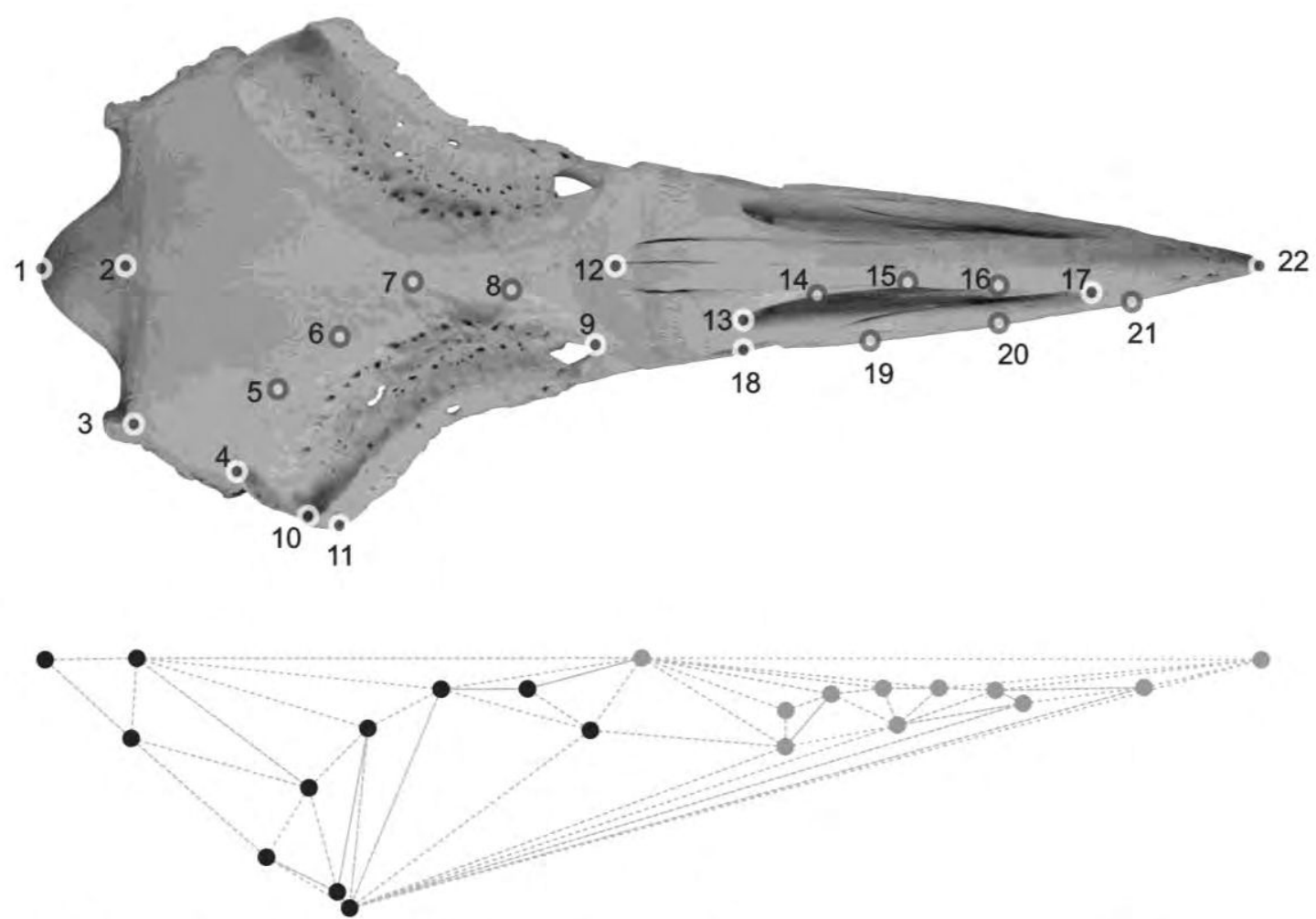

Figura 1 Hipótesis de modularidad del cráneo. En negro el bloque caja craneana, y en gris el bloque pico.

\section{RESULTADOS}

\section{Hipótesis de Modularidad}

La hipótesis de modularidad planteada para el cráneo (ver Métodos, en este mismo capítulo) resultó tener un RV alto, tanto para los datos corregidos del efecto alométrico como los originales. Se encontraron particiones calculadas al azar con RV menores al obtenido para la hipótesis de modularidad propuesta (Tabla 1). 
Tabla 1 Hipótesis de modularidad, valores RV.
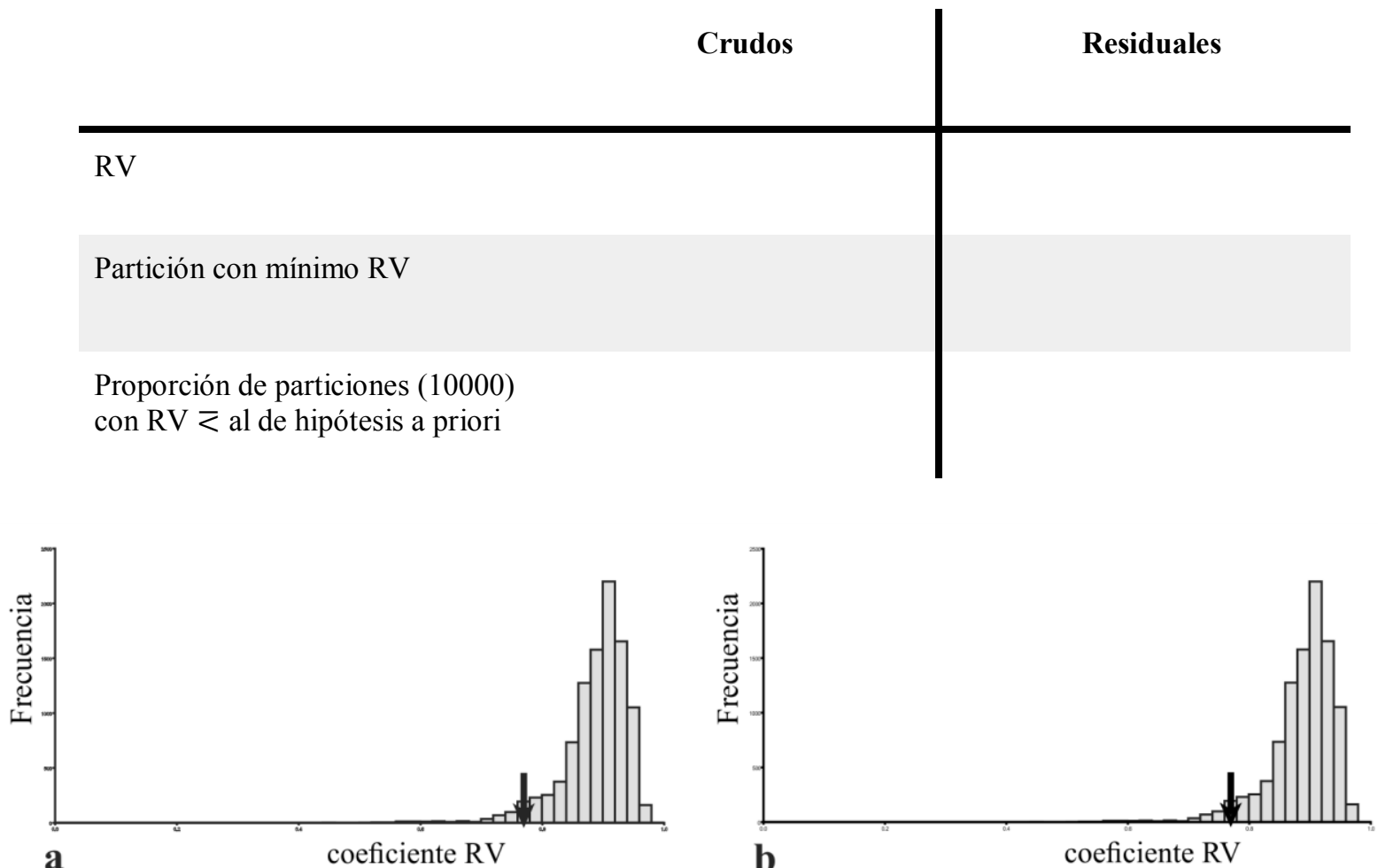

Figura Evaluación de hipótesis de modularidad, valor de coeficiente RV del análisis. a, datos originales; $\mathbf{b}$, datos corregidos.

\section{Covariación entre estructuras: PLS}

\section{PLS: Caja craneana dorsal-Mandíbula}

Para el análisis de mínimos cuadrados parciales de la configuración de la caja craneana y la mandíbula obtuvimos un coeficiente RV alto para los datos originales aunque moderado para los datos corregidos (Tabla 2). El PLS 1 fue el que presentó más de un 98\% de la variación total para ambos análisis.

Tabla 2 Análisis de mínimos cuadrados parciales (PLS) entre la configuración del cráneo dorsal y mandíbula dorsal. Resultados para el conjunto de datos originales de las coordenadas de procrustes, y de los corregidos con los de los residuos de la regresión para corrección del efecto alométrico. 


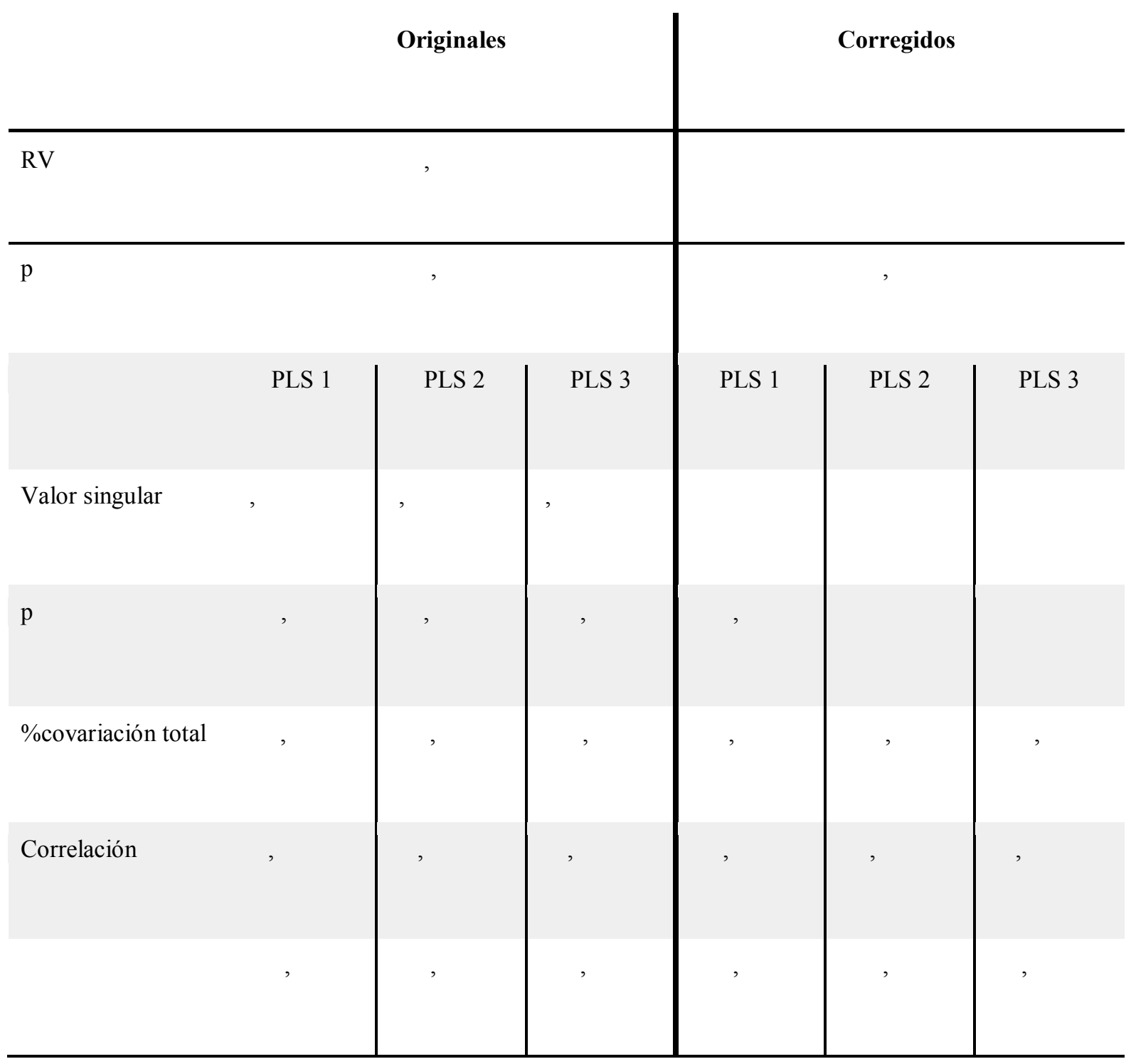

Para el PLS 1, en el bloque 2 (cráneo posterior) vemos que se presentan dos grupos claramente separados: Spheniscus por un lado, y por el otro el resto de las especies (Fig. 3). Para los datos corregidos, estos dos grupos también se formaron aunque, quedando Aptenodytes entre medio. En cuanto a la mandíbula (bloque 1), vemos que para el análisis con datos originales se separa en dos grupos: por un lado Spheniscus y por el otro a todas las demás especies. En el análisis con los datos corregidos, Aptenodytes y Pygoscelis quedan hacia los valores positivos junto con Madrynornis, y hacia los valores negativos estarían Spheniscus, Eudyptula, quedando Eudyptes en valores intermedios. En este último análisis Madrynornis quedó junto con Pygoscelis mientras que para el análisis con datos originales quedó cercano a Eudyptes. 
a
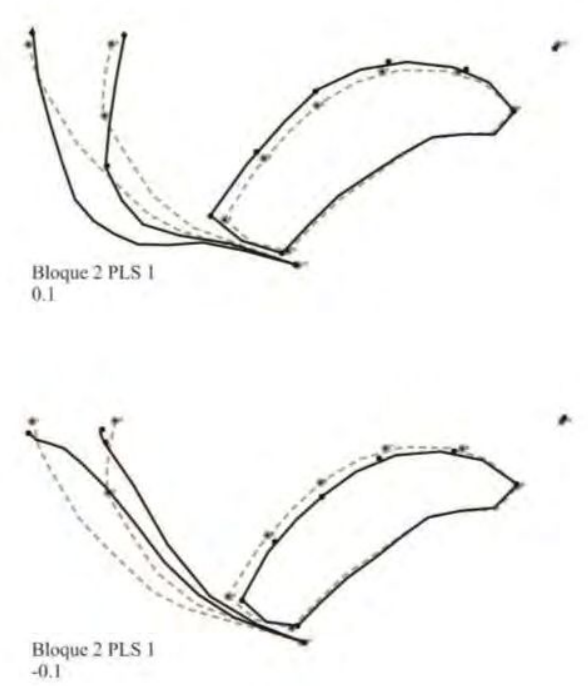

Bloque 2 PLS

$-0.1$
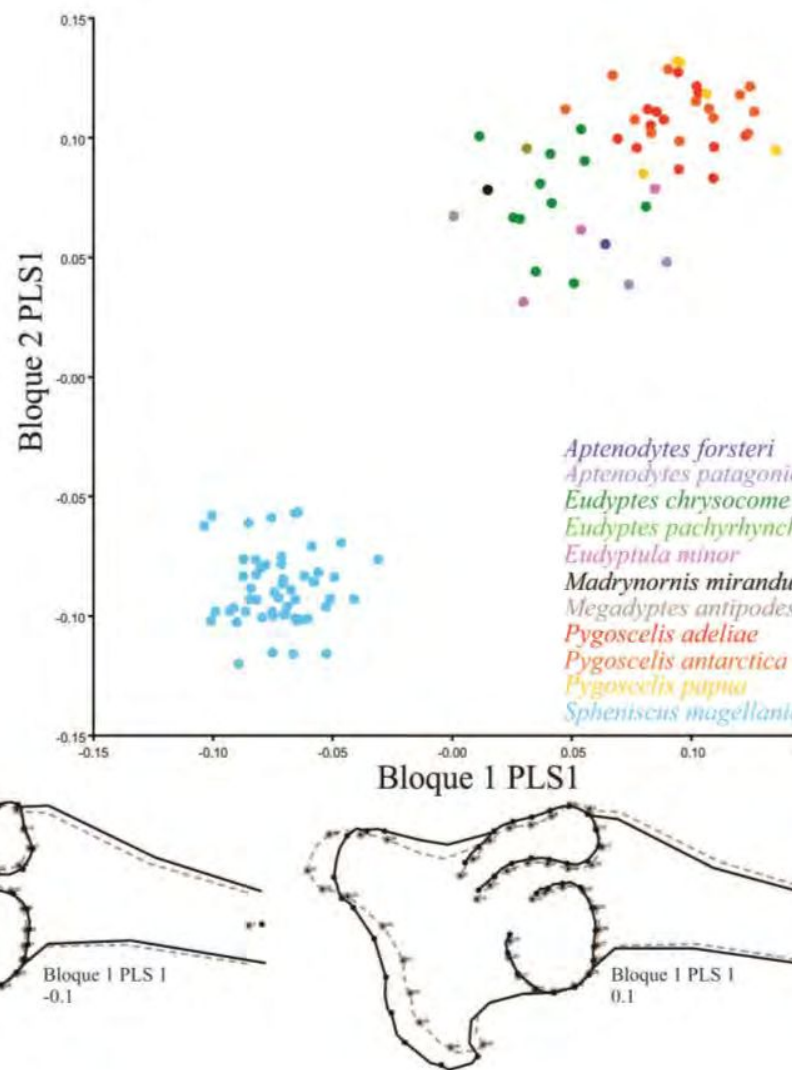

Aptenodytes forsteri Eptentwases patagonicus Eudyptes chrysocome Eudyptes pachyrhynchus Endypiula ninor Madrynornis mirandus Megadyples antipodes Pygoscelis adeliae Pygoscelis antarctica $\mathrm{0}_{0.10}^{0.15}$ Bloque 1 PLS1
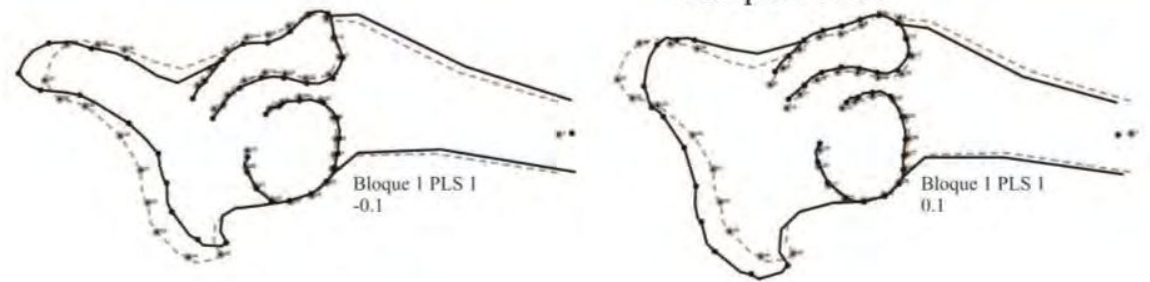

b

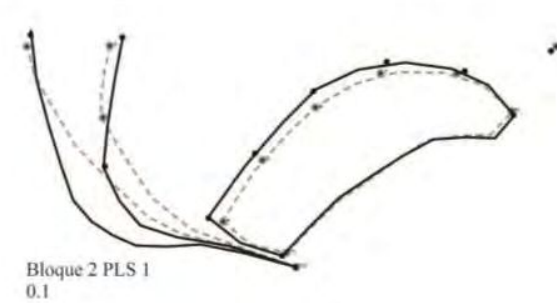

0.1
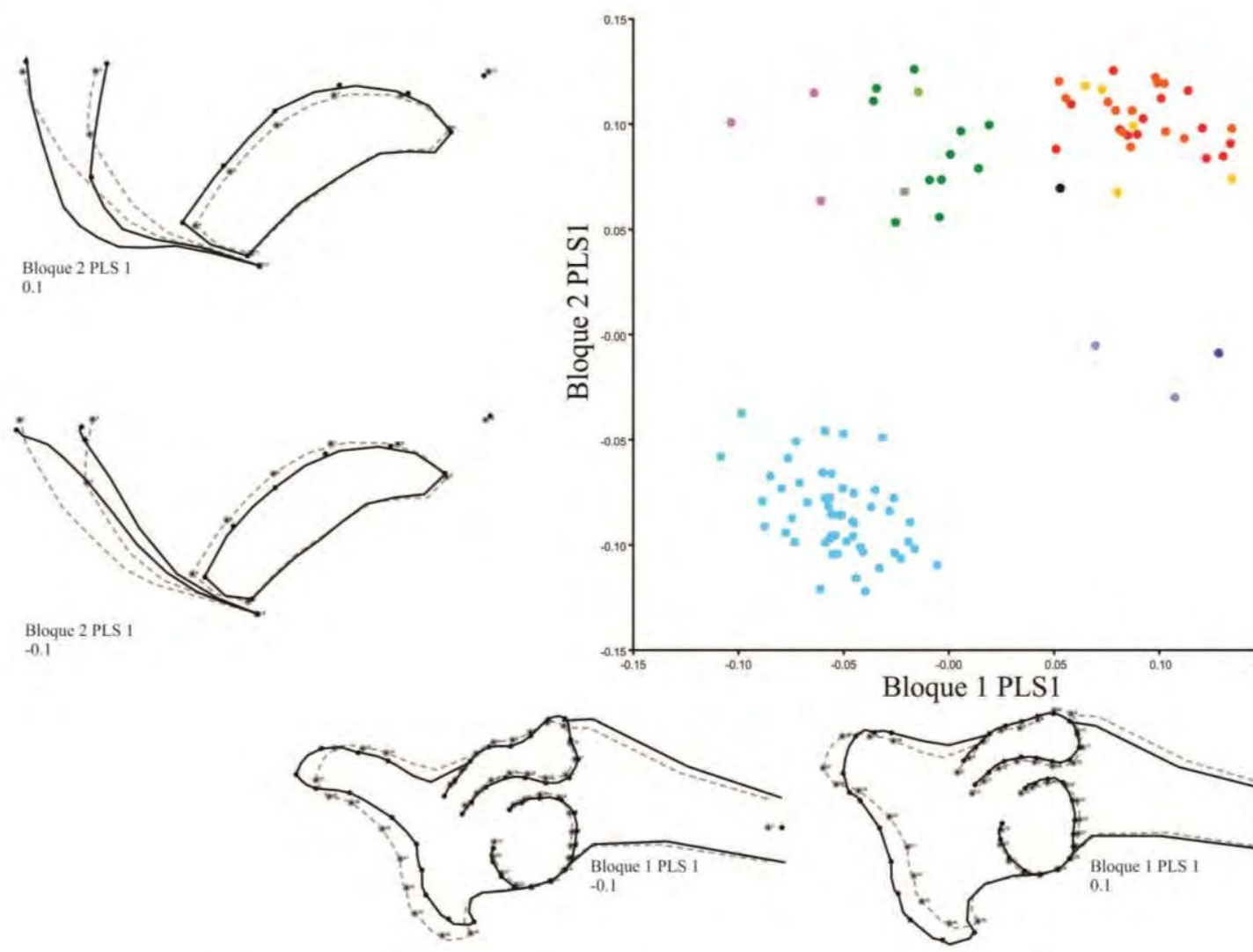

Bloque 2 PLS

$-0.1$

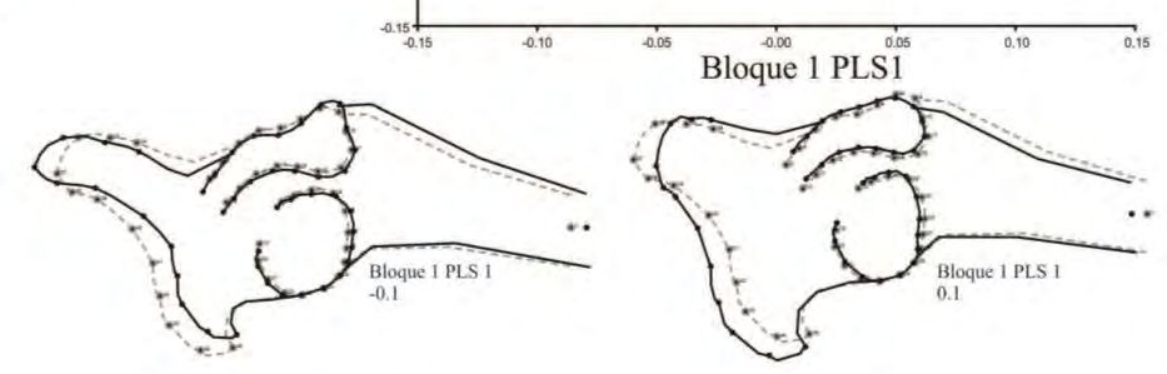

Figura 3 Análisis de mínimos cuadrados parciales entre la mandíbula dorsal y la caja craneana dorsal. Gráficos de dispersión del primer PLS para los dos bloques con el cambio de forma para los valores extremos eje a, datos originales; $\mathbf{b}$, datos corregidos. Las líneas grises punteadas representan la forma promedio mientras que las negras representan los valores extremos de cada bloque. 
Las formas ubicadas hacia los valores positivos del bloque 1, es decir la mandíbula, presentan morfologías con un moderado desarrollo del proceso retroarticular, una cotyla lateralis no claramente separada de la c. caudalis, y un proceso coronoideo más cercano a la articulación (Fig. 3). Estas formas mandibulares (Pygoscelis, Eudyptes, Megadyptes, Aptenodytes y Eudyptula) serían correspondientes con un desarrollo menor de la fosa temporal, y una fosa glandular nasal más desarrollada consecuente con una región frontal más angosta. Por otro lado, las mandíbulas con un proceso retroarticular delgado y protruyente y con una cotyla lateralis claramente separada de la c. caudalis (Spheniscus) se corresponden con formas craneales más gráciles con fosas temporales más desarrolladas y fosas glandulares nasales más angostas. Spheniscus presenta una morfología bien diferenciada en cuanto al desarrollo de la fossa temporalis como del proc. coronoideus, por lo que la separación de este taxón con las demás especies era esperable. Las demás especies piscívoras se acercan a Spheniscus desde diferentes bloques, Aptenodytes por la caja craneana, y Eudyptula por la mandíbula.

\section{PLS: pico-mandíbula}

Para el PLS del pico-mandíbula, los valores RV obtenidos resultaron un poco más bajos que para el anterior análisis (Tabla 3 ). Siendo 0,76 para los datos originales y 0,46 para los corregidos.

Tabla 3 Análisis de mínimos cuadrados parciales (PLS) entre la configuración del pico dorsal y mandíbula dorsal. Resultados para el conjunto de datos originales de las coordenadas de procrustes, y de los corregidos con los de los residuos de la regresión para corrección del efecto alométrico.

\begin{tabular}{|c|c|c|}
\hline & Originales & Corregidos \\
\hline RV & , & , \\
\hline $\mathrm{p}$ & , & , \\
\hline
\end{tabular}




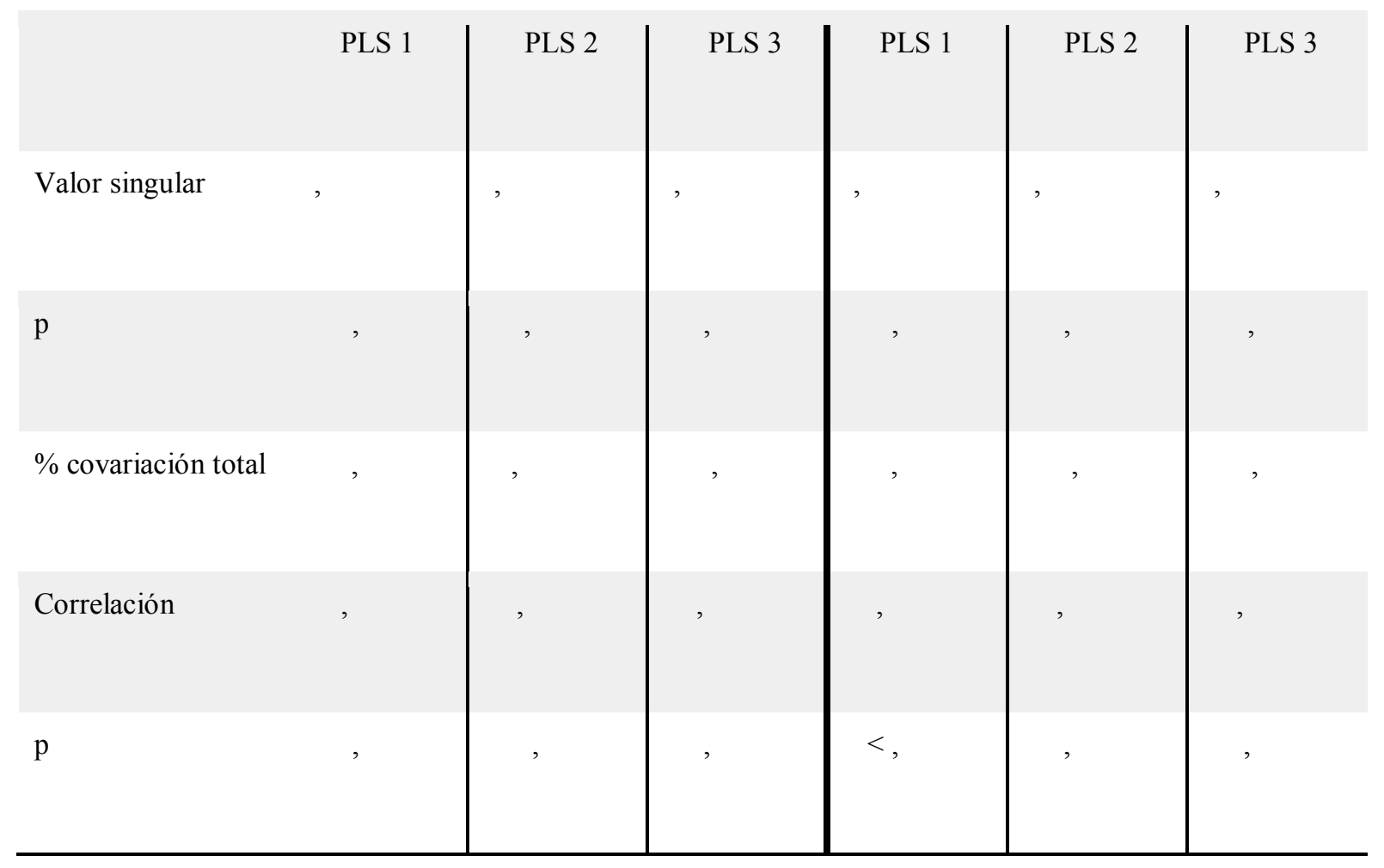

Para el bloque 1, la mandíbula, observamos en el análisis con los datos originales un gradiente desde Spheniscus magellanicus, pasando por Aptenodytes, Eudyptes, Madrynornis, Megadyptes, hasta llegar a Pygoscelis (Fig. 4). En el caso de los análisis con datos corregidos, el bloque 1 agrupa a Spheniscus y Eudyptula, Eudyptes y Megadyptes quedan en los valores intermedios, y Pygoscelis y Aptenodytes hacia los valores positivos. Para el bloque 2 (pico), Spheniscus queda en un extremo opuesto a Pygoscelis, con Eudyptes más cercano a Pygoscelis y Eudyptula y Aptenodytes más cercano a Spheniscus. Si tomamos en cuenta el análisis con los datos corregidos, vemos en el gráfico que las formas piscívoras se acercan entre sí, pero en bloques diferentes, teniendo Eudyptula mayor acercamiento por la mandíbula, mientras que Aptenodytes por el pico. Siguiendo con este análisis (Fig. 4b), las formas mandibulares relacionadas a los crustacívoros con processus retroaticularis más robustos y cortos, con cotylae lateralis y c. caudalis no claramente diferenciables y proc. coronoideos más cercanos a la articulación, se correlacionan de manera moderada a baja con picos robustos con fosas nasales largas y amplias. 
a

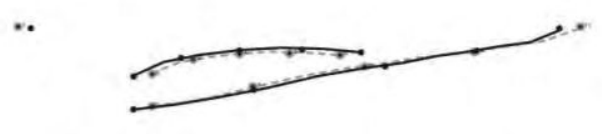

Bloque 2 PLS I
0.1

$\cdots$
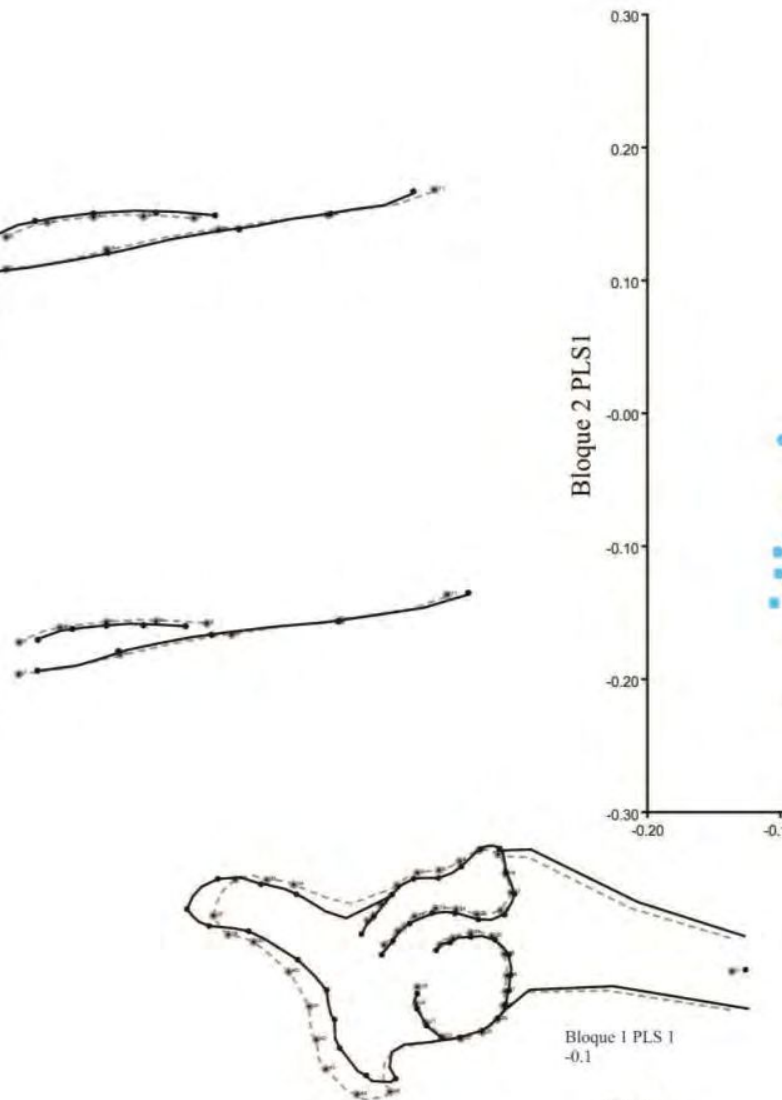

b

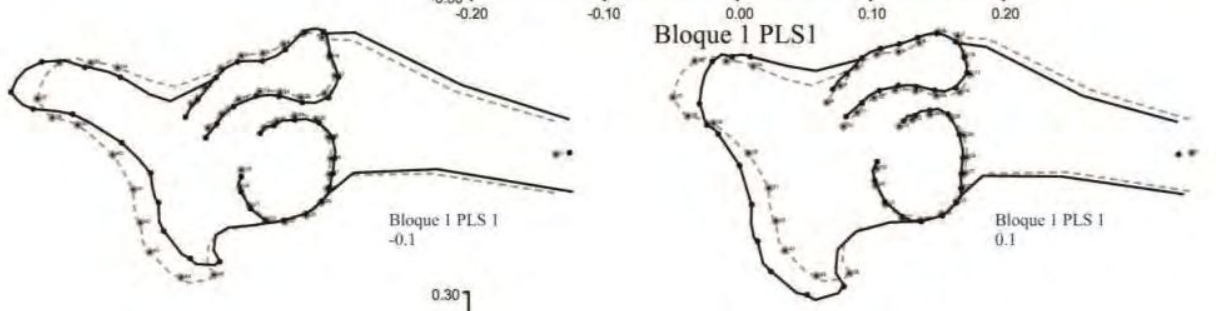

$\cdots$

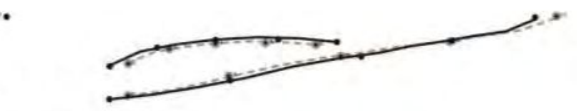

Bloque 2 PLS 1
0.1
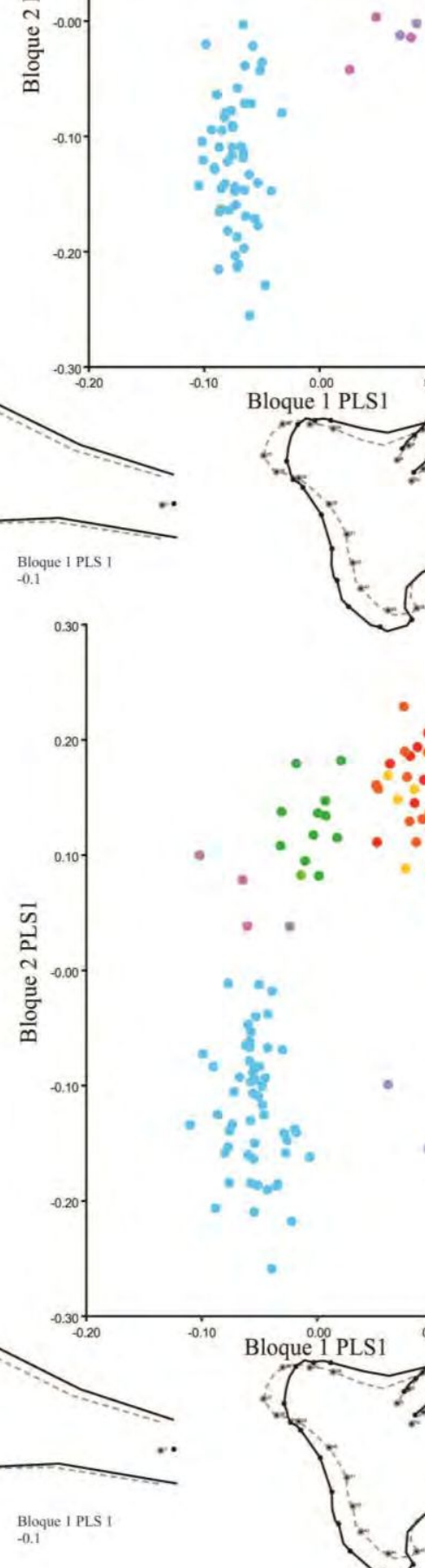

Aptenodytes forsteri Eudyptes chrysocome Eudyptes pachyrhynchus Eudyptula minor Megadyptes antipode. Pygoscelis adeliae Bloque 2 PLS 1
-0.1

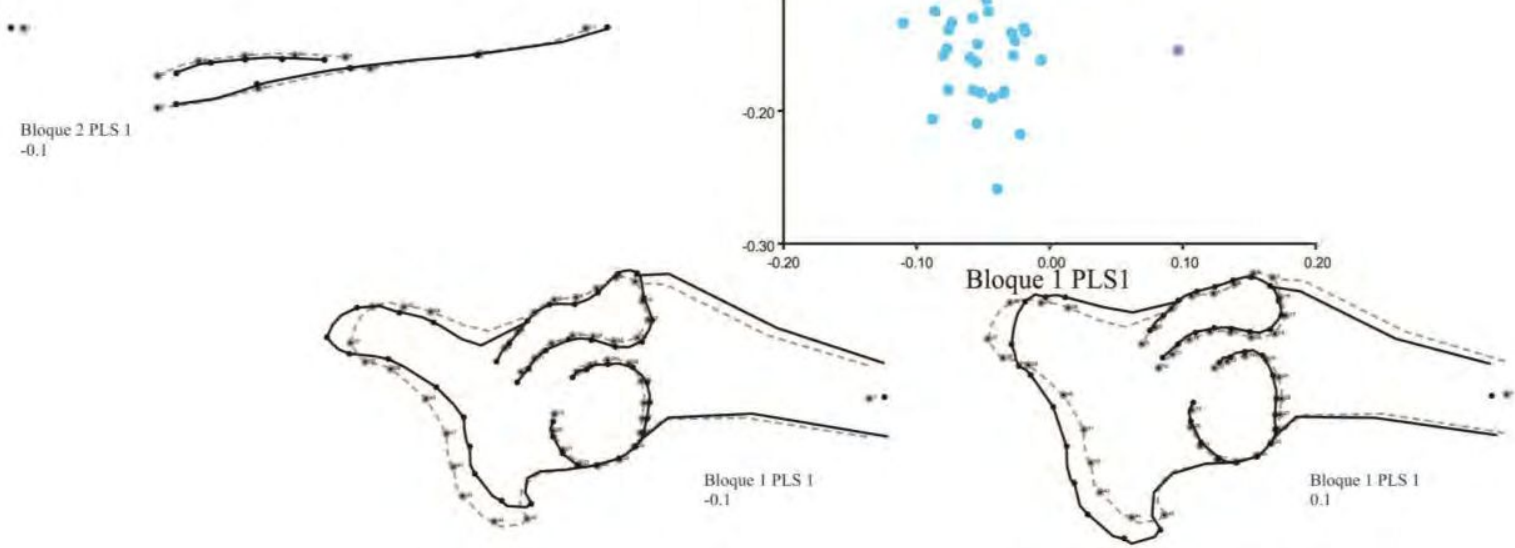

Figura 4 Análisis de mínimos cuadrados parciales entre el húmero caudal y el coracoides dorsal. Gráficos de dispersión del primer PLS para los dos bloques con el cambio de forma para los valores extremos eje a, datos originales; b, datos corregidos. Las líneas grises representan la forma promedio mientras que las negras representan los valores extremos de cada bloque. 


\section{PLS: caja craneana dorsal-húmero dorsal}

Si bien se exploraron las correlaciones entre el cráneo y el húmero en ambas vistas, se optó por discutir los resultados del cráneo con el húmero dorsal, debido a que resultaron similares con ambas configuraciones del húmero. Para esta configuración obtuvimos un coeficiente RV (Tabla 4) moderado a alto y muy similar entre los datos originales y los corregidos. Cabe recordar que para estas dos configuraciones el porcentaje de la variación en forma influenciada por un efecto alométrico resultó bajo.

Tabla 4 Análisis de mínimos cuadrados parciales (PLS) entre la configuración del cráneo dorsal y el húmero dorsal. Resultados para el conjunto de datos originales de las coordenadas de procrustes, y de los corregidos con los de los residuos de la regresión para corrección del efecto alométrico.

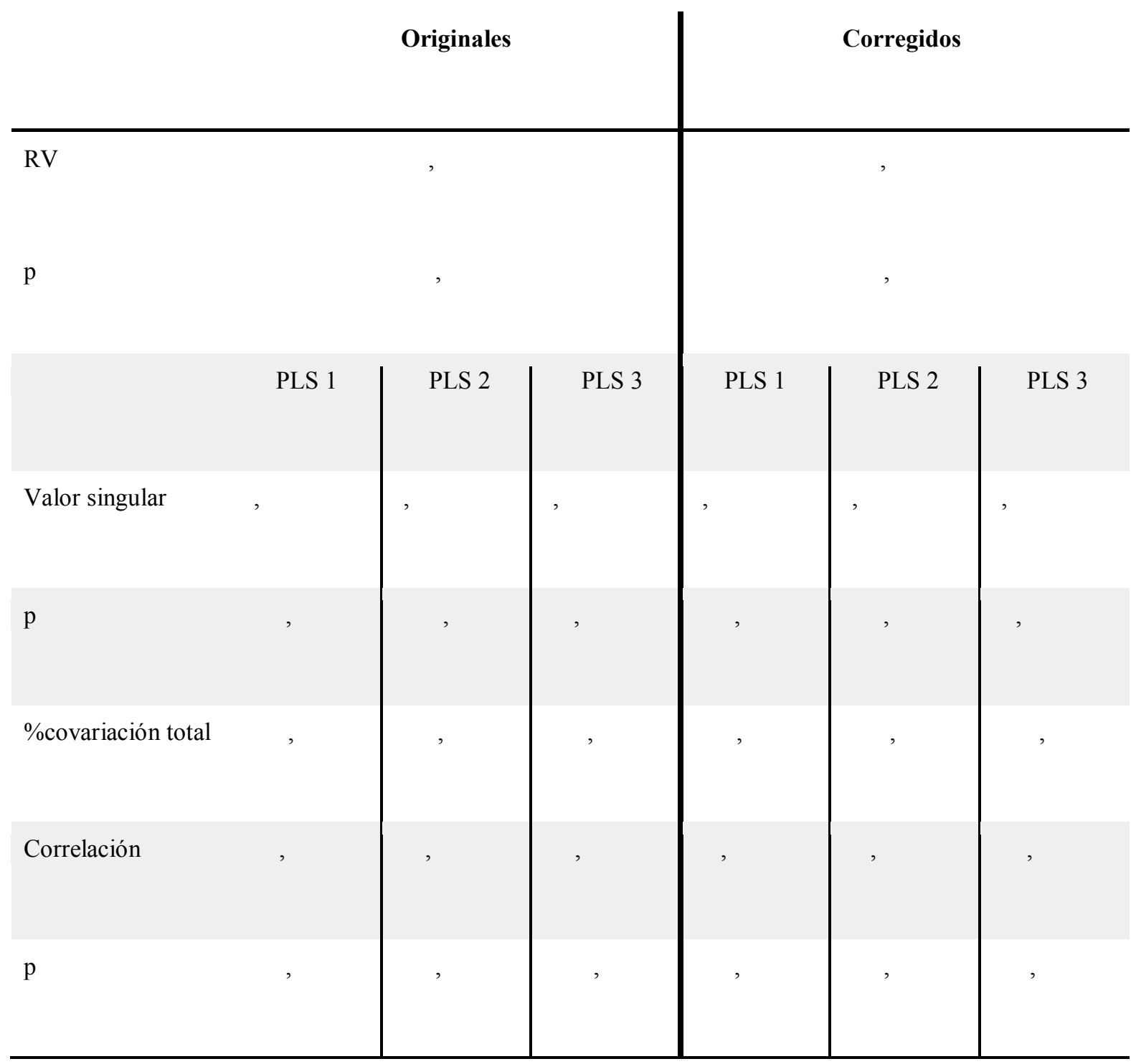


a

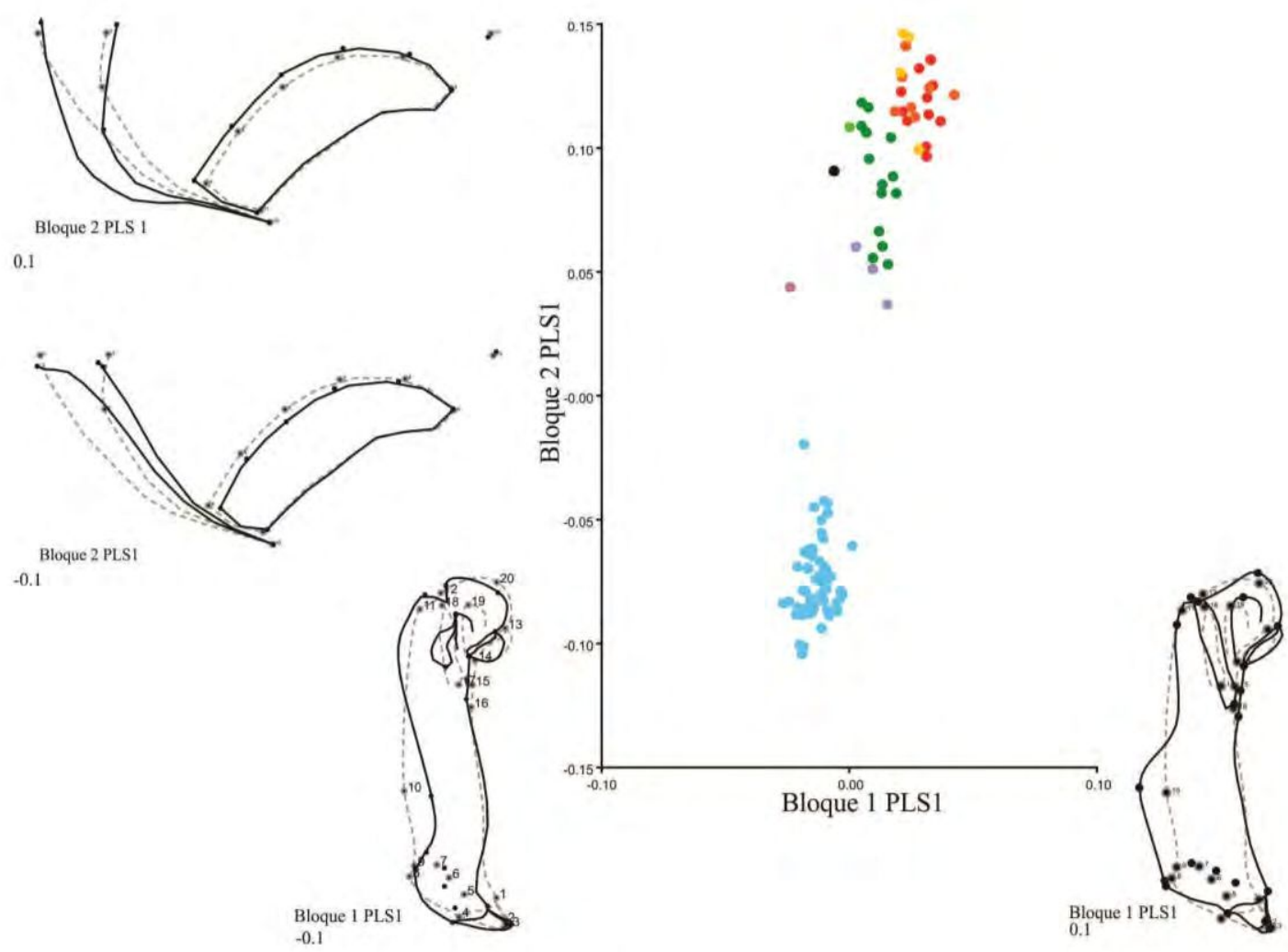

b
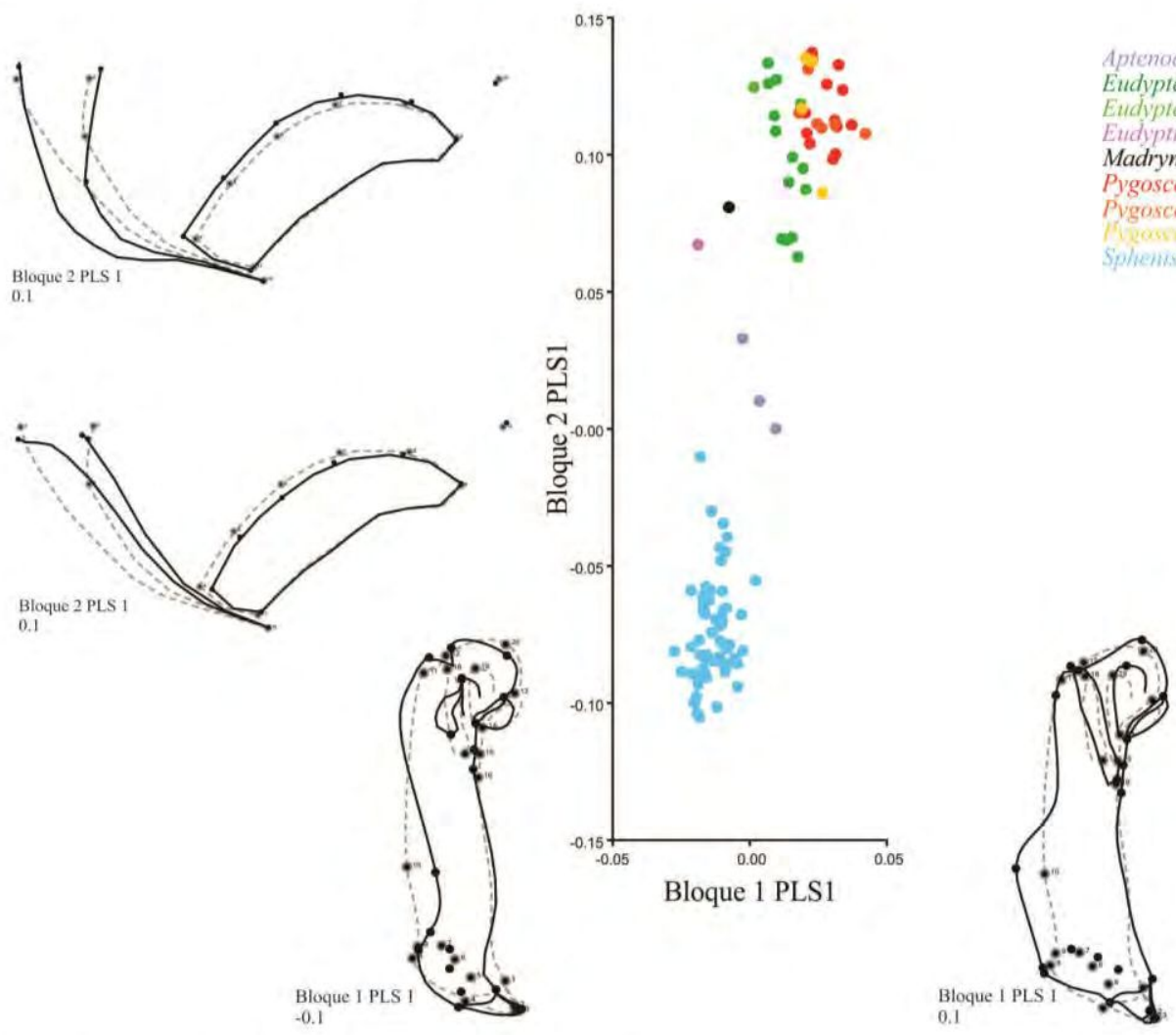

Figura 5 Análisis de mínimos cuadrados parciales entre la caja craneana dorsal y el húmero dorsal. Gráficos de dispersión del primer PLS para los dos bloques con el cambio de forma para los valores extremos eje a, datos originales; $\mathbf{b}$, datos corregidos. Las líneas grises representan la forma promedio mientras que las negras representan los valores extremos de cada bloque. 
Nuevamente observamos un agrupamiento de Spheniscus hacia un cuadrante mientras que Pygoscelis queda en el cuadrante opuesto. Aptenodytes queda en una posición intermedia más cercano a Spheniscus, Eudyptes más cercano a Pygoscelis, y Madrynornis entre medio aunque más cercano a Eudyptes (Fig. 5). Parecería haber una correlación entre las formas con húmeros robustos, con amplias inserciones del $m$. supracoracoideus, con una articulación con el zeugopodio perpendicular a diáfisis, y angulus preaxialis marcados hacia afuera; con cráneos robustos, fosas temporales de moderado desarrollo. Mientras que las formas con humeros gráciles, con una mayor angularidad de la articulación del zeugopodio con respecto a la diáfisis, e inserciones del $m$. supracoracoideus de menor longitud, estarían correlacionadas de manera moderada a alta con formas con amplias fosas temporales en el cráneo, y con fosas glandulares más delgadas.

\section{PLS: húmero dorsal -coracoides dorsal}

Nuevamente, se obtuvo una mínima diferencia entre el RV de los análisis hechos con los datos originales y con los corregidos. El coeficiente resultó de moderado a bajo (Tabla 5).

Tabla 5 Análisis de mínimos cuadrados parciales (PLS) entre la configuración del húmero dorsal y el coracoides dorsal. Resultados para el conjunto de datos originales de las coordenadas de procrustes, y de los corregidos con los de los residuos de la regresión para corrección del efecto alométrico.

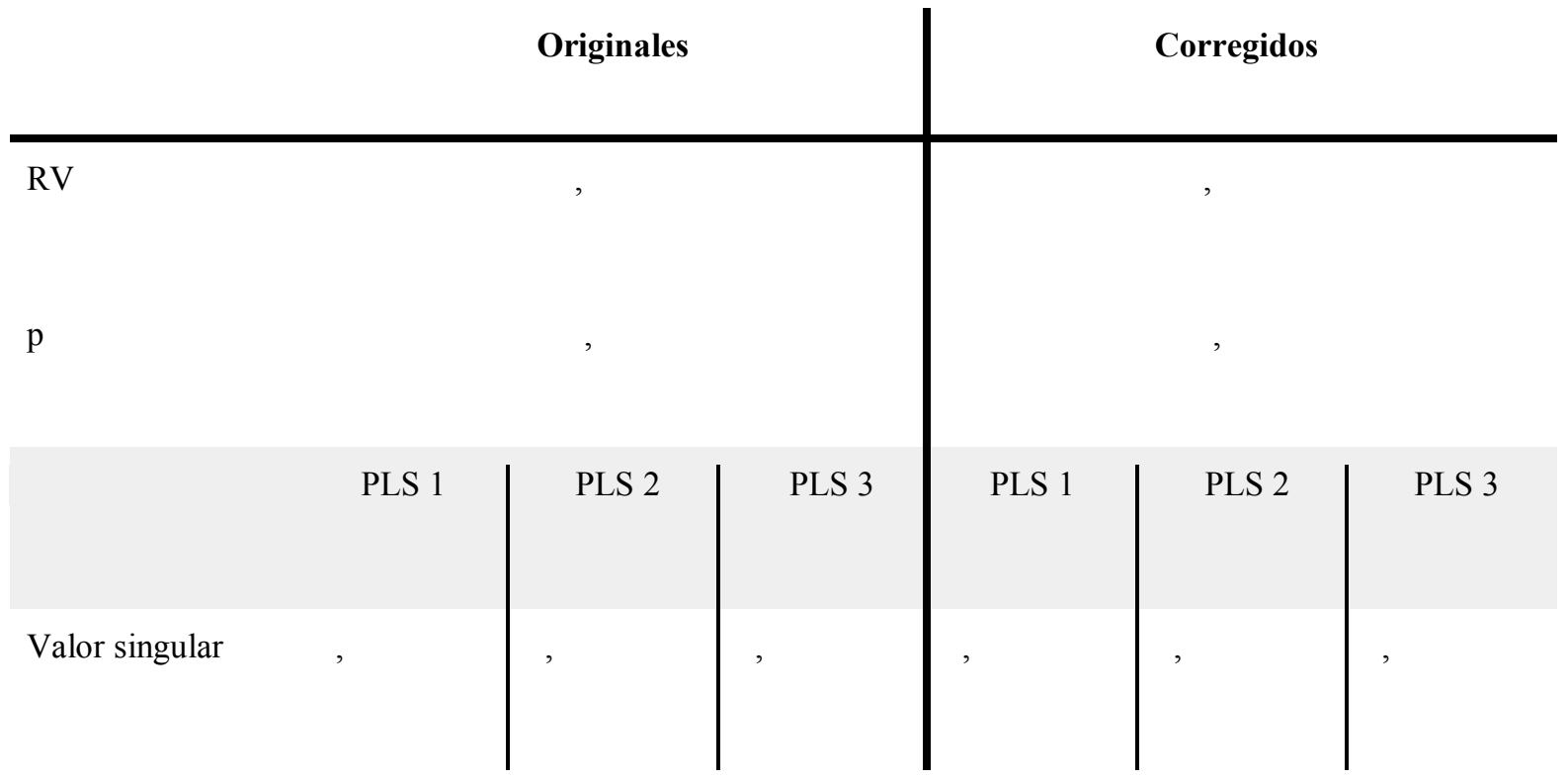




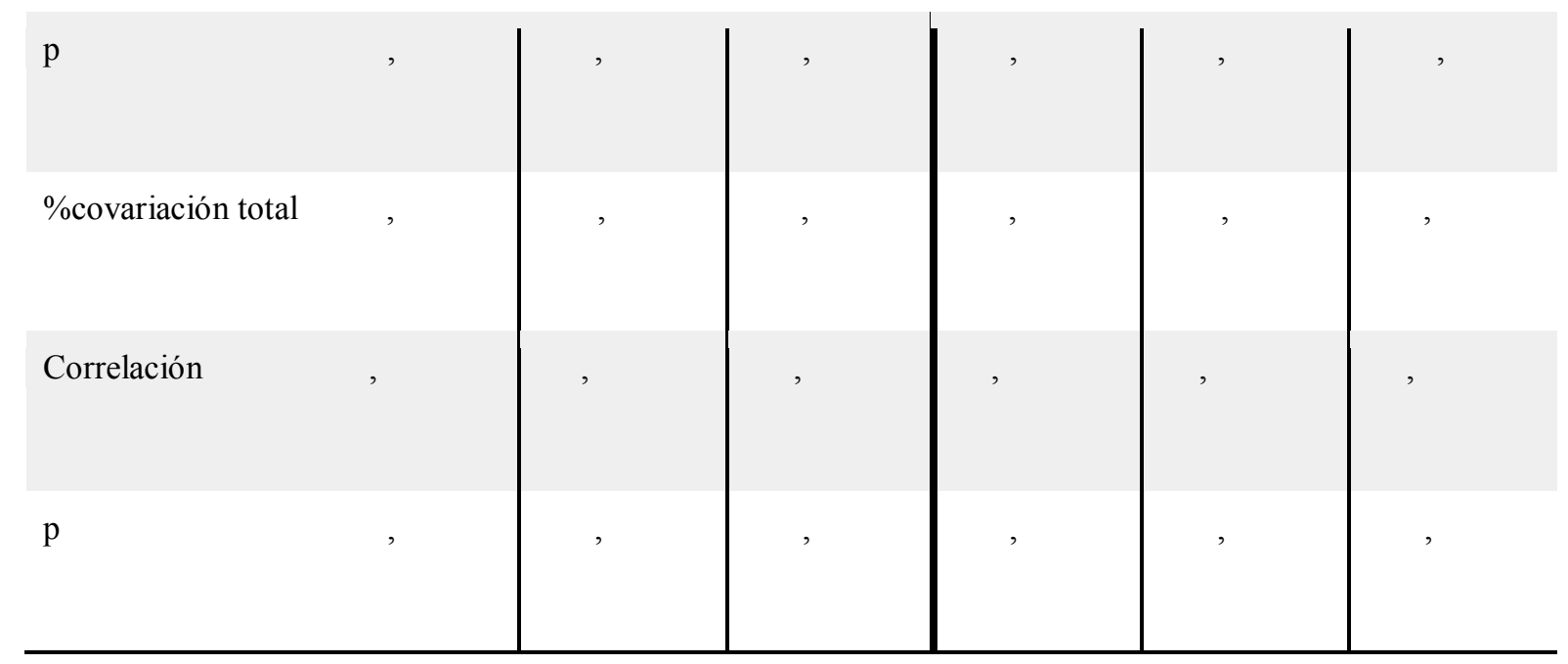

El gráfico de dispersión resultó similar a los demás, en tanto que Spheniscus se ubicó hacia el cuadrante inferior izquierdo mientras que Pygoscelis quedó en el opuesto (Fig. 6). Eudyptes y Aptenodytes resultaron en una ubicación intermedia del gráfico de dispersión, junto con Madrynornis, aunque este último quedó más cercano a Spheniscus para el bloque 1 (húmero). Las formas robustas estarían correlacionadas entre sí. 
a
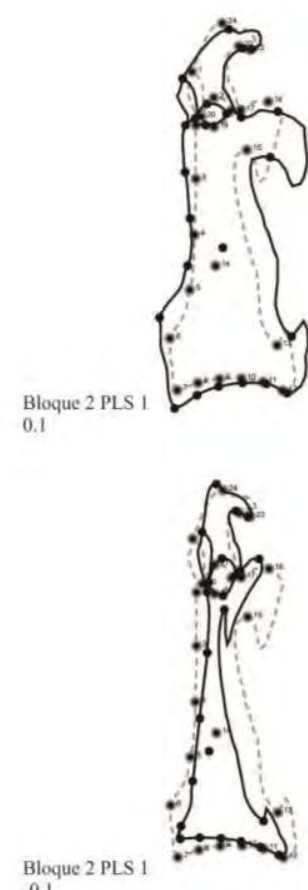

b

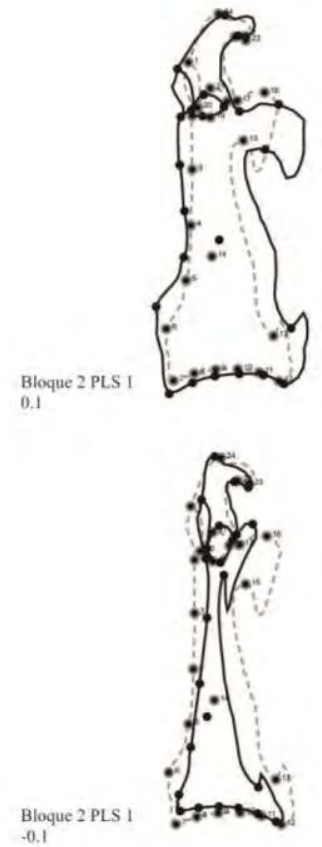

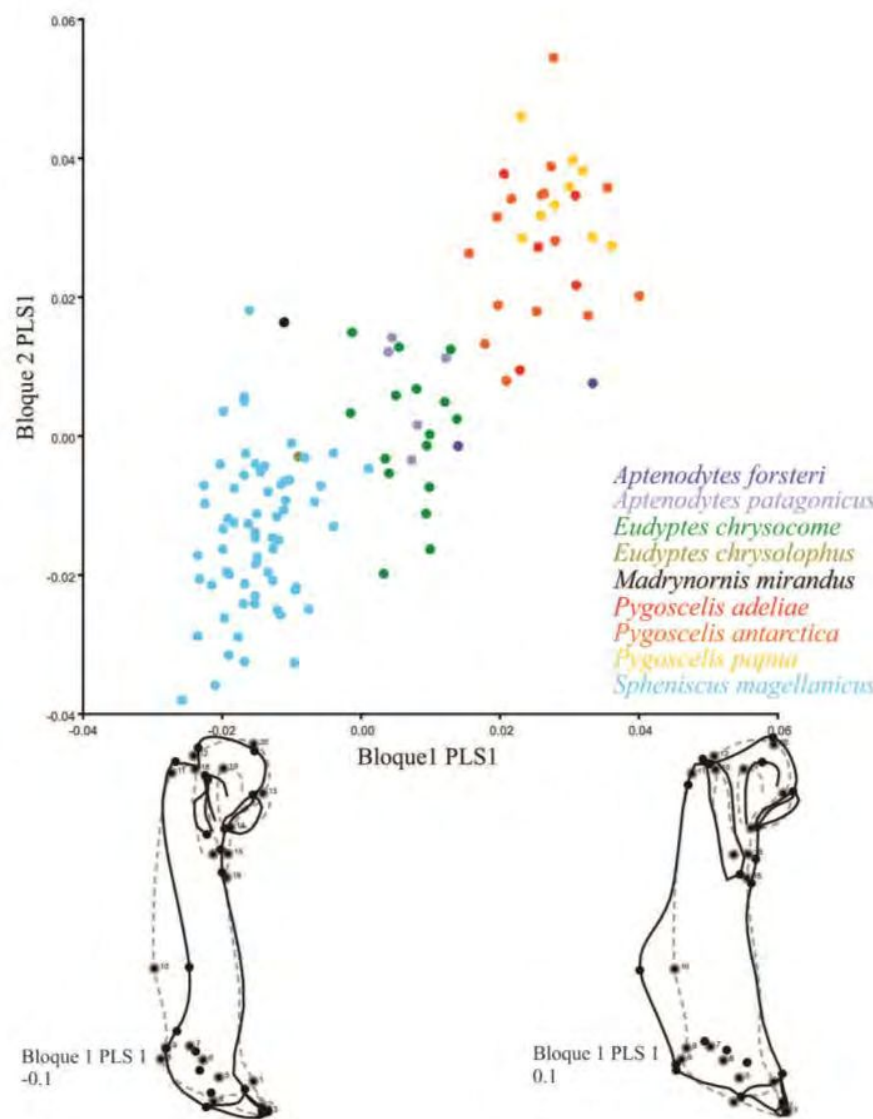

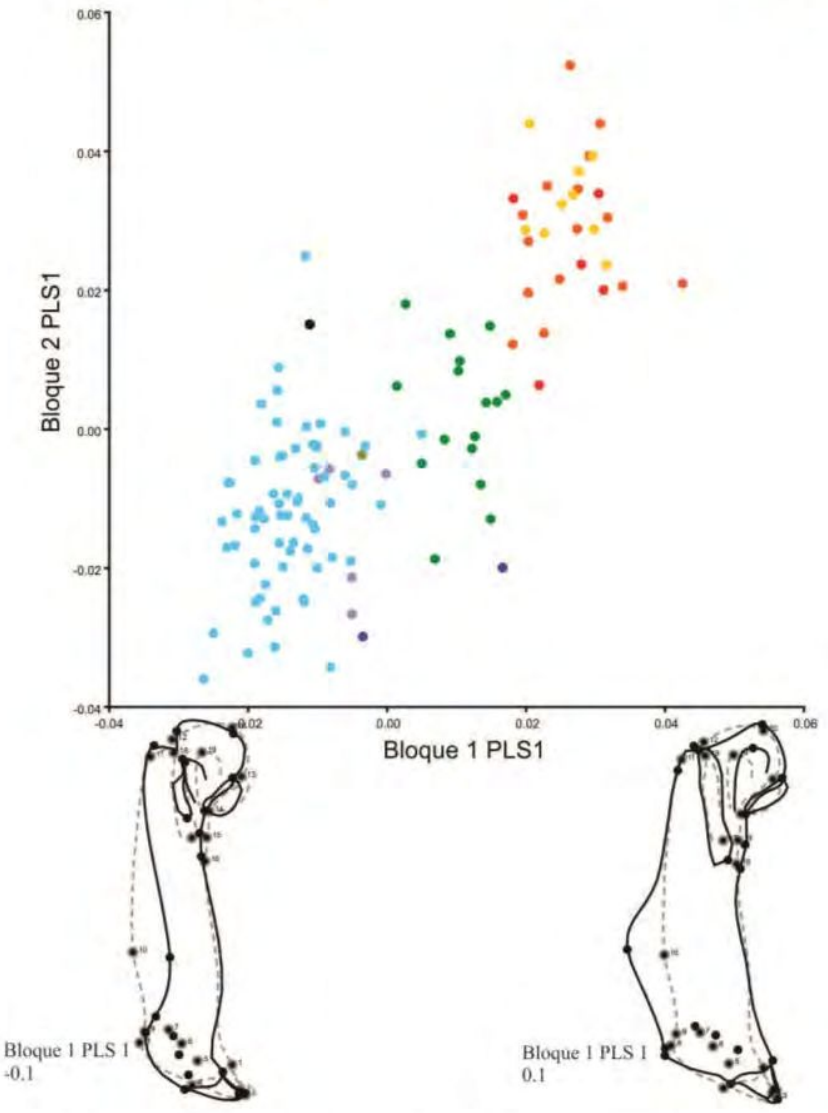

Figura 6 Análisis de mínimos cuadrados parciales entre el húmero caudal y el coracoides dorsal. Gráficos de dispersión del primer PLS para los dos bloques con el cambio de forma para los valores extremos eje a, datos originales; $\mathbf{b}$, datos corregidos. Las líneas grises representan la forma promedio mientras que las negras representan los valores extremos de cada bloque. 


\section{DISCUSIÓN Y CONCLUSIONES}

En base a lo obtenido según la hipótesis de modularidad planteada, el cráneo actuaría como una unidad integrada. Los módulos caja craneana-pico aquí propuestos no covarían de manera diferente. Este resultado concuerda con lo obtenido por Klingenberg y Marugan (2013) y son contrarios a los de Yamasaki et al. (2017), cuyo análisis en el rostro y cráneo posterior (sin incluir pico) resultó ser una unidad integrada.

El pico de los pingüinos es una estructura moderadamente variable, con formas relativamente cortas y robustas, a largos y gráciles, y con una relación directa al tipo de dieta (como se observó en los resultados del Capítulo III; ver también Zusi, 1975). Por lo que se podría haber supuesto que el pico hubiese actuado como un módulo separado al resto del cráneo, y no como una unidad integrada como se obtuvo en este análisis. Si bien no podemos extender este resultado a todas las aves, el estudio incluyó a un gran número de especies de pingüinos, por lo que podríamos considerar a esta condición como uniforme para la familia Spheniscidae. De todas maneras, un estudio mayor con cráneos en 3 dimensiones y con todas las especies actuales incluidas nos ayudará, en el futuro, a testear esta hipótesis con mayor fuerza.

Las diferencias encontradas entre los análisis con los datos originales y los corregidos se deben a que la alometría puede llegar a afectar de manera integral la variación de forma (Klingenberg, 2009). Por lo que resulta más confiable en este caso, considerar los análisis corregidos por sobre los originales. El efecto alométrico, si no es tenido en cuenta, puede enmascarar la modularidad, debido a que afecta al individuo completo conjuntamente (Klingenberg, 2009). En nuestro caso, realizamos el análisis con los datos originales y los corregidos (del efecto alométrico), y encontramos gran variación en los resultados de los PLS de la caja craneana en vista dorsal - mandíbula en vista dorsal y del pico en vista dorsal mandíbula en vista dorsal. Por otra parte, los resultados de los PLS de la caja craneana en vista dorsal - mandíbula en vista dorsal y del húmero en vista dorsal - coracoides en vista dorsal, resultaron muy similares.

En el caso particular del PLS entre la caja craneana y la mandíbula, y entre la caja craneana y el pico, existe una amplia disparidad en el coeficiente RV obtenido para los datos originales con respecto a los corregidos. Esta disparidad se refleja en los gráficos de 
dispersión de los dos bloques para el primer PLS, donde para los datos corregidos Aptenodytes y Eudyptes se encuentran más cercanas a la forma mandibular de Spheniscus, aunque no así a su cráneo. Cabe recordar que para el caso de la mandíbula, el porcentaje explicado por el efecto alométrico es de un 12\% aproximadamente, mientras que para el cráneo es solo del 3\%. Si bien resulta interesante estudiar esta correlación, y cómo varían las dos formas conjuntamente, debemos concluir que la correlación no es significativa si tomamos en cuenta los datos corregidos por el efecto alométrico. El coeficiente RV que nos indica la fuerza de la correlación resulta relativamente alto para los datos originales y moderado a bajo para los datos corregidos.

Es interesante destacar que las correlaciones entre cráneo y húmero, cabeza y ala, resultaron mayores que las halladas entre los elementos craneales entre sí, o de los elementos alares y de la cintura escapular. Si bien los valores de RV para el húmero y cráneo $(\mathrm{RV}=$ $0,68)$ son relativamente altos, ese valor sigue siendo conservador a la hora de afirmar la existencia de una correlación entre estos elementos. Sí podríamos afirmar que en pingüinos hay una correlación moderada entre la morfología del húmero y ala, que resulta significativa, y en la cual la alometría tiene muy poca influencia. 


\section{PINGÜINOS FÓSILES,}

\section{EL CASO DE MADRYNORNIS MIRANDUS}

\section{INTRODUCCIÓN}

\section{Pingüinos fósiles}

Los pingüinos poseen un registro Gondwánico ininterrumpido y su historia evolutiva se remonta al Paleoceno temprano tardío (60.5-61.6 Ma), momento para el cual se registra Waimanu manneringi, el pingüino más antiguo, hallado en Nueva Zelanda (Jones, Ando \& Fordyce, 2006 en Slack et al., 2006). Este pingüino junto con Waimanu tuatahi (Jones, Ando \& Fordyce, 2006 en Slack et al., 2006) posee, entre otras características, un cráneo con una fosa temporal amplia que llegaba hasta la cresta sagital, característica compartida con la mayoría de los pingüinos paleógenos. Además, sus mandíbulas son alargadas y rectas, como en otros pingüinos Eocenos (Ksepka et al., 2008; Acosta Hospitaleche \& Haidr, 2011). La escápula no presenta la característica forma de hoja de las especies actuales, sino que conservaba un grosor lateromedial homogéneo a lo largo de su extensión, con un desarrollo muchísimo menor que en las especies actuales. En cuanto al ala, Waimanu presentaba un húmero elongado y curvado con una cicatriz para la inserción del $m$. supracoracoides bien marcada y sobresaliente aunque más corta y proximal que en el resto de los pingüinos. La ulna y el radio también son más elongados y gráciles aunque con una leve compresión dorsoventral.

Para el Paleoceno tardío se registra para Antártida en la Formación Cross Valley, un esqueleto asociado de pingüino con características morfológicas mucho más derivadas, se trata de Crossvallia unienwillia (Tambussi et al., 2005; Jadwiszczak et al., 2013) el pingüino antártico más antiguo encontrado que presenta un esqueleto asociado. El patrón esqueletario de Crossvallia permite asumir que hacia el Paleoceno tardío los pingüinos ya eran un grupo de aves diversificado y bien establecido (Jadwiszczak et al., 2013; Acosta Hospitaleche et al., 2016). Esto se ve confirmado por el reciente hallazgo de Kumimanu biceae en el Paleoceno de Nueva Zelanda (Mayr et al, ) 
El registro durante el Eoceno resulta abundante, particularmente para Nueva Zelanda, Antártida y Perú. Para esta época aparecen los famosos pingüinos gigantes, como Anthropornis grandis (Antártida), Icadyptes salasi e Inkayacu paracasensis (Perú), Pachydyptes ponderosus (Nueva Zelanda), y Palaeeudyptes klekowskii (Antártida) (Ksepka et al, 2008; Acosta Hospitaleche \& Reguero, 2010; Clarke et al., 2010; Acosta Hospitaleche, 2014; Simpson, 1959, entre otros). Sin embargo, es durante el Eoceno cuando también aparecen las formas más pequeñas de pingüinos que hayan existido, como Aprosdokitos mikrotero (Acosta Hospitaleche et al., 2017). Estás formas son mucho más derivadas, con una clara compresión dorsoventral de los huesos largos del ala. El húmero conserva una curvatura sigmoidea en vista ventral y dorsal, una fossa tricipitalis sin bipartición, la escápula con una longitud mayor pero aún sin la forma en hoja ancha que vemos en las especies de Mioceno hasta la actualidad. El coracoides, por su parte, es proporcionalmente más ancho al nivel de su articulación con el esternón, en comparación con el largo de la diáfisis (con respecto a las especies neógenas), y en vista esternal, la facies articularis sternalis adquiere una forma de "S" El cráneo posee una fossa temporalis ancha que llega hasta la cresta sagital, mientras que los picos son elongados y rectos (Ksepka \& Clarke, 2010; Jadwiszczak, 2006; Acosta Hospitaleche \& Di Carlo, 2010; 2012; Clarke et al., 2010; Haidr \& Acosta Hospitaleche, 2012; Jadwiszczak, 2012).

Hacia el Oligoceno, el registro se encuentra particionado desigualmente. La mayoría de los fósiles conocidos han sido hallados en Nueva Zelanda. Corresponden a individuos de mediano a pequeño tamaño, como Archaeospheniscus lopdelli del Oligoceno tardío (Marples,

), Archaeospheniscus lowei (Marples, 1952), Kairuku waitaki y Kairuku grebneffi del Oligoceno tardío (Ksepka et al., 2012b), Korora oliveri (Marples, 1952), Platydyptes novaezealandiae (Oliver, 1930; Marples, 1952; Ando, 2007). En el Oligoceno tardío/Mioceno temprano se encuentran Platydyptes amiesi (Marples, 1952; Ando, 2007), Platydyptes marplesi (Marples, 1952; Simpson, 1972b), además de varios Sphenisciformes indeterminados de Nueva Zelanda y Australia (Ksepka \& Ando, 2011).

El Mioceno presenta una gran diversidad taxonómica y morfológica de pingüinos, y es la época en donde aparecen las especies más antiguas del grupo corona. En Nueva Zelanda se hallaron a Aptenodytes ridgeni (Mioceno medio-tardío?, Simpson, 1972) especie del mismo género que el pingüino emperador (Aptenodytes forsteri) y pingüino rey (Aptenodytes patagonicus), Marplesornis novaezealandiae (Mioceno medio-tardío?, Marples, 1960), y Pygoscelis tyreei (Mioceno medio-tardío?, Simpson, 1972) (Ksepka \& Ando, 2011). Para 
Sudamérica, la diversidad taxonómica es incluso mayor con 13 especies registradas en Perú, Chile y Patagonia (Ver más adelante) (Moreno \& Mercerat, 1891; Simpson, 1972; Stucchi, 2002; Emslie \& Guerra Correa, 2003; Stucchi et al., 2003; Acosta Hospitaleche et al., 2004; Acosta Hospitaleche \& Canto, 2005; Acosta Hospitaleche \& Stucchi, 2005; Acosta Hospitaleche, 2007; Acosta Hospitaleche et al., 2006, 2007; Gohlich, 2007; Stucchi, 2007; Acosta Hospitaleche et al, ）

En cuanto al Plioceno, el registro se encuentra casi restringido para Sudáfrica a excepción de Spheniscus chilensis del Plioceno de Chile (Emslie \& Guerra Correa, 2003), y Tereingaornis moisleyi del Plioceno de Nueza Zelandia (McKee, 1987). Por su parte, Sudáfrica registra al menos 3 especies aceptadas para el Plioceno temprano, Nucleornis insolitus (Simpson, 1979b), ?Palaeospheniscus huxleyorum (Simpson, 1973), Dege hendeyi (Simpson, 1979a), y Inguza predemersus (Simpson, 1971, 1972b, 1975).

\section{Pingüinos fósiles en Sudamérica}

Sudamérica presenta un registro ininterrumpido desde el Eoceno hasta el Mioceno, principalmente en Patagonia, Perú y Chile, siendo los más antiguos para el Eoceno de Argentina y Perú. Argentina posee un único registro para el Eoceno medio tardío de la Formación Leticia, Tierra del Fuego y consiste en una cintura pélvica y parte del miembro inferior (Clarke et al., 2003) asignado a Palaeeudyptes gunnari, especie que se registra sincrónicamente en Antártida (Acosta Hospitaleche \& Olivero, 2016). En Perú, se han hallado y descrito tres especies: Perudyptes devriesi (Formación Paracas, Eoceno medio a tardío), Icadyptes salasi (Formación Otuma, Eoceno medio-tardío a tardío) (Clarke et al., 2007), e Inkayacu paracasensis (Eoceno superior); se trata en todos los casos de pingüinos de tamaños mediano a grandes y con picos elongados y delgados.

Para el Mioceno, tanto Perú como Chile y Argentina registran diversas especies más relacionadas o dentro del grupo corona Spheniscidae. Para Patagonia, en el Mioceno temprano-medio registra a Arthrodytes andrewsi (Ameghino, 1901), Eretiscus tonnii (Simpson, 1981), Paraptenodytes antarcticus (Moreno \& Mercerat, 1891; Simpson, 1946), Palaeospheniscus patagonicus, P. bergi, P. biloculata (Moreno y Mercerat, 1891); mientras que para el Mioceno tardío tenemos a Madrynornis mirandus (Acosta Hospitaleche et al., 2007), y a cf. Spheniscus urbinai (Acosta Hospitaleche, 2011). En Perú, el Mioceno 
temprano-medio registra a Palaeospheniscus patagonicus y a Spheniscus muizoni (Gohlich, 2007), mientras que en el Mioceno tardío se encuentran a Spheniscus megaramphus (Stucchi et al, ) y S. urbinai (Stucchi, 2002). Por último, Chile registra a Pygoscelis calderensis (Acosta Hospitaleche et al., 2006) para el Mioceno medio-tardío, a P. grandis (Walsh \& Suárez, 2006) para el Mioceno tardio-Plioceno?, a Spheniscus chilensis (Emslie \& Guerra Correa, 2003) para el Plioceno, y Eudyptes calauina (Chávez Hoffmeister et al., 2014) del Plioceno tardío de Chile.

Si bien el número de especies fósiles conocidas para el grupo, así como también la cantidad de registros, es muy elevada, la mayor parte corresponde a elementos aislados. Esto implica que para el tipo de análisis que aquí se plantea, el número de ejemplares disponibles sea bastante menor.

Afortunadamente en los últimos años se ha incrementado el número de esqueletos con elementos asociados y/o articulados hallados en Sudamérica, por lo que al $\mathrm{AMNH}^{8}$ Paraptenodytes antarcticus, se han sumado el MPEF $\mathrm{PV}^{9} \quad$ Palaeospheniscus bergi (Acosta Hospitaleche, 2007), el SGO PV ${ }^{10}$ 21328, el MPC ${ }^{11} \quad$ Spheniscus urbinai (Sallaberry et al., 2008), y el MPEF PV Madrynornis mirandus (Acosta Hospitaleche et al., 2007). Éste último con una grado excepcional de preservación y completitud, único entre los pingüinos fósiles conocidos.

\section{Caso de estudio: Madrynornis mirandus}

Madrynornis mirandus resulta un caso interesante de estudio debido a que preserva un esqueleto articulado casi completo con elementos esqueletales con escaso grado de erosión, deterioro o deformación.

El espécimen, que constituye el holotipo de la especie, y es el único resto conocido para la especie, fue hallado sobre la costa del golfo San José, en Playa Villarino, Península Valdés (Provincia del Chubut). En esta localidad aflora la Formación Puerto Madryn, de edad Mioceno medio o tardío (10.0 $\pm 0.3 \mathrm{Ma}$, Scasso et al , )

\footnotetext{
${ }^{8}$ AMNH American Museum of Natural History, Estados Unidos

${ }^{9}$ MPEF PV Museo Paleontológico Egidio Feruglio, Argentina

10 SGO PV Museo Nacional de Historia Natural de Santiago, Chile

${ }^{11}$ MPC Museo Paleontológico de Caldera, Chile
} 
La diagnosis del género y la especie fue realizada por Acosta Hospitaleche y colaboradores (2007), caracteres que fueron corroborados directamente sobre el material.

Si bien actualmente existe consenso en que Madrynornis mirandus está cercanamente emparentado con las especies actuales, su ubicación dentro del grupo corona Spheniscidae es aún incierta. Acosta Hospitaleche y col. (2007), en base a una matriz que incluyó 44 caracteres y 22 especies (5 fósiles, 14 actuales y 3 outgroups), obtuvieron para el árbol más parsimonioso que Madrynornis mirandus era el grupo hermano de Eudyptes. Si bien el trabajo recuperó clados supraespecíficos previamente propuestos en otros trabajo que incluían además caracteres moleculares, tegumentarios y reproductivos (Giannini \& Bertelli, 2004; Bertelli \& Giannini, 2005), muchas de las relaciones interespecíficas no fueron recuperadas y grupos como Pygoscelis resultaron parafiléticos. Además, la mayoría de los nodos, a excepción del nodo Sphenisciformes y crown group Spheniscidae, fueron definidos por caracteres no exclusivos.

Un estudio más reciente (Degrange et al., ) , que utiliza una matriz de datos combinada con 244 caracteres morfológicos, y 58 especies, recupera nuevamente a Madrynornis como perteneciente al grupo corona, pero en este caso lo ubica como grupo hermano del clado formado por Eudyptula, Inguza, y Spheniscus. De todas maneras, los autores comentan que el costo para posicionar a Madrynornis mirandus como grupo hermano de Eudyptes es de sólo un paso, y que incluso al utilizarse una base de datos sólo morfológica el fósil fue recuperado como el grupo hermano del grupo corona.

Estudios de inferencias dietarias también han tenido a Madrynornis mirandus como protagonista. Tambussi y Acosta Hospitaleche (2008) señalan un notable parecido por parte de Madrynornis mirandus con especies ictiófagas, aunque sin poder afirmar si su dieta consistía o no sólo en peces. Posteriores análisis de la región articular de la mandíbula obtuvieron que Madrynornis mirandus se ubicaba muy cercano a las formas generalistas, y concluyeron a partir de esto y de la morfología de la región temporal del cráneo que habría tenido una dieta generalista sin ningún tipo de preferencia dietaria (Haidr \& Acosta Hospitaleche, 2014). En contraposición, se ha propuesto recientemente una condición piscívora para esta especie, basado exclusivamente en evidencia osteológica (Degrange et al. 2018). Estos últimos autores proponen que los siguientes caracteres: contextura del pico robusta (a pesar de que se encuentra fragmentado e incompleto), barra yugal de escasa curvatura, elongado proc. retroarticularis, fossa temporalis de desarrollo intermedio entre 
Spheniscus (piscívoro) y Eudyptes (considerado por Degrange et al. como consumidor mayoritariamente de crustáceos), y un proc. mediale mandibulae que relacionaron con un mayor desarrollo del $m$. depressor mandibulae, y del $m$. pterygoideus, permiten asumir una condición piscívora para M. mirandus. En ambas propuestas de resultados disímiles, se incluyeron reconstrucciones musculares del cráneo (ver Haidr \& Acosta Hospitaleche, 2014; Degrange et al， )

En el presente capítulo se redescribió el cráneo, mandíbula, coracoides, escápula, esternón, fúrcula y húmero, y se realizó un análisis de discriminantes para las configuraciones de landmarks analizadas en el capítulo III y IV, obteniendo como resultado una clasificación para cada configuración de landmarks de Madrynornis mirandus en base a las categorías dietarias asignadas a los pingüinos actuales. Como resultado, se obtuvo una nueva propuesta para la configuración muscular del cráneo y el ala.

\section{Objetivo}

El presente capítulo tuvo como objetivo determinar los hábitos de buceo y dietarios de Madrynornis mirandus, aplicando los modelos generados a partir de las especies actuales.

\section{MATERIALES}

Madrynornis mirandus está descrito a partir del único espécimen conocido, que presenta un esqueleto casi completo. Se cuenta con cráneo (caja craneana casi entera, pico fragmentado, arcos jugales, lacrimales, y cuadrados), mandíbula (sin sínfisis), 13 vértebras cervicales, 7 vértebras torácicas, 7 vértebras caudales, pigostilo, esternón, 13 costillas derechas e izquierdas, ambos húmeros, sesamoides ulnares, ulna derecha, radio derecho, carpometacarpo derecho, escápula derecha, ambos coracoides, fúrcula, pelvis derecha e izquierda fragmentadas, fémur derecho e izquierdo, patela derecha, ambos tibiotarsos, ambas fíbulas, ambos tarsometatarsos, y 17 falanges pedales, dos de las cuales son ungueales. El espécimen MPEF-PV 100 Madrynornis mirandus se encuentra depositado en el Museo Paleontológico Egidio Feruglio (MPEF PV), de la Ciudad de Trelew, Provincia del Chubut (Argentina). 
Los materiales de comparación utilizados corresponden a Spheniscus magellanicus, Eudyptes chrysocome, Eudyptes chrysolophus, Eudyptes sclateri, Eudyptula minor, Aptenodytes patagonicus, Aptenodytes forsteri, Pygoscelis adeliae, Pygoscelis antarctica, y Pygoscelis papua.

\section{MÉTODOS}

El esqueleto completo del espécimen MPEF-PV 100 fue escaneado con un scanner 3D Next Engine Ultra Hd, perteneciente a la División Paleontología Vertebrados del Museo de La Plata. Los escaneos y sus procesamientos se hicieron con los programas Scan Studio y Meshlab, programa de licencia libre para la edición de mallas 3D. El Scan studio permite editar el escaneo en crudo, alinear las diferentes vistas de los escaneos, fusionar las mallas y exportar la malla final para utilizar en posteriores programas. El Meshlab, permitió una edición más fina de las mallas, y trabajar con todos los escaneos en simultáneo, lo que permitió ensamblar el esqueleto para visualizar cómo habría estado el esqueleto articulado en vida. Las reconstrucciones musculares se realizaron en base a las cicatrices de inserción presentes en el fósil, y comparando siempre con los resultados de las disecciones musculares realizadas en los pingüinos actuales como se explica en los capítulos III y IV. Las especies actuales que sirvieron de comparación para la reconstrucción de la musculatura fueron Spheniscus magellanicus, Pygoscelis adeliae, Pygoscelis papua y Eudyptes chrysocome. Las medidas comparativas entre especies se tomaron a partir de fotografías en TPSDig (Rohlf,

) Los análisis de discriminantes fueron realizados en el Past (ver Capítulo II). 


\section{RESULTADOS: DESCRIPCIÓN OSTEOLÓGICA}

\section{PALEONTOLOGÍA SISTEMÁTICA}

AVEs Linnaeus, 1758

SPHENISCIFORMES Sharpe, 1891

SPHENISCIDAE Bonaparte, 1831

Madrynornis mirandus Acosta Hospitaleche et al.,

\section{Cráneo}

Tanto Acosta Hospitaleche y col. (2007) como Degrange y col. (2018), realizaron una detallada descripción del cráneo. La presente descripción complementa las ya publicadas, pero no se ahondará en aquellas características que ya han sido tratadas en los trabajos anteriores.

La región occipital (Fig. 1e) tiene una forma trapezoidal, con unos proc. paraoccipitales que se proyectan ventralmente (Acosta Hospitaleche et al., 2007; Degrange, et al., 2018) y en vista lateral se encuentran en el mismo plano que la crista nuchalis tranversa. En vista occipital existe una constricción a nivel del foramen rami occipitalis arteriae ophthalmicae externae como en todos los pingüinos actuales. La morfología de la región occipital es similar a Eudyptes en cuanto a que la crista nuchalis tranversa se dirige hacia los proc. paraoccipitalis en línea recta paralelo al plano sagital, en formas como Spheniscus y Pygoscelis la crista nuchalis tranversa se abre ventrocaudalmente. La prominetia cerebellaris se encuentra parcialmente rota, dorsal a la misma aparece una cresta innominada que delimita dos depresiones. Las cristae nuchale tranversae tocan dorsalmente con esta cresta. En Pygoscelis, Aptenodytes y Eudyptes las cristae nuchale transversae se tocan a nivel del plano sagital justo por encima de la prominentia cerebellaris, mientras que en Spheniscus se dirigen anteriormente tocando la cresta sagital. Además, en Madrynornis, la porción dorsal de la crista nuchalis transversa se dirige anteriormente, condición similar a 
Megadyptes antipodes. El foramen rami occipitalis arteriae ophthalmicae externae derecho, que abre de forma oval sobre la crista nuchalis transversa, sigue mediante un surco muy corto, mientras que del lado izquierdo, si bien está presente, no se cierra completamente (Fig. 1c, e). El foramen magnum es subcircular y posee una orientación similar a la de los pingüinos actuales (como notado por Degrange et al., 2018). La forma del foramen vena occipitalis externae, su ubicación y la morfología y longitud del sulcus acompañante varía a nivel intraespecífico en los pingüinos. En Madrynornis se ve que abre a ambos lados del foramen magnum y que ambos poseen un surco que sigue laterodorsalmente y otro ventrolateralmente, todos ellos cortos (Fig. 1e). En Aptenodytes, Eudyptula y Spheniscus, éstos suelen ser mucho más extensos, el foramen abriendo incluso a los lados de la prominentia cerebellaris. En Megadyptes, Eudyptes y Pygoscelis suelen abrir a ambos lados del foramen magnum, y en Megadyptes y Eudyptes los surcos asociados son cortos como en Madrynornis. El condylus occipitalis es arriñonado (Fig. 1e), y posee alrededor una serie de forámenes que corresponden a la salida de las diferentes ramas de los nervios XII (para más detalle ver Degrange et al., 2018). Dorsal al proc. medialis parasphenoidalis se encuentra el foramen metótico por el que salen los nervios IX y XI según Carabajal y Acosta Hospitaleche (2014), y los nervios X y XI según Degrange y colaboradores (2018). Lateral a las anteriores estructuras se aloja una fosa que contiene el foramen interno de la arteria carótida interna y el foramen del n. IX (Degrange et al, ）

La lamina parasphenoidalis es más ancha que en las especies actuales (contra Degrange et al., ） , con una proporción ancho largo mayor que en las especies actuales (Fig. 1a). Los processi medialis parasphenoidalis son robustos, en vista ventral se observa una dirección cráneolateral diagonal de los mismos similar a la hallada en Pygoscelis, aunque más pronunciada (Fig. 1a).

Los proc. lateralis parasphenoidalis están bien desarrollados y su porción más anterior se proyecta ventralmente (Fig. 1a). En las especies actuales el desarrollo de los mismos es variable, pero en Eudyptes se puede apreciar esta proyección ventral en su porción más anterior. Degrange y colaboradores (2018) describieron el proc. lateralis parasphenoidalis bajo el nombre de "capping pad" citando a Bock ( ) Esto constituye un error morfológico y funcional, ya que cuando Bock se refiere a "capping pad" hace referencia a un tejido blando de "fibras de colágeno o fibrocartílago" que recubre una estructura ósea. Esta estructura fue la que le dio el indicio a Bock $(1959,1960)$ de que esa zona oficiaba de contacto entre estructuras óseas. Por otra parte confunden su funcionalidad 
cuando indican que el contacto de esta estructura con el proc. medialis de la mandíbula se da cuando la mandíbula está cerrada, mientras que en realidad el contacto del proc. medialis de la mandíbula y el proc. lateralis parasphenoidalis se da cuando la mandíbula se encuentra totalmente abierta (contra Degrange et al., 2018). Esta diferencia no es menor, ya que se relaciona directamente con el grado de apertura y el tipo de movimientos que el pico es capaz de afrontar. Bock (1960) describe este contacto como la articulación mandibular secundaria, o articulación basitemporal. La orientación de este proceso se corresponde, por lo tanto, con la orientación del margen más medial del proc. medialis, esto se corrobora al observar las especies actuales, y Madrynornis mismo. El $m$. depressor mandibulae inserta en el margen posterior y el $m$. pterygoideus con el anterior. Esta segunda articulación o punto de contacto daría un punto de soporte extra en el momento donde la mandíbula más lo necesita y cuando menos estabilidad tiene que es cuando está abierta (Bock, 1960).

Siguiendo con la región basal del cráneo, el receso timpánico rostral es profundo y se encuentra más alejado del foramen del n. V 2,3 que en Spheniscus o Pygoscelis. La cotyla quadratica otici izquierda no se conserva, pero del lado derecho tanto ésta como la cotyla quadratica squamosi se encuentran en perfectas condiciones. Ambas poseen forma arriñonada, siendo la cotyla quadratica otici la más redondeada (Fig. 1a). En comparación con Pygoscelis y Spheniscus parecieran yacer en Madrynornis en una concavidad más profunda.

El septum interorbitale cuenta con un fonticuli interorbitales que pareciera ser único, y subredondeado. El foramen óptico y aquellos de los nervios II, III, y VI se encuentran bien delimitados y no se unen con el fonticuli interorbitales, como a veces ocurre en las especies actuales (para más detalles de su descripción ver Degrange et al., 2018). La superficie de inserción del $m$. pseudotemporalis superficialis es más profunda y excavada que en las especies actuales (Degrange et al., 2018), y está delimitada lateralmente por el proc. orbitalis que forma una cresta de unión con el proceso zigomático (Fig. 1d). Esta cresta es muy pronunciada en Madrynornis mientras que en las especies actuales está ausente a excepción de Aptenodytes, donde es incipiente.

Los palatinos se encuentran dañados (Fig. 1a), pero conservan el proc. maxillaris; la lamella choanalis está bien marcada y el angulus caudolateralis se extiende más lateralmente que en los pingüinos actuales (Degrange et al, ） 
a

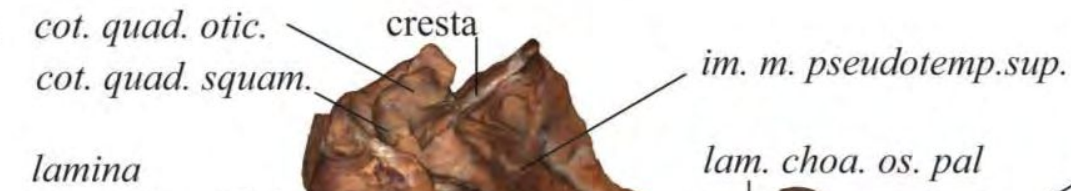

b parasphenoidal
proc. med.
parasph.
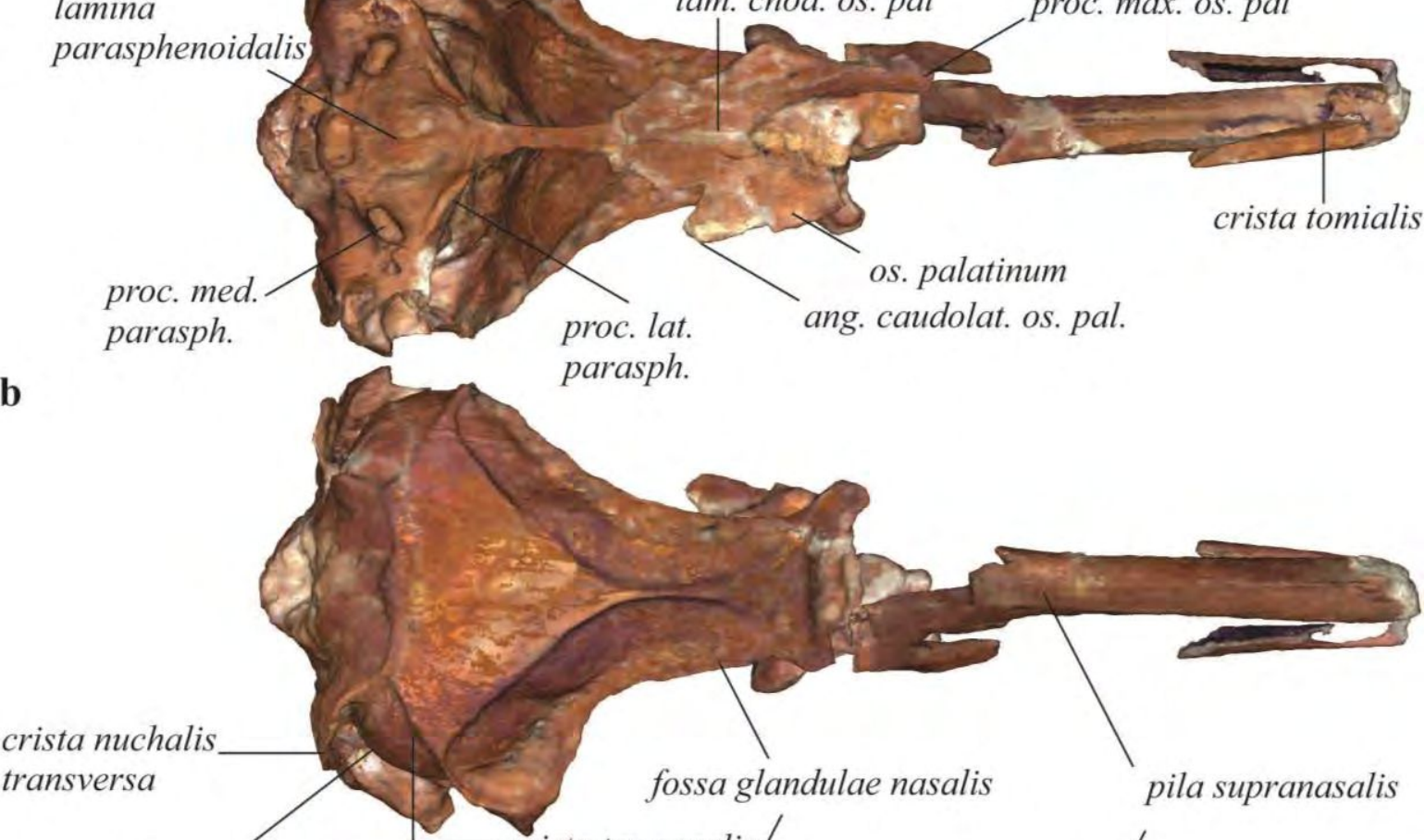

\section{c} fossa temporalis

proc. lat.

os. palatinum

crista tomialis

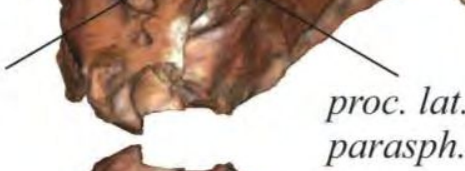

ang. caudolat. os. pal.
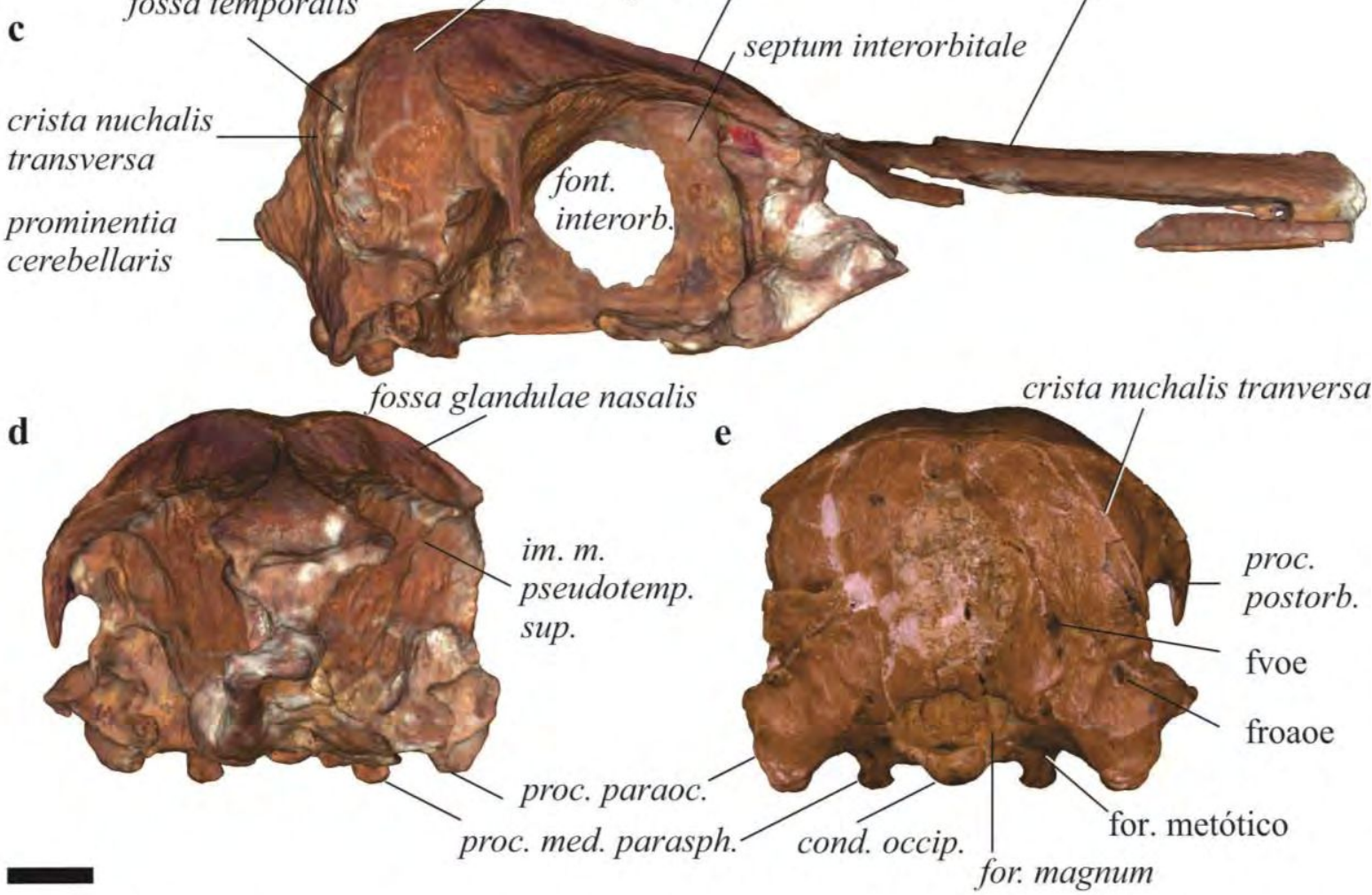

Figura 1 Escaneos 3d del cráneo del MPEF PV 100 Madrynornis mirandus. a, Vista ventral; b, vista dorsal; c, vista lateral; d, vista frontal; $\mathbf{e}$, fotografía de la vista occipital. Escala: $10 \mathrm{~mm}$. Abreviaciones: ang. caudolat., angulus caudolateralis; cond. occip., condylus occipitalis; cot. quad. squam., cotyla quadratica squamosi; cot. quad. otic., cotyla quadratica otici; font. interorb., fonticuli interorbitales; for, foramen; froaoe, foramen rami occipitalis arteriae ophthalmicae externae; fvoe, foramen vena occipitalis externae; im. m. pseudotemp.sup., impressio musculus prseudotemporalis superficialis; lam. parasph., lamina parasphenoidalis; pal.. palatinum; proc. lat. parasph., processus lateralis parasphenoidalis; proc. max., processus maxillaris; proc. med. parasph., processus medialis parasphenoidalis; proc. postorb., processus postorbitalis. 
En cuanto a la región temporal (Fig. 1b, c), la crista temporalis está bien marcada y se dirige desde la crista nuchalis transversa hasta el proc. postorbitalis en línea recta en dirección anterolateral, similar a Eudyptes. La fossa temporalis es profunda, muy similar a Eudyptes, menos que Spheniscus, y mayor que Pygoscelis. El proc. postorbitalis está bien desarrollado (Fig. 1c), es más delgado que en las especies actuales y se extiende recto ventralmente (Acosta Hospitaleche et al., 2007; Degrange et al., 2018). Posteriormente presenta una fosa excavada similar a las que presenta Pygoscelis aunque menos marcada (Fig. 1c).

Las fossae glandulae nasale son anchas caudalmente, angostándose paulatinamente en dirección anterior (Fig. 1b). En Pygoscelis el angostamiento es a la inversa. Pareciera que el reborde lateral que posee la fossa en Eudyptes, Pygoscelis y Megadyptes no estaría presente en Madrynornis, aunque Degrange y col. (2018) proponen que posiblemente se hayan quebrado. En la región frontonasal las fosas están separadas por una fina cresta (Acosta Hospitaleche et al., 2007; Degrange et al., 2018), si bien el grosor de esta separación es variable intra-específicamente (Degrange et al., 2018; y observaciones personales) parecería que es más fina en Madrynornis que en las especies actuales, a excepción de algunos especímenes de Pygoscelis adeliae consultados.

El pico se encuentra incompleto, la punta está ausente, y debido a que la porción anterior de la mandíbula tampoco se conserva, no podemos saber a ciencia cierta la real extensión del pico. Como describieron trabajos anteriores (Acosta Hospitaleche et al., 2007; Degrange et al., 2018), la pila supranasalis es triangular en corte transversal, la parte más anterior posee una cresta dorsal bien marcada (similar a Spheniscus aunque en este es menos notoria), la crista tomialis es afilada (notablemente en el lado izquierdo) y presentan unas narinas externas elongadas (Fig. 1b, c). Las narinas comienzan a apenas unos $11 \mathrm{~mm}$ (aproximados debido a estado de preservación) de la charnela, y se extienden por 47,6 mm. El ancho de la pila supranasalis y su área transversal es homogénea en toda su extensión anteroposterior. El ancho relativo del pico parecería presentar una situación intermedia entre Pygoscelis/Eudyptes y Spheniscus/Aptenodytes/Eudyptula. En vista dorsal las narinas son visibles en Pygoscelis y Eudyptes (Fig. 1b). La morfología del pico resulta en verdad interesante, presentando características similares a Eudyptes, aunque habiendo sido evidentemente más largo que en este género. 
El arco jugal fue detalladamente descrito por Degrange y col. (2018). El grado de curvatura que presenta es intermedio entre Spheniscus/Aptenodytes, y Pygoscelis/Eudyptes (Fig. 2d, e).

Los cuadrados se encuentran completos a excepción del izquierdo al cual le falta una pequeña porción del capitulum oticum. El cuadrado posee el capitulum oticum y squamosum robustos con una incisura intercapitularis superficial (Fig. 2g) (Degrange et al., 2018), en contraposición con las especies actuales en los cuales es profunda. La disposición de ambos es paralela entre sí como en Spheniscus; en Pygoscelis el capitulum squamosum es oblicuo con respecto al otro. El tuberculum subcapitulare (Fig. 2h) es robusto como en las especies actuales (Degrange et al., 2018), pero su punta proyecta dorsalmente mientras que en las especies actuales lo hace anteriormente. Este tuberculum es uno de los puntos de inserción del $m$. adductor mandibulae externus pars profunda (Degrange y col. 2018 nombran este músculo como $m$. adductor mandibulae posterior citando una bibliografía que no se condice con esta nomenclatura). El proc. orbitalis está anteriormente más extendido que las formas actuales (similar a Pygoscelis y Eudyptes), su extremo se curva medialmente y termina en un proceso que se ensancha y cuyo borde plano apunta dorsocraniomedialmente (Fig. $2 \mathrm{f}, \mathrm{g}, \mathrm{h}, \mathrm{i}$ ). Este processus posee una fosa bien excavada, más que Spheniscus y menos que Pygoscelis. Las cotyla medialis y c. lateralis son robustas (Fig. 2f), y aunque la cotyla caudalis no puede ser diferenciada de la c. lateralis (Degrange et al., 2018), la primera se extiende dorsalmente, más que en Pygoscelis. La diferenciación entre estas cotylae se puede ver en Spheniscus, aunque no en todos los especímenes y está representado por un estreñimiento entre ambas. Esta configuración de las cotylae estabiliza la articulación con la mandíbula dando un punto caudal de apoyo. El condylus pterygoideus es ovalado (Degrange et al., 2018), y el surco medial al condylus que también articula con el pterigoides es redondeado, menos excavado que Spheniscus y más que Pygoscelis (Fig. 2f). 
a

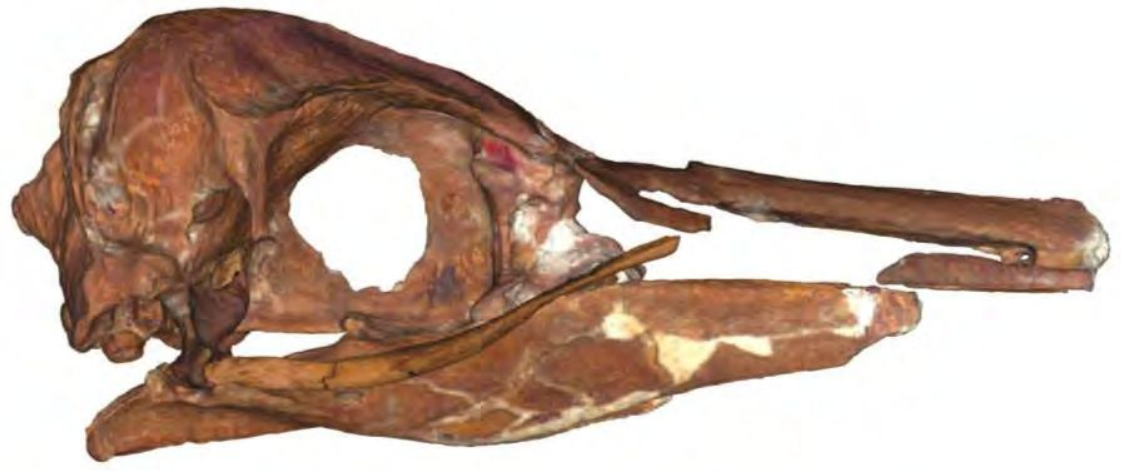

b

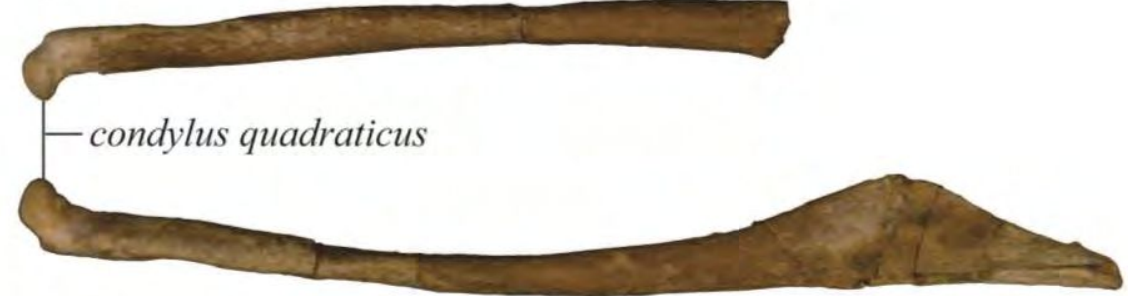

d

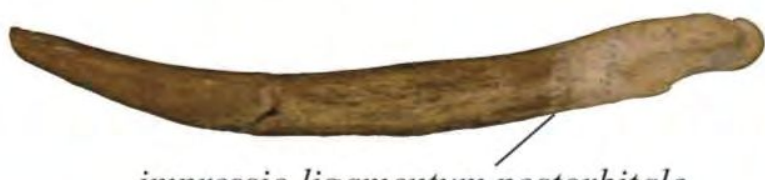

impressio ligamentum postorbitale

e

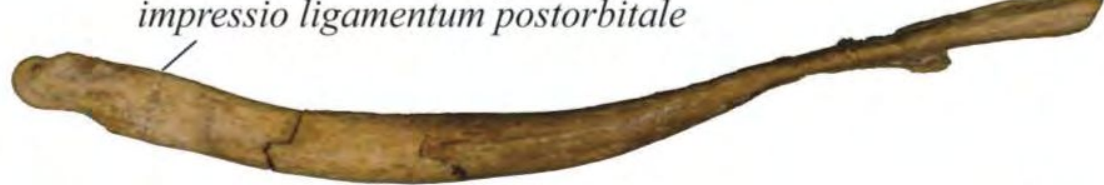

cond. medialis

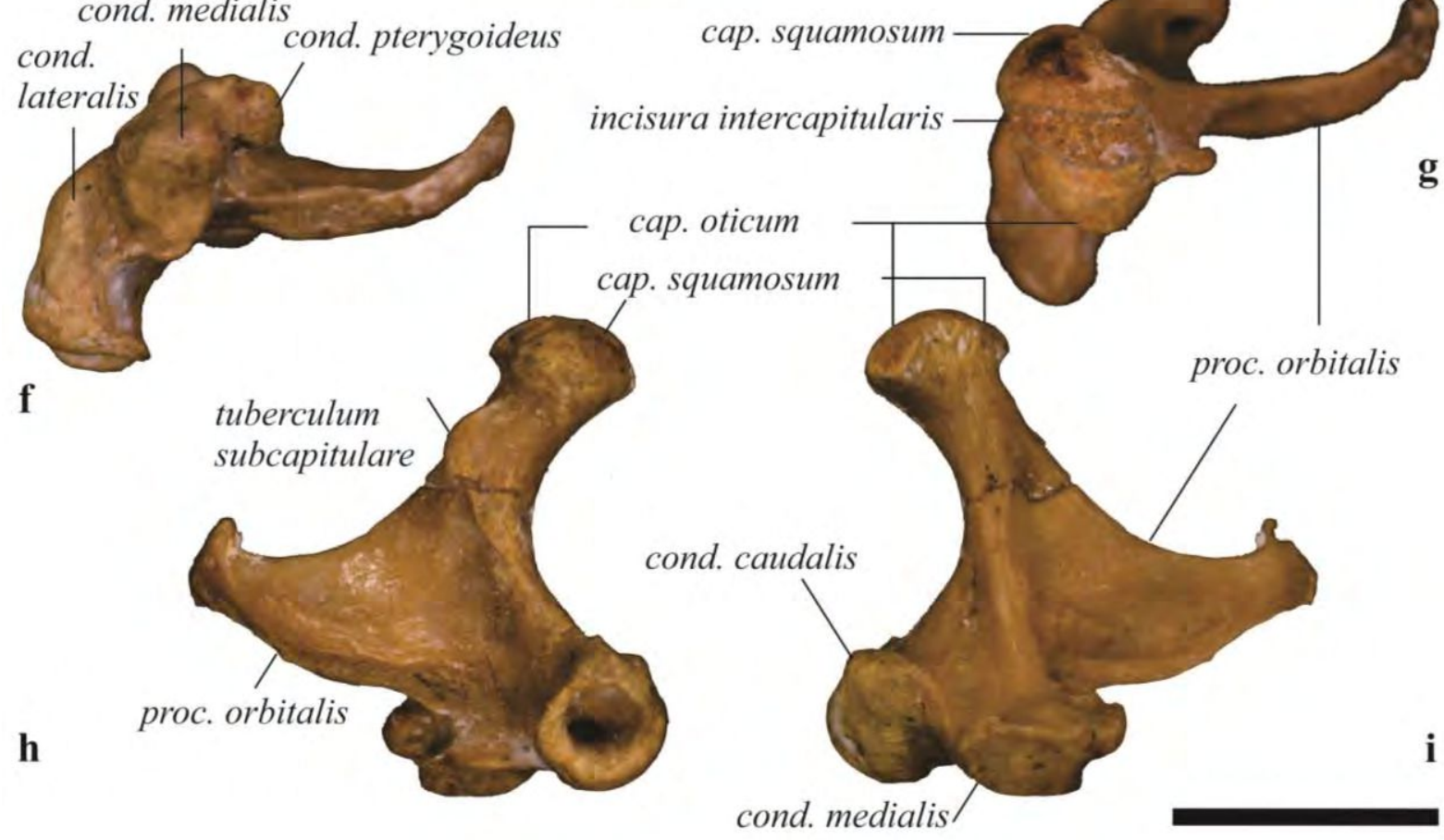

Figura 2 MPEF PV 100 Madrynornis mirandus. a, Vista lateral de escaneo 3D de cráneo; b, c, vista dorsal de arco yugal izquierdo y derecho, d., e. vista lateral de arco yugal izquierdo y derecho, f. vista palatal de cuadrado izquierdo; $\mathbf{g}$, vista dorsal de cuadrado derecho; $\mathbf{h}$, vista lateral de cuadrado izquierdo; $\mathbf{i}$, vista medial de cuadrado izquierdo. Escala: $10 \mathrm{~mm}$. Abreviaciones: cap., capitulum; cond. condylus; proc., processus. 


\section{Mandíbula}

Tanto la ramus mandibulae derecha como la izquierda están conservadas, aunque carecen de la sínfisis y parte de la porción más anterior de las ramas. No se observan foramina neurovascularia, y sólo la mandíbula derecha preserva parte del inicio de la crista tomialis. Por estas características y al comparar con la extensión que se conserva del pico podemos inferir que una parte considerable de las ramas faltan. Las ramas son, proporcionalmente, un poco más altas que en Spheniscus magellanicus, y menos que en Eudyptes y Pygoscelis. En cuanto al grado de gracilidad, y a la curvatura de la mandíbula, Madrynornis resulta muy similar a Megadyptes antipodes.

En vista lateral (Fig. 3b), el angular está fusionado con el surangular, como en todas las especies de pingüinos (contra Degrange et al., 2018 que dice que en Pygoscelis no está fusionado). Posteriormente, en vista lateral, la incisura retroarticularis es profunda, más que en las formas actuales. El proc. coronoideus tiene un desarrollo similar a las especies actuales.

La porción más ventral y posterior del esplenial llega casi a la altura de la fossa aditus canalis mandibulae (Fig. 3a). Esta fosa es fenestrada, y la fenestra es ovalada y amplia, el grado de amplitud de esta fenestra es variable entre individuos. Por otro lado, la fenestra rostralis mandibulae no se encuentra abierta en Madrynornis. El surco sobre el margen medioventral (que inicia posterior a la fossa aditus canalis mandibulae y alcanza el proc. retroarticularis) es profundo y bien desarrollado. En este surco se aloja parte de la pars M del m. pterygoideus, el cual se inserta a lo largo de la cresta posteroventral de la mandíbula y así también como en un tubérculo (innominado hasta lo que conocemos) que se desarrolla en esta cresta (tuberculum $m$. pterygoideus pars $M$, nuevo término). El tuberculum $m$. pterygoideus pars $M$ está bien desarrollado como en todas las especies actuales. El proc. medialis está bien desarrollado, en forma de gancho, y su margen medial tiene la misma inclinación que en Spheniscus, esta porción es la que articula con el proc. lateralis parasphenoidalis.

En la región articular en vista dorsal (Fig. 3d), posterior a la crista transversa fossae e interno al proc. medialis existe una muesca ovalada bien desarrollada que es la cicatriz de inserción del lig. occipitomandibulare que une la mandíbula con el proc. paroccipitalis (Baumel, 1993). Esta cicatriz tiende a ser ovalada y tener un grado de desarrollo similar en las especies actuales. El tuberculum pseudotemporale (Fig. 3) está más desarrollado que en las especies actuales (Degrange et al., 2018), es robusto y se proyecta medial y dorsalmente. 

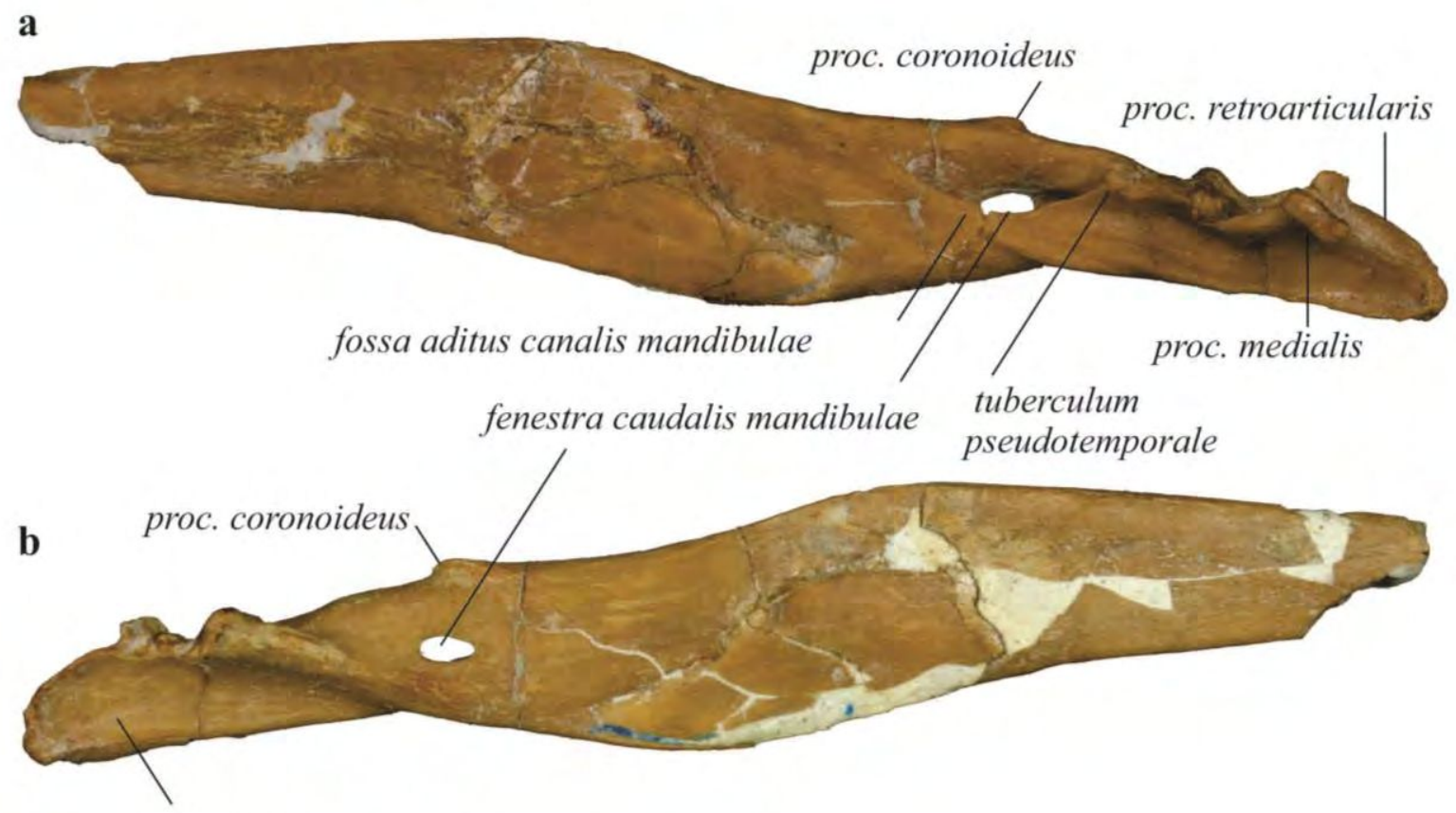

incisura retroarticularis
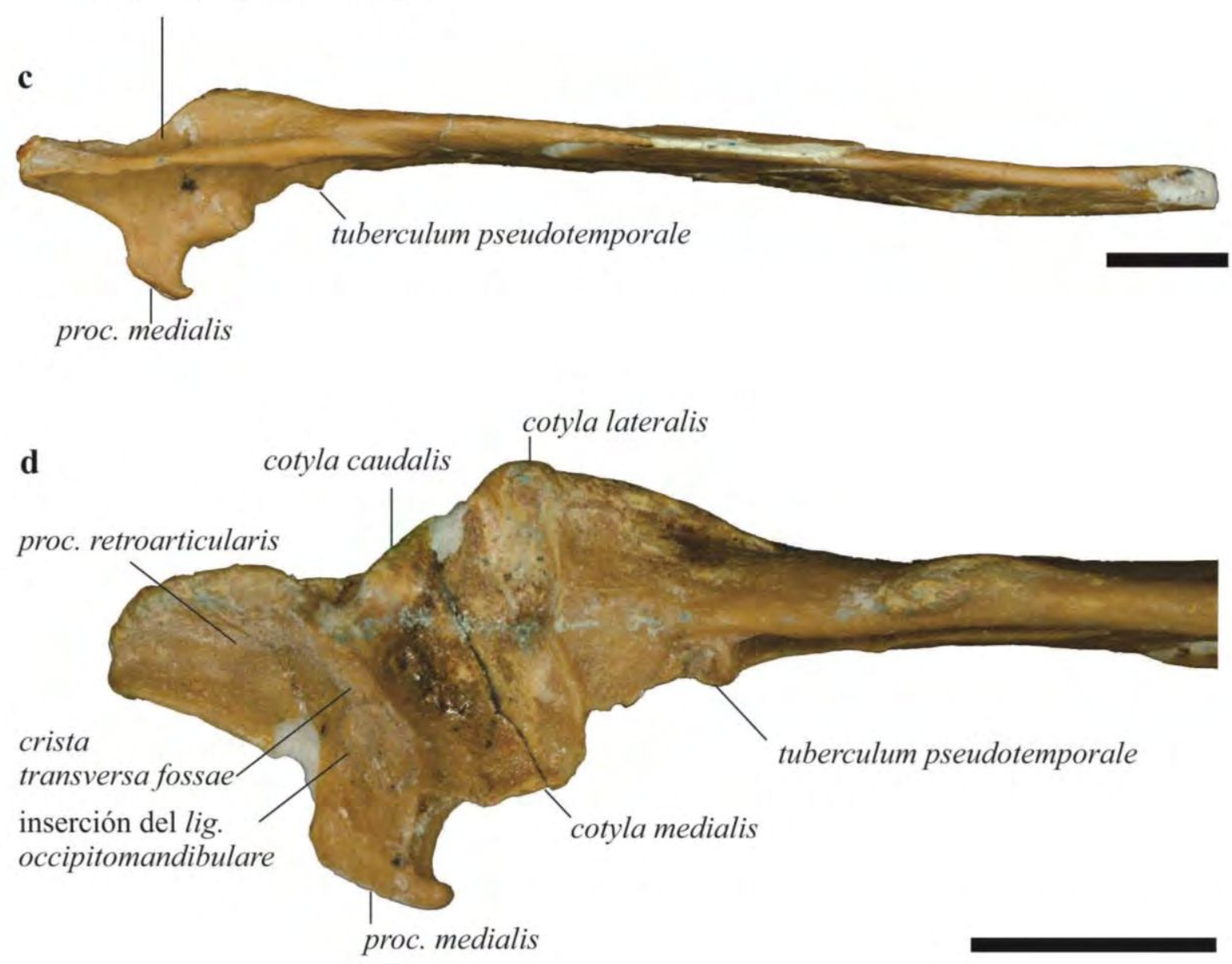

Figura 3 Ramas mandibulares de MPEF PV 100 Madrynornis mirandus. a, vista medial; b, vista lateral; c, vista ventral; d, vista dorsal de región articular. Escala: $10 \mathrm{~mm}$. Abreviaciones: cot., cotyla; lig., ligamentum; proc.$=$ processus . 
En las especies actuales, esta estructura está más bien representada por un tubérculo muy pequeño y una muesca adyacente. La superficie articular es menos profunda que las especies actuales, y la relación ancho largo de las cotylae fossae articularis es mayor que en Spheniscus y Aptenodytes, y similar a Eudyptes y Pygoscelis (Haidr \& Acosta Hospitaleche, 2014). La cotyla medialis se proyecta medialmente, de manera similar a Spheniscus y Aptenodytes, y es redondeada. En el punto de unión entre las cotyla lateralis y c. caudalis ambas mandíbulas están rotas, por lo que no se puede apreciar si ambas cotylae pueden o no ser claramente diferenciadas. De todas maneras, en vista lateral (Fig. 3b) ambas cotylae forman una concavidad diferente como en Spheniscus, la cotyla lateralis está bien ensanchada y extendida lateralmente con un reborde anterior bien marcado. En Madrynornis pareciera no existir un sulcus intercotylaris, ya que la $c$. lateralis posee una cresta en su margen anterior que se extiende hasta la c. medialis lateralis. El proc. retroarticularis se extiende posteriormente, y posee un desarrollo intermedio entre Eudyptes y Spheniscus. La fossa caudalis es profunda, similar a la condición de las especies actuales.

\section{Coracoides}

Tanto el coracoides derecho como el izquierdo se encuentran en perfectas condiciones. En tamaño es mayor a Spheniscus, Eudyptes, y Eudyptula, y menor a Aptenodytes. Posee un largo total similar al hallado en individuos de Pygoscelis adeliae y $P$. papua. A lo largo de su extensión posee forámenes nutricios, siendo los más conspicuos los de la porción media distal. La extremitas omalis coracoidei presenta un proc. acrocoracoideus perpendicular a la diáfisis, una condición similar a la observada en Spheniscus. La facies articularis clavicularis es menos robusta que en Spheniscus y más que en Pygoscelis, que es grácil. El impressio ligamentum acrocoracohumeralis es ovalado, similar a $P$. adeliae. La facies articularis humeralis tiene forma ovoidal, similar a las especies actuales, la facies del coracoides derecho es levemente más elongada que la del izquierdo (Fig. 4c). El sulcus m. supracoracoidei en Madrynornis mirandus (0.18) posee una altura menor en proporción con la diáfisis a Eudyptes chrysocome ( ), Pygoscelis ( ) y Spheniscus (0.194), y mayor a Aptenodytes (0.156), y Eudyptula (0.172) (Tabla 1). 
Tabla 1 Medidas e índice del coracoides y sulcus del $m$. supracoracoideus. Abreviaciones: L CRC, largo diáfisis coracoides; L s supracorac, largo sulcus $m$. supracorcoideus; índice entre L CRC y s supracorac.

\begin{tabular}{|c|c|c|c|}
\hline Taxón & L CRC & L s supracorac & índice \\
\hline Aptenodytes forsteri & , & , & , \\
\hline Aptenodytes patagonicus & , & , & , \\
\hline Aptenodytes & & & , \\
\hline Eudyptes chrysocome & , & , & , \\
\hline Eudyptula minor & , & , & , \\
\hline Pygoscelis adeliae & , & , & , \\
\hline Pygoscelis antarctica & , & , & , \\
\hline Pygoscelis papua & , & , & , \\
\hline Pygoscelis & & & , \\
\hline Spheniscus magellanicus & , & , & , \\
\hline
\end{tabular}

La cotyla scapularis es subcircular (Fig. 4a), con un grado de ovalamiento menor que en Aptenodytes. La incisura nervi supracoracoidei (Fig. 4a, b) es oval y está cerrada como en Eudyptes chrysocome, E. chrysolophus, E. sclateri, Eudyptula minor, y Spheniscus magellanicus, mientras que es abierta en Aptenodytes y Pygoscelis. La crista procoracoidei (Livezey \& Zusi, 2006) se extiende por un 0.44 del largo del margen medial desde el proc. procoracoideus hasta el angulus medialis (Fig. 4a, b). El proc. lateralis forma un ala cuadrangular bien desarrollada, similar a la condición vista en Pygoscelis. Existe una proyección proximal del angulus medialis, como en muchos individuos de Pygoscelis, Spheniscus, Eudyptula. Esa proyección en algunos individuos puede llegar a fusionarse con la crista procoracoidei, no es el caso de este espécimen en particular. 


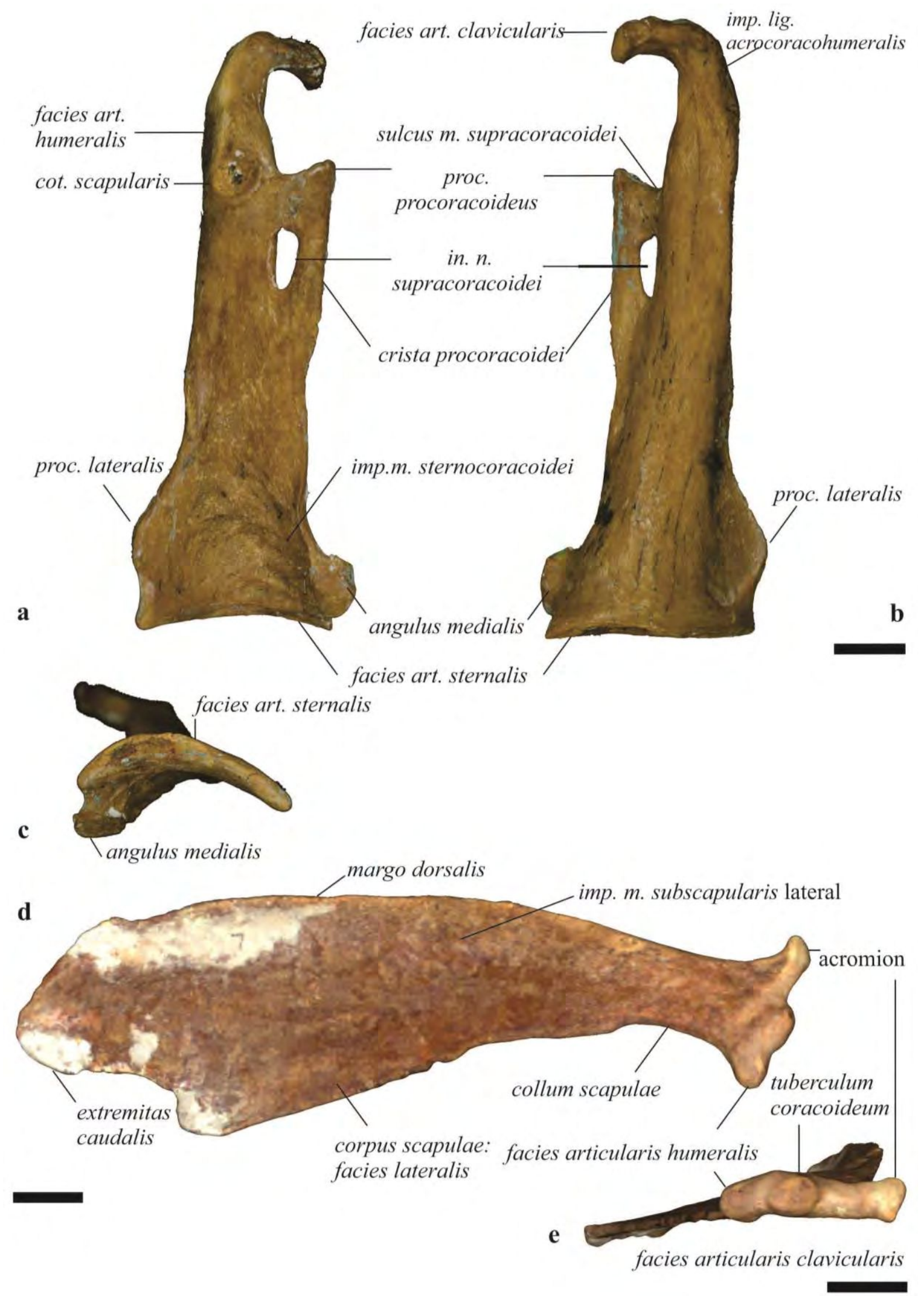

Figura 4 MPEF PV 100 Madrynornis mirandus. a,b, coracoides izquierdo en vista dorsal, ventral y esternal; c, d, escaneo 3D de la escápula derecha en vista lateral y proximal. Escala: $10 \mathrm{~mm}$. Abreviaciones: art., articularis; cot., cotyla; imp., impressio; in., incisura; lig., ligamentum; m., musculus; n., nervi; proc., processus. 
En vista dorsal, la impressio m. sternocoracoidei (Fig. 4a) tiene una forma triangular como en todos los pingüinos actuales, posee forámenes y estriaciones típicas, y el vértice del mismo llega hasta la altura del inicio del proc. lateralis.

Por último, la facies articularis sternalis (Fig. 4c) tiene una forma curva como todas las especies actuales, el grosor ventro-dorsal a lo largo de la facies es variable siendo más grueso en la parte centro-medial de la facies. Esta condición se observa en Eudyptes, y es incluso más evidente en Pygoscelis, mientras que Aptenodytes, Eudyptula y Spheniscus el grosor es homogéneo. En vista medial se observa que el extremo más medial de la facies se extiende distalmente con respecto al angulus medialis.

\section{Escápula}

Se preserva sólo la escápula derecha, en estado completo a excepción de una pequeña fractura en el margen ventroposterior de la extremitas caudalis (Fig. 4d). La hoja del corpus scapulae presenta pliegues en su parte más posterior probablemente producto de deformaciones tafonómicas. Este elemento está particularmente bien preservado dada su naturaleza frágil al ser tan delgado, plano y propenso a las deformaciones y quebraduras como se observa incluso en carcasas de animales recientemente muertos.

La porción proximal de la escápula (Fig. 4e) en vista anterior carece de la curvatura en "s", mientras que en Pygoscelis y Spheniscus, el acromion se proyecta laterodorsalmente, originando una curvatura suave en "s" El tuberculum coracoideo es ovalado como en Aptenodytes, Eudyptes, y Pygoscelis. La porción proximal de la escápula es proporcionalmente más ancha con respecto a la lámina del corpus scapulae en Madrynornis que en cualquier otra de las especies consultadas en este estudio.

En vista lateral (Fig. 4d), el eje del corpus scapulae es casi perpendicular con respecto al margen craneal de la escápula en Madrynornis. En los pingüinos actuales incluidos en este estudio, el corpus scapulae se encuentra inclinado con respecto al margen craneal. Aptenodytes forsteri posee todo su cuerpo curvado y en mayor medida que los demás especímenes actuales consultados, mientras que en Spheniscus el corpus comienza estando perpendicular al margen anterior y luego se curva. En Pygoscelis, la hoja que forma el corpus es mucho más ancha que en las demás especies, el collum scapulae comienza ensanchándose paulatinamente hasta formar una amplia hoja que cambia de ángulo su eje inclinándose 
ventralmente. En Eudyptes este ensanchamiento es relativamente menor, aunque mayor que en Spheniscus, Aptenodytes y Madrynornis, también en Eudyptes el cambio de ángulo del eje se da en la mitad posterior del corpus. En el caso de Madrynornis el ensanchamiento es paulatino e intermedio entre Eudyptes y Spheniscus, su grado de curvatura es muy similar al de Spheniscus magellanicus. La hoja del corpus scapulae es comparativamente más corta que en todas las especies actuales consultadas. En el margo caudalis de algunos de los individuos principalmente de Spheniscus magellanicus, existen una serie de aberturas que forman un borde ondulado, Madrynornis por su parte carece de ellos, y posee una borde suave en su margen caudal. Existe una hendidura a lo largo del cuello del corpus scapulae, que es la cicatriz de inserción del $m$. subscapularis caput laterale.

\section{Esternón}

El esternón presenta un grado de preservación bueno, aunque la carina sterni se encuentra fragmentada en su lado izquierdo, lado que no conserva la trabecula lateralis (Fig. $5 \mathrm{c}, \mathrm{d}, \mathrm{e})$. El lado derecho se encuentra prácticamente entero, a excepción de la punta de la trabecula y parte de la incisura lateralis. Su tamaño es intermedio entre Aptenodytes forsteri y Pygoscelis papua, y su contextura general es más robusta que en las especies actuales consultadas.

Sobre la incisurae costalis existen cinco loculus costalis (Fig. 5e), con cinco facies articularis costalis para la articulación del esternón con cinco costillas esternales. El número de estas facies varía intraespecíficamente en pingüinos actuales siendo entre cinco y seis.

El rostrum sterni posee una spina externa bien desarrollada y redondeada, y una spina interna (proc. craniolateralis en Livezey \& Zusi, 2006) con un desarrollo proporcional mayor a Eudyptes y Spheniscus, y menor a la de Aptenodytes patagonicus. Esta espina es el lugar de inserción del m. coracobrachialis caudalis. El margen anterior de la spina interna es perpendicular al eje de la carina sterni en Madrynornis mirandus, mientras que es oblicuo en las demás especies. Por último, esta espina presenta una fenestra que está abierta sólo en la espina izquierda.

El robusto corpus sterni tiene una forma cuadrangular, proporcionalmente más ancho que en todas las demás especies actuales. La incisura lateralis (Fig. 5c) tiene una forma oval, es comparativamente más ancha y tiene un nivel de ingresión en el corpus similar a Eudyptes, 
Eudyptula y Spheniscus, y menor que Pygoscelis y Aptenodytes. La trabecula lateralis (sólo se conserva la derecha) es ancha, y relativamente más corta que las especies actuales extendiéndose posteriormente hasta el final del corpus sterni. La cresta de inserción de la porción caudolateral del $\mathrm{m}$. pectoralis thoracica no está bien marcada como sí ocurre en la mayoría de individuos de las especies actuales y la línea que corta la trabecula en su inicio alcanza la incisura lateralis casi en su inicio. Las formas actuales presentan un corpus sterni más globoso que Madrynornis mirandus, el cual es comparativamente más chato.

Por último, la carina sterni tiene un grado de desarrollo similar a Eudyptes y Spheniscus, su forma curvada también es similar a estas especies. El margen anterior del apex carinae es recto como en Aptenodytes mientras que es curvado en las demás especies consultadas.

\section{Fúrcula}

Posee un tamaño similar a una fúrcula de Pygoscelis. Carece de la pronunciada curvatura del margen ventral en "U" presente en los pingüinos actuales, en Madrynornis mirandus esta curvatura es mucho más abierta (Fig. 5a, b). El largo de la extremitas omalis claviculae es más corto en comparación en Madrynornis que en las especies actuales. El proc. acromialis posee una cicatriz de articulación de mayor desarrollo que en Pygoscelis o Spheniscus. De la misma manera, el proc. acrocoracoideus se proyecta como un proceso redondeado en el fósil estudiado. La fossa del margo internus donde hace contacto parte del m. supracoracoideus es más marcada y de mayor tamaño que en Pygoscelis y Spheniscus. Por último, se observa una fosa profunda inmediatamente anterior al proc. acrocoracoideo en la cara externa (lateral). El grado de profundidad de esta fosa no se observa en ninguna de las especies actuales consultadas. 
a

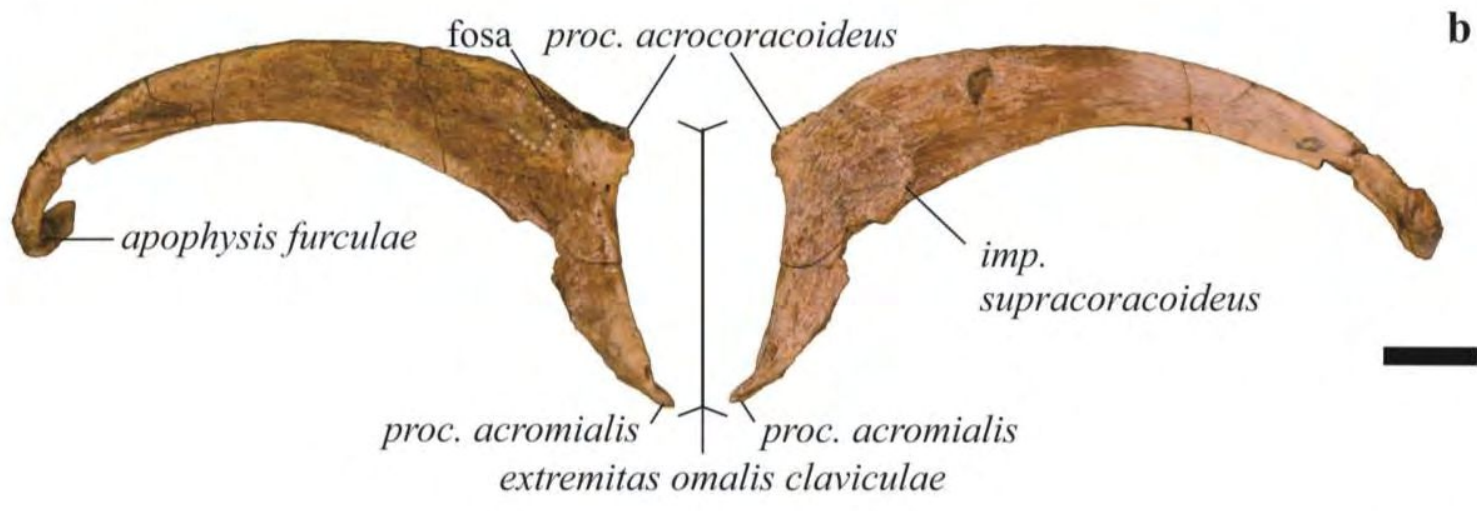

c

d

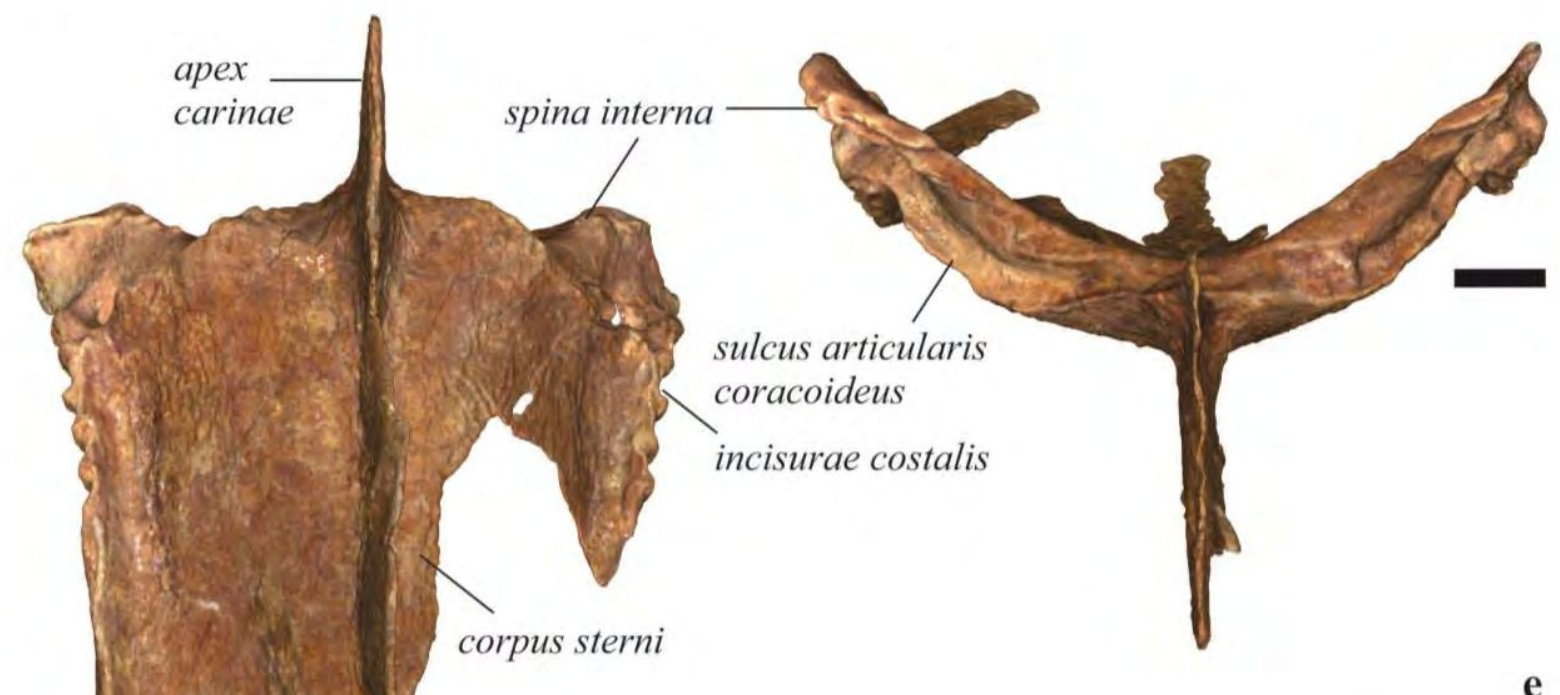

spina externa
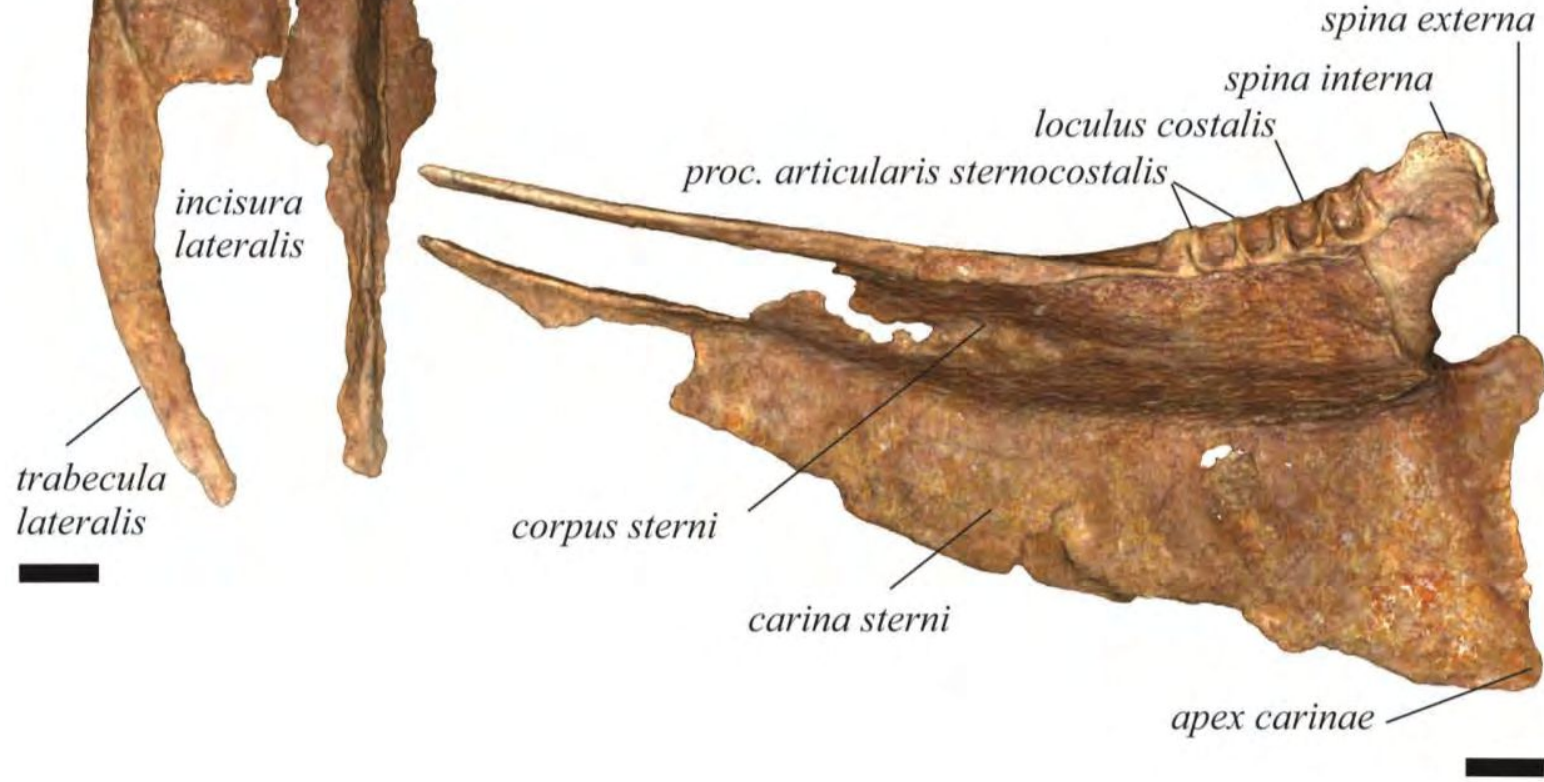

Figura 5 MPEF PV 100 Madrynornis mirandus. a, b, fúrcula en vista ventral, anterior; b, c, d, escaneos 3D del esternón en ventral, anterior y lateral. Escala: $10 \mathrm{~mm}$. Abreviaciones: imp., impressio; proc., processus. 


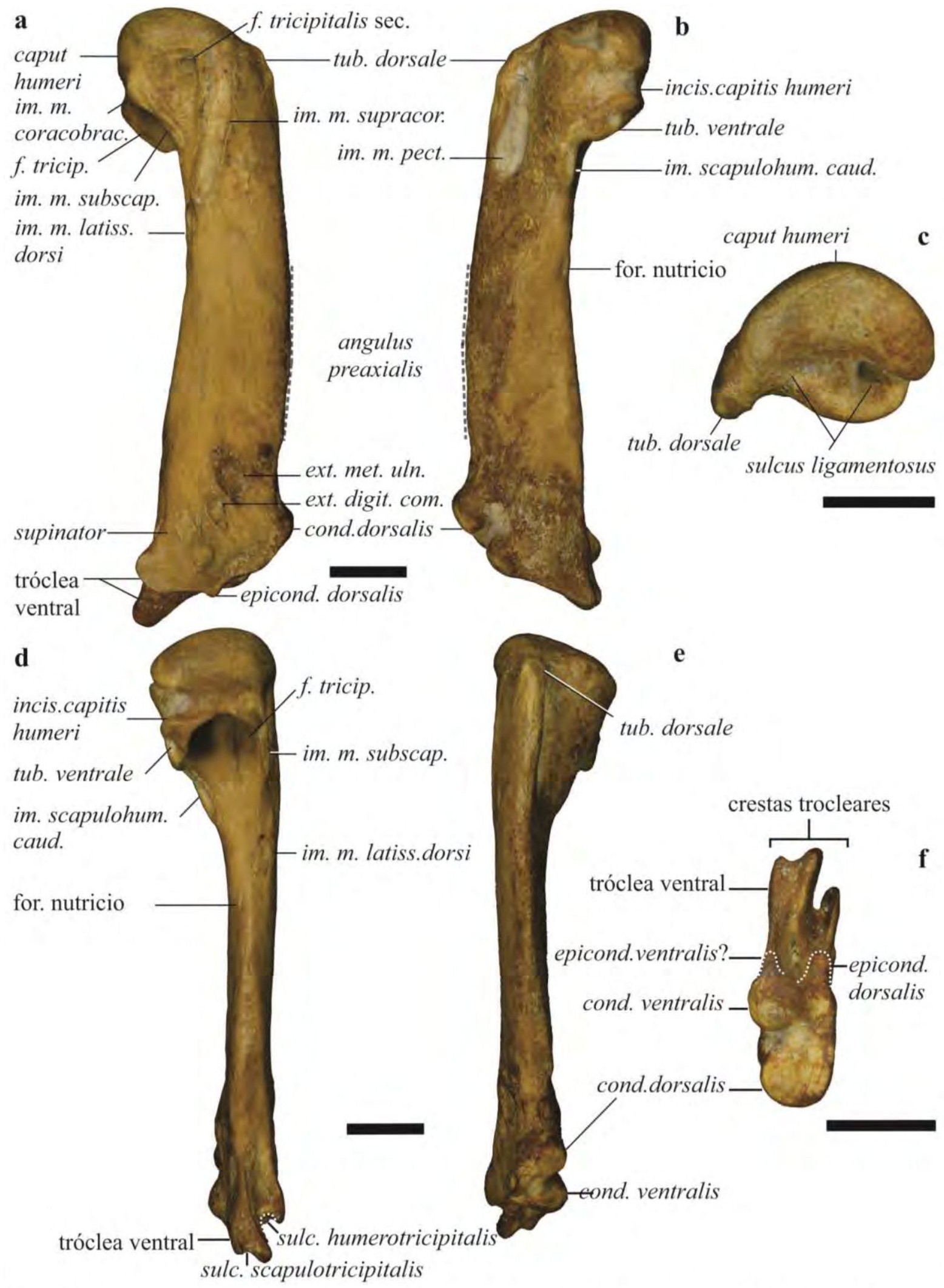

Figura 6 Húmero derecho del MPEF PV 100 Madrynornis mirandus. a, Vista dorsal; b, vista ventral; c, vista proximal; $\mathbf{d}$, vista posterior; e, vista anterior; $\mathbf{f}$, vista distal. Escala: $10 \mathrm{~mm}$. Abreviaciones: cond., condylus; epicond., epicondylus; ext. digit. com., impressio musculus extensor digitorum communis; ext. met. uln., impressio musculus extensor metacarpi ulnaris; f. tricip., fossa tricipitalis; f. tricipitalis sec., fossa tricipitalis secundaria; for., foramen; im. m. coracobrac., impressio musculuscoracobrchialis; im. m. latiss. dorsi, impressio musculus latissimus dorsi; im. m. pect., impressio musculus pectoralis; im. m. scapulohum. caud, impressio musculus scapulohumeralis caudalis; im. m. subscap., impressio musculus subscapularis; im. m. supracor, impressio musculus supracoracoideus; incis., incisura; sulc., sulcus; tub., tuberculum. 


\section{Húmero}

El tamaño del húmero es similar al de Pygoscelis papua. Proximalmente, la morfología del caput humeri es similar a la de los pingüinos actuales. El sulcus ligamentosus presenta dos fosas (Fig. 6c), la posterior es profunda, más que en Spheniscus y Pygoscelis, y redondeada, mientras que la más anterior es superficial, similar a Pygoscelis. El tuberculum dorsale (Fig. 6a, b) posee una inclinación más paralela a la diáfisis, mientras que en las especies actuales es más oblicua. La impressio $m$. pectoralis es ovalada y similar en desarrollo a los taxa consultados (Fig. 6b). La incisura capitis humeri es profunda y similar en desarrollo a Spheniscus y Pygoscelis. El tuberculum ventrale (Fig. 6b, d) es robusto y triangular, su margen interno, que delimita la fossa tricipitalis, forma una línea convexa en lugar de cóncava como en las especies actuales. La fossa tricipitalis secundaria es menos profunda que en Pygoscelis y Spheniscus. La impressio m. supracoracoideus (Fig. 6a) empieza proximalmente a la altura del inicio de la fossa tricipitalis secundaria y continúa en diagonal hasta terminar inmediatamente por encima y caudal a la impressio $\mathrm{m}$. latissimus dorsi, condición similar a Eudyptes. La fossa tricipitalis es bipartita como en todas las especies actuales y del Mioceno (exceptuando a Paraptenodytes antarcticus). El foramen nutricio (Fig. 6b, d), que se ubica inmediatamente craneal a la impressio m. latissimus dorsi y en el margen posterior de la diáfisis del húmero en la mayoría de las formas actuales, en Madrynornis se encuentra prácticamente en la cara craneal del húmero. Esta condición también se vislumbra en Eudyptes aunque en menor medida. La diáfisis de MPEF PV 100 es grácil como en Spheniscus y Eudyptula, no es recta como en las especies actuales sino que dibuja líneas curvas, dando como resultado una muy sútil forma sigmoidea con curvas muy abiertas. En este marco, el angulus preaxialis que en mayor o menor grado de curvatura existe en todas las especies actuales, en Madrynornis está ausente. Siguiendo con la diáfisis, al igual que en todas las especies actuales las impresiones vasculares se encuentran bien marcadas sobre la cara craneal (Fig. 6b). Las impresiones sobre la cara caudal de la epífisis distal de los extensor metacarpi ulnaris, extensor digitorum communis, y el supinator forman una línea que en lugar de correr paralela a los cóndilos articulares, como en Pygoscelis, forman un ángulo agudo con respecto a ellos. Esta condición se observa en menor medida en Eudyptes, Eudyptula y Spheniscus. Las crestas trocleares presentan algunas particularidades. En vista distal la cresta troclear media llega más posteriormente que las otras, mientras que para todas las especies actuales, esa condición la presenta la tróclea ventral (proc. flexorius). La tróclea caudal está proporcionalmente más desarrollada que las 
formas actuales y posee un contorno más cuadrangular en lugar de puntiagudo. En vista craneal su punta sobresale de la diáfisis, esta condición sólo está presente en Pygoscelis y en menor medida en Aptenodytes. El sulcus scapulohumerotricipitalis (Fig. 6d) es menos profundo que en las especies actuales, mientras que lo contrario ocurre con el sulcus $m$. humerotricipitalis el cual es más profundo. En cuanto a los cóndilos, ambos son circulares en vista distal. En todas las especies actuales tanto en el margen ventrocaudal como dorsocaudal del condylus ventralis existen dos procesos, el epicondylus dorsalis y epicondylus ventralis, que contactan con la ulna y le dan estabilidad a la articulación. Madrynornis prácticamente carece de epicondylus ventralis. Además, el epicondylus dorsalis en vista distal es puntiagudo y no redondeado como en las especies actuales. Por último, los cóndilos en vista dorsal/ventral forman un ángulo con la diáfisis, de más obtuso a más agudo encontramos a Aptenodytes, Pygoscelis adeliae, P. antarctica, Eudyptula, P. papua, Eudyptes, Madrynornis y Spheniscus. La inclinación resulta muy similar a Spheniscus.

\section{RESULTADOS: INFERENCIAS DIETARIAS}

\section{Análisis discriminantes}

Los análisis discriminantes en los cuales se incluyó a Madrynornis mirandus como incógnita arrojaron resultados diversos en cuanto a la asignación de categoría dietaria para cada configuración (los resultados se presentan en la Tabla 2). Para la configuración de la caja craneana y mandíbula, fue clasificado como piscívoro. Para el húmero, en vista ventral fue ubicado con los crustacívoros para los datos originales y generalista para los datos sin corregir. Mientras que para la vista dorsal, fue clasificado como piscívoro para ambos conjuntos de datos. Para las configuraciones del coracoides en vista esternal y dorsal, fue clasificado como generalista (datos originales), y piscívoro (datos corregidos). En el caso del esternón, la vista ventral fue clasificada dentro de los generalistas (datos originales), y piscívoros (corregidos), mientras que la vista lateral cayó dentro de los crustacívoros. 
Tabla 2. Clasificación asignada para Madrynornis mirandus a partir de un análisis de discriminantes para cada configuración. Referencias: $\mathrm{p}=$ piscívoro, $\mathrm{c}=$ crustacívoro, $\mathrm{g}=$ generalista.

\section{Clasificación}

\begin{tabular}{|c|c|c|c|}
\hline Elemento óseo & Configuración & & \\
\hline & & datos originales & datos corregidos \\
\hline caja craneana & dorsal & $\mathrm{p}$ & $\mathrm{p}$ \\
\hline mandíbula & dorsal & $\mathrm{p}$ & $\mathrm{p}$ \\
\hline húmero & ventral & $\mathrm{c}$ & g \\
\hline & dorsal & $\mathrm{p}$ & $\mathrm{p}$ \\
\hline coracoides & ventral & $\mathrm{c}$ & $\mathrm{p}$ \\
\hline & dorsal & g & $\mathrm{p}$ \\
\hline & esternal & g & $\mathrm{p}$ \\
\hline esternón & ventral & $\mathrm{g}$ & $\mathrm{p}$ \\
\hline & lateral & $\mathrm{c}$ & $\mathrm{c}$ \\
\hline
\end{tabular}




\section{CONCLUSIÓN Y DISCUSIÓN}

Los análisis realizados a lo largo de la tesis indican que el cráneo y mandíbula, pero sobre todo el pico, son indicadores del tipo de presa a atrapar. También pudimos corroborar preliminarmente que el pico y la caja craneana actuarían como una unidad integrada.

Si bien, los análisis exploratorios (Análisis de componentes principales, Capítulo III y IV) tienden a ubicar a Madrynornis más cercano a Eudyptes (generalista), Pygoscelis (crustacívoro) y Eudyptula (piscívoro), que a Spheniscus (piscívoro por excelencia); los análisis de discriminantes clasifican a Madrynornis como piscívoro.

Madrynornis presenta una fosa temporal de similar desarrollo con Eudyptes (generalista). La fosa temporal es el lugar de origen del $m$. adductor mandibulae externo (Fig. 7a), el cual está muy desarrollado en formas piscívoras como Spheniscus magellanicus y que se relaciona con un hábito piscívoro (Zusi, 1975; Tambussi \& Acosta Hospitaleche, 2008). Posee una profunda inserción del m. pseudotemporalis superficialis (Fig. 7b), mayor a cualquier forma actual (Degrange et al, ), el cual es uno de los músculos adductores de la mandíbula (inferior). Su proc. postorbitalis es delgado y recto (Acosta Hospitaleche et al., 2007; Degrange et al., 2018), lo que podría ser un indicativo de un no tan robusto lig. postorbitalis (Fig. 7a), cuya presencia da estabilidad a la mandíbula y posibilita la apertura del pico (superior) mediante el $m$. depressor mandibulae. El arco jugal posee un grado de curvatura intermedio entre Spheniscus/Aptenodytes, y Pygoscelis/Eudyptes, característica que ha sido relacionada con la profundidad de la mandíbula y la respiración (Zusi, 1975). El pico de Madrynornis posee un ancho relativo intermedio entre Pygoscelis/Eudyptes y Spheniscus/Aptenodytes/Eudyptula, y las apertura nasi ossea se visualizan en vista dorsal. Lo que Zusi (1975) relaciona con un pico ancho, como en las formas que se alimentan de crustáceos. 
a

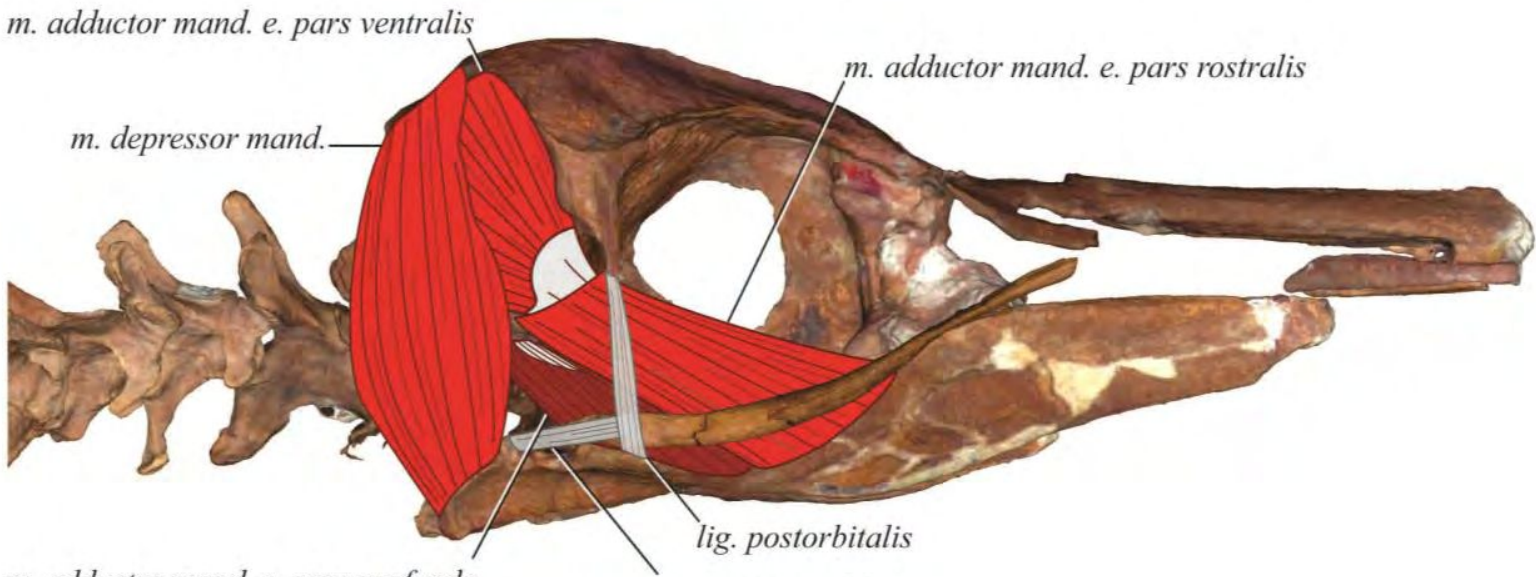

m. adductor mand. e. pars profunda

lig. jugomandibulare

b
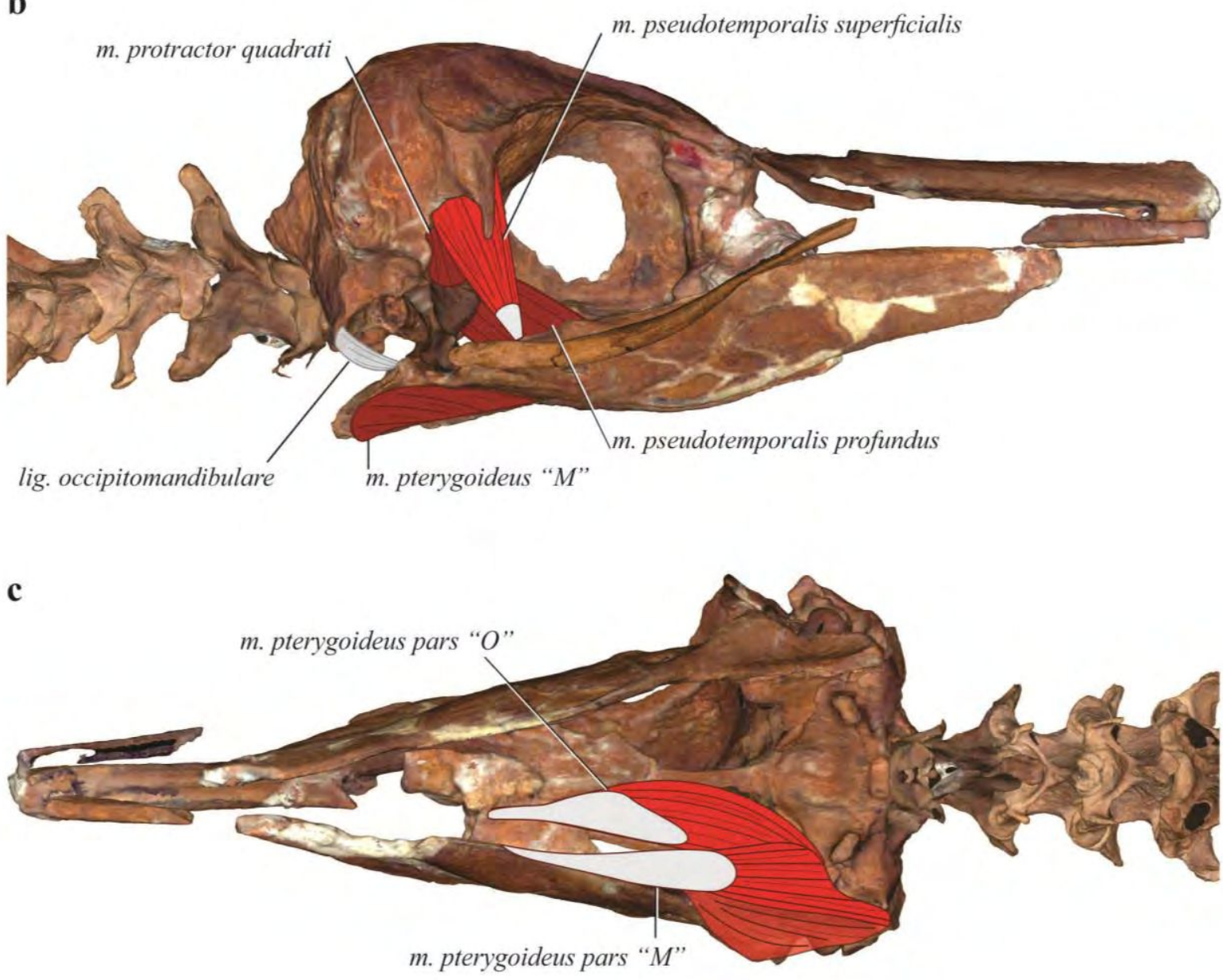

Figura 7 Reconstrucción muscular del cráneo de MPEF PV 100 Madrynornis mirandus. a,b, vista lateral de capa superficial y profunda; c, músculos pterygoideus en vista ventral. Abreviaciones: m., musculus; mand., mandibulae; e., externus. 
La mandíbula posee una morfología de la articulación que, si bien es ancha como podría ser la articulación de Pygoscelis (Haidr \& Acosta Hospitaleche, 2014), posee cierta separación de las cotylae lateralis y caudalis mayor que Pygoscelis y similar a Spheniscus. Además, el reborde anterior de la cotyla lateralis daría un punto estable anterior a la articulación con el cuadrado. El proc. medialis es muy similar a Spheniscus, y articula con el basicráneo en la llamada articulación secundaria (Bock, 1960), dando mayor estabilidad a la mandíbula. Además, el proc. medialis es lugar de origen del m. pterygoideus (Fig. 7c) (Bock, 1960; Zusi, 1975; Degrange et al., 2018), uno de los músculos vinculados al cierre del pico (adducción). Por último, el proc. retroarticularis está muy desarrollado y es muy similar a Spheniscus, aunque estaría un poco menos desarrollado que este último. Este proceso es el lugar de inserción del $m$. depressor mandibulae, principal músculo involucrado en la apertura de la mandíbula e indirectamente en la apertura del pico (Bock, 1960, 1999; Zusi, 1967). Mientras que en su cara ventral es lugar de inserción del $m$. pterygoideus (Fig. 7c), por lo que su alto grado de desarrollo también aumentaría el brazo de palanca de entrada de este músculo, además de ser un indicativo de un mayor desarrollo transversal de ambos músculos, lo que se traduce en más fibras musculares y mayores fuerzas.

En cuanto al ala y cintura escapular, para el coracoides los resultados de los PCA resultaron dispares entre las diferentes configuraciones, quedando en la vista esternal intermedio entre Spheniscus y Pygoscelis en el PC1, y el PC2 entre los generalistas y los especialistas; mientras que la vista dorsal cayó más cercano a Pygoscelis, y en la vista ventral quedó alejado de todas las especies actuales. Por otro lado, el análisis de discriminantes ubicó a Madrynornis dentro del grupo generalista, excepto para la vista ventral en la cual cayó como crustacívoro. Mientras que para los datos corregidos fue clasificado como piscívoro. Esto se condice con lo que se observa a simple vista de la superficie articular, la cual es similar a Eudyptes. Posee similitud en cuanto al cierre del foramen n. supracoracoideus con las formas piscívoras, y a la formación del sulcus $m$. supracoracoideus, pero en los análisis morfogeométricos lamentablemente esta condición no pudo señalarse con landmarks. Algunas características como el desarrollo del proc. lateralis (similar a Pygoscelis) que acerca el origen del m. subcoracoideus (Fig. 11) a su inserción, como la proyección anterior de la articulación esternal con respecto al desarrollo del angulus medialis (no presente en las especies actuales) el cual brinda un punto de apoyo estable del coracoides con respecto al esternón, valen la pena ser mencionadas debido a su significado funcional y ya que no pudieron ser representadas en los análisis morfogeométricos. Cabe destacar además, que el 


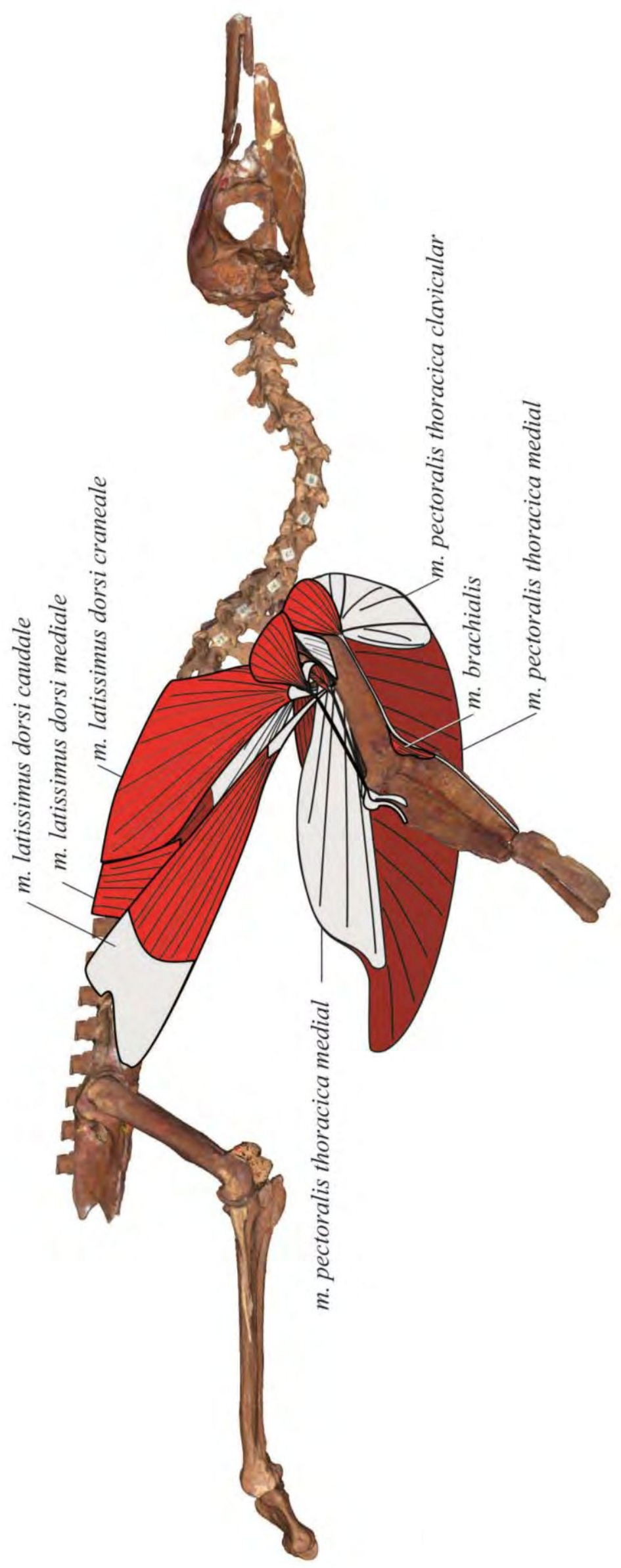


coracoides posee el foramen $n$. supracoracoidei cerrado, pero no llega a formarse un "puente óseo" entre el angulus medialis y el proc. procoracoidei. Sin embargo, la osificación de esta zona varía entre especies, poblaciones, individuo, e inclusive edad (Bannasch, 1986b), y las fuerzas que se generan en ella son las responsables, en última instancia, de esta osificación. De todas maneras, la condición que presenta Madrynornis (la misma que Eudyptes, Eudyptula y Spheniscus) permite la formación de un surco (sulcus m. supracoracoideus) que oficia de polea para el paso del m. supracoracoideus (Fig.), músculo principal en la elevación del ala.

Ambas vistas del esternón fueron clasificadas dentro del grupo generalista, y en los PCA fueron agrupados cercanos a Eudyptes, y en menor medida a Spheniscus.

La fúrcula, por su parte, carece de la pronunciada curvatura característica de las especies actuales, estimamos que la apophysis furculae no habría llegado a hacer contacto con el apex carinae del esternón. Podemos inferir además, que dado que el largo de la extremitas omalis claviculae es proporcionalmente menor en Madrynornis que en las especies actuales, la apertura del foramen trióseo también lo habría sido y por ende el área transversal del m. supracoracoideus (Fig. 9). De todas maneras, la cicatriz de unión entre músculo y la fúrcula está bien marcada. En la cara lateral de la fúrcula inserta parte del $\mathrm{m}$. pectoralis thoracica (la porción clavicular) (Fig. 8), y es en esta cara en la porción más dorsal donde aparece una fosa muy profunda, que sólo se observa en Madrynornis. Está fosa daría un punto de anclaje extra al $\mathrm{m}$. pectoralis thoracica (Fig. 8), músculo involucrado en la adducción del ala. Entonces, la fúrcula nos daría un indicio del grado de desarrollo de los dos músculos principales del vuelo subacuático, con una porción clavicular del músculo pectoral con un punto fuerte de anclaje, y un m. supracoracoideus (Fig. 9) tal vez proporcionalmente menos robusto que las especies actuales, una condición, entonces donde la fuerza que origina un movimiento hacia abajo del ala en supinación habría resultado importante, en contraposición con un menos eficiente músculo elevador.

En cuanto a la escápula, más arriba se comentó esa ausencia de la curvatura en "s" que se observa en Pygoscelis y Spheniscus, esto se traduciría en una reducción en el punto de contacto dorsal de la escápula con la fúrcula. El corpus scapularis es de una menor envergadura en comparación con las especies actuales, en pingüinos pichones y juveniles gran parte de la extremitas caudalis es cartilaginosa, pero Madrynornis no posee evidencia de ser un pingüino juvenil, por lo que creemos que la hoja escapular estaba totalmente osificada. 
El músculo que origina en el corpus scapulae es el m. scapulohumeralis caudalis (Fig. 9a, 10a). Según las reconstrucciones hechas del esqueleto articulado para Madrynornis (Fig. 8), pudimos medir un ángulo aproximado de la resultante de la fuerza de este músculo con respecto al eje corporal de alrededor de $25^{\circ}$. Aunque el valor real que habría tenido es inconfirmable, el ángulo calculado para las especies actuales es de $30^{\circ}$ para Aptenodytes y de $40^{\circ}$ a $45^{\circ}$ para las demás especies (Bannasch, 1986b). El valor obtenido Madrynornis en esta reconstrucción indica un ángulo menor. Esto se traduce en un componente mayor de la fuerza en el eje $\mathrm{x}$ que en el eje $\mathrm{y}$, es decir una componente mayor en el movimiento hacia atrás del ala que hacia arriba. El ángulo de curvatura del corpus con respecto a la porción anterior de la escápula es similar a Aptenodytes, es decir que el margo dorsalis no posee la extensión dorsal característica presente en Pygoscelis y Eudyptes. Por esta razón, creemos que los valores calculados no solo no estarían errados, sino que se habrían aproximado bastante a la realidad. También hemos observado que el corpus scapulae es proporcionalmente más corto al de las formas actuales, por lo que el grado de desarrollo del $\mathrm{m}$. scapulohumeralis caudalis habría sido menor que en las especies modernas (Fig. 9a, 10a).

El húmero en vista dorsal se ubicó cercano a Spheniscus, y Eudyptes resultó ser el segundo grupo más cercano (Análisis de Componentes Principales, Capítulo IV). Los discriminantes clasificaron esta vista como de un pingüino piscívoro. Por otro lado, el húmero en vista ventral en el PCA cayó cercano a Spheniscus y Eudyptula (y Aptenodytes patagonicus para los datos corregidos por tamaño) para el PC1, todas formas piscívoras. El PC 2 lo encontró en valores cercanos a las formas especialistas, es decir, lejano a Pygoscelis papua y Eudyptes. El discriminante para la vista ventral agrupó a Madrynornis dentro de los crustacívoros para los datos originales y como generalista para los corregidos. Al estudiar el húmero notamos que la morfología del caput humeri es muy similar a la de los pingüinos actuales, por lo que la amplitud de los movimientos de la cabeza del húmero habrían sido similares, con una rotación excéntrica en dos ejes (Bannasch, 1994). Si bien en los análisis de morfometría geométrica las diferencias apuntaron a una ubicación más anterior de la fossa tricipitalis secundaria, a simple vista, las diferencias son menos obvias. Podemos afirmar, de todas maneras, que Madrynornis poseía una fossa tricipitalis secundaria bien desarrollada aunque más superficial que la de las formas actuales. Esto sería indicativo de una posible inserción del ligamentum scapulohumerale dorsale y del lig. coracohumerale dorsale más débil. Recordemos que el primero limita el movimiento de pronación y deslizamiento anterior del húmero, mientras que el segundo, junto con otros ligamentos, limita la supinación y el 

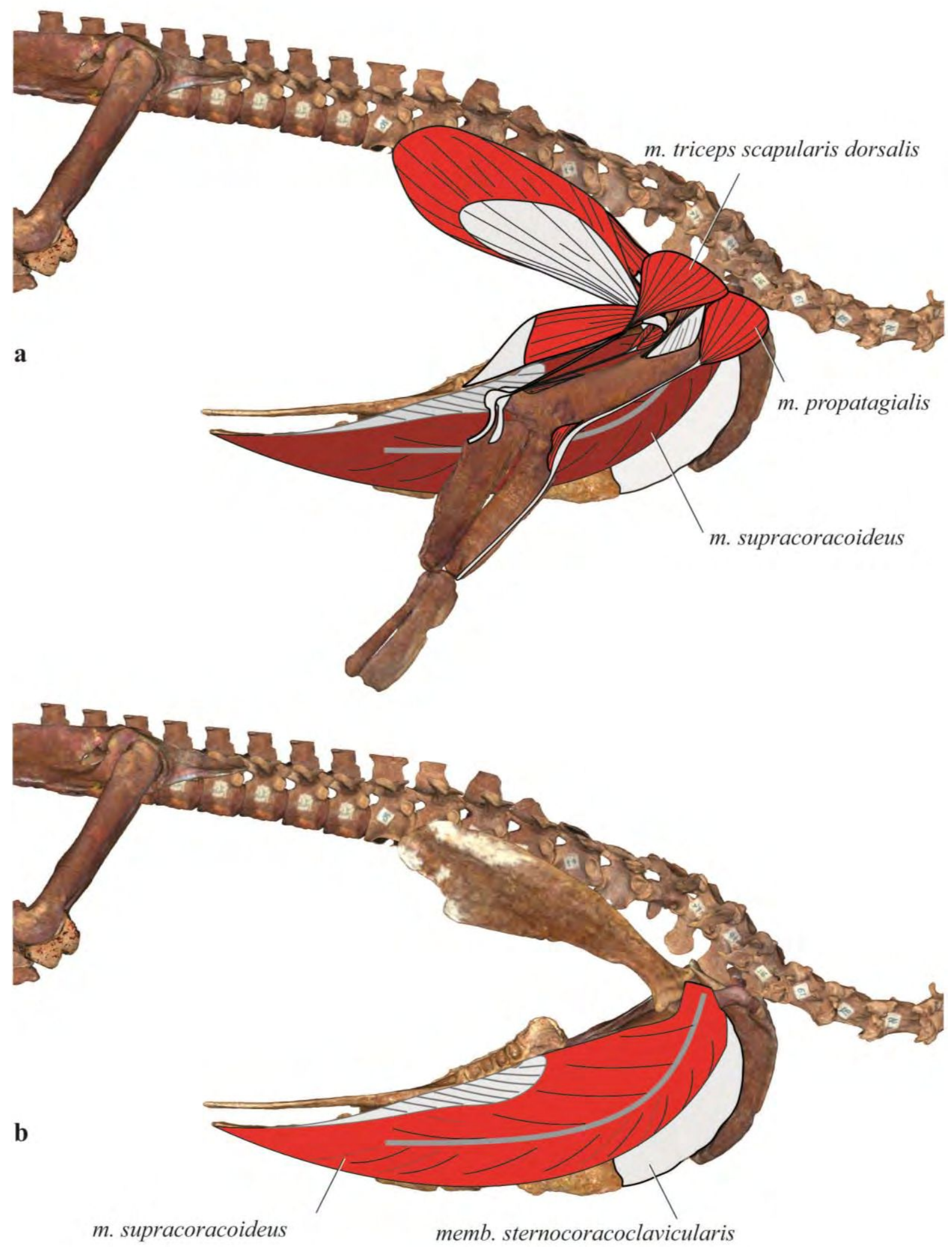

Figura 9 Reconstrucción de los músculos involucrados en el ala de MPEF PV 100 Madrynornis mirandus en vista lateral derecha, tercera capa. a, reconstrucción completa de la capa; b, esquema del m. supracoracoideus con elementos óseos del ala removidos. Abreviaciones: memb. membrana; m., musculus. 
deslizamiento del caput humeri hacia atrás (Bannasch, 1986b; Bannasch, 1994). La fosa posterior del sulcus ligamentosus es, en contraparte, más profunda que las formas actuales, y es el sitio de inserción del ligamentum acrocoracohumerale. Anteriormente, se discutió la variación en el tuberculum dorsale de una posición más alejada del caput humeri en formas crustacívoras, aumentando el brazo de palanca de entrada (de una palanca de tercer grado como lo es la articulación del húmero con la cintura pectoral). Madrynornis posee, a ojo desnudo, un tuberculum dorsale con una inclinación más paralela a la diáfisis, mientras que en las especies actuales es más diagonal. La impressio m. supracoracoideus es similar a Eudyptes.

Si bien presenta un buen desarrollo de la fosa de inserción del ligamentum acrocoracohumerale (que a su vez presenta una conspicua área de origen en el coracoides similar a las especies actuales) que da soporte ventral a la cabeza del húmero en pronación, la estabilidad del caput humeri en cuanto al deslizamiento anterior y posterior y de la pronación y la supinación, habría sido menor que en las especies actuales.

La forma grácil de la diáfisis humeral recuerda a aquellas de Spheniscus (piscívoro) y Eudyptes (generalista). Cabe recordar que para los PCA de ambas vistas, el húmero cayó cercano a estos grupos. Pero si bien lo anterior es cierto, Madrynornis presenta un dibujo sigmoideo de su diáfisis prácticamente carente de angulus preaxialis, cosa que no se observa en ninguna especie actual. Esta característica probablemente no esté relacionada con una funcionalidad sino a su posición filogenética, ese tipo de diáfisis en "S" se observa en pingüinos eocenos y paleocenos mucho más pronunciadamente. Las impresiones del extensor metacarpi ulnaris, extensor digitorum communis, y el supinator dibujan una línea que forma un ángulo agudo con respecto a los cóndilos, condición que comparte con Spheniscus y Eudyptes. Esta extensión del alcance de los tendones podría implicar una mayor estabilidad a la articulación del codo en el plano dorsoventral. Ahora bien, la articulación del codo puede también ser analizada mediante el grado de desarrollo de los huesos sesamoideos. El grado de desarrollo de la troclea caudal podría significar un sesamoideo ulnar del $\mathrm{m}$. triceps humeralis más robusto, mientras que el sesamoideo correspondiente al $m$. tríceps scapularis sería más pequeño. El único sesamoideo que se conserva es muy robusto pero no se pudo determinar si se trata del humeral o del scapular. Por otro lado, el epicondylus dorsalis y el ulnaris, que aportan firmeza a la articulación con la ulna, varían en su desarrollo, estando el epicóndilo ventral muy poco desarrollado. 


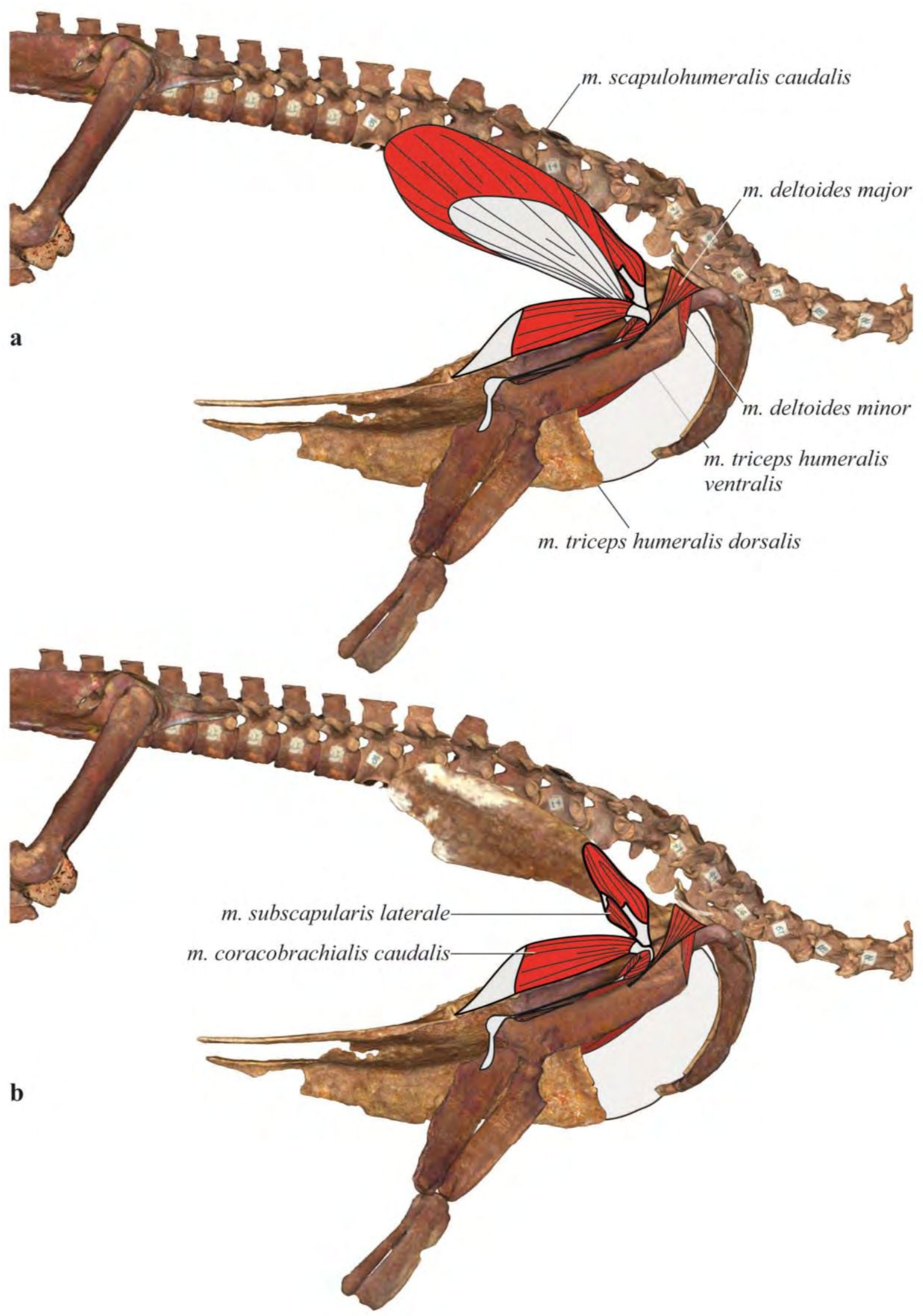

Figura 10 Reconstrucción de los músculos involucrados en el ala de MPEF PV 100 Madrynornis mirandus en vista lateral derecha. a, cuarta capa; b, quinta capa. 
La morfología de los elementos óseos de Madrynornis mirandus nos indicaría, entonces, un menor grado de desarrollo de la musculatura, en particular del $m$. supracoracoideus y el $\mathrm{m}$. scapulohumeralis caudalis (sobre todo en su componente de elevación de ala), es decir, de aquellos músculos que elevan el ala (Fig. 9 y 10). Como se ha dicho en trabajos anteriores, el desarrollo de estos músculos es progresivo en la historia evolutiva. Son los músculos que mayor variación poseen en cuanto a su grado de desarrollo con respecto a las aves voladoras, y también a lo largo de la ontogenia de los pingüinos (Schreiweis, 1982; Bannasch, 1986b). Su desarrollo e importancia han sido explicados por el cambio del medio en que se desplazan, pasando a uno más denso en el cual la elevación del ala pasa a requerir más esfuerzo que en el aire. En base a esto, cabe esperar que las formas más basales o aquellas más antiguas hayan tenido un desarrollo menor de estos músculos. Los músculos principales de elevación ( $m$. supracoracoideus) y adducción del ala ( $m$. pectoralis thoracica) habrían estado comparativamente menos desarrollados. Esto queda también evidenciado por un esternón con un desarrollo comparativamente menor y con unas trabéculas laterales cortas que no se extienden más allá del cuerpo esternal (Fig. 8). El húmero presenta características que lo acercan a las formas piscívoras como son su gracilidad, la disposición de los extensor metacarpi ulnaris, extensor digitorum communis, y el supinator, y la disposición de los cóndilos.

Las formas piscívoras no poseen necesariamente músculos más robustos, sino todo lo contrario. Poseen mayor especificidad de movimientos, que los vemos en la separación de los caput en el caso del $m$. latissimus dorsi por ejemplo, o en la mayor amplitud de movimientos que permiten algunas articulaciones, y de la mayor cantidad de puntos de estabilidad para las posiciones más extremas y que requieren mayor esfuerzo como por ejemplo: el desarrollo de una mayor cantidad de puntos de estabilidad en la articulación mandibular cuando el pico está abierto. El m. latissimus dorsi fue reconstruido para Madrynornis (Fig. 8), con sus tres divisiones separadas y sin la lengua anterior de la división cranial (presente en Pygoscelis y Aptenodytes), basado en dos motivos. Primero, porque en los dos estudios filogenéticos más significativos para la especie, es ubicado cercano a Spheniscus o a Eudyptes (Acosta Hospitaleche et al., 2007; Degrange et al., 2018), y segundo, porque los resultados obtenidos en esta tesis nos inducen a pensar que estaría más cercano a estas formas. La ponderación de la variación morfológica debida a una carga filogenética se encuentra más allá de los objetivos y alcances de esta tesis y se espera que pueda ser evaluado en un futuro cercano. 

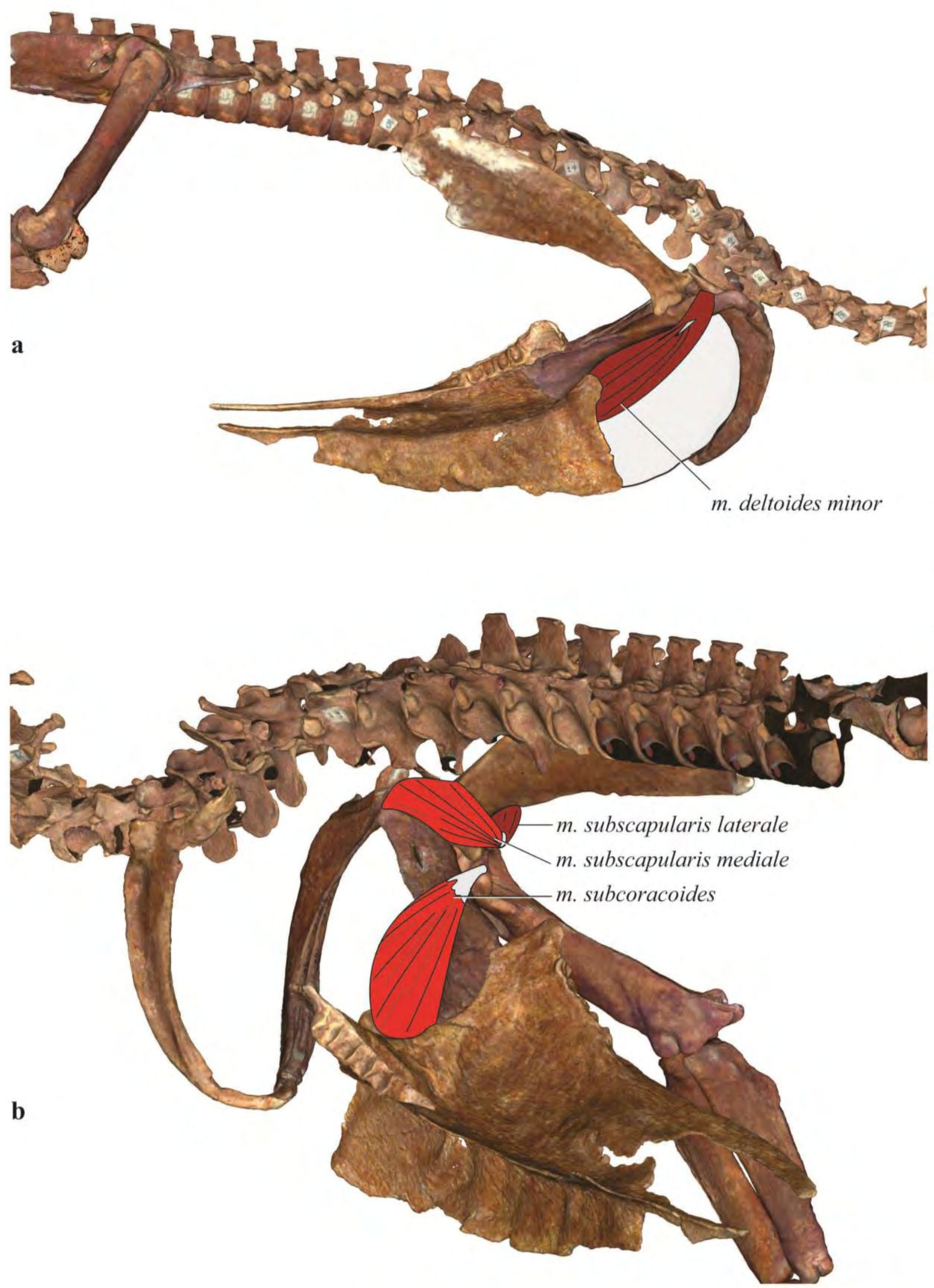

Figura 11 Reconstrucción de los músculos involucrados en el ala de MPEF PV 100 Madrynornis mirandus, quinta capa, derecha. a, Vista lateral con elementos óseos del ala, y mayoría de los músculos removidos, esquema del cuerpo y origen del $m$. deltoides minor; $\mathbf{b}$, vista interna posterior. 
El caso de Madrynornis mirandus es particular en cuanto presenta un mosaico de caracteres basales y derivados, y similitud con morfologías diversas dentro de los pingüinos que habitan el Hemisferio Sur hoy en día. La mayoría de las características morfológicas del cráneo, ala y cintura escapular acercan a Madrynornis mirandus a Spheniscus magellanicus y Eudyptes, formas piscívoras y generalistas respectivamente. Los análisis discriminantes resultaron muy ambiguos, dando resultados diversos dependiendo el tipo de datos a utilizar y los elementos seleccionados. Para los análisis discriminantes de la cintura escapular y húmero, Madrynornis mirandus fue clasificado como crustacívoro, piscívoro y generalista cuando se utilizaron los datos originales, y piscívoro (a excepción del húmero ventral, generalista y esternón lateral crustacívoro) cuando se utilizaron los datos corregidos. Mientras que todos los análisis del cráneo y mandíbula clasificaron a Madrynornis como piscívoro. Esto resulta llamativo, ya que a partir de los análisis de componentes principales exploratorios, esta relación no resultó tan obvia.

$\mathrm{Si}$ bien los resultados del capítulo $\mathrm{V}$ resultaron la mayoría con una moderada correlación, cabe resaltar que todos los resultados resultaron significativos. Llamativa y oportunamente para los fines de esta tesis, los valores de RV hallados más altos resultaron ser entre la caja craneana y el húmero. Lo cual nos habilitaría a afirmar que existe una correlación al menos moderada entre el ala y el cráneo. Más precisamente entre la caja craneana (lugar de inserción de los poderosos músculos adductores mandibulares que cierran la mandíbula), y el húmero (lugar de inserción de los principales músculos involucrados en el movimiento del ala). Para el PLS entre la caja craneana y el húmero, Madrynornis queda en una posición cercana a Eudyptes, un pingüino generalista y oportunista con buceos generalmente superficiales; aunque también se acerca a los piscívoros, animales con buceos más complejos, y con presas más escurridizas; mientras que los crustacívoros quedan todos agrupados a una distancia relativamente corta de Madrynornis. En todos los PLS, Madrynornis cayó cercano a Eudyptes, y sólo en algunos casos se observó una tendencia a acercarse a Spheniscus.

Madrynornis mirandus (MPEF PV 100) ha sido considerado como un posible pingüino piscívoro del Mioceno de Patagonia en base a su morfología craneana (Tambussi \& Acosta Hospitaleche, 2008; Degrange et al., 2018), y como generalista en base a su mandíbula (Haidr \& Acosta Hospitaleche, 2014). Desde esta tesis se buscó obtener herramientas que nos ayudaran a interpretar con un mayor fundamento su tipo de dieta, desde 
una mirada integrada y estudiando la mayor cantidad de especies actuales con las que se contaba y de las cuales se conoce su modo de vida.

Por un lado, obtuvimos una clasificación mediante análisis de discriminantes del fósil en diferentes categorías dietarias dependiendo del hueso a analizar. Estos hallazgos resultaron muy dispares para los datos originales, aunque para los datos corregidos por el efecto alométrico fue mayoritariamente clasificado como piscívoro. Puntualmente para el caso de la caja craneana y la mandíbula, Madrynornis mirandus fue clasificado como piscívoro. Por otro lado, si tomamos en cuenta los análisis de PLS, vemos que en estos análisis de correlación entre estructuras Madrynornis cae siempre cercano a Eudyptes, un pingüino clasificado como generalista oportunista y con cierta tendencia a crustáceos de talla pequeña. Estos mismos resultados lo agrupan tendiente a las formas piscívoras, aunque no muy lejano a los crustacívoros.

Los análisis indican que Madrynornis mirandus habría sido un pingüino piscívoro que anidaba en las colonias reproductivas de las costas patagónicas durante el óptimo climático del Mioceno medio. De todas maneras, las similitudes con otras morfologías, y la proximidad en muchos de los análisis exploratorios (PCA), así como las similitudes, lo acercan a formas generalistas como Eudyptes. Dada su distribución patagónica, no sería raro que Madrynornis haya tenido preferencias por los peces, siendo un eventual oportunista. Este es el caso del pingüino magallánico que, siendo una especie piscívora, habitualmente consume munida (un pequeño crustáceo) sobre todo en las poblaciones del extremo sur de Patagonia (Schiavini et al, )

Creemos que esta tesis aporta información sustancial y novedosa acerca de la anatomía y paleobiología de Madrynornis. No obstante, análisis tridimensionales serán encarados a la brevedad, a fin de obtener datos aún más precisos para las configuraciones que resultaron más informativas. Además, la elaboración de un set de datos que fue empleado como proxy para el estudio de Madrynornis mirandus constituye también un importante aporte al estudio de los Sphenisciformes. A saber, descripciones morfo-anatómicas del esqueleto osteo-muscular de pingüinos representantes de distintos tipos morfológicos, de acuerdo a su dieta y estilo de buceo. 


\section{FUTURO}

En este punto resulta oportuno reflexionar sobre los aspectos futuros que se desprenden de esta tesis. En primera medida, un estudio completo del esqueleto de Madrynonis mirandus desde el punto de visto osteológico y muscular podría derivar en novedosos resultados que complementen la información aquí brindada. Sus relaciones filogenéticas resultan aún inciertas, por lo que ahondar en ese tema, de la mano de metodologías que complementen los estudios filogenéticos tradicionales con nuevos caracteres traídos desde la morfometría geométrica, resulta un campo prometedor. En esta tesis se estudiaron aspectos anatómicos desde la morfometría geométrica en dos dimensiones, pero se espera poder comparar en breve estos resultados con análisis en tres dimensiones. Esto nos permitirá reducir el error que involucra la toma de imágenes en dos dimensiones, además de darnos la posibilidad de estudiar la forma real desde todas sus aristas. Desde el punto de vista de la miología, resulta posible y necesario ahondar en la relación entre el peso de los músculos para las diferentes especies.

Si bien queda mucho por hacer, en esta tesis se analizó desde un punto de vista exhaustivo un gran número de especies de pingüinos en busca de generar modelos anatómicos que nos permitan detectar fácilmente las diferencias morfológicas asociadas a los diferentes tipos ecológicos en pingüinos. Esto pudo lograrse de manera exitosa, no sólo para el cráneo y mandíbula, sino también para los elementos del ala. Encontramos una moderada correlación entre los elementos craneales y el húmero, lo cual en el futuro podrá ser analizado con más detalle. Se corroboró para el caso puntual de los pingüinos, lo propuesto por otros autores para aves en general (Klingenberg \& Marugán Lobón, 2013), indicando que el cráneo habría evolucionado como una estructura integrada. Por último se integraron todos los resultados obtenidos para proponer el hábito alimenticio de Madrynornis mirandus, el pingüino mejor conservado hasta la fecha. Esperamos que los resultados contribuyan a incrementar el conocimiento que se tiene de las especies aquí tratadas y de los pingüinos en general. 


\section{VII \\ BIBLIOGRAFÍA}

Abel, O. (1912). Grundzüge der Palaeobiologie der Wirbeltiere. E. Schweizerbart.

Acosta Hospitaleche, C. (2007). Revisión sistemática de Palaeospheniscus biloculata (Simpson) nov. comb.(Aves, Spheniscidae) de la Formación Gaiman (Mioceno Temprano), Chubut, Argentina. Ameghiniana, ( ), -

Acosta Hospitaleche, C. (2009). Variation in the cranial morphometry of the Magellanic Penguin (Spheniscus magellanicus). Ornitología Neotropical, ( ), -

Acosta Hospitaleche, C. (2011). A new early Miocene penguin skull from Patagonia: taxonomic and paleobiological value. Ameghiniana, ( ), -

Acosta Hospitaleche, C. (2013). New crania from Seymour Island (Antarctica) shed light on anatomy of Eocene penguins. Polish Polar Research, ( ), -

Acosta Hospitaleche, C. 2014. New giant penguin bones from Antarctica: systematic and paleobiological significance. C. R. Palevol. 13, 555-

Acosta Hospitaleche, C., \& Canto, J. (2005). Primer registro de cráneos asignados a Palaeospheniscus (Aves, Spheniscidae) procedentes de la Formación Bahía Inglesa (Mioceno medio-tardío), Chile. Revista chilena de historia natural, ( ), -

Acosta Hospitaleche, C., Pérez, L., Marenssi, S., Reguero, M. 2016. Taphonomic analysis of Crossvallia unienwillia Tambussi et al. 2005: significance of the oldest penguin record of Antarctica. Ameghiniana, 53: 282-

Acosta Hospitaleche, C.., \& Tambussi, C. (2006). Skull morphometry of Pygoscelis (Sphenisciformes): inter and intraspecific variations. Polar Biology, ( ),

Acosta Hospitaleche, C.., \& Di Carlo, U. (2010). The coracoids in functional and morphological studies of penguins (Aves, Spheniscidae) of the Eocene of Antarctica. Rivista Italiana di Paleontologia e Stratigrafia (Research In Paleontology and Stratigraphy), ( )

Acosta Hospitaleche, C., \& Haidr, N. (2011). Penguin (Aves, Sphenisciformes) cranial remains from the La Meseta Formation (Eocene) of Antarctic Peninsula (Antarctica). Antarctic Science, ， -

Acosta Hospitaleche, C., \& Reguero, M. (2010). First articulated skeleton of Palaeeudyptes gunnari from the late Eocene of Isla Marambio (Seymour Island), Antarctica. Antarctic Science, （ ）, - 
Acosta Hospitaleche, C. \& Stucchi, M. (2005). Nuevos restos terciarios de Spheniscidae (Aves, Sphenisciformes) procedentes de la costa del Perú. Revista Española de Paleontología, （ ), -

Acosta Hospitaleche, C., \& Di Carlo, U. (2012). Una singular escápula de pingüino (Aves; Sphenisciformes) del Eoceno de Antártida: reconstrucción muscular e implicancias funcionales. Rivista Italiana di Paleontologia e Stratigrafia, , , -

Acosta Hospitaleche, C., \& Olivero, E. (2016). Re-evaluation of the fossil penguin Palaeeudyptes gunnari from the Eocene Leticia Formation, Argentina: additional material, systematics and palaeobiology. Alcheringa: An Australasian Journal of Palaeontology, ( ), -

Acosta Hospitaleche, C., Tambussi, C., \& Cozzuol, M. (2004). Eretiscus tonnii Simpson 1981 (Aves, Sphenisciformes): materiales adicionales, status taxonómico y distribución geográfica. Revista del Museo Argentino de Ciencias Naturales, ( ),

Acosta Hospitaleche, C., Chávez, M., \& Fritis, O. (2006). Pingüinos fósiles (Pygoscelis calderensis sp. nov.) en la Formación Bahía Inglesa (Mioceno Medio-Plioceno), Chile. Revista geológica de Chile, (),

Acosta Hospitaleche, C., Tambussi, C., Donato, M., \& Cozzuol, M. (2007). A new Miocene penguin from Patagonia and its phylogenetic relationships. Acta Palaeontologica Polonica, ( )

Acosta Hospitaleche, C., Castro, L., Tambussi, C., \& Scasso, R. A. (2008). Palaeospheniscus patagonicus (Aves, Sphenisciformes): new discoveries from the early Miocene of Argentina. Journal of Paleontology, ( ), -

Acosta Hospitaleche, C., Reguero, M., \& Santillana, S. (2017). Aprosdokitos mikrotero gen. et sp. nov., the tiniest Sphenisciformes that lived in Antarctica during the Paleogene. Neues Jahrbuch für Geologie und Paläontologie-Abhandlungen, ( ), -

Adams, D. C., Rohlf, F. J., \& Slice, D. E. (2004). Geometric morphometrics: ten years of progress following the ,revolutionee Italian Journal of Zoology, ( ), -

Ainley, D. G. (2002). The Adelie Penguin: bellwether of climate change. Columbia University Press, New York

Ameghino, F. (1901). L'age des formations sédimbntaires de patagonie. In Anales de la Sociedad Científica Argentina (Vol. 51, p. 20). Sociedad Científica Argentina.

Ando, T. (2007). New Zealand fossil penguins: origin, pattern, and process (Doctoral dissertation, University of Otago).

Bannasch, R. (1986a). Morphologic-functional study of the locomotor system of penguins as a general model of movement in under-water flight. I. Gegenbaurs Morphologisches Jahrbuch, （ ) , 
Bannasch, R. (1986b). Morphologico-functional study of the locomotor system of penguins as a principle of the general motor model of" underwater flight." II. Gegenbaurs morphologisches Jahrbuch,

Bannasch, R. (1994). Functional anatomy of the ,flight"apparatus in penguins Mechanics and physiology of animal swimming,

Barlow, K. E., \& Croxall, J. P. (2002). Seasonal and interannual variation in foraging range and habitat of macaroni penguins Eudyptes chrysolophus at South Georgia. Marine Ecology Progress Series, ,

Baumel, J. J. (Ed.). (1993). Handbook of avian anatomy. Nuttall Ornithological Club.

Bertelli, S., \& Giannini, N. P. (2005). A phylogeny of extant penguins (Aves: Sphenisciformes) combining morphology and mitochondrial sequences. Cladistics, ( ), -

Bethge, P., Nicol, S., Culik, B. M., \& Wilson, R. P. (1997). Diving behaviour and energetics in breeding little penguins (Eudyptula minor). Journal of Zoology, ( ), -

Bhullar, B. A. S., Marugán-Lobón, J., Racimo, F., Bever, G. S., Rowe, T. B., Norell, M. A., \& Abzhanov, A. (2012). Birds have paedomorphic dinosaur skulls. Nature, （）,

Bhullar, B. A. S., Hanson, M., Fabbri, M., Pritchard, A., Bever, G. S., \& Hoffman, E. (2016). How to make a bird skull: major transitions in the evolution of the avian cranium, paedomorphosis, and the beak as a surrogate hand. Integrative and comparative biology, ( ), -

Bock, W. J. (1959). Preadaptation and multiple evolutionary pathways. Evolution, 13(2), 194-

Bock, W. J. (1960). Secondary articulation of the avian mandible. The Auk, ( ), -

Bock, W. J. (1964). Kinetics of the avian skull. Journal of Morphology, ～( ), -

Bock, W. J. (1994). Concepts and methods in ecomorphology. Journal of Biosciences, （ ), -

Bock, W. J. (1999). Avian cranial kinesis revisited. Acta Ornithologica, ( ), -

Bock, W. J., \& Kummer, B. (1968). The avian mandible as a structural girder. Journal of biomechanics, ( ),

Bock, W. J., \& von Wahlert, G. (1965). Adaptation and the form-function complex. Evolution,

Boersma, P. D. (1976). An ecological and behavioral study of the Galapagos Penguin. Living Bird, , , -

Bonaparte, C. L. (1831). Saggio di una distribuzione metodica degli animali vertebrati. Boulzaler.

Bookstein, F. L. (1978). Linear machinery for morphological distortion. 
Bookstein, F. L. (1986). Size and shape spaces for landmark data in two dimensions. Statistical science, ( ),

Bookstein, F. L. (1991). Morphometric tools for landmark data. Cambridge, New York, .

Bookstein, F. L., Streissguth, A. P., Sampson, P. D., Connor, P. D., \& Barr, H. M. (2002). Corpus callosum shape and neuropsychological deficits in adult males with heavy fetal alcohol exposure. Neuroimage, ( ), -

Bost, C. A., Zorn, T., Le Maho, Y., \& Duhamel, G. (2002). Feeding of diving predators and diel vertical migration of prey: King penguins diet versus trawl sampling at Kerguelen Islands. Marine Ecology Progress Series, , , -

Boswall, J., \& MacIver, D. (1975). The magellanic penguin Spheniscus magellanicus. The biology of penguins,

Bright, J. A., Marugán-Lobón, J., Cobb, S. N., \& Rayfield, E. J. (2016). The shapes of bird beaks are highly controlled by nondietary factors. Proceedings of the National Academy of Sciences of the United States of America, 113, 5352- $\quad$ https://doi.org/10.1073/pnas.1602683113

Brown, C. R., \& Klages, N. T. (1987). Seasonal and annual variation in diets of Macaroni (Eudyptes chrysolophus chrysolophus) and Southern rockhopper (E chrysocome chrysocome) penguins at subAntarctic Marion Island. Journal of Zoology, ( ), -

Buhler, P. (1981). Functional anatomy of the avian jaw apparatus. Form and function in birds, , -

Bruner, E, Martin-Loeches, M, \& Colom, R ( ) Human midsagittal brain shape variation patterns, allometry and integration. Journal of Anatomy, ， ) , -

Carabajal, P. A., Acosta-Hospitaleche, C., \& Yury-Yáñez, R. E. (2015). Endocranial morphology of Pygoscelis calderensis (Aves, Spheniscidae) from the Neogene of Chile and remarks on brain morphology in modern Pygoscelis. Historical Biology, ( ), -

Chavez Hoffmeister, M. C., Briceño, J. D. C., \& Nielsen, S. N. (2014). The evolution of seabirds in the Humboldt Current: new clues from the Pliocene of central Chile. PloS one, 9(3), e90043.

Cherel, Y. (2008). Isotopic niches of emperor and Adélie penguins in Adélie Land, Antarctica. Marine Biology, ( ), -

Cherel, Y., \& Kooyman, G. L. (1998). Food of emperor penguins (Aptenodytes forsteri) in the western Ross Sea, Antarctica. Marine Biology, （ ),

Cherel, Y., \& Ridoux, V. (1992). Prey species and nutritive value of food fed during summer to king penguin Aptenodytes patagonica chicks at Possession Island, Crozet Archipelago. Ibis, 134(2), 118- 
Cherel Y, Ridoux V, Rodhouse PG. 1996. Fish and squid in the diet of king penguin chicks, Aptenodytes patagonicus, duringwinter at sub-Antarctic Crozet Islands.Polar Biol, 126:559-

Cherel, Y., Tremblay, Y., Guinard, E., \& Georges, J. Y. (1999). Diving behaviour of female northern rockhopper penguins, Eudyptes chrysocome moseleyi, during the brooding period at Amsterdam Island (Southern Indian Ocean). Marine Biology, ， ， -

Chiaradia, A., Costalunga, A., \& Kerry, K. (2003). The diet of little penguins Eudyptula minor at Phillip Island, Victoria, following the 1995 mass mortality of one of their main prey, the pilchard Sardinops sagax. Emu,

Chiaradia, A., Forero, M. G., Hobson, K. A., Swearer, S. E., Hume, F., Renwick, L., \& Dann, P. (2012). Diet segregation between two colonies of little penguins Eudyptula minor in southeast Australia. Austral Ecology, ( ), -

Clark, B. D., \& Bemis, W. (1979). Kinematics of swimming of penguins at the Detroit Zoo. Journal of Zoology, ( ) -

Clarke, J., Manly, B., Kerry, K., Gardner, H., Franchi, E., Corsolini, S., \& Focardi, S. (1998). Sex differences in Adélie penguin foraging strategies. Polar Biology, ( ), -

Clarke, J. A., Olivero, E. B., \& Puerta, P. (2003). Description of the earliest fossil penguin from South America and first Paleogene vertebrate locality of Tierra del Fuego, Argentina. American Museum Novitates,

Clarke, J. A., Ksepka, D. T., Stucchi, M., Urbina, M., Giannini, N., Bertelli, S., ... \& Boyd, C. A. (2007). Paleogene equatorial penguins challenge the proposed relationship between biogeography, diversity, and Cenozoic climate change. Proceedings of the National Academy of Sciences,

Clarke, J. A., Ksepka, D. T., Salas-Gismondi, R, Altamirano, A J, Shawkey, M D , DAlba, L, \& Baby, P. (2010). Fossil evidence for evolution of the shape and color of penguin feathers. Science, （ ) ,

Clausen, A. P., \& Pütz, K. (2002). Recent trends in diet composition and productivity of gentoo, magellanic and rockhopper penguins in the Falkland Islands. Aquatic Conservation: Marine and Freshwater Ecosystems, ( ), -

Ropert-Coudert, Y., Kato, A., Baudat, J., Bost, C. A., Le Maho, Y., \& Naito, Y. (2001). Feeding strategies of free-ranging Adélie penguins Pygoscelis adeliae analysed by multiple data recording. Polar Biology, ( ) -

Croxall, J. P., \& Prince, P. A.. (1980) The food of the Gentoo Penguin Pygoscelis papua and Macaroni Penguin Eudytes chrysolophus at South Georgia. Ibis, 
Croxall, J. P. (Ed.). (1987). Seabirds: feeding ecology and role in marine ecosystems. Cambridge University Press.

Croxall, J. P., Briggs, D. R., Kato, A., Naito, Y., Watanuki, Y., \& Williams, T. D. (1993). Diving pattern and performance in the macaroni penguin Eudyptes chrysolophus. Journal of Zoology, ～( ) , -

Croxall, J. P., Davis, R. W., \& O'Connell, M. J. (1988). Diving patterns in relation to diet of gentoo and macaroni penguins at South Georgia. Condor, -

Deagle, B. E., Gales, N. J., Evans, K., Jarman, S. N., Robinson, S., Trebilco, R., \& Hindell, M. A. (2007). Studying seabird diet through genetic analysis of faeces: a case study on macaroni penguins (Eudyptes chrysolophus). PLoS One, (9), e831.

Degrange, F. J., Ksepka, D. T., \& Tambussi, C. P. (2018). Redescription of the oldest crown clade penguin: cranial osteology, jaw myology, neuroanatomy, and phylogenetic affinities of Madrynornis mirandus. Journal of Vertebrate Paleontology, (2), e1445636.

del Castillo, D. L., Viglino, M., Flores, D. A., \& Cappozzo, H. L. (2017). Skull ontogeny and modularity in two species of Lagenorhynchus: Morphological and ecological implications. Journal of morphology, ( )

Drake, A. G., \& Klingenberg, C. P. (2010). Large-scale diversification of skull shape in domestic dogs: disparity and modularity. The American Naturalist, $\quad$ ( ), -

Dryden, I. L., \& Mardia, K. V. (1998). Statistical analysis of shape. Wiley.

Elzanowski, A. (2013). More evidence for plesiomorphy of the quadrate in the Eocene anseriform avian genus Presbyornis. Acta Palaeontologica Polonica, ( ), -

Emslie, S. D., \& Guerra Correa, C. (2003). A new species of penguin (Spheniscidae: Spheniscus) and other birds from the late Pliocene of Chile. Proceedings of the Biological Society of Washington, ( ),

Escoufier, Y. (1973). Le traitement des variables vectorielles. Biometrics, -

Esteban-Trivigno, S. D. (2011). Ecomorfología de xenartros extintos: análisis de la mandíbula con métodos de morfometría geométrica. Ameghiniana, ( ), -

Feduccia, A. (1999). The origin and evolution of birds. Yale University Press.

Fortelius, M., \& Solounias, N. (2000). Functional characterization of ungulate molars using the abrasionattrition wear gradient: a new method for reconstructing paleodiets. American Museum Novitates, -

Furbringer, M. (1888). Untersuchungen zur Morphologie \& Systematik der Vögel, zugleich ein beitrage zur Anatomie der Stuta-\& Bewegungsorgane.

Gales, R., Williams, C., \& Ritz, D. (1990). Foraging behaviour of the little penguin, Eudyptula minor: initial results and assessment of instrument effect. Journal of Zoology, ( ), - 
García Borboroglu, P.., \& Boersma, P. D. (Eds.). ( ) Penguins: natural history and conservation. University of Washington Press.

Gauthier-Clerc M, Le Maho Y, Clerquin Y, Bost C-A, HandrichY. 2002. Seabird reproduction in an unpredictable environment:How king penguins provide their young chicks with food.MarEcol Prog Ser, 237:291-

George, J. C., \& Berger, A. J. (1966). Avian myology (No. Sirsi) a386876).

Giannini, N. P., \& Bertelli, S. (2004). Phylogeny of extant penguins based on integumentary and breeding characters. The Auk, -

Gohlich, U. B. (2007). The oldest fossil record of the extant penguin genus Spheniscus-a new species from the Miocene of Peru. Acta Palaeontologica Polonica, ( )

Gómez-Robles, A., Martinón-Torres, M., de Castro, J. M. B., Prado-Simón, L., \& Arsuaga, J. L. (2011). A geometric morphometric analysis of hominin upper premolars. Shape variation and morphological integration. Journal of human evolution, ( ), -

Grant, P. R., \& Grant, B. R. (1992). Hybridization of bird species. Science, （） ， -

Green, K., Williams, R., \& Green, M. G. (1998). Foraging ecology and diving behaviour of macaroni penguins Eudyptes chrysolophus at Heard Island. Mar Ornithol, , , -

Guinard, G., \& Marchand, D. (2010). Modularity and complete natural homeoses in cervical vertebrae of extant and extinct penguins (Aves: Sphenisciformes). Evolutionary biology, ( ), -

Haidr, N., \& Hospitaleche, C. A. (2012). Feeding habits of Antarctic Eocene penguins from a morphofunctional perspective. Neues Jahrbuch für Geologie und Paläontologie-Abhandlungen, （ ) , - -

Haidr, N., \& Acosta Hospitaleche, C. (2014). Miocene Patagonian penguins: craniomandibular morphology and functional mechanics. Alcheringa: An Australasian Journal of Palaeontology, （ ), - -

Haidr, N. S., \& Acosta Hospitaleche, C. (2017). New data on the humerotriceps of penguins and its implications in the evolution of the fossa tricipitalis. Historical Biology, -

Haidr, N., \& Acosta Hospitaleche, C. (2017). A new penguin cranium from Antarctica and its implications for body size diversity during the Eocene. Neues Jahrbuch für Geologie und PaläontologieAbhandlungen, ( ), -

Haidr, N. S., \& Acosta Hospitaleche, C. 2018. Fossil penguin beaks from the Eocene of Antarctica: new materials from La Meseta Formation. Contribuciones Científicas del Museo Argentino de Ciencias Naturales Bernardino Rivadavia, , -

Hallgrímsson, B., Jamniczky, H., Young, N. M., Rolian, C., Parsons, T. E., Boughner, J. C., \& Marcucio, R. S. (2009). Deciphering the palimpsest: studying the relationship between morphological integration and phenotypic covariation. Evolutionary biology, ( ), 
Hammer, Ø., Harper, D. A. T., \& Ryan, P. D. (2001). PAST-Palaeontological statistics. www. uv. es/ pardomv/pe/2001_1/past/pastprog/past.pdf, acessado em, ( ),

Herrel, A., Podos, J., Huber, S. K., \& Hendry, A. P. (2005). Evolution of bite force in Darwin's finches: a key role for head width. Journal of evolutionary biology, ， ), -

Herrel, A., Moore, J. A., Bredeweg, E. M., \& Nelson, N. J. (2010). Sexual dimorphism, body size, bite force and male mating success in tuatara. Biological Journal of the Linnean Society,

( )

Hindell,MA .1988. The Diet of the Rockhopper Penguin Eudyptes chrysocome at Macquarie Island. Emu ( )

Hopson, J. A. (2001). Ecomorphology of avian and nonavian theropod phalangeal proportions: implications for the arboreal versus terrestrial origin of bird flight. New perspectives on the origin and early evolution of Birds, -

Hopson, J. A., \& Ballance, L. T. (2001). Ecomorphology of avian and nonavian theropod phalangeal proportions: implications for the arboreal versus terrestrial origin of bird flight. New perspectives on the origin and early evolution of Birds,

Hoskins, A. J., Dann, P., Ropert-Coudert, Y., Kato, A., Chiaradia, A., Costa, D. P., \& Arnould, J. P. (2008). Foraging behaviour and habitat selection of the little penguin Eudyptula minor during early chick rearing in Bass Strait, Australia. Marine Ecology Progress Series, , -

Ivanović, A \& Kalezić, M L ( ) Testing the hypothesis of morphological integration on a skull of a vertebrate with a biphasic life cycle: a case study of the alpine newt. Journal of Experimental Zoology Part B: Molecular and Developmental Evolution, ( ), -

Jadwiszczak, P. (2006). Eocene penguins of Seymour Island, Antarctica: Taxonomy. Pol. Polar Res, ( ), -

Jadwiszczak, P ( ) Partial limb skeleton of a "giant penguin" Anthropornis from the Eocene of Antarctic Peninsula. Polish Polar Research, ( ), -

Jadwiszczak, P., Acosta Hospitaleche, C., \& Reguero, M. (2013). Redescription of Crossvallia unienwillia: the only Paleocene Antarctic penguin. Ameghiniana, ( )

Jamniczky, H. A., \& Hallgrímsson, B. (2011). Modularity in the skull and cranial vasculature of laboratory mice: implications for the evolution of complex phenotypes. Evolution \& development, $\quad(), \quad$ -

Jojić, V, Blagojević, J \& \& Vujošević, M ( ) Two-module organization of the mandible in the yellownecked mouse: a comparison between two different morphometric approaches. Journal of evolutionary biology, ( ) , - ;

Jones, C. M., Ando, T., \& Fordyce, R. E en Slack, K. E., Jones, C. M., Ando, T., Harrison, G. L., Fordyce, R. E., Arnason, U., \& Penny, D. (2006). Early penguin fossils, plus mitochondrial genomes, calibrate avian evolution. Molecular biology and evolution, () 
Juáres, M. A., Santos, M., Mennucci, J. A., Coria, N. R., \& Mariano-Jelicich, R. (2016). Diet composition and foraging habitats of Adélie and gentoo penguins in three different stages of their annual cycle. Marine biology, ( ),

Kanda, K., Takagi, K., \& Seki, Y. (1982). Movement of the larger swarms of Antarctic krill Euphausia superba population off Enderby Land during 1976-1977 season. Journal of the Tokyo University of Fisheries (Japan).

Karr, J. R., \& James, F. C. (1975). Ecomorphological configurations and convergent evolution in species and communities. Ecology and evolution of communities,

Keast, A. (1970). Adaptive evolution and shifts in niche occupation in island birds. Biotropica, -

Kendall, D. G. (1977). The diffusion of shape. Advances in applied probability, ( ), -

Kerry, K. R., Agnew, D. J., Clarke, J. R., \& Else, G. D. (1992). Use of morphometric parameters for the determination of sex of Adélie Penguins. Wildlife Research, ( ), -

Kimmel, C. B., Hohenlohe, P. A., Ullmann, B., Currey, M., \& Cresko, W. A. (2012). Developmental dissociation in morphological evolution of the stickleback opercle. Evolution \& development, ( ),

Kirkwood, R., \& Robertson, G. (1997). Seasonal change in the foraging ecology of emperor penguins on the Mawson Coast, Antarctica. Marine Ecology Progress Series, ， ～-

Klages, N. (1989). Food and feeding ecology of emperor penguins in the eastern Weddell Sea. Polar Biology, ( ),

Klingenberg, C. P. (2009). Morphometric integration and modularity in configurations of landmarks: tools for evaluating a priori hypotheses. Evolution \& development, ( ), -

Klingenberg, C. P. (2011). MorphoJ: an integrated software package for geometric morphometrics. Molecular ecology resources, ( ), -

Klingenberg, W. (2013). A course in differential geometry (Vol. 51). Springer Science \& Business Media.

Klingenberg, C. P. (2014). Studying morphological integration and modularity at multiple levels: concepts and analysis. Phil. Trans. R. Soc. B, ( ），

Klingenberg, C. P. (2016). Size, shape, and form: concepts of allometry in geometric morphometrics. Development genes and evolution, ( ),

Klingenberg, C. P., \& Marugán-Lobón, J. (2013). Evolutionary covariation in geometric morphometric data: analyzing integration, modularity, and allometry in a phylogenetic context. Systematic biology, ( ), 
Klingenberg, C. P., Debat, V., \& Roff, D. A. (2010). Quantitative genetics of shape in cricket wings: developmental integration in a functional structure. Evolution: International Journal of Organic Evolution, ( ), -

Klingenberg, C. P., Leamy, L. J., \& Cheverud, J. M. (2004). Integration and modularity of quantitative trait locus effects on geometric shape in the mouse mandible. Genetics,

( ), -

Klomp, N. I. (1987). The breeding biology and diet of the little penguin Eudyptula minor (Forster) on Penguin Island, Western Australia. B. Sc.(Hons) Thesis, Murdoch University, Perth.

Klomp, N. I., \& Wooller, R. D. (1988). Diet of little penguins, Eudyptula minor, from Penguin Island, western Australia. Marine and Freshwater Research, ( ), -

Kokubun, N., Takahashi, A., Mori, Y., Watanabe, S., \& Shin, H. C. (2010). Comparison of diving behavior and foraging habitat use between chinstrap and gentoo penguins breeding in the South Shetland Islands, Antarctica. Marine Biology, ( ), -

Kooyman, G. L., \& Kooyman, T. G. (1995). Diving behavior of emperor penguins nurturing chicks at Coulman Island, Antarctica. Condor, -

Kooyman, G. L., Cherel, Y., Maho, Y. L., Croxall, J. P., Thorson, P. H., Ridoux, V., \& Kooyman, C. A. (1992). Diving behavior and energetics during foraging cycles in king penguins. Ecological Monographs, ( ), -

Kooyman, G. L., Siniff, D. B., Stirling, I., \& Bengtson, J. L. (2004). Moult habitat, pre-and post-moult diet and post-moult travel of Ross Sea emperor penguins. Marine Ecology Progress Series, ， - .

Ksepka, D. T., \& Bertelli, S. (2006). Fossil penguin (Aves: Sphenisciformes) cranial material from the Eocene of Seymour Island (Antarctica). Historical Biology, ( ), -

Ksepka, D. T., \& Clarke, J. A. (2010). The basal penguin (Aves: Sphenisciformes) Perudyptes devriesi and a phylogenetic evaluation of the penguin fossil record. Bulletin of the American Museum of Natural History, ( ), -

Ksepka, D. T., \& Ando, T. (2011). Penguins past, present, and future: trends in the evolution of the Sphenisciformes. Living Dinosaurs,

Ksepka, D. T., Bertelli, S., \& Giannini, N. P. (2006). The phylogeny of the living and fossil Sphenisciformes (penguins). Cladistics, ( ), -

Ksepka, D. T., Clarke, J. A., DeVries, T. J., \& Urbina, M. (2008). Osteology of Icadyptes salasi, a giant penguin from the Eocene of Peru. Journal of Anatomy, ， ( ), -

Ksepka, D. T., Balanoff, A. M., Walsh, S., Revan, A., \& Ho, A. (2012a). Evolution of the brain and sensory organs in Sphenisciformes: new data from the stem penguin Paraptenodytes antarcticus. Zoological Journal of the Linnean Society, ( ), - 
Ksepka, D. T., Fordyce, R. E., Ando, T., \& Jones, C. M. (2012b). New fossil penguins (Aves, Sphenisciformes) from the Oligocene of New Zealand reveal the skeletal plan of stem penguins. Journal of Vertebrate Paleontology, ( ), -

Laffont, R., Renvoisé, E., Navarro, N., Alibert, P., \& Montuire, S. (2009). Morphological modularity and assessment of developmental processes within the vole dental row (Microtus arvalis, Arvicolinae, Rodentia). Evolution \& development, ( ), -

Lakjer, T. (1926). Studien über die Trigeminus-Versorgte Kaumuskulatur der Sauropsiden. CA Reitzel, Copenhagen.

Lederer, R. J. (1984). A view of avian ecomorphological hypotheses. Oekologie Vogel, ,

Lele, S. R., \& Richtsmeier, J. T. (2001). An invariant approach to statistical analysis of shapes. Chapman and Hall/CRC.

Linnaeus, C. V. (1758). Systema Naturae per regna tria naturae. Secundum classes, ordines, genera, species, cum characteribus, differentiis, synonymis, locis. Editio, ( ) ,

Livezey, B. C. (1989). Morphometric patterns in Recent and fossil penguins (Aves, Sphenisciformes). Journal of Zoology, ( ), -

Livezey \& Zusi, 2006. Phylogeny of neornithes. Bulletin of Carnegie Museum of Natural History, ， -

Marples, B. J., \& Finlay, H. J. (1952). Early Tertiary penguins of New Zealand. Print. by J. McIndoe by authority RE Owen, Government Printer.

Marples, B. J. (1960). A fossil penguin from the Late Tertiary of North Canterbury. Records of the Canterbury museum, ( ), -

Martínez, I. (1992). Order Sphenisciformes. Handbook of the Birds of the World, 1, 140-

Martínez-Abadías, N , Esparza, M , Sjøvold, T , González-José, R, Santos, M , Hernández, M , \& Klingenberg, C. P. (2012). Pervasive genetic integration directs the evolution of human skull shape. Evolution: International Journal of Organic Evolution, ( ),

Mattern, T., Ellenberg, U., Houston, D. M., \& Davis, L. S. (2007). Consistent foraging routes and benthic foraging behaviour in yellow-eyed penguins. Marine Ecology Progress Series,

Mayr, G., Scofield, R. P., De Pietri, V. L., \& Tennyson, A. J. (2017). A Paleocene penguin from New Zealand substantiates multiple origins of gigantism in fossil Sphenisciformes. Nature communications, ( ),

McKee, J. W. (1987). The occurrence of the Pliocene penguin Tereingaornis moisleyi (Sphenisciformes: Spheniscidae) at Hawera, Taranaki, New Zealand. New Zealand Journal of Zoology，（）， - 
Meister, W. (1962). Histological structure of the long bones of penguins. The Anatomical Record,

Mitteroecker, P., \& Bookstein, F. (2008). The evolutionary role of modularity and integration in the hominoid cranium. Evolution: International Journal of Organic Evolution, （ ）， -

Montague, T. L. (1982). The food and feeding ecology of the little penguin (Eudyptula minor) at Phillip Island, Victoria, Australia. M. Sc. Thesis, Monash University.

Montague, T. L., \& Cullen, J. M. (1988). The diet of the little penguin Eudyptula minor at Phillip Island, Victoria. Emu-Austral Ornithology, 88(3), 138-

Moore, P. J., \& Wakelin, M. D. (1997). Diet of the yellow-eyed penguin Megadyptes antipodes, South Island, New Zealand, 1991Marine Ornithology, , -

Moore, P. J., Murray M. W., Douglas E., McKinlay, B. Nelson, D., \& Murphyet, B. 1995. Yellow-eyed penguin foaraging studym south-eastern New Zealand, 1991-1993. Wellington, N.Z. : Dept. of Conservation, 1995. 1 v. ; 30 cm. (Science \& Research service, 0113-3713 ; no. 83.) ISBN 0478016565. Yellow-eyed penguin.Science \& research series ; no. 83. I. Moore, Peter J. II. Series: 598.44120 zbn95-

Moore, P. J. (1999). Foraging range of the Yellow-eyed Penguin Megadyptes antipodes. Marine Ornithology,

Moreno, F. P., \& Mercerat, A. (1891). Catálogo de los pájaros fósiles de la república Argentina conservados en el Museo de La Plata, por Francisco P. Moreno... y Alcides Mercerat... Catalogue des oiseaux fossiles de la Republique Argentine conservés au Musée de La Plata, par François P. Moreno... et Alcide Mercerat... Taller de publicaciones del Museo.

Mori, Y., \& Boyd, I. L. (2004). The behavioral basis for nonlinear functional responses and optimal foraging in Antarctic fur seals. Ecology, ( ), -

Niemandt, C., Kovacs, K. M., Lydersen, C., Dyer, B. M., Isaksen, K., Hofmeyr, G. G., ... \& de Bruyn, P. N. (2016). Chinstrap and macaroni penguin diet and demography at Nyrøysa, Bouvetøya. Antarctic Science, ( ), -

Oliver WRB. 1930. New Zealand Birds. Fine Arts:Wellington.

Otley, H., Clausen, A., Christie, D., Huin, N., \& Pütz, K. (2007). Breeding patterns of king penguins on the Falkland Islands. Emu-Austral Ornithology, ( ), -

Offredo, C., \& Ridous, V. (1986). The diet of emperor penguins Aptenodytes forsteri in Adélie Land, Antarctica. Ibis, ( 
Parsons, T. E., Schmidt, E. J., Boughner, J. C., Jamniczky, H. A., Marcucio, R. S., \& Hallgrímsson, B. (2011). Epigenetic integration of the developing brain and face. Developmental Dynamics,

Paschetta, C., \& González-José, R. (2014). Estimaciones de fuerza de mordida y su relación con las características de la dieta. Revista argentina de antropología biológica, ( ), -

Perez, S. I., Bernal, V., \& Gonzalez, P. N. (2006). Differences between sliding semi-landmark methods in geometric morphometrics, with an application to human craniofacial and dental variation. Journal of anatomy, ( ), -

Proctor, N. S., \& Lynch, P. J. (1993). Manual of ornithology: avian structure and function. Yale University Press.

Proffitt, J. V., Clarke, J. A., \& Scofield, R. P. (2016). Novel insights into early neuroanatomical evolution in penguins from the oldest described penguin brain endocast. Journal of anatomy, , ( ) , _

Pütz, K., Rey, A. R., Schiavini, A., Clausen, A. P., \& Lüthi, B. H. (2006). Winter migration of rockhopper penguins (Eudyptes c. chrysocome) breeding in the Southwest Atlantic: is utilisation of different foraging areas reflected in opposing population trends?. Polar Biology, ( ), -

Pycraft, W. P. (1898, November). Contributions to the Osteology of Birds. Part II. Impennes 1. In Proceedings of the Zoological Society of London (Vol. 66, No. 4, pp. 958-989). Oxford, UK: Blackwell Publishing Ltd.

Raclot, T., Groscolas, R., Cherel, Y. (1998). Fatty acid evidence for the importance of myctophid fishes in the diet of king penguin,Aptenodytes patagonicus.Mar Biol, 132:522-

Radinsky, L. B. (1987). evolution of vertebrate design.

Raikow, R. J., Bicanovsky, L., \& Bledsoe, A. H. (1988). Forelimb joint mobility and the evolution of wingpropelled diving in birds. The Auk,

Raya Rey, A., \& Schiavini, A. (2005). Inter-annual variation in the diet of female southern rockhopper penguin (Eudyptes chrysocome chrysocome) at Tierra del Fuego. Polar Biology, ( ), -

Rayfield, E J ( ) Strain in the ostrich mandible during simulated pecking and validation of specimenspecific finite element models. Journal of Anatomy, ( ), -

Rayner, J. M. (1988). Form and function in avian flight. In Current ornithology (pp. 1-66). Springer, Boston, MA.

Ridoux, V., \& Offredo, C. (1989). The diets of five summer breeding seabirds in Adélie Land, Antarctica. Polar Biology, ( ),

Rodary, D., Bonneau, W., Le Maho, Y., \& Bost, C. A. (2000a). Benthic diving in male emperor penguins Aptenodytes forsteri foraging in winter. Marine Ecology Progress Series, 
Rodary, D., Wienecke, B. C., \& Bost, C. A. (2000b). Diving behaviour of Adelie penguins (Pygoscelis adeliae) at Dumont D'Urville, Antarctica: nocturnal patterns of diving and rapid adaptations to changes in seaice condition. Polar Biology, ( ), -

Rohlf, F. J. (2002). Geometric morphometrics and phylogeny. Systematics Association Special Volume, 64,

Rohlf, F.J. (2004) tps serie softwares. Department of Ecology and Evolution, State University New York, Stony Brook. Available at http//life.bio.sunysb.edu/morph/.

Rohlf, F. J. (2005). Geometric morphometrics simplified.

Rohlf, F. J., \& Corti, M. (2000). Use of two-block partial least-squares to study covariation in shape. Systematic Biology, ( ), -

Sala, J. E., Wilson, R. P., Frere, E., \& Quintana, F. (2014). Flexible foraging for finding fish: variable diving patterns in Magellanic penguins Spheniscus magellanicus from different colonies. Journal of ornithology, ( ), -

Sallaberry, M., Yury-Yáñez, R. E., Soto-Acuña, S., \& Rubilar-Rogers, D. (2008). Las aves fósiles de la Formación Bahía Inglesa: hallazgos y perspectivas. In Primer Simposio Paleontología en Chile, Libro de Actas, -

Sanger, T. J., Mahler, D. L., Abzhanov, A., \& Losos, J. B. (2012). Roles for modularity and constraint in the evolution of cranial diversity among Anolis lizards. Evolution: International Journal of Organic Evolution, ( ), -

Sato, K., Naito, Y., Kato, A., Niizuma, Y., Watanuki, Y., Charrassin, J. B., ... \& Le Maho, Y. (2002). Buoyancy and maximal diving depth in penguins: do they control inhaling air volume?. Journal of Experimental Biology, ( ),

Scasso, R A, McArthur, J M, Del Rio, C J, Martınez, S , \& Thirlwall, M F ( ) S r/ S r Late Miocene age of fossil molluses in the ,Entrerriense of the Valdés Peninsula (Chubut, Argentina) Journal of South American Earth Sciences, ( ), -

Schiavini, A., Yorio, P., Gandini, P. A., Raya Rey, A., Dee Boersma, P. (2005) Los pingüinos de las costas argentinas: estado poblacional y conservación. Hornero, 20 ( ) , -

Schoepss, C. G. (1829). Dissertatio inauguralis medica sistens musculorum, quibus volandi motus in omnium ordinum avibus perficitur, descriptionis partem priorem. Typis Expressum Gebaueriis.

Schreiweis, D. O. (1982). A comparative study of the appendicular musculature of penguins (Aves, Sphenisciformes). 
Scioscia, G., Rey, A. R., Samaniego, R. A. S., Florentín, O., \& Schiavini, A. (2014). Intra-and interannual variation in the diet of the Magellanic penguin (Spheniscus magellanicus) at Martillo Island, Beagle Channel. Polar biology, ( ), -

Seddon, P. J., \& Van Heezik, Y. (1990). Diving depths of the yellow-eyed penguin Megadyptes antipodes. Emu, ( ), -

Sharpe, R. B. (1891). Aves. Taylor \& Francis.

Shiomi, K., Sato, K., Handrich, Y., \& Bost, C. A. (2016). Diel shift of king penguin swim speeds in relation to light intensity changes. Marine Ecology Progress Series,

Shufeldt, R. W. (1901). Osteology of the penguins. Journal of anatomy and physiology, （Pt 3), 390.

Silva, L. A., Siles, L., Cardona, L., Tavares, M., Crespo, E., \& Gandini, P. (2015). Diferencias estacionales en la dieta de individuos juveniles del Pingüino Patagónico (Spheniscus magellanicus) reveladas en base al análisis de isótopos estables en uñas. El hornero, ( ), -

Simpson, G. G. (1946). Fossil penguins. Bulletin of the American Museum of Natural History, (1), UR6.

Simpson, G. G. (1959). A new fossil penguin from Australia. Proceedings of the Royal Society of Victoria, (Part 2), 113-

Simpson GG. (1971). Fossil Penguin from the Late Cenozoic of South Africa. Science, ， , 1144-

Simpson, G. G. (1972a). Conspectus of Patagonian fossil penguins. American Museum Novitates, , , 1-

Simpson, G. G. (1972b). Pliocene penguins from North Canterbury, New Zealand. Records of the Canterbury Museum, ( ),

Simpson, G. G. (1973). Tertiary penguins (Sphenisciformes, Spheniscidae) from Ysterplaats, Cape Town, South Africa. South African Journal of Science, , , 342-

Simpson, G. G. (1975). Notes on variation in penguins and on fossil penguins from the Pliocene of Langebaanweg, Cape Province, South Africa. South African Museum.

Simpson, G. G. (1976). Penguins: past and present, here and there. Yale University Press.

Simpson, G. G. (1979a). Tertiary penguins from the Duinefontein site, Cape Province, South Africa. South African Museum.

Simpson, G. G. (1979b). A new genus of Late Tertiary penguin from Langebaanweg, South Africa. South African Museum.

Simpson, G. G. (1981). Notes on some fossil penguins, including a new genus from Patagonia. Ameghiniana,

$(-)$ 
Slack, K. E., Jones, C. M., Ando, T., Harrison, G. L., Fordyce, R. E., Arnason, U., \& Penny, D. (2006). Early penguin fossils, plus mitochondrial genomes, calibrate avian evolution. Molecular biology and evolution, (),

Sladen, W. J. (1958). The Pygoscelid penguins: I. Methods of study. II. The Adélie penguin (Vol. 17). HMSO.

Sosa, M. A., \& Acosta Hospitaleche, C. (2018). Ontogenetic variations of the head of Aptenodytes forsteri (Aves, Sphenisciformes): muscular and skull morphology. Polar Biology, ( )

Steinfurth, A. (2007). Marine ecology and conservation of the Galápagos penguin, Spheniscus mendiculus (Doctoral dissertation, Universitätsbibliothek Kiel).

Stephan, B. (1979). Vergleichende Osteologie der Pinguine. Mitteilungen aus dem Zoologischen Museum in Berlin, (Supplement 3), 3-

Stucchi, M. (2002). Una nueva especie de Spheniscus (Aves: Spheniscidae) de la formación Pisco, Perú. Boletín de la Sociedad Geológica del Perú, ,

Stucchi, M. (2007). Los pingüinos de la formación Pisco (Neógeno), Perú. In 4th European Meeting on the Palaeontology and Stratigraphy of Latin America Cuadernos del Museo Geominero (Vol. 8, pp. 367) Madrid: Instituto Geológico y Minero de España.

Stucchi, M., Urbina, M., \& Giraldo, A. (2003). Una nueva especie de Spheniscidae del Mioceno tardío de la Formación Pisco, Perú. Bulletin de l'Institut français d'études andines, ( () ), - -

Takahashi, A., Dunn, M. J., Trathan, P. N., Sato, K., Naito, Y., \& Croxall, J. P. (2003). Foraging strategies of chinstrap penguins at Signy Island, Antarctica: importance of benthic feeding on Antarctic krill. Marine Ecology Progress Series, , , -

Takahashi, A., Sato, K., Nishikawa, J., Watanuki, Y., \& Naito, Y. (2004). Synchronous diving behavior of Adélie penguins. Journal of Ethology, ( ), -

Tambussi, C. P., \& Acosta Hospitaleche, C. (2008). Skull shape analysis and diet of South American fossil penguins (Sphenisciformes). Oryctos, , -

Tambussi, C. P., Reguero, M. A., Marenssi, S. A., \& Santillana, S. N. (2005). Crossvallia unienwillia, a new Spheniscidae (Sphenisciformes, Aves) from the late Paleocene of Antarctica. Geobios, ( ), -

Tokita, M., Kiyoshi, T., \& Armstrong, K. N. (2007). Evolution of craniofacial novelty in parrots through developmental modularity and heterochrony. Evolution \& development, ( )

Tremblay, Y., Guinard, E., \& Cherel, Y. (1997). Maximum diving depths of northern rockhopper penguins (Eudyptes chrysocome moseleyi) at Amsterdam Island. Polar Biology, ( ), 
van der Meij, M. A., \& Bout, R. G. (2008). The relationship between shape of the skull and bite force in finches. Journal of Experimental Biology, ( ), -

van Heezik, Y. (1988). The Growth and Diet of the Yellow-eyed Penguin, Megadyptes Antipodes: A Thesis Submitted for the Degree of Doctor of Philosophy at the University of Otago, Dunedin (Doctoral dissertation, University of Otago).

Van Heezik, Y. (1990). Diets of yellow-eyed, Fiordland crested, and little blue penguins breeding sympatrically on Codfish Island, New Zealand. New Zealand Journal of Zoology, ， ), -

van Heezik, Y. (1990). Seasonal, geographical, and age-related variations in the diet of the yellow-eyed penguin (Megadyptes antipodes). New Zealand Journal of Zoology, ( ), -

Vanden Berge, J. C., \& Zweers, G. A. (1993). Myologia, p. 189- Handbook of avian anatomy: nomina anatomica avium. Publications of the Nuttall Ornithological Club, Cambridge.

Vargas, A O, Ruiz-Flores, M, Soto-Acu a, S, Haidr, N, Acosta-Hospitaleche, C., Ossa-Fuentes, L., \& Muñoz-Walther, V. (2017). The origin and evolutionary consequences of skeletal traits shaped by embryonic muscular activity, from basal theropods to modern birds. Integrative and comparative biology, ( ),

Viscosi, V., \& Cardini, A. (2011). Leaf morphology, taxonomy and geometric morphometrics: a simplified protocol for beginners. PloS one, (10), e25630.

Vizcaíno, S. F., Bargo, M. S:, \& Fariña, R. A. (2008). Form, function, and paleobiology in xenarthrans En Vizcaíno, S F, \& Loughry, W J ( ） Biology of the Xenarthra. University Press of Florida, pp.

Vizcaíno, S. F., Cassini, G. H., Fernicola, J. C., \& Bargo, M. S. (2011). Evaluating habitats and feeding habits through ecomorphological features in glyptodonts (Mammalia, Xenarthra). Ameghiniana, ( ), -

Volkman, N.J., Presler P., Trivelpiece W.Z. 1980. Diets of pygoscelid penguins at King- George Island Antarctica. The Condor 82: 373-

Walsh, S. A., \& Suárez, M. E. (2006). New penguin remains from the Pliocene of northern Chile. Historical Biology, ( ), -

Waluda, C. M., Collins, M. A., Black, A. D., Staniland, I. J., \& Trathan, P. N. (2010). Linking predator and prey behaviour: contrasts between Antarctic fur seals and macaroni penguins at South Georgia. Marine Biology, ( ),

Watkins, J. L., \& Murray, A. W. A. (1998). Layers of Antarctic krill, Euphausia superba: are they just long krill swarms?. Marine Biology, ( ),

Watkins JL, Buchholz F, Priddle J, Morris DJ, Ricketts C (1992) Variation in reproductive status of Antarctic krill swarms; evidence for a size-related sorting mechanism? Mar Ecol Prog Ser 82: 163 \pm 174 ; 
Watson, M. (1883). Report on the anatomy of the Spheniscidae collected during the voyage of H. M. S. Challenger. Pages 1-244 in Report on the Scientific Results of the Voyage of H. M. S. Challenger During the Years 1873-1876, vol. 7 (J. Murray, Ed.). Neill and Company, Edinburgh,United Kingdom.

Wellens, H L L, Kuijpers-Jagtman, A M \& \& Halazonetis, D J ( ) Geometric morphometric analysis of craniofacial variation, ontogeny and modularity in a cross-sectional sample of modern humans. Journal of Anatomy, ( ), -

Whitehead, T. O., Kato, A., Ropert-Coudert, Y., \& Ryan, P. G. (2016). Habitat use and diving behaviour of macaroni Eudyptes chrysolophus and eastern rockhopper E. chrysocome filholi penguins during the critical pre-moult period. Marine biology, ( ),

Wienecke, B. C., \& Robertson, G. (1997). Foraging space of emperor penguins Aptenodytes forsteri in Antarctic shelf waters in winter. Marine Ecology Progress Series,

Wienecke, B. C., Lawless, R., Rodary, D., Bost, C. A., Thomson, R., Pauly, T., ... \& LeMaho, Y. (2000). Adélie penguin foraging behaviour and krill abundance along the Wilkes and Adélie land coasts, Antarctica. Deep Sea Research Part II: Topical Studies in Oceanography, 47(12- ) ,

Wienecke, B., \& Robertson, G. (2006). Comparison of foraging strategies of incubating king penguins Aptenodytes patagonicus from Macquarie and Heard islands. Polar Biology, （ ) , - -

Wienecke, B., Robertson, G., Kirkwood, R., \& Lawton, K. (2007). Extreme dives by free-ranging emperor penguins. Polar Biology, ( ), -

Williams TD (1995) The penguins Spheniscidae. Oxford University Press, Oxford

Wilson, R. P., Ryan, P. G., James, A., \& Wilson, M. P. T. (1987). Conspicuous coloration may enhance prey capture in some piscivores. Animal Behaviour.

Wilson, R. P., B. Culik, H. J. Spairani, N. R. Coria, and D. Adelung. 1991. Depth utilization by penguins and gentoo penguin dive patterns. Journal fur Ornithologie 132:47-

Wilson, R. P., Puetz, K., Bost, C. A., Culik, B. M., Bannasch, R., Reins, T., \& Adelung, D. (1993). Diel dive depth in penguins in relation to diel vertical migration of prey: whose dinner by candlelight?. Marine Ecology Progress Series, , -

Xavier, J. C., Cherel, Y., Medeiros, R., Velez, N., Dewar, M., Ratcliffe, N., ... \& Trathan, P. N. (2018). Conventional and molecular analysis of the diet of gentoo penguins: contributions to assess scats for non-invasive penguin diet monitoring. Polar Biology, -

Yamasaki, T., Aoki, S., \& Tokita, M. (2018). Allometry and integration do not strongly constrain beak shape evolution in large-billed (Corvus macrorhynchos) and carrion crows (Corvus corone) Ecology and Evolution. 
Zeek, P. M. (1951). Double trachea in penguins and sea lions. The Anatomical Record,

( )

Zimmer I, Piatkowski U, Brey T (2007) The trophic link between squid and the emperor penguin Aptenodytes forsteri at Pointe Géologie, Antarctica. Mar Biol 152:1187-

Zimmer I, Wilson RP, Gilbert C, Beaulieu M, Ancel A, Plötz J (2008) Foraging movements of emperor penguins at Pointe Géologie, Antarctica. Polar Biol 31:229-

Zusi, R. L. (1959). The function of the depressor mandibulae muscle in certain passerine birds. The Auk, ( ),

Zusi, R. L. (1967). The role of the depressor mandibulae muscle in kinesis of the avian skull. Proceedings of the United States National Museum.

Zusi, R. L. (1975). An interpretation of skull structure in the penguins. The biology of penguins, -

Zusi, R. L. (1984). A functional and evolutionary analysis of rhynchokinesis in birds.

Zusi, R. L. (1993). Patterns of diversity in the avian skull. The skull, , - 


\section{ANEXO I}

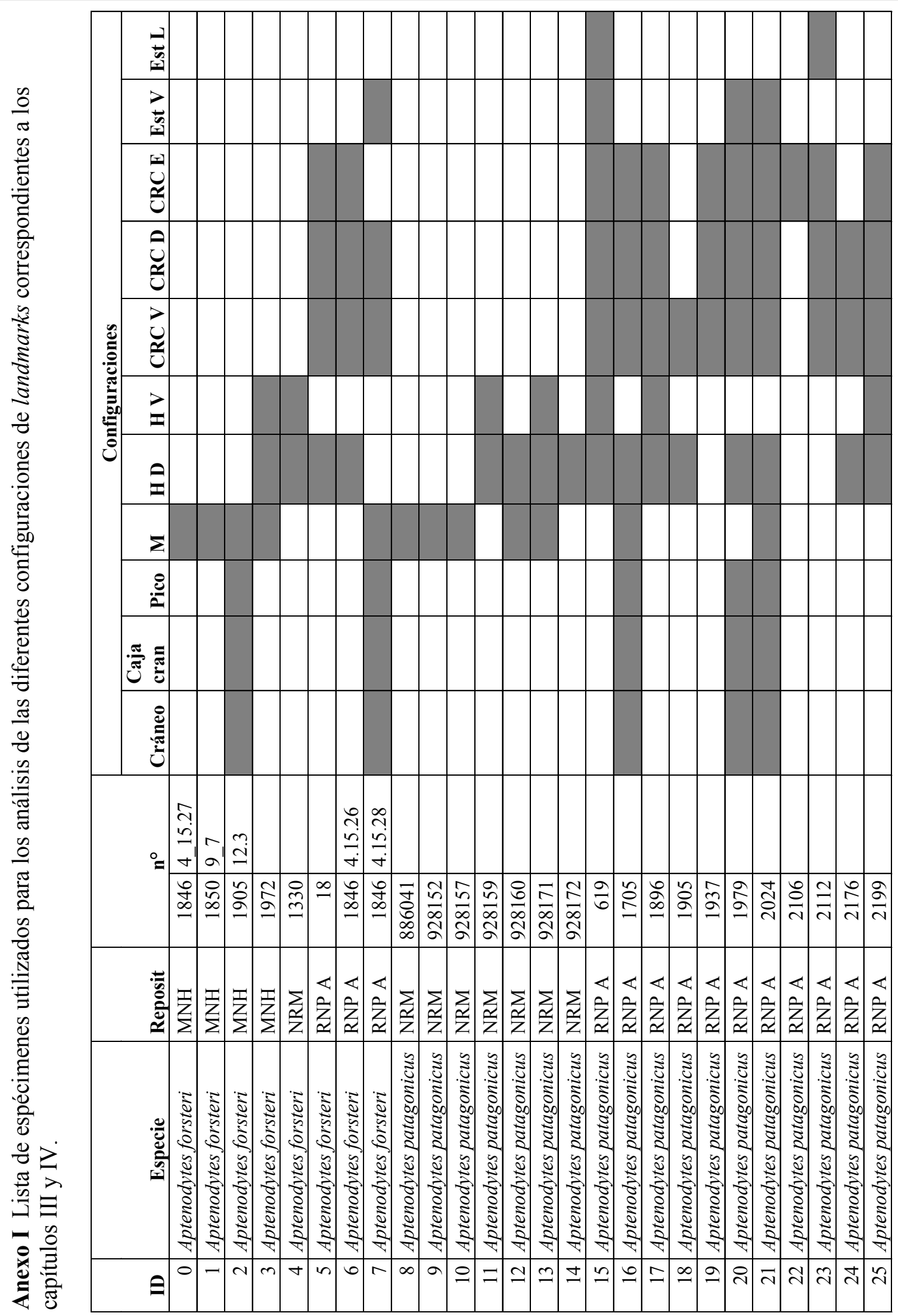




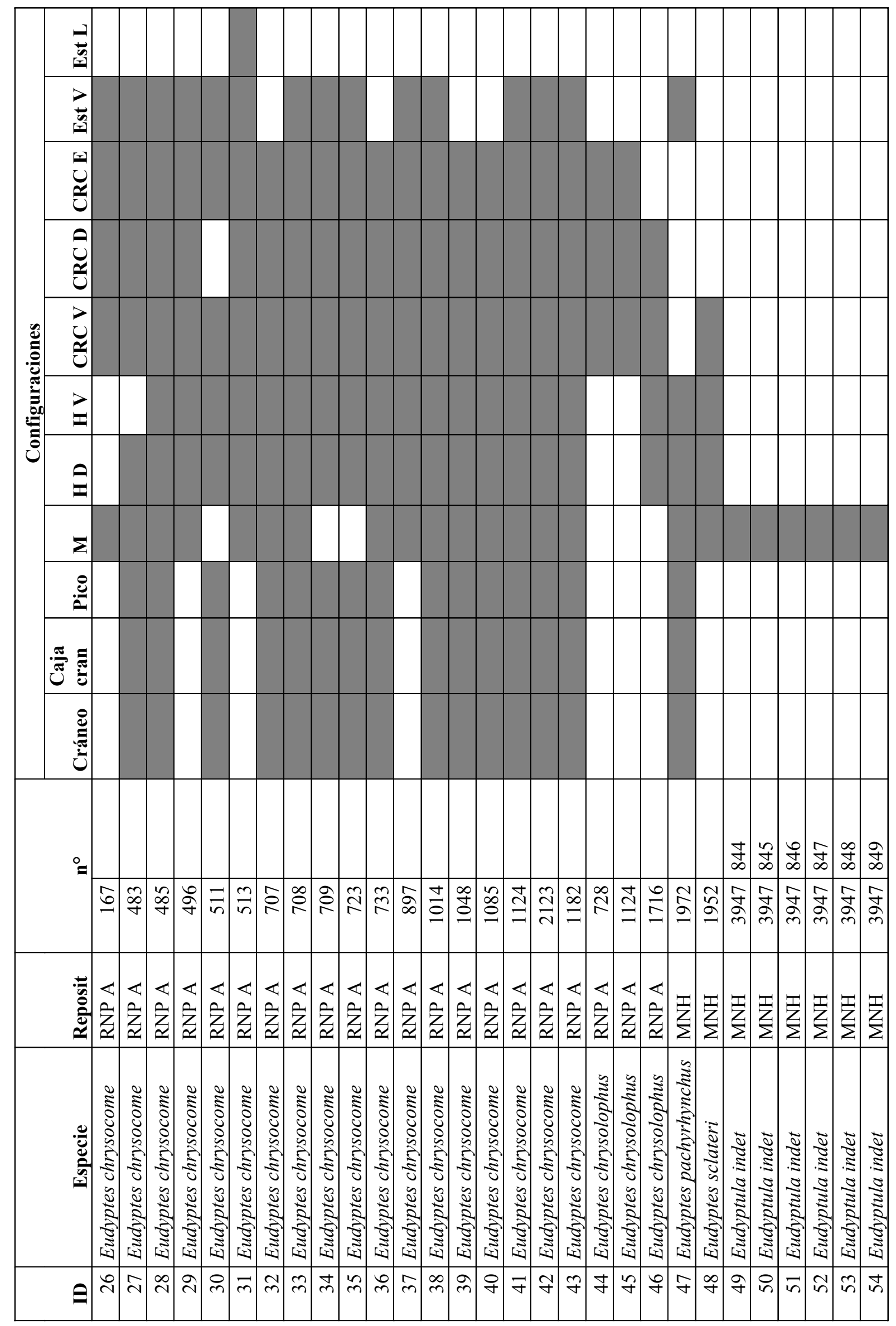




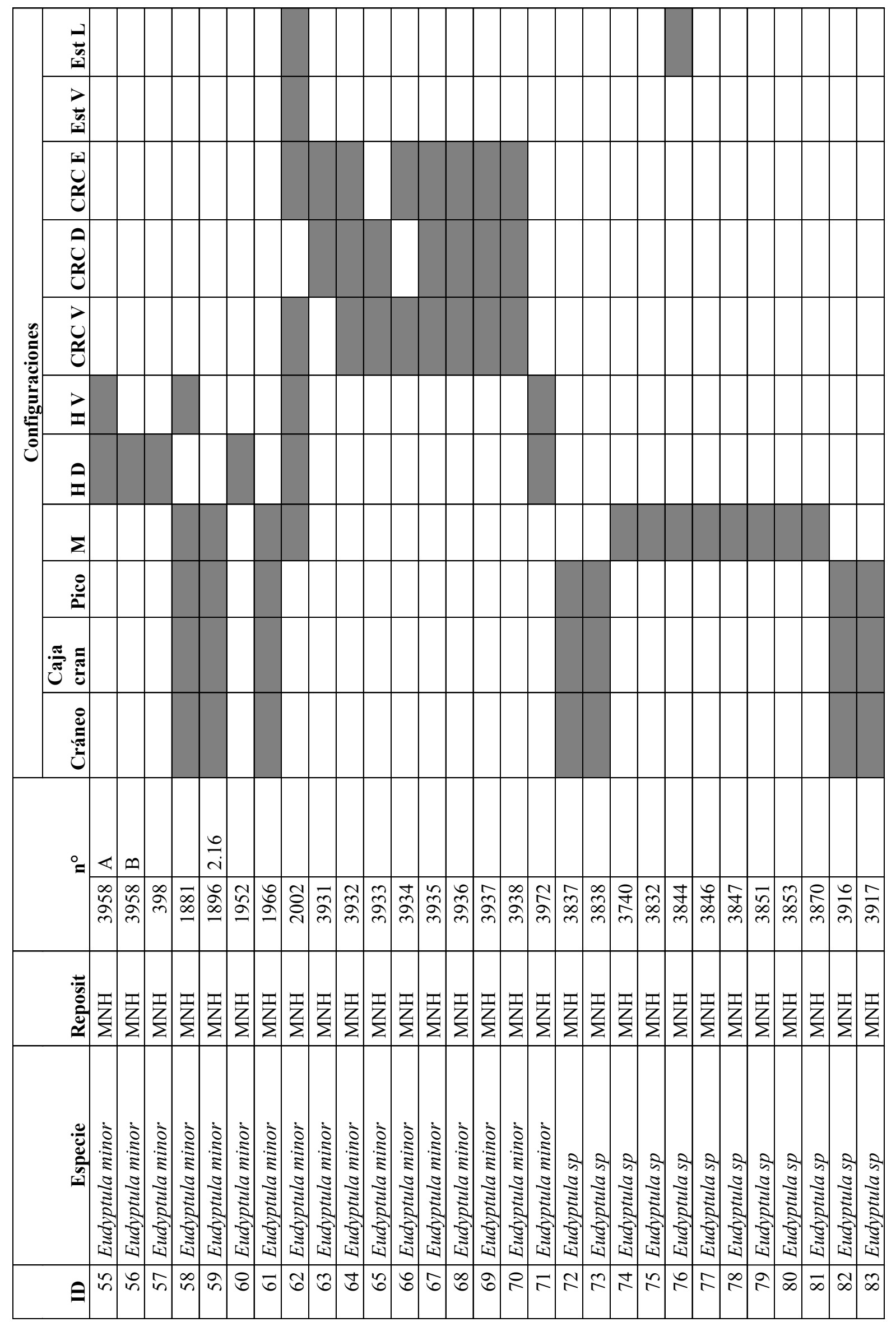




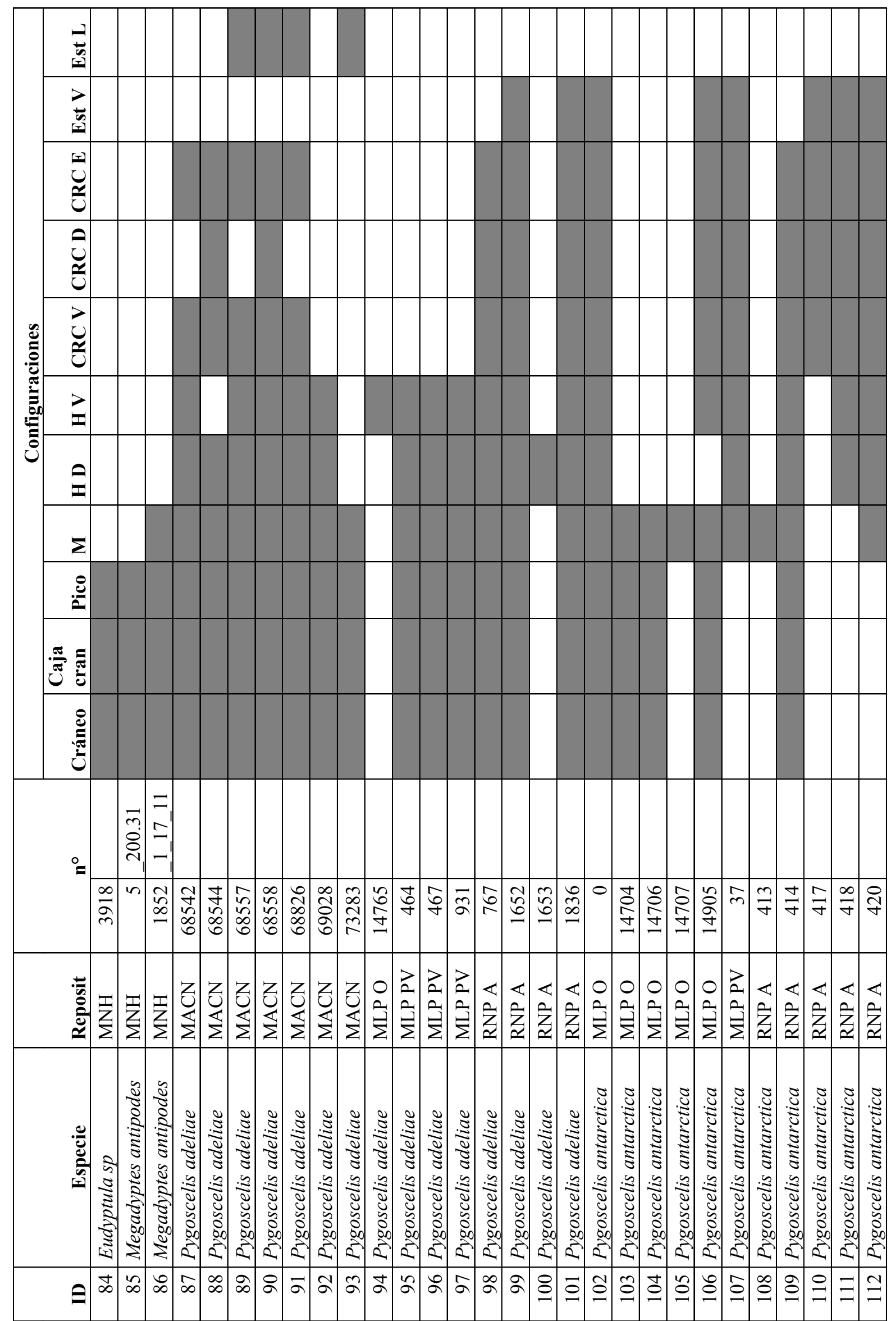




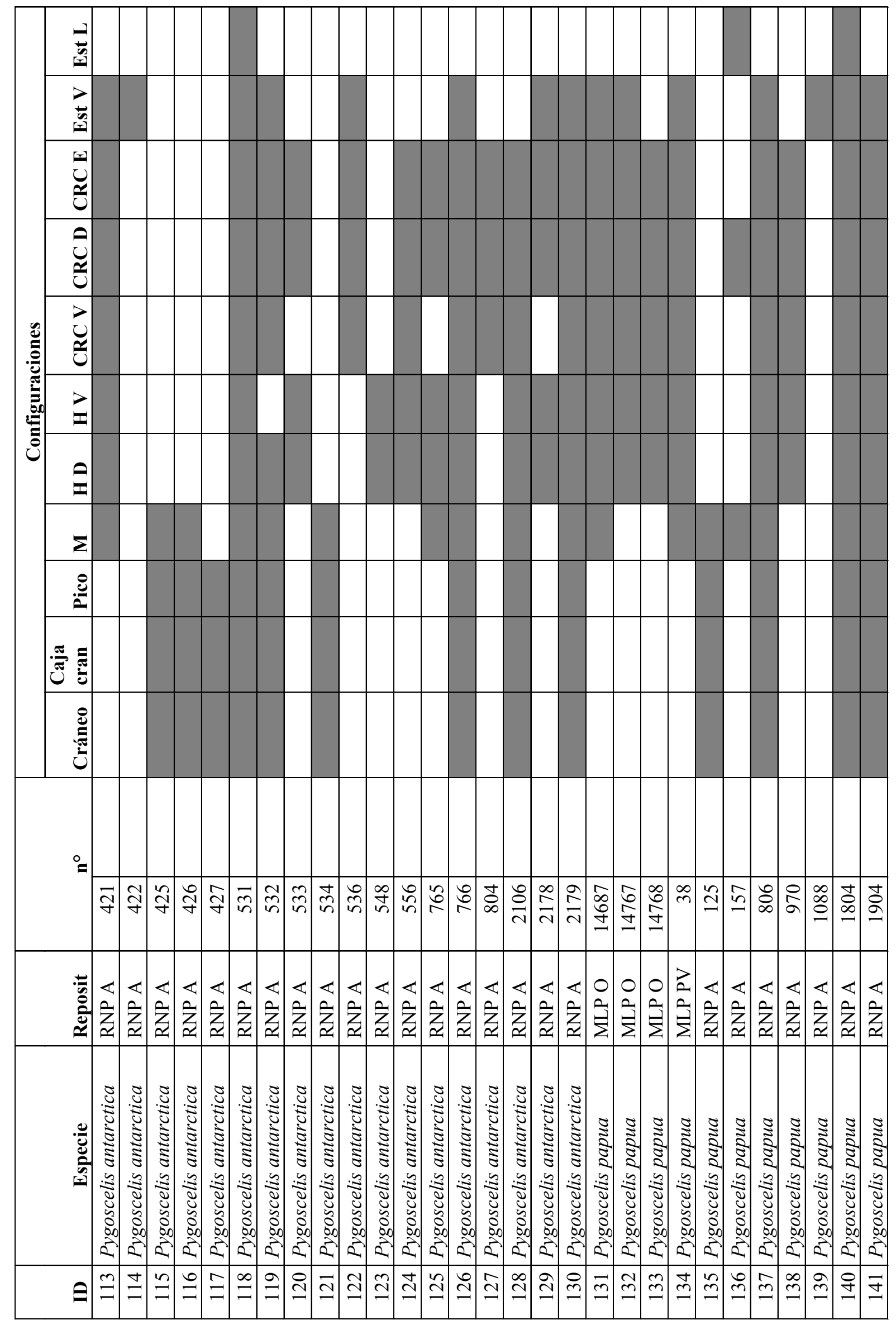




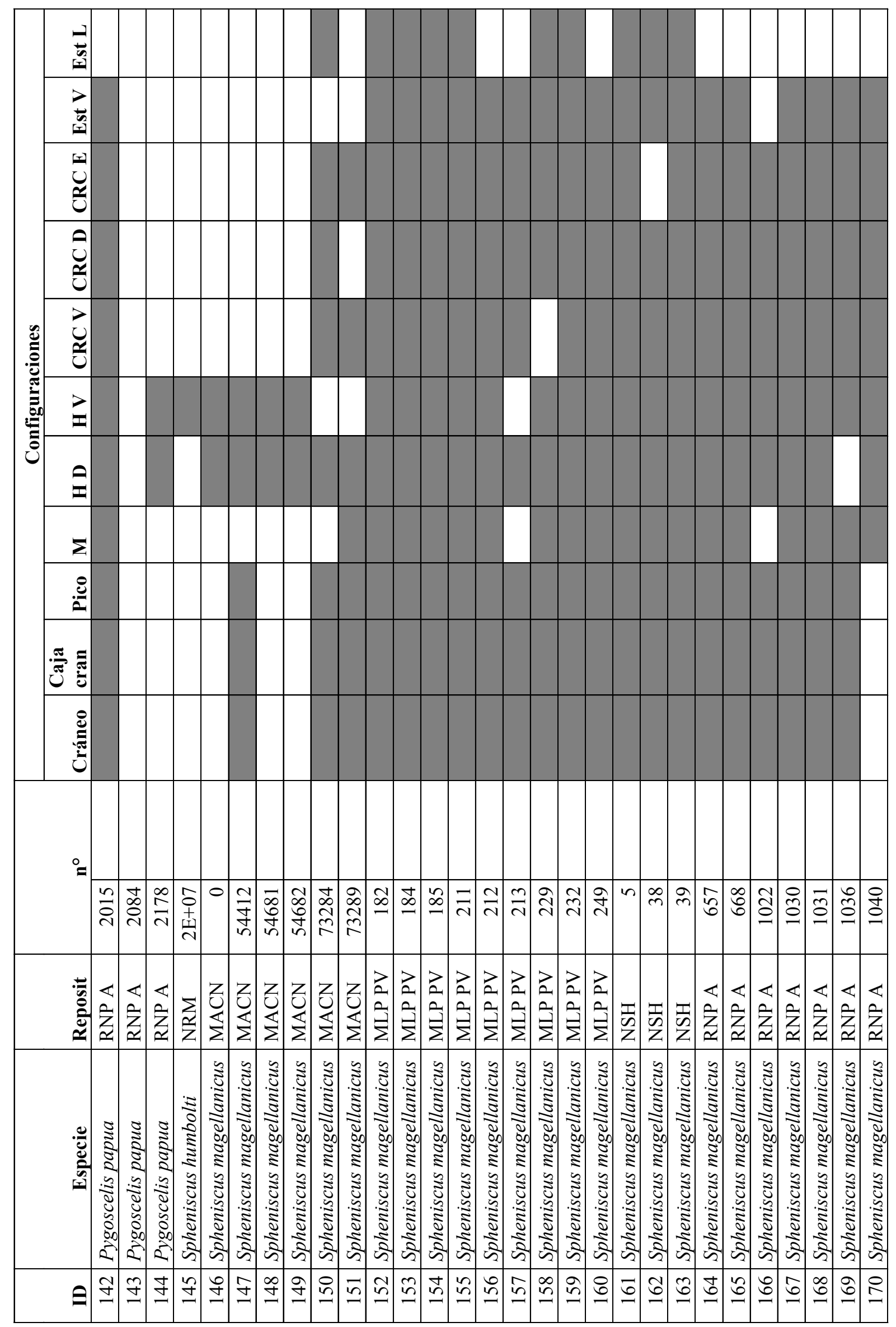




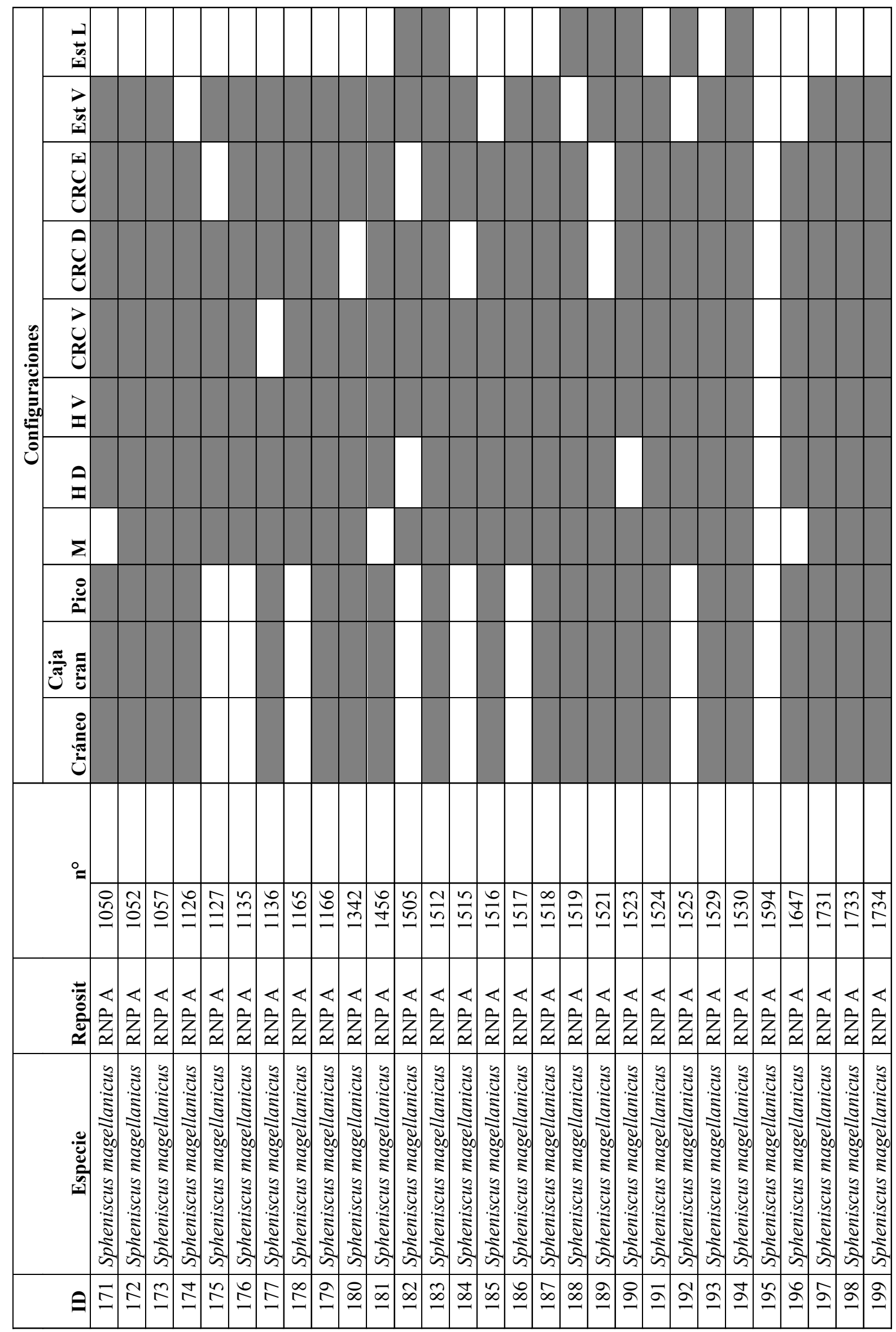




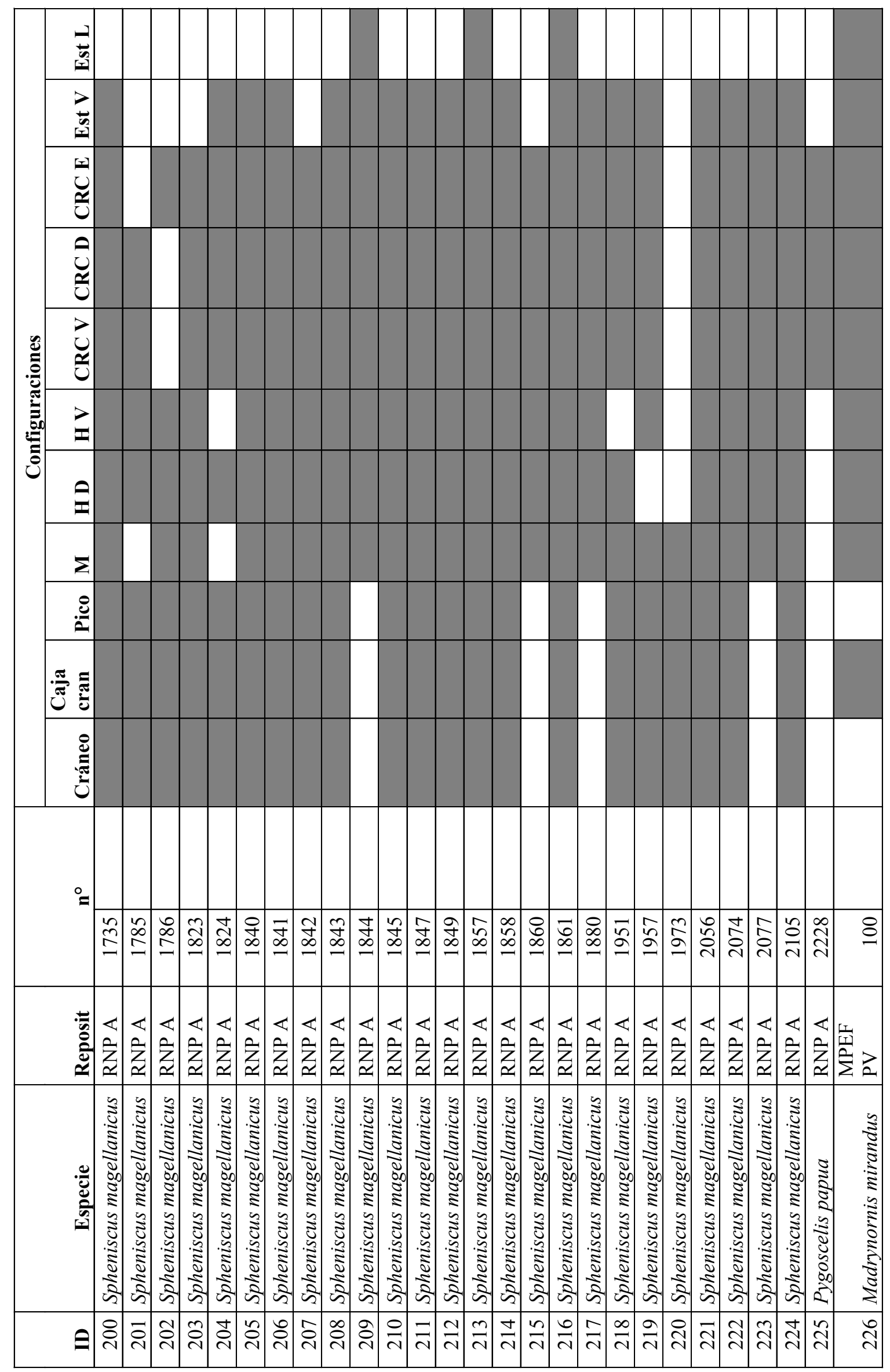




\section{ANEXO II}

Lista de especímenes utilizados para los análisis de las diferentes configuraciones de landmarks correspondientes a los capítulos III y IV.

\begin{tabular}{|c|c|c|c|c|c|c|c|}
\hline \multirow[b]{2}{*}{ ID } & \multirow[b]{2}{*}{ Especie } & \multirow[b]{2}{*}{ Reposit } & \multirow[b]{2}{*}{$\mathbf{n}^{\circ}$} & \multicolumn{4}{|c|}{ PLS } \\
\hline & & & & $\begin{array}{l}\text { Mand- } \\
\text { Cráneo }\end{array}$ & $\begin{array}{l}\text { Pico- } \\
\text { Mand }\end{array}$ & $\begin{array}{l}\text { H D- } \\
\text { Cráneo }\end{array}$ & $\begin{array}{l}\text { H D- } \\
\text { CRC D }\end{array}$ \\
\hline & Aptenodytes forsteri & MNH & & & & & \\
\hline & Aptenodytes forsteri & MNH & & & & & \\
\hline & Aptenodytes forsteri & MNH & & & & & \\
\hline & Aptenodytes forsteri & MNH & & & & & \\
\hline & Aptenodytes forsteri & NRM & & & & & \\
\hline & Aptenodytes forsteri & RNP A & & & & & \\
\hline & Aptenodytes forsteri & RNP A & & & & & \\
\hline & Aptenodytes forsteri & RNP A & & & & & \\
\hline & Aptenodytes patagonicus & NRM & & & & & \\
\hline & Aptenodytes patagonicus & NRM & & & & & \\
\hline & Aptenodytes patagonicus & NRM & & & & & \\
\hline & Aptenodytes patagonicus & NRM & & & & & \\
\hline & Aptenodytes patagonicus & NRM & & & & & \\
\hline & Aptenodytes patagonicus & NRM & & & & & \\
\hline & Aptenodytes patagonicus & NRM & & & & & \\
\hline & Aptenodytes patagonicus & RNP A & & & & & \\
\hline & Aptenodytes patagonicus & RNP A & & & & & \\
\hline & Aptenodytes patagonicus & RNP A & & & & & \\
\hline & Aptenodytes patagonicus & RNP A & & & & & \\
\hline & Aptenodytes patagonicus & RNP A & & & & & \\
\hline & Aptenodytes patagonicus & RNP A & & & & & \\
\hline & Aptenodytes patagonicus & RNP A & & & & & \\
\hline & Aptenodytes patagonicus & RNP A & & & & & \\
\hline & Aptenodytes patagonicus & RNP A & & & & & \\
\hline & Aptenodytes patagonicus & RNP A & & & & & \\
\hline & Aptenodytes patagonicus & RNP A & & & & & \\
\hline & Eudyptes chrysocome & RNP A & & & & & \\
\hline & Eudyptes chrysocome & RNP A & & & & & \\
\hline & Eudyptes chrysocome & RNP A & & & & & \\
\hline & Eudyptes chrysocome & RNP A & & & & & \\
\hline & Eudyptes chrysocome & RNP A & & & & & \\
\hline & Eudyptes chrysocome & RNP A & & & & & \\
\hline & Eudyptes chrysocome & RNP A & & & & & \\
\hline & Eudyptes chrysocome & RNP A & & & & & \\
\hline & Eudyptes chrysocome & RNP A & & & & & \\
\hline & Eudyptes chrysocome & RNP A & & & & & \\
\hline & Eudyptes chrysocome & RNP A & & & & & \\
\hline & Eudyptes chrysocome & RNP A & & & & & \\
\hline & Eudyptes chrysocome & RNP A & & & & & \\
\hline & Eudyptes chrysocome & RNP A & & & & & \\
\hline
\end{tabular}




\begin{tabular}{|c|c|c|c|c|c|c|c|c|}
\hline \multirow[b]{2}{*}{ ID } & \multirow[b]{2}{*}{ Especie } & \multirow[b]{2}{*}{ Reposit } & \multirow[b]{2}{*}{$n^{\circ}$} & & \multicolumn{4}{|c|}{ PLS } \\
\hline & & & & & $\begin{array}{l}\text { Mand- } \\
\text { Cráneo }\end{array}$ & $\begin{array}{l}\text { Pico- } \\
\text { Mand }\end{array}$ & $\begin{array}{l}\text { H D- } \\
\text { Cráneo }\end{array}$ & $\begin{array}{l}\text { H D- } \\
\text { CRC D }\end{array}$ \\
\hline & Eudyptes chrysocome & RNP A & & & & & & \\
\hline & Eudyptes chrysocome & RNP A & & & & & & \\
\hline & Eudyptes chrysocome & RNP A & & & & & & \\
\hline & Eudyptes chrysocome & RNP A & & & & & & \\
\hline & Eudyptes chrysolophus & RNP A & & & & & & \\
\hline & Eudyptes chrysolophus & RNP A & & & & & & \\
\hline & Eudyptes chrysolophus & RNP A & & & & & & \\
\hline & Eudyptes pachyrhynchus & MNH & & & & & & \\
\hline & Eudyptes sclateri & MNH & & & & & & \\
\hline & Eudyptula indet & MNH & & & & & & \\
\hline & Eudyptula indet & MNH & & & & & & \\
\hline & Eudyptula indet & MNH & & & & & & \\
\hline & Eudyptula indet & MNH & & & & & & \\
\hline & Eudyptula indet & MNH & & & & & & \\
\hline & Eudyptula indet & $\mathrm{MNH}$ & & & & & & \\
\hline & Eudyptula minor & $\mathrm{MNH}$ & & A & & & & \\
\hline & Eudyptula minor & $\mathrm{MNH}$ & & B & & & & \\
\hline & Eudyptula minor & $\mathrm{MNH}$ & & & & & & \\
\hline & Eudyptula minor & MNH & & & & & & \\
\hline & Eudyptula minor & $\mathrm{MNH}$ & & & & & & \\
\hline & Eudyptula minor & MNH & & & & & & \\
\hline & Eudyptula minor & MNH & & & & & & \\
\hline & Eudyptula minor & MNH & & & & & & \\
\hline & Eudyptula minor & $\mathrm{MNH}$ & & & & & & \\
\hline & Eudyptula minor & MNH & & & & & & \\
\hline & Eudyptula minor & $\mathrm{MNH}$ & & & & & & \\
\hline & Eudyptula minor & MNH & & & & & & \\
\hline & Eudyptula minor & $\mathrm{MNH}$ & & & & & & \\
\hline & Eudyptula minor & $\mathrm{MNH}$ & & & & & & \\
\hline & Eudyptula minor & MNH & & & & & & \\
\hline & Eudyptula minor & MNH & & & & & & \\
\hline & Eudyptula minor & MNH & & & & & & \\
\hline & Eudyptula $s p$ & MNH & & & & & & \\
\hline & Eudyptula $s p$ & MNH & & & & & & \\
\hline & Eudyptula $s p$ & MNH & & & & & & \\
\hline & Eudyptula $s p$ & MNH & & & & & & \\
\hline & Eudyptula sp & MNH & & & & & & \\
\hline & Eudyptula $s p$ & $\mathrm{MNH}$ & & & & & & \\
\hline & Eudyptula $s p$ & MNH & & & & & & \\
\hline & Eudyptula sp & MNH & & & & & & \\
\hline & Eudyptula sp & $\mathrm{MNH}$ & & & & & & \\
\hline & Eudyptula $s p$ & MNH & & & & & & \\
\hline & Eudyptula sp & MNH & & & & & & \\
\hline & Eudyptula $s p$ & MNH & & & & & & \\
\hline
\end{tabular}




\begin{tabular}{|c|c|c|c|c|c|c|c|}
\hline \multirow[b]{2}{*}{ ID } & \multirow[b]{2}{*}{ Especie } & \multirow[b]{2}{*}{ Reposit } & \multirow[b]{2}{*}{$n^{\circ}$} & \multicolumn{4}{|c|}{ PLS } \\
\hline & & & & $\begin{array}{l}\text { Mand- } \\
\text { Cráneo }\end{array}$ & $\begin{array}{l}\text { Pico- } \\
\text { Mand }\end{array}$ & $\begin{array}{l}\text { H D- } \\
\text { Cráneo }\end{array}$ & $\begin{array}{l}\text { H D- } \\
\text { CRC D }\end{array}$ \\
\hline & Eudyptula sp & $\mathrm{MNH}$ & & & & & \\
\hline & Megadyptes antipodes & $\mathrm{MNH}$ & & & & & \\
\hline & Megadyptes antipodes & MNH & & & & & \\
\hline & Pygoscelis adeliae & MACN & & & & & \\
\hline & Pygoscelis adeliae & MACN & & & & & \\
\hline & Pygoscelis adeliae & MACN & & & & & \\
\hline & Pygoscelis adeliae & MACN & & & & & \\
\hline & Pygoscelis adeliae & MACN & & & & & \\
\hline & Pygoscelis adeliae & MACN & & & & & \\
\hline & Pygoscelis adeliae & MACN & & & & & \\
\hline & Pygoscelis adeliae & MLP O & & & & & \\
\hline & Pygoscelis adeliae & MLP PV & & & & & \\
\hline & Pygoscelis adeliae & MLP PV & & & & & \\
\hline & Pygoscelis adeliae & MLP PV & & & & & \\
\hline & Pygoscelis adeliae & RNP A & & & & & \\
\hline & Pygoscelis adeliae & RNP A & & & & & \\
\hline & Pygoscelis adeliae & RNP A & & & & & \\
\hline & Pygoscelis adeliae & RNP A & & & & & \\
\hline & Pygoscelis antarctica & MLP O & & & & & \\
\hline & Pygoscelis antarctica & MLP O & & & & & \\
\hline & Pygoscelis antarctica & MLP O & & & & & \\
\hline & Pygoscelis antarctica & MLP O & & & & & \\
\hline & Pygoscelis antarctica & MLP O & & & & & \\
\hline & Pygoscelis antarctica & MLP PV & & & & & \\
\hline & Pygoscelis antarctica & RNP A & & & & & \\
\hline & Pygoscelis antarctica & RNP A & & & & & \\
\hline & Pygoscelis antarctica & RNP A & & & & & \\
\hline & Pygoscelis antarctica & RNP A & & & & & \\
\hline & Pygoscelis antarctica & RNP A & & & & & \\
\hline & Pygoscelis antarctica & RNP A & & & & & \\
\hline & Pygoscelis antarctica & RNP A & & & & & \\
\hline & Pygoscelis antarctica & RNP A & & & & & \\
\hline & Pygoscelis antarctica & RNP A & & & & & \\
\hline & Pygoscelis antarctica & RNP A & & & & & \\
\hline & Pygoscelis antarctica & RNP A & & & & & \\
\hline & Pygoscelis antarctica & RNP A & & & & & \\
\hline & Pygoscelis antarctica & RNP A & & & & & \\
\hline & Pygoscelis antarctica & RNP A & & & & & \\
\hline & Pygoscelis antarctica & RNP A & & & & & \\
\hline & Pygoscelis antarctica & RNP A & & & & & \\
\hline & Pygoscelis antarctica & RNP A & & & & & \\
\hline & Pygoscelis antarctica & RNP A & & & & & \\
\hline & Pygoscelis antarctica & RNP A & & & & & \\
\hline & Pygoscelis antarctica & RNP A & & & & & \\
\hline
\end{tabular}




\begin{tabular}{|c|c|c|c|c|c|c|c|}
\hline \multirow[b]{2}{*}{ ID } & \multirow[b]{2}{*}{ Especie } & \multirow[b]{2}{*}{ Reposit } & \multirow[b]{2}{*}{$n^{\circ}$} & \multicolumn{4}{|c|}{ PLS } \\
\hline & & & & $\begin{array}{l}\text { Mand- } \\
\text { Cráneo }\end{array}$ & $\begin{array}{l}\text { Pico- } \\
\text { Mand }\end{array}$ & $\begin{array}{l}\text { H D- } \\
\text { Cráneo }\end{array}$ & $\begin{array}{l}\text { H D- } \\
\text { CRC D }\end{array}$ \\
\hline & Pygoscelis antarctica & RNP A & & & & & \\
\hline & Pygoscelis antarctica & RNP A & & & & & \\
\hline & Pygoscelis antarctica & RNP A & & & & & \\
\hline & Pygoscelis papua & MLP O & & & & & \\
\hline & Pygoscelis papua & MLP O & & & & & \\
\hline & Pygoscelis papua & MLP O & & & & & \\
\hline & Pygoscelis papua & MLP PV & & & & & \\
\hline & Pygoscelis papua & RNP A & & & & & \\
\hline & Pygoscelis papua & RNP A & & & & & \\
\hline & Pygoscelis papua & RNP A & & & & & \\
\hline & Pygoscelis papua & RNP A & & & & & \\
\hline & Pygoscelis papua & RNP A & & & & & \\
\hline & Pygoscelis papua & RNP A & & & & & \\
\hline & Pygoscelis papua & RNP A & & & & & \\
\hline & Pygoscelis papua & RNP A & & & & & \\
\hline & Pygoscelis papua & RNP A & & & & & \\
\hline & Pygoscelis papua & RNP A & & & & & \\
\hline & Spheniscus humboldti & NRM & $2 \mathrm{E}+07$ & & & & \\
\hline & Spheniscus magellanicus & MACN & & & & & \\
\hline & Spheniscus magellanicus & MACN & & & & & \\
\hline & Spheniscus magellanicus & MACN & & & & & \\
\hline & Spheniscus magellanicus & MACN & & & & & \\
\hline & Spheniscus magellanicus & MACN & & & & & \\
\hline & Spheniscus magellanicus & MACN & & & & & \\
\hline & Spheniscus magellanicus & MLP PV & & & & & \\
\hline & Spheniscus magellanicus & MLP PV & & & & & \\
\hline & Spheniscus magellanicus & MLP PV & & & & & \\
\hline & Spheniscus magellanicus & MLP PV & & & & & \\
\hline & Spheniscus magellanicus & MLP PV & & & & & \\
\hline & Spheniscus magellanicus & MLP PV & & & & & \\
\hline & Spheniscus magellanicus & MLP PV & & & & & \\
\hline & Spheniscus magellanicus & MLP PV & & & & & \\
\hline & Spheniscus magellanicus & MLP PV & & & & & \\
\hline & Spheniscus magellanicus & $\mathrm{NSH}$ & & & & & \\
\hline & Spheniscus magellanicus & $\mathrm{NSH}$ & & & & & \\
\hline & Spheniscus magellanicus & $\mathrm{NSH}$ & & & & & \\
\hline & Spheniscus magellanicus & RNP A & & & & & \\
\hline & Spheniscus magellanicus & RNP A & & & & & \\
\hline & Spheniscus magellanicus & RNP A & & & & & \\
\hline & Spheniscus magellanicus & RNP A & & & & & \\
\hline & Spheniscus magellanicus & RNP A & & & & & \\
\hline & Spheniscus magellanicus & RNP A & & & & & \\
\hline & Spheniscus magellanicus & RNP A & & & & & \\
\hline & Spheniscus magellanicus & RNP A & & & & & \\
\hline
\end{tabular}




\begin{tabular}{|c|c|c|c|c|c|c|c|}
\hline \multirow[b]{2}{*}{ ID } & \multirow[b]{2}{*}{ Especie } & \multirow[b]{2}{*}{ Reposit } & \multirow[b]{2}{*}{$n^{\circ}$} & \multicolumn{4}{|c|}{ PLS } \\
\hline & & & & $\begin{array}{l}\text { Mand- } \\
\text { Cráneo }\end{array}$ & $\begin{array}{l}\text { Pico- } \\
\text { Mand }\end{array}$ & $\begin{array}{l}\text { H D- } \\
\text { Cráneo }\end{array}$ & $\begin{array}{l}\text { H D- } \\
\text { CRC D }\end{array}$ \\
\hline & Spheniscus magellanicus & RNP A & & & & & \\
\hline & Spheniscus magellanicus & RNP A & & & & & \\
\hline & Spheniscus magellanicus & RNP A & & & & & \\
\hline & Spheniscus magellanicus & RNP A & & & & & \\
\hline & Spheniscus magellanicus & RNP A & & & & & \\
\hline & Spheniscus magellanicus & RNP A & & & & & \\
\hline & Spheniscus magellanicus & RNP A & & & & & \\
\hline & Spheniscus magellanicus & RNP A & & & & & \\
\hline & Spheniscus magellanicus & RNP A & & & & & \\
\hline & Spheniscus magellanicus & RNP A & & & & & \\
\hline & Spheniscus magellanicus & RNP A & & & & & \\
\hline & Spheniscus magellanicus & RNP A & & & & & \\
\hline & Spheniscus magellanicus & RNP A & & & & & \\
\hline & Spheniscus magellanicus & RNP A & & & & & \\
\hline & Spheniscus magellanicus & RNP A & & & & & \\
\hline & Spheniscus magellanicus & RNP A & & & & & \\
\hline & Spheniscus magellanicus & RNP A & & & & & \\
\hline & Spheniscus magellanicus & RNP A & & & & & \\
\hline & Spheniscus magellanicus & RNP A & & & & & \\
\hline & Spheniscus magellanicus & RNP A & & & & & \\
\hline & Spheniscus magellanicus & RNP A & & & & & \\
\hline & Spheniscus magellanicus & RNP A & & & & & \\
\hline & Spheniscus magellanicus & RNP A & & & & & \\
\hline & Spheniscus magellanicus & RNP A & & & & & \\
\hline & Spheniscus magellanicus & RNP A & & & & & \\
\hline & Spheniscus magellanicus & RNP A & & & & & \\
\hline & Spheniscus magellanicus & RNP A & & & & & \\
\hline & Spheniscus magellanicus & RNP A & & & & & \\
\hline & Spheniscus magellanicus & RNP A & & & & & \\
\hline & Spheniscus magellanicus & RNP A & & & & & \\
\hline & Spheniscus magellanicus & RNP A & & & & & \\
\hline & Spheniscus magellanicus & RNP A & & & & & \\
\hline & Spheniscus magellanicus & RNP A & & & & & \\
\hline & Spheniscus magellanicus & RNP A & & & & & \\
\hline & Spheniscus magellanicus & RNP A & & & & & \\
\hline & Spheniscus magellanicus & RNP A & & & & & \\
\hline & Spheniscus magellanicus & RNP A & & & & & \\
\hline & Spheniscus magellanicus & RNP A & & & & & \\
\hline & Spheniscus magellanicus & RNP A & & & & & \\
\hline & Spheniscus magellanicus & RNP A & & & & & \\
\hline & Spheniscus magellanicus & RNP A & & & & & \\
\hline & Spheniscus magellanicus & RNP A & & & & & \\
\hline & Spheniscus magellanicus & RNP A & & & & & \\
\hline & Spheniscus magellanicus & RNP A & & & & & \\
\hline
\end{tabular}




\begin{tabular}{|c|c|c|c|c|c|c|c|}
\hline \multirow[b]{2}{*}{ ID } & \multirow[b]{2}{*}{ Especie } & \multirow[b]{2}{*}{ Reposit } & \multirow[b]{2}{*}{$n^{\circ}$} & \multicolumn{4}{|c|}{ PLS } \\
\hline & & & & $\begin{array}{l}\text { Mand- } \\
\text { Cráneo }\end{array}$ & $\begin{array}{l}\text { Pico- } \\
\text { Mand }\end{array}$ & $\begin{array}{l}\text { H D- } \\
\text { Cráneo }\end{array}$ & $\begin{array}{l}\text { H D- } \\
\text { CRC D }\end{array}$ \\
\hline & Spheniscus magellanicus & RNP A & & & & & \\
\hline & Spheniscus magellanicus & RNP A & & & & & \\
\hline & Spheniscus magellanicus & RNP A & & & & & \\
\hline & Spheniscus magellanicus & RNP A & & & & & \\
\hline & Spheniscus magellanicus & RNP A & & & & & \\
\hline & Spheniscus magellanicus & RNP A & & & & & \\
\hline & Spheniscus magellanicus & RNP A & & & & & \\
\hline & Spheniscus magellanicus & RNP A & & & & & \\
\hline & Spheniscus magellanicus & RNP A & & & & & \\
\hline & Pygoscelis papua & RNP A & & & & & \\
\hline & Madrynornis mirandus & MPEF PV & & & & & \\
\hline
\end{tabular}

